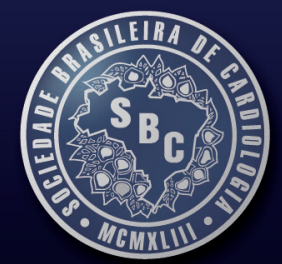

www.cardiol.br

Arquivos Brasileiros de

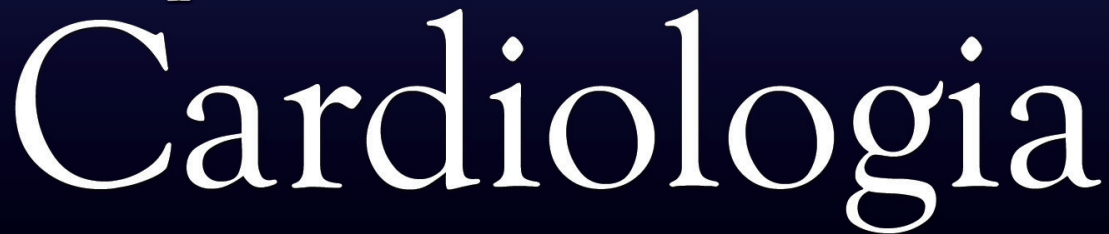

Sociedade Brasileira de Cardiologia •ISSN-0066-782X • Volume 101, № 6, Supl. 2, Dezembro 2013

www.arquivosonline.com.br

\title{
I DIRETRIZ BRASILEIRA DE PREVENÇÃO CARDIOVASCULAR
}




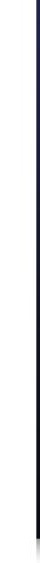




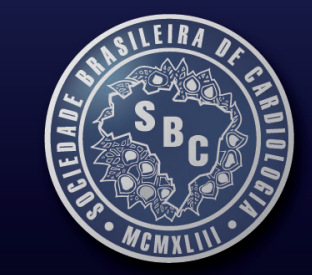

\section{Arquivos Brasileiros de}

www.cardiol.br

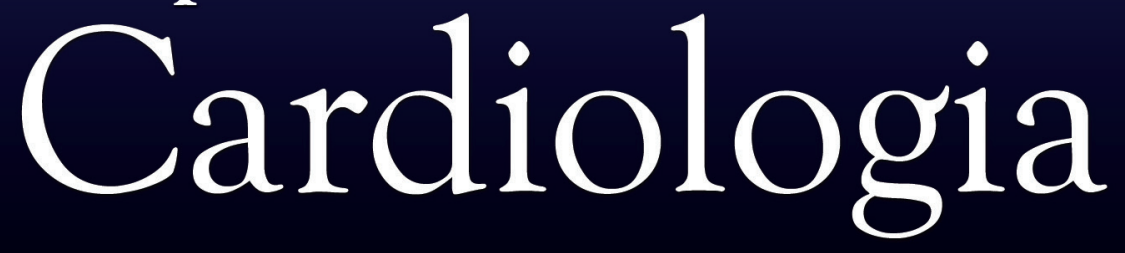

\section{Diretriz Brasileira de Prevenção Cardiovascular}

\section{Autores da Diretriz:}

Simão AF, Precoma DB, Andrade JP, Correa Filho H, Saraiva JFK, Oliveira GMM, Murro ALB, Campos A, Alessi A, Avezum Junior A, Achutti AC, Miguel ACMG, Sousa ACS, Lotemberg AMP, Lins AP,

Falud AA, Brandão AA, Sanjuliani AF, Sbissa AS, Alencar Filho AC, Herdy AH, Polanczyk CA, Lantieri CJ, Machado CA, Scherr C, Stoll C, Amodeo C, Araújo CGS, Saraiva D, Moriguchi EH, Mesquita ET, Fonseca FAH, Campos GP, Soares GP, Feitosa GS, Xavier HT,

Castro I, Giuliano ICB, Rivera IV, Guimaraes ICB, Issa JS, Souza JRM, Faria Neto JR, Cunha LBN,

Pellanda LC, Bortolotto LA, Bertolami MC, Miname MH, Gomes MAM, Tambascia M, Malachias MVB, Silva MAM, Izar MC, Magalhães MEC, Bacellar MSC, Milani M,

Wajngarten M, Ghorayeb N, Coelho OR, Villela PB, Jardim PCBV, Santos Filho RD, Stein R, Cassani RSL, D'Avila RL, Ferreira RM, Barbosa RB, Povoa RMS, Kaiser SE, Ismael SC, Carvalho T, Giraldez VZR, Coutinho W, Souza WKSB. 



\section{Arquivos Brasileiros de Cardiologia}

Diretor Científico

Luiz Alberto Piva e Mattos

\section{Editor-Chefe}

Luiz Felipe P. Moreira

Editores Associados

Cardiologia Clínica

José Augusto Barreto-Filho

Cardiologia Cirúrgica

Paulo Roberto B. Evora
Cardiologia Intervencionista

Pedro A. Lemos

Cardiologia Pediátrica/Congênitas

Antonio Augusto Lopes

Arritmias/Marcapasso

Mauricio Scanavacca

Métodos Diagnósticos Não-Invasivos

Carlos E. Rochitte

Pesquisa Básica ou Experimental

Leonardo A. M. Zornoff
Epidemiologia/Estatística

Lucia Campos Pellanda

Hipertensão Arterial

Paulo Cesar B. V. Jardim

Ergometria, Exercício e

Reabilitação Cardíaca

Ricardo Stein

Primeiro Editor (1948-1953)

† Jairo Ramos

\section{Conselho Editorial}

\section{Brasil}

Adib D. Jatene (SP)

Alexandre A. C. Abizaid (SP)

Alfredo José Mansur (SP)

Álvaro Avezum (SP)

Amanda G. M. R. Sousa (SP)

André Labrunie (PR)

Andrei Sposito (DF)

Angelo A. V. de Paola (SP)

Antonio Augusto Barbosa Lopes (SP)

Antonio Carlos C. Carvalho (SP)

Antônio Carlos Palandri Chagas (SP)

Antonio Carlos Pereira Barretto (SP)

Antonio Cláudio L. Nóbrega (RJ)

Antonio de Padua Mansur (SP)

Ari Timerman (SP)

Armênio Costa Guimarães (BA)

Ayrton Klier Péres (DF)

Ayrton Pires Brandão (RJ)

Barbara M. Ianni (SP)

Beatriz Matsubara (SP)

Braulio Luna Filho (SP)

Brivaldo Markman Filho (PE)

Bruce B. Duncan (RS)

Bruno Caramelli (SP)

Carisi A. Polanczyk (RS)

Carlos Alberto Pastore (SP)

Carlos Eduardo Negrão (SP)

Carlos Eduardo Rochitte (SP)

Carlos Eduardo Suaide Silva (SP)

Carlos Vicente Serrano Júnior (SP)

Celso Amodeo (SP)

Charles Mady (SP)

Claudio Gil Soares de Araujo (RJ)

Cleonice Carvalho C. Mota (MG)

Dalton Valentim Vassallo (ES)

Décio Mion Jr (SP)

Denilson Campos de Albuquerque (RJ)

Dikran Armaganijan (SP)

Djair Brindeiro Filho (PE)

Domingo M. Braile (SP)

Edmar Atik (SP)

Edson Stefanini (SP)

Elias Knobel (SP)

Eliudem Galvão Lima (ES)

Emilio Hideyuki Moriguchi (RS)

Enio Buffolo (SP)
Eulógio E. Martinez Fo (SP)

Evandro Tinoco Mesquita (RJ)

Expedito E. Ribeiro da Silva (SP)

Fábio Sândoli de Brito Jr. (SP)

Fábio Vilas-Boas (BA)

Fernando A. P. Morcerf (RJ)

Fernando Bacal (SP)

Flávio D. Fuchs (RS)

Francisco Antonio Helfenstein Fonseca (SP)

Francisco Laurindo (SP)

Francisco Manes Albanesi Fo (RJ)

Gilmar Reis (MG)

Gilson Soares Feitosa (BA)

Ínes Lessa (BA)

Iran Castro (RS)

Ivan G. Maia (RJ)

Ivo Nesralla (RS)

Jarbas Jakson Dinkhuysen (SP)

João Pimenta (SP)

Jorge Ilha Guimarães (RS)

Jorge Pinto Ribeiro (RS)

José A. Marin-Neto (SP)

José Antonio Franchini Ramires (SP)

José Augusto Soares Barreto Filho (SE)

José Carlos Nicolau (SP)

José Geraldo de Castro Amino (RJ)

José Lázaro de Andrade (SP)

José Péricles Esteves (BA)

José Teles Mendonça (SE)

Leopoldo Soares Piegas (SP)

Luís Eduardo Rohde (RS)

Luiz A. Machado César (SP)

Luiz Alberto Piva e Mattos (SP)

Lurildo Saraiva (PE)

Marcelo C. Bertolami (SP)

Marcia Melo Barbosa (MG)

Marco Antônio Mota Gomes (AL)

Marcus V. Bolívar Malachias (MG)

Maria Cecilia Solimene (SP)

Mario S. S. de Azeredo Coutinho (SC)

Maurício I. Scanavacca (SP)

Mauricio Wajngarten (SP)

Max Grinberg (SP)

Michel Batlouni (SP)

Nabil Ghorayeb (SP)

Nadine O. Clausell (RS)

Nelson Souza e Silva (RJ)
Orlando Campos Filho (SP)

Otávio Rizzi Coelho (SP)

Otoni Moreira Gomes (MG)

Paulo A. Lotufo (SP)

Paulo Cesar B. V. Jardim (GO)

Paulo J. F. Tucci (SP)

Paulo J. Moffa (SP)

Paulo R. A. Caramori (RS)

Paulo R. F. Rossi (PR)

Paulo Roberto S. Brofman (PR)

Paulo Zielinsky (RS)

Protásio Lemos da Luz (SP)

Renato A. K. Kalil (RS)

Roberto A. Franken (SP)

Roberto Bassan (RJ)

Ronaldo da Rocha Loures Bueno (PR)

Sandra da Silva Mattos (PE)

Sergio Almeida de Oliveira (SP)

Sérgio Emanuel Kaiser (RJ)

Sergio G. Rassi (GO)

Sérgio Salles Xavier (RJ)

Sergio Timerman (SP)

Silvia H. G. Lage (SP)

Valmir Fontes (SP)

Vera D. Aiello (SP)

Walkiria S. Avila (SP)

William Azem Chalela (SP)

Wilson A. Oliveira Jr (PE)

Wilson Mathias Jr (SP)

\section{Exterior}

Adelino F. Leite-Moreira (Portugal)

Alan Maisel (Estados Unidos)

Aldo P. Maggioni (Itália)

Cândida Fonseca (Portugal)

Fausto Pinto (Portugal)

Hugo Grancelli (Argentina)

James de Lemos (Estados Unidos)

João A. Lima (Estados Unidos)

John G. F. Cleland (Inglaterra)

Maria Pilar Tornos (Espanha)

Pedro Brugada (Bélgica)

Peter A. McCullough (Estados Unidos)

Peter Libby (Estados Unidos)

Piero Anversa (Itália) 
Presidente

Jadelson Pinheiro de Andrade

Vice-Presidente

Dalton Bertolim Précoma

Presidente-Eleito

Angelo Amato Vincenzo de Paola

Diretor Administrativo

Marcelo Souza Hadlich

Diretor Financeiro

Eduardo Nagib Gaui

Diretor de Relações Governamentais

Daniel França Vasconcelos

Diretor de Comunicação

Carlos Eduardo Suaide Silva

Diretor de Qualidade Assistencial José Xavier de Melo Filho

Diretor Científico

Luiz Alberto Piva e Mattos

Diretor de Promoção de Saúde

Cardiovascular - SBC/Funcor

Carlos Alberto Machado

Diretor de Relações

Estaduais e Regionais

Marco Antonio de Mattos

Diretor de Departamentos

Especializados

Gilberto Venossi Barbosa

Diretor de Tecnologia da Informação

Carlos Eduardo Suaide Silva

Diretor de Pesquisa

Fernando Bacal

Editor-Chefe Arquivos Brasileiros de Cardiologia

Luiz Felipe P. Moreira
Editor do Jornal SBC

Fábio Vilas-Boas Pinto

Coordenador do Conselho de Projeto

Epidemiológico

David de Pádua Brasil

Coordenadores do Conselho de Ações Sociais

Alvaro Avezum Junior

Ari Timerman

Coordenadora do Conselho de Novos Projetos Glaucia Maria Moraes Oliveira

Coordenador do Conselho de Aplicação de Novas Tecnologias

Washington Andrade Macie

Coordenador do Conselho de Inserção do Jovem Cardiologista

Fernando Augusto Alves da Costa

Coordenador do Conselho de Avaliação da Qualidade da Prática Clínica e Segurança do Paciente

Evandro Tinoco Mesquita

Coordenador do Conselho de

Normatizações e Diretrizes

Harry Correa Filho

Coordenador do Conselho de Educação

Continuada

Antonio Carlos de Camargo Carvalho

Comitê de Atendimento de Emergência e Morte Súbita

Manoel Fernandes Canesin

Nabil Ghorayeb

Sergio Timerman

Comitê de Prevenção Cardiovascular Antonio Delduque de Araujo Travessa Sergio Baiocchi Carneiro

Regina Coeli Marques de Carvalho

Comitê de Planejamento Estratégico Fabio Sândoli de Brito

José Carlos Moura Jorge

Walter José Gomes

Comitê de Assistência ao Associado

Maria Fatima de Azevedo

Mauro José Oliveira Goncalves

Ricardo Ryoshim Kuniyoshi
Comitê de Relações Internacionais

Antonio Felipe Simão

João Vicente Vitola

Oscar Pereira Dutra

Presidentes das Estaduais e Regionais da SBC

SBC/AL - Alfredo Aurelio Marinho Rosa

SBC/AM - Jaime Giovany Arnez Maldonado

SBC/BA - Augusto José Gonçalves de Almeida

SBC/CE - Eduardo Arrais Rocha

SBC/CO - Hernando Eduardo Nazzetta (GO)

SBC/DF - Renault Mattos Ribeiro Junior

SBC/ES - Antonio Carlos Avanza Junior

SBC/GO - Luiz Antonio Batista de Sá

SBC/MA - Magda Luciene de Souza Carvalho

SBC/MG - Maria da Consolação Vieira

Moreira

SBC/MS - Sandra Helena Gonsalves de Andrade

SBC/MT - José Silveira Lage

SBC/NNE - Aristoteles Comte de Alencar Filho (AM)

SBC/PA - Claudine Maria Alves Feio

SBC/PB - Alexandre Jorge de Andrade Negri

SBC/PE - Silvia Marinho Martins

SBC/PI - Ricardo Lobo Furtado

SBC/PR - Álvaro Vieira Moura

SBC/RJ - Glaucia Maria Moraes Oliveira

SBC/RN - Carlos Alberto de Faria

SBC/RS - Justo Antero Sayão Lobato Leivas

SBC/SC - Conrado Roberto Hoffmann Filho

SBC/SE - Eduardo José Pereira Ferreira

SBC/SP - Carlos Costa Magalhães

SBC/TO - Adalgele Rodrigues Blois

\section{Presidentes dos Departamentos Especializados e Grupos de Estudos}

SBC/DA - Hermes Toros Xavier (SP)

SBC/DCC - Evandro Tinoco Mesquita (RJ)

SBC/DCM - Orlando Otavio de Medeiros (PE)

SBC/DCC/CP - Estela Suzana Kleiman Horowitz (RS)

SBC/DECAGE - Abrahão Afiune Neto (GO)

SBC/DEIC - João David de Souza Neto (CE)

SBC/DERC - Pedro Ferreira de

Albuquerque $(\mathrm{AL})$
SBC/DFCVR - José Carlos Dorsa Vieira Pontes (MS)

SBC/DHA - Weimar Kunz Sebba Barroso de Souza $(\mathrm{GO})$

SBC/DIC - Jorge Eduardo Assef (SP)

SBC/SBCCV - Walter José Gomes (SP)

SBC/SBHCI - Marcelo Antonio Cartaxo Queiroga Lopes (PB)

SBC/SOBRAC - Adalberto Menezes Lorga Filho (SP)

SBC/DCC/GAPO - Daniela Calderaro (SP)
SBC/DCC/GECETI - João Fernando Monteiro Ferreira (SP)

SBC/DCC/GEECABE - Luis Claudio Lemos Correia (BA)

SBC/DCC/GEECG - Carlos Alberto Pastore (SP)

SBC/DCP/GECIP - Angela Maria Pontes Bandeira de Oliveira (PE)

SBC/DERC/GECESP - Daniel Jogaib Daher (SP)

SBC/DERC/GECN - José Roberto Nolasco de Araújo (AL) 


\section{Arquivos Brasileiros de Cardiologia}

Volume 101, № 6, Suplemento 2, Dezembro 2013

Indexação: ISI (Thomson Scientific), Cumulated Index Medicus (NLM), SCOPUS, MEDLINE, EMBASE, LILACS, SciELO, PubMed

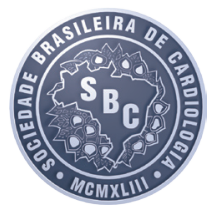

Av. Marechal Câmara, 160 - 3o andar - Sala 330

20020-907 • Centro • Rio de Janeiro, RJ • Brasil

Tel.: (21) 3478-2700

E-mail: arquivos@cardiol.br

www.arquivosonline.com.br

SCIELO: www.scielo.br

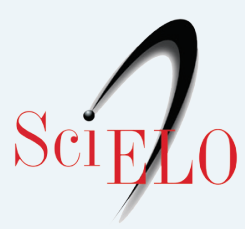

AMB

Filiada à Associação Médica Brasileira

\section{Produção Gráfica e Diagramação}

Ampel Produções Editoriais
Departamento Comercial

Telefone: (11) 3411-5500

e-mail: comercialsp@cardiol.br

Produção Editorial

SBC - Núcleo Interno de Publicações
Os anúncios veiculados nesta edição são de exclusiva responsabilidade dos anunciantes, assim como os conceitos emitidos em artigos assinados são de exclusiva responsabilidade de seus autores, não refletindo necessariamente a opinião da SBC.
Material de distribuição exclusiva à classe médica. Os Arquivos Brasileiros de Cardiologia não se responsabilizam pelo acesso indevido a seu conteúdo e que contrarie a determinação em atendimento à Resolução da Diretoria Colegiada (RDC) no 96/08 da Agência Nacional de Vigilância Sanitária (Anvisa), que atualiza o regulamento técnico sobre Propaganda, Publicidade, Promoção e informação de Medicamentos. Segundo o artigo 27 da insígnia, "a propaganda ou publicidade de medicamentos de venda sob prescrição deve ser restrita, única e exclusivamente, aos profissionais de saúde habilitados a prescrever ou dispensar tais produtos (...)".

Garantindo o acesso universal, o conteúdo científico do periódico continua disponível para acesso gratuito e integral a todos os interessados no endereço: www.arquivosonline.com.br.
APOIO

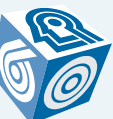

QCNPq GO ANOS

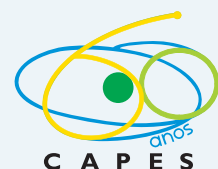

C A P E S
Ministério da

Educação

\section{Ministério da Ciência e Tecnologia}

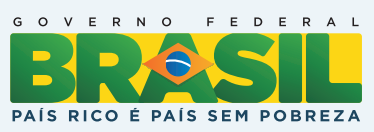




\section{Sumário}

Apresentação

página 2

Introdução

página 2

1. Estratificação de risco

página 3

Estratificação de risco cardiovascular para prevenção e tratamento da aterosclerose

página 3

Estratificação de risco por etapas

página 3

Fase 1 - Presença de doença aterosclerótica significativa ou de seus equivalentes.

página 3

Fase 2 - Escore de risco

página 3

Fase 3 - Fatores agravantes

página 3

Fase 4 - Estratificação do risco pelo tempo de vida

página 5

2. Fumo

página 7

Prevenção do Tabagismo

página 7

Prevenção primordial do tabagismo

página 7

Fatores que contribuem para a iniciação de fumar ......................................................................... página 7

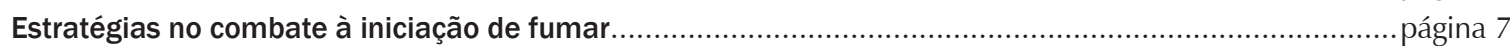

Como tratar a dependência psicológica do fumante ................................................................... página 8

Instrumentos que ajudam na avaliação e na compreensão do perfil do paciente: ................................. página 8

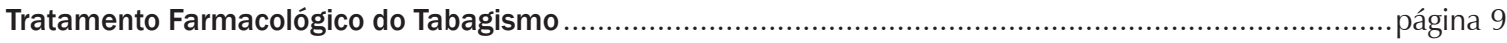

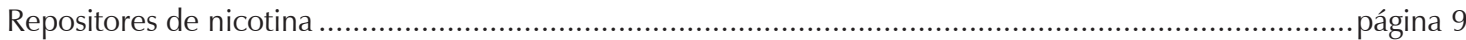

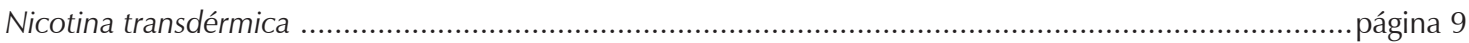

Nicotina de uso oral - goma ou pastilha de nicotina ...................................................................... página 10

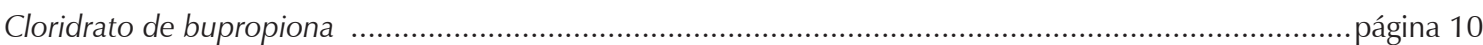

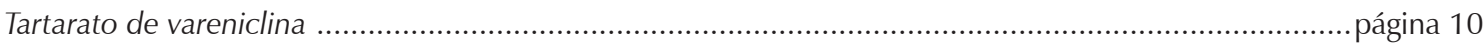

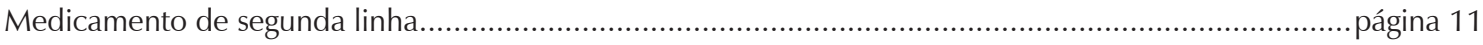

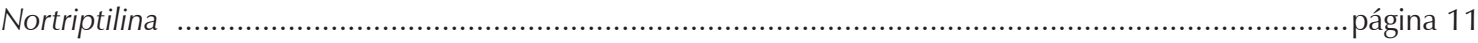

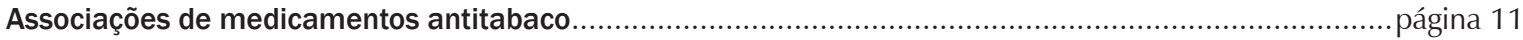

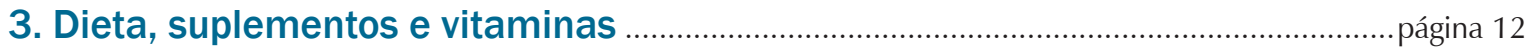

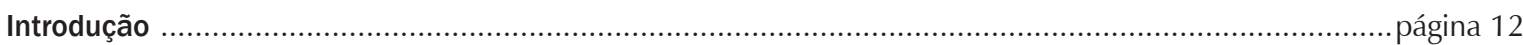

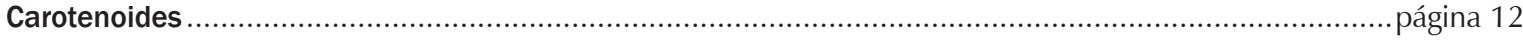

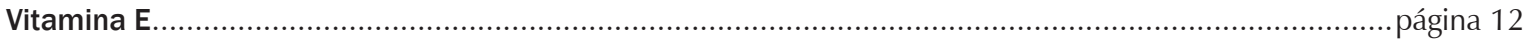

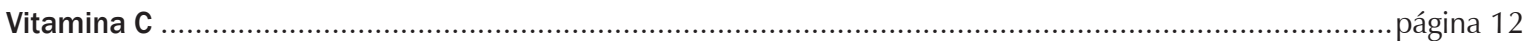

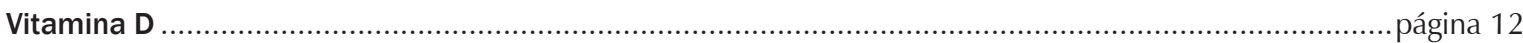

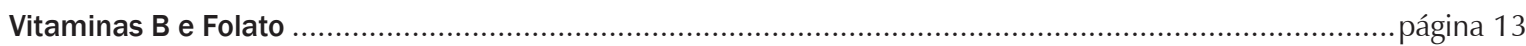

Ácidos graxos poliinsaturados ômega-3 de origem marinha (docosaexaenoico (DHA) e

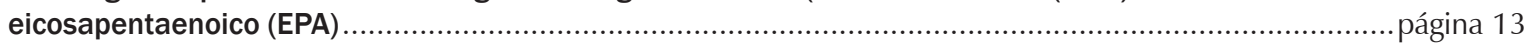

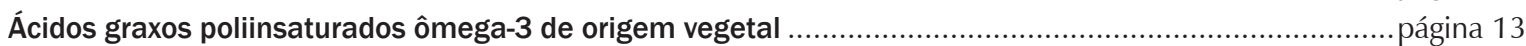

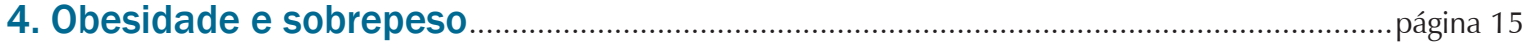

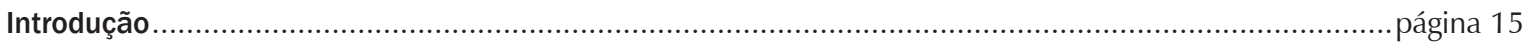

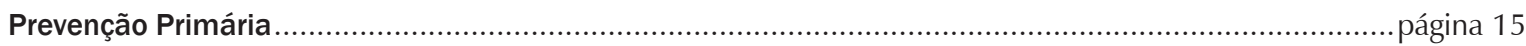

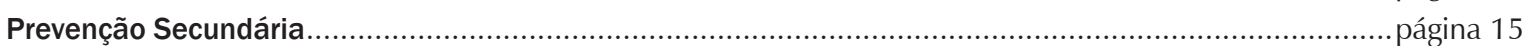

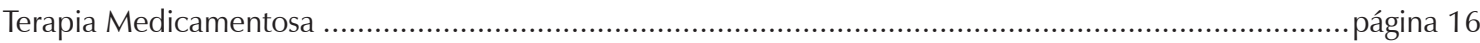

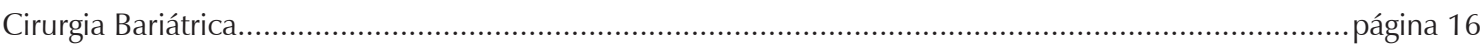

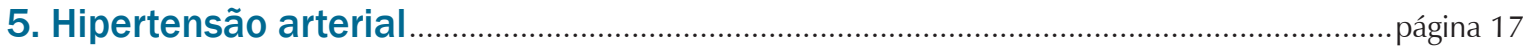

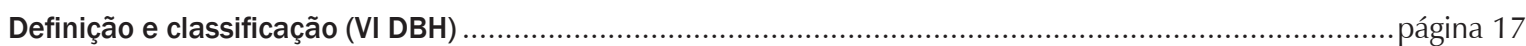




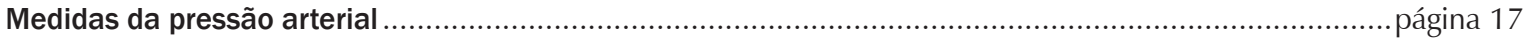

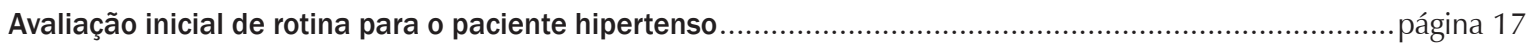

Identificação de lesões subclínicas de órgãos-alvo....................................................................... página 18

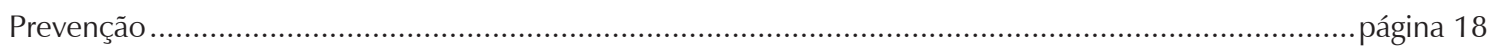

Prevenção Primária da HAS ........................................................................................................... página 18

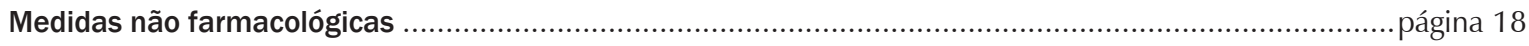

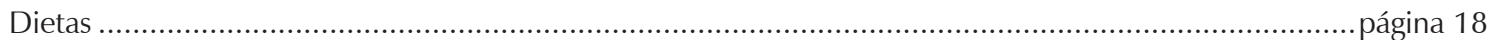

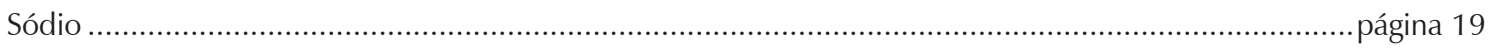

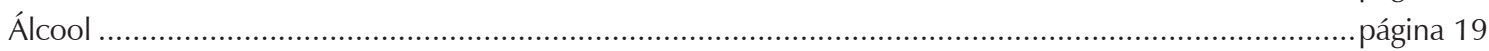

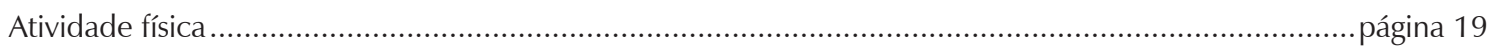

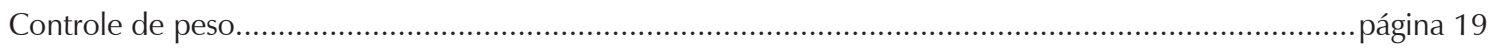

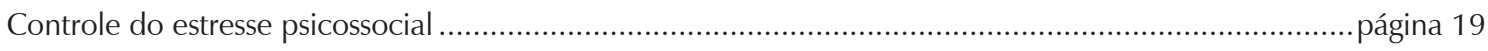

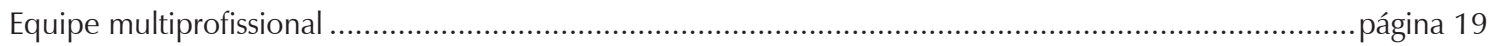

Outras estratégias não farmacológicas para o controle da pressão arterial ......................................... página 19

Medidas medicamentosas na prevenção da hipertensão .................................................................... página 19

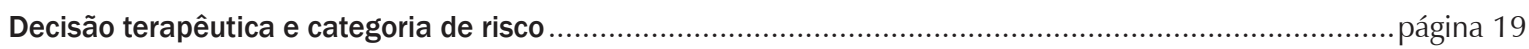

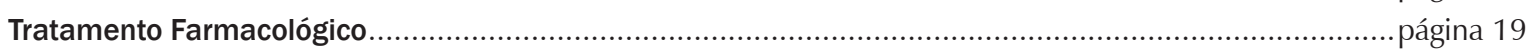

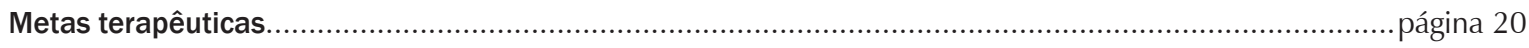

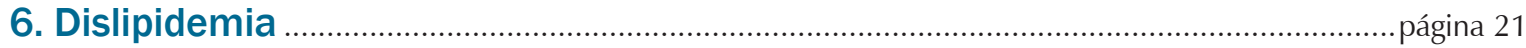

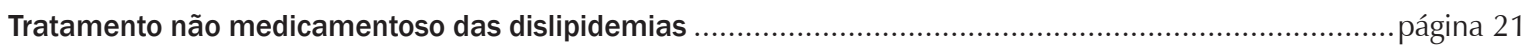

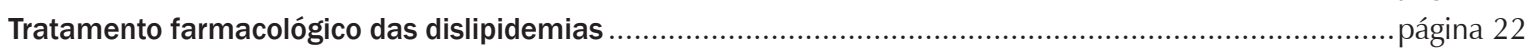

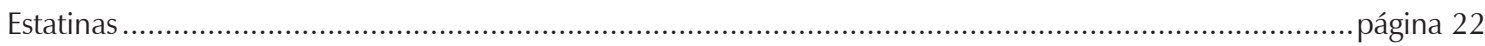

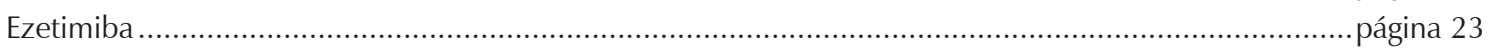

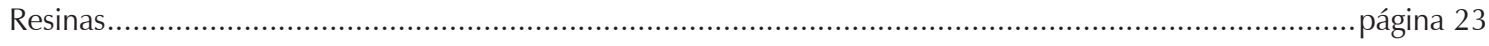

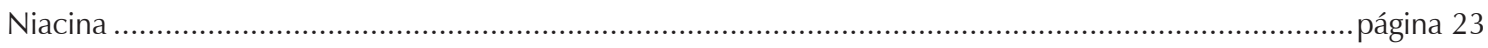

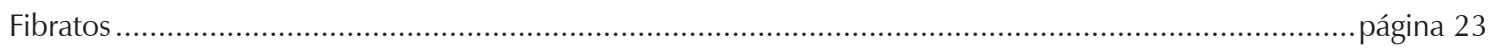

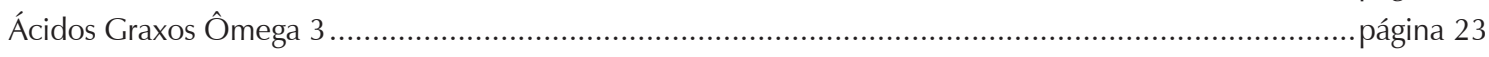

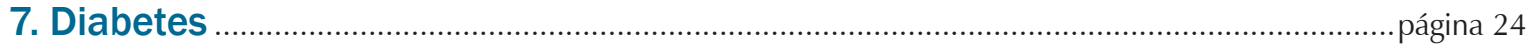

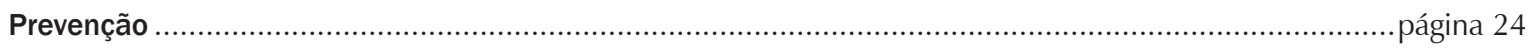

8. Síndrome Metabólica ....................................................................................................página 25

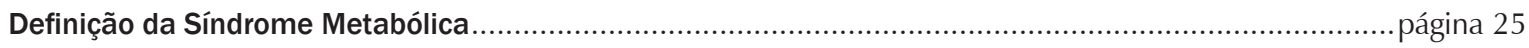

Prevalência da síndrome metabólica em diferentes grupos populacionais......................................... página 25

Riscos Cardiovascular e Metabólico Associados à SM ..................................................................... página 25

Fatores de Risco para a Síndrome Metabólica................................................................................ página 26

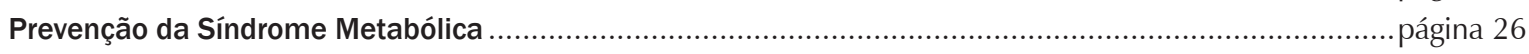

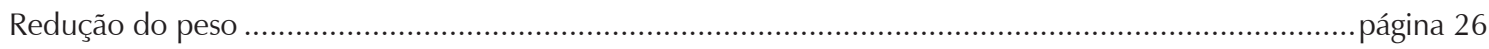

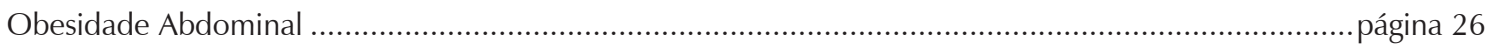

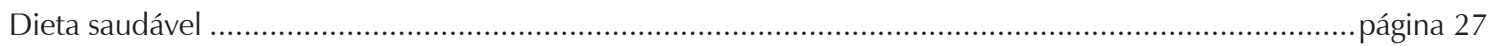

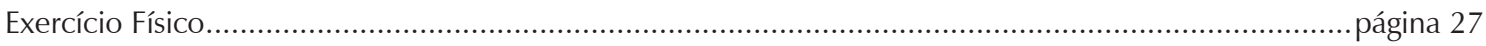

Modificações no estilo de vida versus terapia farmacológica ........................................................... página 27

9. Atividade física, exercício físico e esporte .................................................................. página 28

Conceitos e expressões mais relevantes......................................................................................... página 28

Principais Efeitos Agudos e Crônicos do Exercício ......................................................................... página 28

Fundamentação Epidemiológica dos Benefícios do Exercício Físico ..................................................página 29 
Riscos da Prática da Atividade Física, do Exercício Físico e do Esporte.

página 29

Prescrição de Exercícios.

página 29

Atividade Física Formal e Informal: Estratégias para Incentivar o Encaminhamento, o Implemento e

a Adesão

página 30

10. Fatores de risco psicossociais.

página 31

Definições e Impacto.

página 31

Avaliação dos fatores de risco psicossociais.

página 31

Valor das Intervenções sobre os Fatores de Risco Pricossociais

página 31

"Dez passos estratégicos" para melhorar o aconselhamento para mudanças comportamentais

página 32

Futuras Direções

página 32

Adesão às estratégias em prevenção cardiovascular: estilo de vida e medicamentos.....

página 32

Definição

página 32

Impacto

página 33

Causas

página 33

Avaliação

página 33

Intervenções.

página 33

11. Infância e adolescência

página 35

Dislipidemia

página 35

Epidemologia no Brasil

página 35

Triagem

página 35

Valores de referência

página 35

Tratamento

página 35

Mudança do estilo de vida

página 35

Terapia medicamentosa....

página 35

Obesidade

página 38

Definição e Epidemiologia.

página 38

Prognóstico .....

página 38

Diagnóstico.....

página 38

Prevenção e Tratamento

página 38

Hipertensão Arterial Sistêmica.

página 38

Atividade física

página 40

12. Legislação e prevenção dos fatores de riscos para doenças cardiovasculares

página 42

Introdução

página 42

13. Tópicos em prevenção

página 46

Doenças autoimunes e doença cardiovascular

página 46

Influenza e doença cardiovascular.

página 47

Doença Renal crônica

página 48

Doença Arterial Obstrutiva

página 48

Fatores Socioeconômicos

página 49

Apneia obstrutiva do sono

página 49

Disfunção erétil

página 50

Periodontite

página 50

Referências bibliográficas 


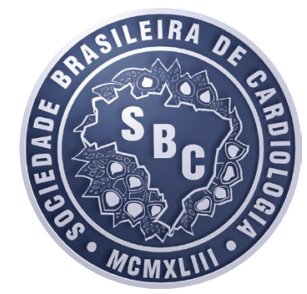

\section{Diretriz Brasileira de Prevenção Cardiovascular}

\section{REALIZAÇÃo}

Sociedade Brasileira de Cardiologia

\section{Conselho de Normatizações e Diretrizes}

Antônio Carlos Sobral Sousa, Harry Correa Filho, Iran Castro, Marcus Vinícius Bolivar Malachias, Mário Sérgio de Carvalho Bacellar

\section{Coordenador do Conselho de Normatizações e Diretrizes}

Harry Correa Filho

\section{CoOrdenador}

Antônio Felipe Simão

\section{Presidente da Sociedade Brasileira de Cardiologia (GESTÃo 2012-2013)}

Jadelson Pinheiro de Andrade

\section{ConselHo de Redação}

Harry Correa Filho, Antônio Felipe Simão, Dalton Bertolim Précoma, Gláucia Maria Moraes de Oliveira

\section{EDITORES}

Jadelson Pinheiro de Andrade, Andrei de Carvalho Sposito, Dalton Bertolim Précoma, Jose Francisco Kerr Saraiva, Oscar Pereira Dutra e Gláucia Maria Moraes de Oliveira

Esta diretriz deverá ser citada como:

Simão AF, Précoma DB, Andrade JP, Correa Filho H, Saraiva JFK, Oliveira GMM, et al. Sociedade Brasileira de Cardiologia. I Diretriz Brasileira de Prevenção Cardiovascular.

Arq Bras Cardiol. 2013: 101 (6Supl.2): 1-63

Correspondência:

Sociedade Brasileira de Cardiologia

Av. Marechal Câmara, 360/330 - Centro - Rio de Janeiro - CEP: 20020-907

e-mail: sbc@cardiol.br 


\section{Grupos de trabalho}

\section{Grupo 1 - Estratificação de Risco}

Coordenador: Francisco Antonio Helfenstein Fonseca. Participantes: Sergio Emanuel Kaiser, Marcelo Chiara Bertolami, Maria Cristina O Izar e Emilio H Moriguchi.

\section{Grupo 2 - Fumo}

Coordenador: Aristoteles Comte de Alencar Filho. Participantes: Aloyzio Achutti, Carla Janice Lantieri, Jaqueline Scholz Issa, Silvia Cury Ismael.

\section{Grupo 3 - Dieta, Suplementos e Vitaminas}

Coordenador: Raul Dias dos Santos Filho. Participantes: Ana Maria Pita Lotemberg, Ana Carolina Moron Gagliardi, Roberta Lara Cassani, Marcio Hihoshi Miname.

\section{Grupo 4 - Obesidade e Sobrepeso}

Coordenador: Carlos Scherr. Participantes: Walmir Coutinho, Adriana Campos e Ana Paula Lins.

\section{Grupo 5 - Hipertensão Arterial}

Coordenador: Marcus Vinícius Bolivar Malachias. Participantes: Weimar Kunz Sebba Barroso de Souza, Celso Amodeo, Paulo Cesar Brandão Veiga Jardim, Luiz Aparecido Bortolotto, Rui Manuel dos Santos Povoa.

\section{Grupo 6 - Dislipidemia}

Coordenador: Jose Rocha Faria Neto. Participantes: Andre Arpad Faludi, Carolina Stoll, Hermes Toros Xavier, Marcelo Chiara Bertolimi, Viviane Z. Rocha.

Grupo 7 - Diabetes

Coordenador: Otávio Rizzi Coelho. Participantes: Jose Roberto Matos de Souza.

\section{Grupo 8 - Síndrome Metabólica}

Coordenador: Andréa Araujo Brandão. Participantes: Emilia Moriguchi, Maria Eliane Campos Magalhães, Walmir Coutinho, Alexandre Alessi e Antonio Felipe Sanjuliani.

\section{Grupo 9 - Atividade Física}

Coordenador: Artur Haddad Herdy. Participantes: Claudio Gil Soares de Araujo, Mauricio Milani, Nabil Ghorayeb, Ricardo Stein e Tales de Carvalho

\section{Grupo 10 - Fatores Psicosociais}

Coordenador: Mauricio Wajngarten. Participantes: Alvaro Avezum Junior, Carise Anne Polanczyk, Evandro Tinoco Mesquita e Gilson Soares Feitosa.

\section{Grupo 11 - Infância e Adolescência}

Coordenadora: Isabela de Carlos Back Giuliano. Participantes: Lucia Campos Pellanda, Ivan Romero Rivera e Maria Alayde Mendonça R.Rivera.

\section{Grupo 12 - Legislação}

Coordenador: Carlos Alberto Machado. Participantes: Antonio Silveira Sbissa, Marco Antonio Mota Gomes, Geniberto Paiva Campos, Lucelia Batista N. Cunha, Lenildo de Moura e Romero Bezerra Barbosa.

\section{Grupo 13 - Tópicos em Prevenção}

Coordenador: Glaucia Maria Moraes de Oliveira. Participantes: Roberto Muniz Ferreira, Paolo Branco Vilela e Gabriel Porto Soares. 


\begin{tabular}{|c|c|c|c|c|c|c|c|}
\hline $\begin{array}{c}\text { Nomes Integrantes } \\
\text { da Diretriz }\end{array}$ & $\begin{array}{l}\text { Participou de estudos } \\
\text { clínicos elou experimentais } \\
\text { subvencionados pela } \\
\text { indústria farmacêutica } \\
\text { ou de equipamentos } \\
\text { relacionados à diretriz em } \\
\text { questão } \\
\end{array}$ & $\begin{array}{l}\text { Foi palestrante } \\
\text { em eventos } \\
\text { ou atividades } \\
\text { patrocinadas } \\
\text { pela indústria } \\
\text { relacionados à } \\
\text { diretriz em questão } \\
\end{array}$ & $\begin{array}{c}\text { Foi (é) membro } \\
\text { do conselho } \\
\text { consultivo ou } \\
\text { diretivo da indústria } \\
\text { farmacêutica ou de } \\
\text { equipa- } \\
\text { mentos } \\
\end{array}$ & $\begin{array}{c}\text { Participou } \\
\text { de comitês } \\
\text { normativos de } \\
\text { estudos científicos } \\
\text { patroci- } \\
\text { nados pela } \\
\text { indústria } \\
\end{array}$ & $\begin{array}{l}\text { Recebeu auxílio } \\
\text { pessoal ou } \\
\text { institucional da } \\
\text { indústria }\end{array}$ & $\begin{array}{l}\text { Elaborou textos } \\
\text { científicos em } \\
\text { periódicos } \\
\text { patroci- } \\
\text { nados pela } \\
\text { indústria }\end{array}$ & $\begin{array}{l}\text { Tem } \\
\text { ações } \\
\text { da } \\
\text { indústria }\end{array}$ \\
\hline \multicolumn{8}{|c|}{ Informar o nome da empresa em caso de resposta positiva } \\
\hline $\begin{array}{c}\text { Adriana Campos } \\
\text { Junqueira de Souza }\end{array}$ & Não & Não & Não & Não & Não & Não & Não \\
\hline Alexandre Alessi & Não & Não & Não & Não & Não & Não & Não \\
\hline Álvaro Avezum Junior & Não & Não & Não & $\begin{array}{c}\text { Population } \\
\text { Health Research } \\
\text { Institute, McMaster } \\
\text { University, } \\
\text { Hamilton, Canada }\end{array}$ & Não & Não & Não \\
\hline $\begin{array}{c}\text { Aloyzio Cechella } \\
\text { Achutti }\end{array}$ & Não & Não & Não & Não & Não & Não & Não \\
\hline $\begin{array}{c}\text { Ana Carolina Moron } \\
\text { Gagliardi }\end{array}$ & Não & Não & Não & Não & Não & Não & Não \\
\hline $\begin{array}{l}\text { Ana Maria Pita } \\
\text { Lotemberg }\end{array}$ & Não & Não & Não & Não & Não & Não & Não \\
\hline $\begin{array}{c}\text { Ana Paula Machado } \\
\text { Lins }\end{array}$ & Não & Não & Não & Não & Não & Não & Não \\
\hline Andre Arpad Falud & Não & Não & Não & Não & Não & Não & Não \\
\hline Andrea Araújo Brandão & Não & $\begin{array}{l}\text { Servier, Biolab, } \\
\text { Astra Zeneca, } \\
\text { Novartis, Chiesi, } \\
\text { Daiichi Sankyo }\end{array}$ & Biolab, Servier & Não & $\begin{array}{l}\text { Servier, Daiichi } \\
\text { Sankyo, Biolab }\end{array}$ & $\begin{array}{l}\text { Medley, Biolab, } \\
\text { Servier, Astra } \\
\text { Zeneca, } \\
\text { Novartis, Daiichi } \\
\text { Sankyo }\end{array}$ & Não \\
\hline Antônio Felipe Simão & Não & Não & Não & Não & Não & Não & Não \\
\hline $\begin{array}{l}\text { Antônio Felipe } \\
\text { Sanjuliani }\end{array}$ & Não & Não & Não & Não & Não & Não & Não \\
\hline Antônio Silveira Sbissa & Não & Não & Não & Não & Não & Não & Não \\
\hline $\begin{array}{l}\text { Aristóteles Comte } \\
\text { Alencar Filho }\end{array}$ & Não & Não & Não & Não & $\begin{array}{l}\text { Biolab, Pfizer, } \\
\text { Bayer }\end{array}$ & Não & Não \\
\hline Artur Haddad Herdy & Não & Não & Não & Não & Não & Não & Não \\
\hline Carise Anne Polanczyk & Não & Não & Não & Não & Não & Não & Não \\
\hline Carla Janice Lantieri & Não & Não & Não & Não & Não & Não & Não \\
\hline $\begin{array}{l}\text { Carlos Alberto } \\
\text { Machado }\end{array}$ & Não & Não & Não & Não & Não & Não & Não \\
\hline Carlos Scherr & Não & Coca-Cola, Unilever & Não & Não & $\begin{array}{c}\text { Novartis, Biolab, } \\
\text { Astrazeneca, } \\
\text { Bayer, Ache,MSD, } \\
\text { Boehringer }\end{array}$ & MSD, Nycomed & Não \\
\hline Carolina Stoll & Não & Não & Não & Não & Não & Não & Não \\
\hline Celso Amodeo & $\begin{array}{c}\text { astra zeneca, Biolab, ache, } \\
\text { novartis, Sankyo, Takeda }\end{array}$ & $\begin{array}{c}\text { astra zeneca, } \\
\text { Biolab, ache, } \\
\text { novartis, Sankyo, } \\
\text { Takeda }\end{array}$ & $\begin{array}{c}\text { astra zeneca, Biolab, } \\
\text { ache, novartis, } \\
\text { Sankyo, Takeda }\end{array}$ & $\begin{array}{c}\text { astra zeneca, } \\
\text { Biolab, ache, } \\
\text { novartis, Sankyo, } \\
\text { Takeda }\end{array}$ & $\begin{array}{c}\text { astra zeneca, } \\
\text { Biolab, ache, } \\
\text { novartis, Sankyo, } \\
\text { Takeda }\end{array}$ & $\begin{array}{c}\text { astra zeneca, } \\
\text { Biolab, ache, } \\
\text { novartis, } \\
\text { Sankyo, Takeda }\end{array}$ & Não \\
\hline $\begin{array}{c}\text { Cláudio Gil Soares de } \\
\text { Araújo }\end{array}$ & Não & Não & Não & Não & Não & Não & Não \\
\hline $\begin{array}{l}\text { Dalton Bertolim } \\
\text { Precoma }\end{array}$ & Não & Não & Não & Não & Não & Não & Não \\
\hline Denise Saraiva & Não & Não & Não & Não & Não & Não & Não \\
\hline Emílio H. Moriguchi & Pfizer & $\begin{array}{l}\text { Biolab, Daiichi- } \\
\text { Sankyo, MSD }\end{array}$ & $\begin{array}{c}\text { Merck, } \\
\text { Daiichi-Sankyo }\end{array}$ & Não & $\begin{array}{l}\text { Merck, Daiichi- } \\
\text { Sankyo, Biolab }\end{array}$ & Biolab & Não \\
\hline $\begin{array}{l}\text { Evandro Tinoco } \\
\text { Mesquita }\end{array}$ & Não & Não & Não & Não & Não & Não & Não \\
\hline $\begin{array}{l}\text { Francisco Antônio } \\
\text { Helfenstein Fonseca }\end{array}$ & $\begin{array}{c}\text { Novartis, Aché, Libbs, } \\
\text { MSD, AstraZeneca, Torrent, } \\
\text { Novartis }\end{array}$ & & & Novartis & & $\begin{array}{c}\text { AstraZeneca, } \\
\text { Novartis, } \\
\text { Biolab, Aché, } \\
\text { Pfizer, BMS, } \\
\text { Libbs, MSD, } \\
\text { Nestlé, } \\
\text { Hypermarcas }\end{array}$ & \\
\hline $\begin{array}{l}\text { Geniberto Paiva } \\
\text { Campos }\end{array}$ & Não & Não & Não & Não & Não & Não & Não \\
\hline Gabriel Porto Soares & Não & Não & Não & Não & Novartis & Aché, Bristol & Não \\
\hline Gilson Soares Feitosa & Não & Não & Não & Não & Não & Não & Não \\
\hline $\begin{array}{c}\text { Gláucia Maria Moraes } \\
\text { de Oliveira }\end{array}$ & Não & Não & Não & Não & Não & Não & Não \\
\hline Harry Correa Filho & Não & Não & Não & Não & Não & Não & Não \\
\hline Hermes Toros Xavier & Pfizer, AstraZeneca & $\begin{array}{l}\text { Aché, Amgen, } \\
\text { AstraZeneca, } \\
\text { Biolab, Chiesi, } \\
\text { MSD, Novartis, } \\
\text { Pfizer, Torrent }\end{array}$ & $\begin{array}{l}\text { Amgen, MSD, } \\
\text { Torrent }\end{array}$ & Não & $\begin{array}{l}\text { Amgen, MSD, } \\
\text { Torrent }\end{array}$ & $\begin{array}{l}\text { Aché, Amgen, } \\
\text { AstraZeneca, } \\
\text { Biolab, Chiesi, } \\
\text { MSD, Novartis, } \\
\text { Pfizer, Torrent. }\end{array}$ & Não \\
\hline $\begin{array}{c}\text { Isabela de Carlo Back } \\
\text { Giuliano }\end{array}$ & Não & Não & Não & Não & Não & Não & Não \\
\hline Ivan Romero Rivera & Não & Não & Não & Não & Não & Não & Não \\
\hline
\end{tabular}




\begin{tabular}{|c|c|c|c|c|c|c|c|}
\hline $\begin{array}{c}\text { Nomes Integrantes } \\
\text { da Diretriz }\end{array}$ & $\begin{array}{l}\text { Participou de estudos } \\
\text { clínicos elou experimentais } \\
\text { subvencionados pela } \\
\text { indústria farmacêutica } \\
\text { ou de equipamentos } \\
\text { relacionados à diretriz em } \\
\text { questão } \\
\end{array}$ & $\begin{array}{l}\text { Foi palestrante } \\
\text { em eventos } \\
\text { ou atividades } \\
\text { patrocinadas } \\
\text { pela indústria } \\
\text { relacionados à } \\
\text { diretriz em questão } \\
\end{array}$ & $\begin{array}{c}\text { Foi (é) membro } \\
\text { do conselho } \\
\text { consultivo ou } \\
\text { diretivo da indústria } \\
\text { farmacêutica ou de } \\
\text { equipa- } \\
\text { mentos } \\
\end{array}$ & $\begin{array}{c}\text { Participou } \\
\text { de comitês } \\
\text { normativos de } \\
\text { estudos científicos } \\
\text { patroci- } \\
\text { nados pela } \\
\text { indústria } \\
\end{array}$ & $\begin{array}{l}\text { Recebeu auxílio } \\
\text { pessoal ou } \\
\text { institucional da } \\
\text { indústria }\end{array}$ & $\begin{array}{l}\text { Elaborou textos } \\
\text { científicos em } \\
\text { periódicos } \\
\text { patroci- } \\
\text { nados pela } \\
\text { indústria }\end{array}$ & $\begin{array}{l}\text { Tem } \\
\text { ações } \\
\text { da } \\
\text { indústria }\end{array}$ \\
\hline \multicolumn{8}{|c|}{ Informar o nome da empresa em caso de resposta positiva } \\
\hline $\begin{array}{c}\text { Isabel Cristina Britto } \\
\text { Guimaraes }\end{array}$ & Não & Não & Não & Não & Não & Não & Não \\
\hline $\begin{array}{l}\text { Jadelson Pinheiro de } \\
\text { Andrade }\end{array}$ & Não & Não & Não & Não & Não & Não & Não \\
\hline Jaqueline Scholz Issa & Pfizer & $\begin{array}{c}\text { Pfizer, } \\
\text { Johnson\&Johnson, } \\
\text { Glaxo-Smith Kline }\end{array}$ & Não & Não & Não & Não & Não \\
\hline $\begin{array}{l}\text { Jose Francisco Kerr } \\
\text { Saraiva }\end{array}$ & AstraZeneca, Daichii Sankyo & $\begin{array}{l}\text { AstraZeneca, } \\
\text { Boheringer, Pfizer, } \\
\text { BMS, Chiesi, Daichii } \\
\text { Sankyo }\end{array}$ & $\begin{array}{l}\text { Boheringer, Pfizer, } \\
\text { BMS, NovoNordisk }\end{array}$ & AstraZeneca & Não & $\begin{array}{l}\text { Novartis, Nova } \\
\text { Quimica, } \\
\text { Boheringer }\end{array}$ & Não \\
\hline $\begin{array}{c}\text { José Roberto Matos de } \\
\text { Souza }\end{array}$ & Não & Não & Não & Não & Não & Não & Não \\
\hline José Rocha Faria Neto & Astra Zeneca, Daichi Sankyo & $\begin{array}{l}\text { Astra Zeneca, } \\
\text { Daichi Sankyo, } \\
\text { Boehringer } \\
\text { Ingelheim, MSD }\end{array}$ & Não & Não & Não & MSD & Não \\
\hline $\begin{array}{l}\text { Lucelia Batista N. } \\
\text { Cunha }\end{array}$ & Não & Não & Não & Não & Não & Não & Não \\
\hline $\begin{array}{l}\text { Lucia Campos } \\
\text { Pellanda }\end{array}$ & Não & Não & Não & Não & Não & Não & Não \\
\hline $\begin{array}{l}\text { Luiz Aparecido } \\
\text { Bortolotto }\end{array}$ & Não & Não & Não & Não & Não & Não & Não \\
\hline $\begin{array}{l}\text { Marcelo Chiara } \\
\text { Bertolami }\end{array}$ & $\begin{array}{l}\text { MSD, Astrazeneca, Schering- } \\
\text { Plough, Pfizer, Novartis }\end{array}$ & $\begin{array}{c}\text { MSD, Astrazeneca, } \\
\text { Biolab, Pfizer, } \\
\text { Novartis, Aché, } \\
\text { Novaquímica, } \\
\text { Novonordisk, Bayer, } \\
\text { Libbs }\end{array}$ & Não & Não & Não & $\begin{array}{l}\text { MSD, Pfizer, } \\
\text { Novaquímica, } \\
\text { Aché }\end{array}$ & Não \\
\hline Márcio Hihoshi Miname & Não & Não & Não & Não & Não & Não & Não \\
\hline $\begin{array}{l}\text { Marco Antônio Mota } \\
\text { Gomes }\end{array}$ & Não & Não & $\begin{array}{l}\text { Biolab, Servier, } \\
\text { Omron }\end{array}$ & Torrent & $\begin{array}{l}\text { Biolab, Daiichi } \\
\text { Sankyo, Novartis, } \\
\text { Takeda }\end{array}$ & $\begin{array}{l}\text { Biolab, Torrent, } \\
\text { Novartis }\end{array}$ & Não \\
\hline $\begin{array}{c}\text { Marcus Vinícius Bolivar } \\
\text { Malachias }\end{array}$ & Não & $\begin{array}{l}\text { Servier, Boehringer- } \\
\text { Ingelheim, Torrent, } \\
\text { AstraZeneca, Pfizer, } \\
\text { Novartis }\end{array}$ & Não & Não & Não & $\begin{array}{l}\text { Servier, Nova } \\
\text { Química, Libbs, } \\
\text { Bayer }\end{array}$ & não \\
\hline $\begin{array}{c}\text { Maria Alayde } \\
\text { Mendonça da Silva }\end{array}$ & Não & Não & Não & Não & Não & Não & Não \\
\hline $\begin{array}{l}\text { Maria Cristina de } \\
\text { Oliveira Izar }\end{array}$ & $\begin{array}{c}\text { Amgen, Genzyme, Novartis, } \\
\text { Aché, MSD, Aegerion, } \\
\text { Unilever, Libbs }\end{array}$ & $\begin{array}{l}\text { MSD, Aché, } \\
\text { Aegerion, } \\
\text { UNILEVER }\end{array}$ & Não & Não & Aegerion & $\begin{array}{l}\text { Torrent, } \\
\text { Genzyme, } \\
\text { Libbs }\end{array}$ & Não \\
\hline $\begin{array}{c}\text { Maria Eliane Campos } \\
\text { Magalhães }\end{array}$ & Não & $\begin{array}{c}\text { AstraZeneca, Pfizer, } \\
\text { MSD }\end{array}$ & Não & Não & $\begin{array}{c}\text { Pfizer, } \\
\text { AstraZeneca }\end{array}$ & Nova Química & Não \\
\hline Maurício Milani & Não & Não & Não & Não & Não & Não & Não \\
\hline Maurício Wajngarten & Não & Não & Não & Não & Não & Não & Não \\
\hline Nabil Ghorayeb & Não & Não & Não & Não & Não & Não & Não \\
\hline Otávio Rizzi Coelho & Improve & Pfizer e Bayer & $\begin{array}{l}\text { Pilzer, Novo NoralsK } \\
\text { e Biolab }\end{array}$ & Não & $\begin{array}{l}\text { lakeda, Bayer e } \\
\text { Pfizer }\end{array}$ & AstraZeneca & Não \\
\hline Paolo Blanco Villela & Não & Não & Não & Não & Não & Não & Não \\
\hline $\begin{array}{l}\text { Paulo César Brandão } \\
\text { Veiga Jardim }\end{array}$ & Servier & $\begin{array}{l}\text { Novartis, Biolab, } \\
\text { Aché }\end{array}$ & Não & Não & Não & $\begin{array}{c}\text { Novartis, } \\
\text { Biolab, Aché }\end{array}$ & Não \\
\hline $\begin{array}{l}\text { Raul Dias dos Santos } \\
\text { Filho }\end{array}$ & $\begin{array}{l}\text { Pfizer, Astra Zeneca, ISIS, } \\
\text { MSD, Roche }\end{array}$ & $\begin{array}{l}\text { Pfizer, Astra } \\
\text { Zeneca, biolab, } \\
\text { BMS, Aegerion, } \\
\text { Novartis, MSD }\end{array}$ & $\begin{array}{l}\text { Pfizer,Astra Zeneca, } \\
\text { BMS, Biolab, } \\
\text { Aegerion, Genzyme, } \\
\text { Boehringer }\end{array}$ & nao & $\begin{array}{l}\text { Genzyme, } \\
\text { Aegerion, Biolab, } \\
\text { Sanofi, MSD }\end{array}$ & Biolab, MSD & Não \\
\hline Ricardo Stein & Não & Não & Não & Não & Não & Não & Não \\
\hline $\begin{array}{l}\text { Roberta Soares Lara } \\
\text { Cassani }\end{array}$ & Não & Gomes da Costa & Não & Não & Não & Não & Não \\
\hline $\begin{array}{l}\text { Roberto Luiz D'Avila } \\
\text { Roberto Muniz Ferreira }\end{array}$ & $\begin{array}{l}\text { Não } \\
\text { Não }\end{array}$ & $\begin{array}{l}\text { Não } \\
\text { Não }\end{array}$ & $\begin{array}{l}\text { Não } \\
\text { Não }\end{array}$ & $\begin{array}{l}\text { Não } \\
\text { Não }\end{array}$ & $\begin{array}{l}\text { Não } \\
\text { Não }\end{array}$ & $\begin{array}{l}\text { Não } \\
\text { Não }\end{array}$ & $\begin{array}{l}\text { Não } \\
\text { Não }\end{array}$ \\
\hline $\begin{array}{c}\text { Romero Bezerra } \\
\text { Barbosa }\end{array}$ & Não & Não & Não & Não & Não & Não & Não \\
\hline $\begin{array}{l}\text { Rui Manuel dos Santos } \\
\text { Povoa }\end{array}$ & Não & Não & Não & Não & Não & Não & Não \\
\hline Sérgio Emanuel Kaiser & Não & $\begin{array}{l}\text { MSD, Abbott, } \\
\text { Farmasa }\end{array}$ & Não & Não & Não & $\begin{array}{l}\text { Novaquimica, } \\
\text { Medley }\end{array}$ & Não \\
\hline $\begin{array}{l}\text { Silvia Cury Ismael } \\
\text { Tales de Carvalho }\end{array}$ & $\begin{array}{l}\text { Não } \\
\text { Não }\end{array}$ & $\begin{array}{l}\text { Não } \\
\text { Não }\end{array}$ & $\begin{array}{l}\text { Não } \\
\text { Não }\end{array}$ & $\begin{array}{l}\text { Não } \\
\text { Não }\end{array}$ & $\begin{array}{l}\text { Não } \\
\text { Não }\end{array}$ & $\begin{array}{l}\text { Não } \\
\text { Não }\end{array}$ & $\begin{array}{l}\text { Não } \\
\text { Não }\end{array}$ \\
\hline $\begin{array}{l}\text { Viviane Zorzanelli } \\
\text { Rocha Giraldez }\end{array}$ & Não & Não & Não & Não & Não & Não & Não \\
\hline Walmir Coutinho & Não & Não & Não & Não & Não & Não & Não \\
\hline $\begin{array}{l}\text { Weimar Kunz Sebba } \\
\text { Barroso de Souza }\end{array}$ & Não & Não & Não & Não & Não & Não & Não \\
\hline
\end{tabular}




\section{Definições para grau de recomendação e nível de evidência:}

\section{Grau de recomendação}

Classe I: condições para as quais há evidências conclusivas, na sua falta, consenso geral de que o procedimento é seguro e útil/eficaz.

Classe II: condições para as quais há evidências conflitantes e/ou divergência de opinião sobre segurança e utilidade/eficácia do procedimento.

Classe IIA: peso ou evidência/opinião a favor do procedimento. Aprovado pela maioria dos profissionais.

Classe IIB: segurança e utilidade/eficácia menos bem estabelecidas, não havendo predomínio de opiniões a favor do procedimento.

Classe III: condições para as quais há evidências e/ou consenso de que o procedimento não é útil/eficaz e, em alguns casos, pode ser prejudicial.

\section{Nível de evidência}

Nível A: dados obtidos a partir de múltiplos estudos randomizados de bom porte, concordantes e/ou de metanálise robusta de estudos clínicos randomizados.

Nível B: dados obtidos a partir de metanálise menos robusta, a partir de um único estudo randomizado ou de estudos não randomizados (observacionais).

Nível C: dados obtidos de opiniões consensuais de especialistas.

Vale salientar que níveis de evidência classificados como B ou C não podem ser interpretados como recomendações fracas. Existem muitas recomendações consensuais, portanto com grau de recomendação I, com nível de evidência C (opiniões de experts). Por outro lado, algumas indicações consideradas controversas (grau de recomendação II) poderão estar alicerçadas em ensaios clínicos randomizados (nível de evidência A). 


\section{Diretrizes}

\section{Apresentação}

Ao analizarmos a epidemiologia das Doenças Cardiovasculares, observamos que têm o mesmo comportamento neste inicio de século que tinham as grandes endemias dos séculos passados.

Isto fica claro observando os dados da Organização Mundial da Saúde, (OMS) nas últimas décadas nos quais das 50 milhões de mortes as Doenças Cardiovasculares (DCV) foram responsáveis por 30\% desta mortalidade, ou seja, 17 milhões de pessoas $^{1,2}$.

A identificação dos fatores de risco de maior prevalência populacional permitiu que programas de prevenção cardiovascular bem conduzidos em vários países a exemplo dos Estados Unidos, Canadá, Finlandia, Reino Unido, Australia e Japão, conseguissem reduzir de forma expressiva a mortalidade por doenças cardiovasculares ${ }^{3}$.

A partir deste perfil epidemiológico, da identificação dos fatores de risco e do resultado da aplicação destes programas, a Organização Mundial da Saúde estabeleceu como meta a redução de 25\% da Doenças Crônicas Não Tansmissiveis, (DCNT) dentre elas as Doenças Cardiovasculares até o ano de $2025^{4}$.

Em sintonia com esta proposta global e considerando que a realidade epidemiológica no Brasil, apresenta índices igualmente alarmantes de $30 \%$ de mortes por DCV dentre todas as outras causas relacionadas, a diretoria da Sociedade Brasileira de Cardiologia (SBC), na atual gestão, resolveu elaborar o "Programa Nacional de Prevenção Cardiovascular" e implementa-lo no país com objetivo de modificar esta realidade epidemiológica.

Diversos braços do Programa Nacional de Prevenção Cardiovascular já estão sendo aplicados no Brasil e com reflexos internacionais a exemplo da "Carta do $\operatorname{Rio}^{5}$ elaborada e assinada conjuntamente pela SBC e pelas mais importantes sociedades de cardiologia do mundo e divulgada nos seus portais e revistas de cardiologia. O Programa SBC vai a Escola, os Registros Brasileiros Cardiovasculares ${ }^{6}$, o acordo de Cooperação entre a SBC/OPAS/MS para aplicação do programa TECA A e TECA B ${ }^{7}$, o acordo de Cooperação com as Secretarias Estaduais e Municipais de Saúde para qualificação dos médicos de Saúde Pública ${ }^{8}$ e o acordo SBC/ CNBB/ Pastoral da Saúde, são alguns destes exemplos que já começa a mostra impacto de resultados com divulgaçãoo no Brasil e em foruns internacionais.

A proposta da realizaçãoo da I Diretriz Brasileira de Prevenção Cardiovascular da Sociedade Brasileira de Cardiologia é mais uma etapa relevante deste programa.

Com este documento a SBC apresenta a cardiolgia brasileira um instrumento importante para uniformizar as condutas quanto a Prevenção Cardiovascular no Brasil.

Os nossos agradecimentos a todos os que contribuíram na elaboração desta diretriz que certamente será mais um marco relevante do Programa Nacional de Prevenção Cardiovascular da SBC.

\section{Introdução}

Desde que a Sociedade Brasileira de Cardiologia (SBC) estabeleceu como meta, seguindo o exemplo da Organização Mundial da Saúde (OMS), de reduzir a mortalidade cardiovascular em 25\% até o ano 2025, ficou clara a necessidade de fazermos a I Diretriz Brasileira de Prevenção Cardiovascular ${ }^{9}$.

A primeira medida tomada nesse sentido foi a "Carta do Rio", documento elaborado durante a realização do III Brasil Prevent \& I Latin America Prevent, realizado na cidade do Rio de Janeiro em dezembro de $2012^{5}$.

A doença CV deverá aumentar a incapacidade ajustada para anos de vida (DALYs) de 85 milhões de pacientes para 150 milhões no mundo todo até 2020, levando a uma notável queda da produtividade global ${ }^{10,11}$.

A OMS estima que $3 / 4$ da mortalidade cardiovascular podem ser diminuídos com adequadas mudanças no estilo de vida, e esse é o grande desafio das diversas diretrizes existentes em prevenção $\mathrm{CV}^{9}$.

Necessitamos, dessa maneira, adotar medidas governamentais associadas às medidas institucionais e dos orgãos responsáveis pela prevenção em saúde no nosso país em todos os níveis. A SBC está fazendo a sua parte.

A I Diretriz Brasileira de Prevenção tem esse objetivo: discutir as medidas necessárias para serem adotadas como guia prático no dia a dia do cardiologista brasileiro.

As bases da prevenção têm suas raízes na epidemiologia $\mathrm{CV}$ e na medicina baseada em evidências. Com base nisso, a equipe de editores e colaboradores da I Diretriz Brasileira de Prevenção elegeram 13 itens como alicerce dessa diretriz, os quais serão propostos e discutidos ao longo do documento.

Antonio Felipe Simão Coordenador
Jadelson P. Andrade Presidente SBC Gestão 2012/ 2013 


\section{Estratificação de risco}

Estratificação de risco cardiovascular para prevenção e tratamento da aterosclerose

Um evento coronariano agudo é a primeira manifestação da doença aterosclerótica em pelo menos metade das pessoas que apresentam essa complicação. Desta forma, a identificação dos indivíduos assintomáticos que estão mais predispostos é crucial para a prevenção efetiva com a correta definição das metas terapêuticas ${ }^{11}$. Para estimar a gravidade da doença cardiovascular (DCV), foram criados os chamados escores de risco e algoritmos baseados em análises de regressão de estudos populacionais, por meio dos quais a identificação do risco global é aprimorada substancialmente.

Entre os algoritmos existentes, o Escore de Risco de Framingham (ERF) ${ }^{12}$, o Escore de Risco de Reynolds (ERR) ${ }^{13-14}$, o Escore de Risco Global (ERG) $)^{15}$ e o Risco pelo Tempo de Vida $(R T V)^{16-18}$, são opções que serão discutidas adiante.

O ERF estima a probabilidade de ocorrer infarto do miocárdio ou morte por doença coronária no período de 10 anos em indivíduos sem diagnóstico prévio de aterosclerose clínica ${ }^{12}$. Embora esta estimativa de risco seja sujeita a correções conforme indicadores epidemiológicos da população estudada, o ERF identifica adequadamente indivíduos de alto e baixo riscos, o ERR inclui a proteína C-reativa (PCR) e o antecedente familiar de doença coronária prematura e estima a probabilidade de infarto do miocárdio, AVC, morte e revascularização em 10 anos $^{13,14}$. O ERG estima o risco de infarto do miocárdio, acidente vascular encefálico (AVE), insuficiência vascular periférica e insuficiência cardíaca em 10 anos $^{15}$. Já o RTV, avalia a probabilidade de um indivíduo, a partir de 45 anos, apresentar um evento isquêmico ${ }^{16-18}$. O cálculo do RTV considera que o indivíduo pertença exclusivamente a uma das seguintes categorias: a) aqueles sem fatores de risco, ou com todos os fatores de risco ótimos aos 45 anos; b) os que possuam um ou mais fatores de risco não ótimos; c) aqueles com um ou mais fatores de risco elevados; d) os com um dos principais fatores de risco; e) aqueles com dois ou mais dos principais fatores de risco ${ }^{16-18}$.

A combinação desses diversos escores permite uma meIhor estimativa de risco. A justificativa para o emprego de um escore de curto prazo e outro de longo prazo é o fato de que grande parte das mulheres e de homens adultos jovens encontra-se na faixa de baixo risco predito em curto prazo, no entanto, parte destes continuará sendo de baixo risco, enquanto outra parte será de alto risco predito ao longo da vida. Assim, a abordagem do risco pelo tempo de vida pode ser usada para melhorar a motivação de indivíduos com baixo risco predito em curto prazo, mas com alto risco predito em longo prazo, e intensificar as mudanças de estilo de vida e o controle de fatores de risco.

Esta Diretriz recomenda a utilização do $\mathrm{ERG}^{15}$ para avaliação do risco em 10 anos e do RTV ${ }^{16-18}$ para estimar o risco ao longo da vida em indivíduos acima de 45 anos.

Obs.: Todos os demais escores podem ser utilizados como ferramentas de estratificação de risco.

\section{Estratificação de risco por etapas}

A estratificação de risco proposta por esta Diretriz propõe quatro fases:
Fase 1 - Presença de doença aterosclerótica significativa ou de seus equivalentes

O risco de doença aterosclerótica é estimado com base na análise conjunta de características que aumentam a chance de um indivíduo desenvolver a doença. Portanto, o mais claro identificador de risco é a manifestação prévia da própria enfermidade. Desta forma, o primeiro passo na estratificação do risco é a identificação de manifestações clínicas da doença aterosclerótica ou de seus equivalentes (como a presença de diabetes melito tipos 1 ou 2, ou de doença renal crônica significativa, mesmo em prevenção primária) (Quadro1.1). Indivíduos assim identificados, homens e mulheres, possuem risco superior a $20 \%$ em 10 anos de apresentar novos eventos cardiovasculares ${ }^{19}$ ou de um primeiro evento cardiovascular ${ }^{19}$

O paciente que se enquadrar em uma dessas categorias, não requer outras etapas para estratificação de risco, sendo considerado automaticamente de ALTO RISCO.

São condições de alto risco as apresentadas na Tabela1.1. ${ }^{20}$

Tabela 1.1 - Critérios de identificação de pacientes com alto risco de eventos coronários (fase 1$)^{20}$.

- Doença aterosclerótica arterial coronária, cerebrovascular ou obstrutiva
periférica, com manifestações clínicas (eventos cardiovasculares), e ainda na
forma subclínica documentada por metodologia diagnóstica.
- Procedimentos de revascularização arterial.
- Diabete melito tipo 1 e tipo 2.
- Doença renal crônica.

\section{Fase 2 - Escore de risco}

O Escore de Risco Global (ERG) ${ }^{15}$ (http://www.zunis.org/ FHS CVD Risk Calc 2008.htm) deve ser utilizado na avaliação inicial entre os indivíduos que não foram enquadrados nas condições de alto risco (Tabelas 1.2, 1.3, 1.4, 1.5).

São considerados de BAIXO RISCO por esta Diretriz, aqueles com probabilidade $<5 \%$ de apresentarem os principais eventos cardiovasculares (doença arterial coronariana - DAC, AVC, doença arterial obstrutiva periférica ou insuficiência cardíaca) em 10 anos. Os pacientes classificados nessa categoria e que apresentem histórico familiar de doença cardiovascular prematura serão reclassificados para risco intermediário.

São considerados de risco INTERMEDIÁRIO, homens com risco calculado $\geq 5 \%$ e $\leq 20 \%$ e mulheres com risco calculado $\geq 5 \%$ e $\leq 10 \%$ de ocorrência de algum dos eventos citados ${ }^{12,20,21}$.

São considerados de ALTO RISCO, aqueles com risco calculado $>20 \%$ para homens e $>10 \%$ para mulheres no período de 10 anos. $^{21}$

\section{Fase 3 - Fatores agravantes}

Nos indivíduos de risco intermediário devem-se utilizar os fatores agravantes, que quando presentes (pelo menos um deles) reclassificam o indivíduo para a condição de alto risco. (Quadro 1.1)22 e os critérios de síndrome metabólica, de acordo com a IDF (Quadro 1.2) ${ }^{23,24}$.

O diagnóstico de síndrome metabólica requer a presença de obesidade abdominal, como condição essencial e dois ou mais dos critérios expostos no Quadro 1.2 $\mathbf{2}^{23,24}$. 


\section{Diretrizes}

Tabela 1.2 - Atribuição de pontos de acordo com o risco global, para mulheres. ${ }^{19,20}$

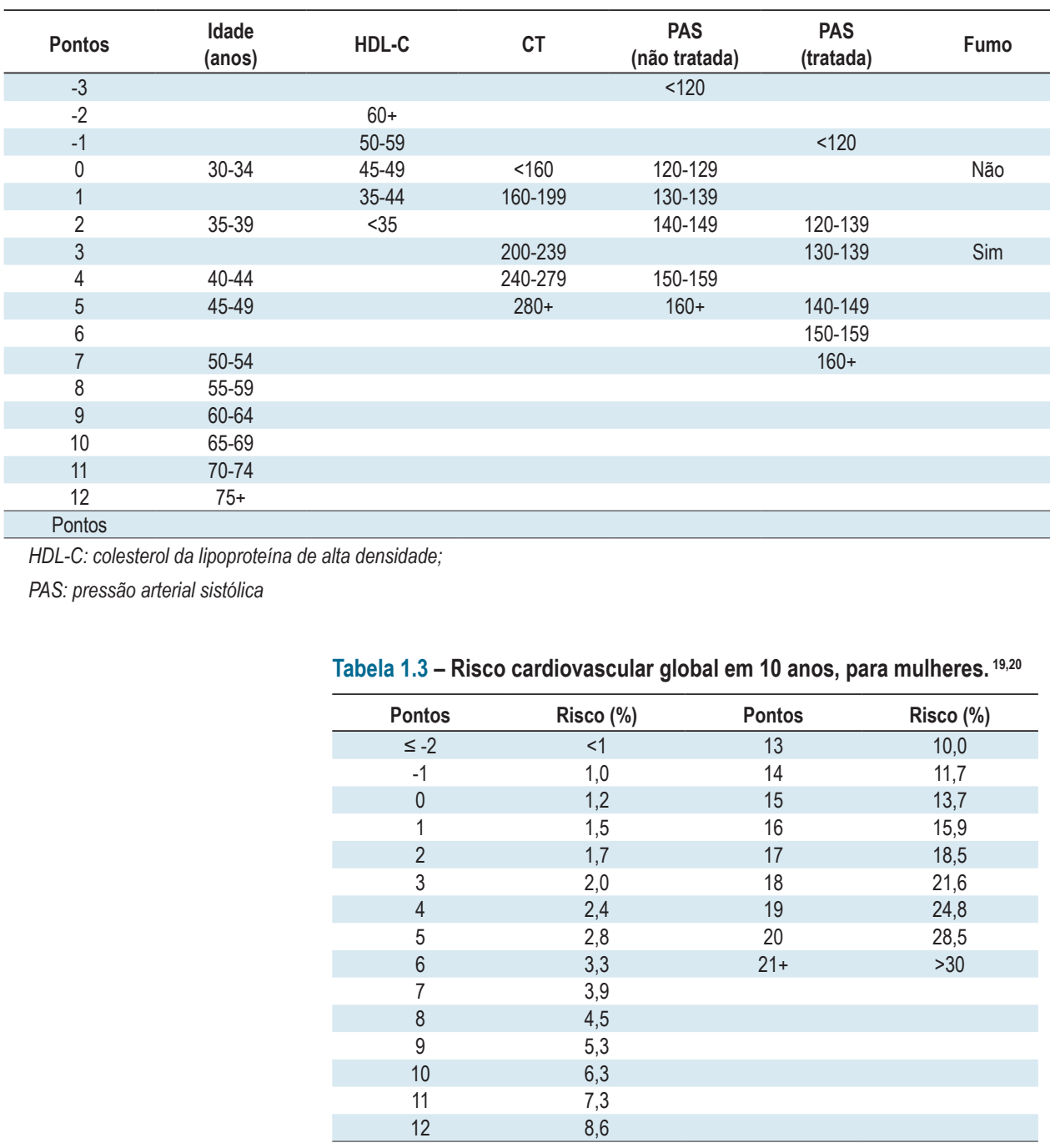

Tabela 1.4 - Atribuição de pontos de acordo com o risco global, para homens. ${ }^{19,20}$

\begin{tabular}{|c|c|c|c|c|c|c|c|}
\hline Pontos & $\begin{array}{l}\text { Idade } \\
\text { (anos) }\end{array}$ & HDL-C & CT & $\begin{array}{l}\text { PAS (não } \\
\text { tratada) }\end{array}$ & $\begin{array}{c}\text { PAS } \\
\text { (tratada) }\end{array}$ & Fumo & Diabetes \\
\hline-2 & & $60+$ & & $<120$ & & & \\
\hline-1 & & $50-59$ & & & & & \\
\hline 0 & $30-34$ & $45-49$ & $<160$ & $120-129$ & $<120$ & Não & Não \\
\hline 1 & & $35-44$ & $160-199$ & $130-139$ & & & \\
\hline 2 & $35-39$ & $<35$ & $200-239$ & $140-159$ & $120-139$ & & \\
\hline 3 & & & $240-279$ & $160+$ & $130-139$ & & Sim \\
\hline 4 & & & $280+$ & & $140-159$ & Sim & \\
\hline 5 & $40-44$ & & & & $160+$ & & \\
\hline 6 & $45-49$ & & & & & & \\
\hline \multicolumn{8}{|l|}{7} \\
\hline 8 & $50-54$ & & & & & & \\
\hline \multicolumn{8}{|l|}{9} \\
\hline 10 & $55-59$ & & & & & & \\
\hline 11 & $60-64$ & & & & & & \\
\hline 12 & $65-69$ & & & & & & \\
\hline \multicolumn{8}{|l|}{13} \\
\hline 14 & $70-74$ & & & & & & \\
\hline 15 & $75+$ & & & & & & \\
\hline Pontos & & & & & & & Total \\
\hline
\end{tabular}

HDL-C: colesterol da lipoproteina de alta densidade; PAS: pressão arterial sistólica; CT: colesterol total 
Tabela 1.5 - Risco cardiovascular global em 10 anos, para homens. ${ }^{19,20}$

\begin{tabular}{cccc}
\hline Pontos & Risco $(\%)$ & Pontos & Risco $(\%)$ \\
\hline$\leq-3$ ou menos & $<1$ & 13 & 15,6 \\
-2 & 1,1 & 14 & 18,4 \\
-1 & 1,4 & 15 & 21,6 \\
0 & 1,6 & 16 & 25,3 \\
1 & 1,9 & 17 & 29,4 \\
2 & 2,3 & $18+$ & $>30$ \\
3 & 2,8 & & \\
4 & 3,3 & & \\
5 & 3,9 & & \\
6 & 4,7 & & \\
7 & 5,6 & & \\
8 & 6,7 & & \\
9 & 7,9 & & \\
10 & 9,4 & & \\
11 & 11,2 & & \\
12 & 13,2 & & \\
\hline
\end{tabular}

\section{Quadro 1.1 - Fatores agravantes de risco ${ }^{12}$}

- História Familiar de doença arterial coronariana prematura (parente de primeiro grau masculino $<55$ anos ou feminino $<65$ anos)

- Critérios de síndrome metabólica de acordo com a International Diabetes Federation 24,25

- Microalbuminúria (30-300 mg/min) ou macroalbuminúria (>300 mg/min)

- Hipertrofia Ventricular Esquerda

- Proteína-C reativa de alta sensibilidade $>3 \mathrm{mg} / \mathrm{L}$

- Evidência de doença aterosclerótica subclínica

- Estenose/espessamento de carótida (EMI) $>1 \mathrm{~mm} 26$

- Escore de cálcio coronário > 100 ou > percentil 75 para idade ou sexo27

- Índice tornozelo braquial (ITB) $<0,9$

Quadro 1.2 - Critérios diagnósticos de síndrome metabólica ${ }^{23,24}$

\begin{tabular}{|ll|}
\hline \multicolumn{1}{|c|}{ Critérios } & \multicolumn{1}{c|}{ Definição } \\
\hline - Obesidade abdominal & \\
- Homens & $\cdot \geq 94$ \\
- Brancos de origem europeia e negros & $\cdot \geq 90$ \\
- Sul-asiáticos, amerindios e chineses & $\cdot \geq 85 \mathrm{~cm}$ \\
- Japoneses & $\cdot \geq 80 \mathrm{~cm}$ \\
- Mulheres & $\cdot \geq 90 \mathrm{~cm}$ \\
- Brancas de origem europeia, negras, sul-asiáticas, ameríndias e chinesas & $\cdot \geq 150 \mathrm{mg} / \mathrm{dL}$ \\
- Japonesas & $\cdot<40 \mathrm{mg} / \mathrm{dL}$ \\
- Triglicérides & $\cdot<50 \mathrm{mg} / \mathrm{dL}$ \\
- HDL-colesterol & $\cdot \geq 130 \mathrm{mmHg}$ ou tratamento para hipertensão arterial \\
- Mulheres & $\cdot \geq 85 \mathrm{mmHg}$ ou tratamento para hipertensão arterial \\
- Pressão arterial & $\cdot$ Jejum $\geq 100 \mathrm{mg} / \mathrm{dL}$ \\
\hline
\end{tabular}

\section{Fase 4 - Estratificação do risco pelo tempo de vida}

Visando reduzir a carga da doença cardiovascular, tem-se enfatizado o cálculo do risco global em 10 anos. No entanto, observa-se que grande parte dos indivíduos considerados de baixo risco em 10 anos, é, na verdade, de alto risco ao longo do tempo de vida. A estimativa do risco de doença cardiovascular pelo tempo de vida permite estratificar de forma mais abrangente a carga de doença cardiovascular na população geral, no momento e no futuro, pois leva em conta o risco de doença cardiovascular enquanto o indivíduo envelhece. Essa ferramenta pode auxiliar em políticas públicas de saúde, permitindo projeções da carga de doença cardiovascular global na população. Esta diretriz recomenda o uso do Risco pelo Tempo de Vida em indivíduos de riscos baixo e intermediário, a partir dos 45 anos.

A Tabela 1.6. classifica os fatores de risco, de acordo com o controle e/ou importância dos mesmos em ótimos, não-ótimos, elevados e principais.

As Tabela 1.7 e Tabela 1.8 mostram o cálculo do RTV para homens e mulheres, respectivamente, a partir dos 45 anos, com base na exposição a esses fatores ao longo do Tempo de Vida.

O risco predito pelo Tempo de Vida acima de 39\% em homens ou superior a 20,2\% em mulheres caracteriza condição de alto risco pelo tempo de vida. ${ }^{25,26}$

O algoritmo da Figura 1 resume e auxilia na estratificação do risco cardiovascular.

Tabela 1.6 - Classificação dos fatores de risco, de acordo com o controle e/ou a importância do(s) mesmo(s). ${ }^{19,20}$

\begin{tabular}{|c|c|c|c|c|}
\hline Fator de risco & Fatores de risco ótimos & 1 Fator de risco não ótimos & Fatores de risco elevados & Fatores de risco principais \\
\hline Colesterol total & $<180 \mathrm{mg} / \mathrm{dl}$ & $180-190 \mathrm{mg} / \mathrm{dl}$ & $200-239 \mathrm{mg} / \mathrm{dl}$ & $>240 \mathrm{mg} / \mathrm{dl}$ \\
\hline Pressão arterial sistólica & Não tratada $<120 \mathrm{mmHg}$ & Não tratada 120-139 mmHg & Não tratada 140-159 mmHg & $\begin{array}{c}\text { Tratamento para HAS ou PAS } \\
\text { não tratada } \geq 160 \mathrm{mmHg}\end{array}$ \\
\hline Pressão arterial diastólica & Não tratada $<80 \mathrm{mmHg}$ & Não tratada $80-89 \mathrm{mmHg}$ & Não tratada $90-99 \mathrm{mmHg}$ & $\begin{array}{l}\text { Tratamento para HAS ou PAD } \\
\text { não tratada } \geq 100 \mathrm{mmHg}\end{array}$ \\
\hline Fumo & Não & Não & Não & Sim \\
\hline Diabetes & Não & Não & Não & Sim \\
\hline
\end{tabular}

PAS: pressão arterial sistólica: PAD: pressão arterial diastólica: HAS: hipertensão arterial sistêmica. 
Tabela 1.7 - Risco de eventos cardiovasculares fatais e não-fatais pelo Tempo de Vida em homens, de acordo com a exposição aos fatores de risco ao longo da vida. ${ }^{19,20}$

\begin{tabular}{|c|c|c|c|c|c|}
\hline \multirow{2}{*}{ Variável } & \multicolumn{5}{|c|}{ Situação de acordo com os fatores de risco } \\
\hline & $\begin{array}{l}\text { Todos os fatores } \\
\text { de risco ótimos }\end{array}$ & $\begin{array}{l}\geq 1 \text { Fator(es) de } \\
\text { risco não ótimo(s) }\end{array}$ & $\begin{array}{l}\geq 2 \text { Fator(es) de } \\
\text { risco elevado(s) }\end{array}$ & 1 Fator de risco principal & $\begin{array}{l}\geq 2 \text { Fatores de } \\
\text { risco principais }\end{array}$ \\
\hline \multicolumn{6}{|c|}{ Risco percentual (Intervalo de confiança 95\%) } \\
\hline \multicolumn{6}{|l|}{ Risco a partir dos 45 anos } \\
\hline DAC fatal ou IAM não fatal & $1,7(0-4,3)$ & $27,5(15,7-39,3)$ & $32,7(24,5-41,0)$ & $34,0(30,4-37,6)$ & $42,0(37,6-46,5)$ \\
\hline AVC fatal ou não fatal & $6,7(1,4-11,9)$ & $7,7(5,0-10,4)$ & $8,5(6,9-15,6)$ & $8,4(7,5-9,4)$ & $10,3(9,0-11,7)$ \\
\hline Morte por doença cardiovascular & $9,1(0-18,6)$ & $13,1(9,9-16,3)$ & $15,3(13,3-17,3)$ & $20,7(19,4-22,2)$ & $32,5(30,5-34,5)$ \\
\hline $\begin{array}{l}\text { Total de eventos relacionados } \\
\text { à DCV aterosclerótica }\end{array}$ & $1,4(0-3,4)$ & $31,2(17,6-44,7)$ & $35,0(26,8-43,2)$ & $39,6(35,7-43,6)$ & $49,5(45,0-53,9)$ \\
\hline
\end{tabular}

DAC: doença arterial coronariana; IAM: infarto agudo do miocárdio; AVC: acidente vascular cerebral; DCV: doença cardiovascular.

Tabela 1.8 - Risco de eventos cardiovasculares fatais e não-fatais pelo Tempo de Vida em mulheres, de acordo com a exposição aos fatores de risco ao longo da vida ${ }^{19,20}$.

\begin{tabular}{|c|c|c|c|c|c|}
\hline \multirow[t]{2}{*}{ Variável } & \multicolumn{5}{|c|}{ Situação de acordo com os fatores de risco } \\
\hline & $\begin{array}{l}\text { Todos os fatores } \\
\text { de risco ótimos }\end{array}$ & $\begin{array}{l}\geq 1 \text { Fator(es) de } \\
\text { risco não ótimo(s) }\end{array}$ & $\begin{array}{l}\geq 2 \text { Fator(es) de } \\
\text { risco elevado(s) }\end{array}$ & 1 Fator de risco principal & $\begin{array}{l}\geq 2 \text { Fatores de } \\
\text { risco principais }\end{array}$ \\
\hline \multicolumn{6}{|c|}{ Risco percentual (Intervalo de confiança 95\%) } \\
\hline \multicolumn{6}{|l|}{ Risco a partir dos 45 anos } \\
\hline DAC fatal ou IAM não fatal & $1,6(0-4,3)$ & $9,3(3,0-15,6)$ & $9,3(5,0-13,7)$ & $12,7(10,3-15,0)$ & $21,5(17,5-25,5)$ \\
\hline AVC fatal ou não fatal & $8,3(3,8-12,8)$ & $8,9(6,5-11,3)$ & $9,1(7,5-10,9)$ & $9,1(7,9-15,9)$ & $11,5(9,5-13,5)$ \\
\hline Morte por doença cardiovascular & $4,8(0,8-8,7)$ & $4,9(3,1-6,7)$ & $6,9(5,4-8,3)$ & $11,2(9,9-12,5)$ & $21,9(19,4-24,5)$ \\
\hline $\begin{array}{l}\text { Total de eventos relacionados } \\
\text { à DCV aterosclerótica }\end{array}$ & $4,1(0-8,2)$ & $12,2(4,6-19,7)$ & $15,6(10,3-20,9)$ & $20,2(17,2-23,2)$ & $30,7(26,3-35,0)$ \\
\hline
\end{tabular}

Tabela 1.9 - Grau de recomendação e Nível de evidência para a estratificação de risco na prevenção cardiovascular

\begin{tabular}{|c|c|c|}
\hline Recomendação & Classe & $\begin{array}{l}\text { Nível de } \\
\text { evidência }\end{array}$ \\
\hline $\begin{array}{l}\text { - Manifestações clínicas da doença aterosclerótica ou de seus equivalentes (como a presença de diabetes melito tipos } 1 \text { ou } 2 \text {, ou de doença } \\
\text { renal crônica significativa, mesmo em prevenção primária, possuem risco }>20 \% \text { em } 10 \text { anos de apresentar novos eventos cardiovasculares } \\
\text { ou de um primeiro evento cardiovascular. }\end{array}$ & I & A \\
\hline $\begin{array}{l}\text { - Os pacientes classificados como risco intermediário e que apresentem histórico familiar de doença cardiovascular prematura serão } \\
\text { reclassificados para risco alto. }\end{array}$ & Ila & B \\
\hline $\begin{array}{l}\text { - São considerados como de risco INTERMEDIÁRIO, homens com risco calculado } \geq 5 \% \text { e } \leq 20 \% \text { e mulheres com risco calculado } \geq 5 \% \text { e } \leq 10 \% \\
\text { de ocorrência de algum dos eventos citados. }\end{array}$ & I & A \\
\hline - São considerados de ALTO RISCO, aqueles com risco calculado > 20\% para homens e >10\% para mulheres no período de 10 anos. & I & A \\
\hline $\begin{array}{l}\text { - Nos indivíduos de risco intermediário devem-se utilizar os fatores agravantes, que quando presentes (pelo menos um desses fatores) } \\
\text { reclassificam o indivíduo para a condição de alto risco (Recomendação Classe lla, nível de evidência B). }\end{array}$ & Ila & B \\
\hline - Uso do Risco pelo Tempo de Vida em indivíduos de baixo risco e de risco intermediário, a partir dos 45 anos. & Ila & B \\
\hline
\end{tabular}

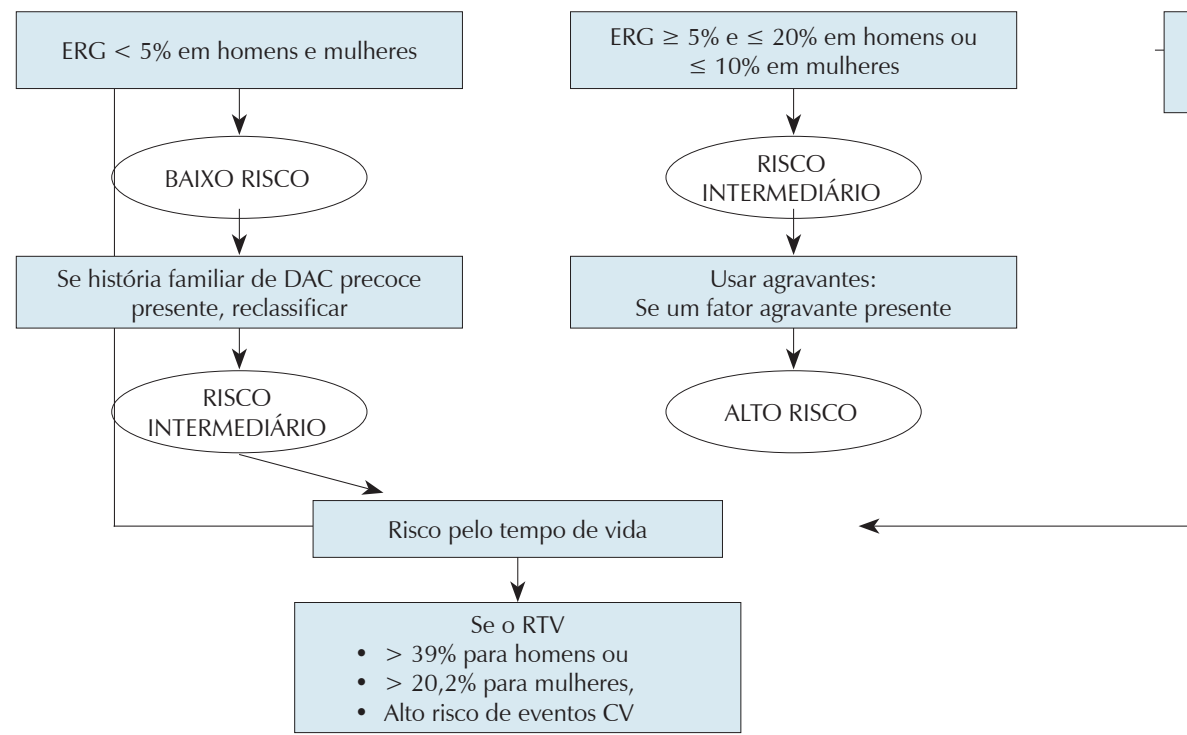

Condição de alto risco presente ou ERG $>20 \%$ em homens e $>10 \%$ em mulheres

Figura 1 - Algoritmo de estratificação do risco cardiovascular ${ }^{19,20}$ 


\section{Fumo}

Existem mais de 1 bilhão de fumantes no mundo e $80 \%$ deles vivem em países de baixa e média rendas onde a carga das doenças e mortes relacionadas com o tabaco é mais pesada. Estima-se que os fumantes atuais consumam cerca de 6 trilhões de cigarros todos os anos ${ }^{27}$.

Cerca de 50\% das mortes evitáveis entre indivíduos fumantes poderiam ser evitadas se esse vício fosse abolido, sendo a maioria por DCVs. O risco relativo de infarto do miocárdio apresenta-se aumentado duas vezes entre os fumantes com idade superior a 60 anos e cinco vezes entre os com idade inferior a 50 anos, se forem comparados com os não fumantes. O consumo de tabaco vem diminuído na população em geral, porém apresentou incremento entre os indivíduos de baixo nível socioeconômico e entre as mulheres. Nas mulheres, seus efeitos deletérios parecem ser maiores, relacionando-se ao metabolismo acelerado da nicotina, com maior relevância naquelas que fazem uso concomitante de contraceptivos orais ${ }^{28}$.

\section{Prevenção do Tabagismo}

A Convenção-Quadro para o Controle do Tabaco (CQCT) foi o primeiro tratado internacional de saúde pública da história da Organização Mundial da Saúde e representou um instrumento de resposta dos 192 países membros da Assembléia Mundial da Saúde à crescente epidemia do tabagismo em todo o mundo. ${ }^{27}$

Em 1989, cerca de 32\% da população de 15 anos ou mais era fumante de acordo com a Pesquisa Nacional sobre Saúde e Nutrição/IBGE. Os dados do inquérito domiciliar chamado Pesquisa Especial de Tabagismo (PeTab) revelaram que no Brasil no ano de 2008 existiam cerca de 25 milhões de fumantes e 26 milhões de ex-fumantes. A prevalência de fumantes era de $17,2 \%$ da população com 15 anos ou mais em 2008, demonstrando a queda ocorrida ao longo desses 20 anos. No entanto, os dados da Vigilância de Fatores de Risco e Proteção para Doenças Crônicas por Inquérito Telefônico (VIGITEL) divulgados em abril de 2012 revelaram uma queda ainda maior, com 14,8\% de fumantes no Brasil, acima de 18 anos de idade. Entre os homens, o percentual de fumantes ficou em $18,1 \%$ e entre as mulheres, $12 \%$. Entre aqueles que fumam 20 cigarros ou mais por dia, 5,4\% são homens e 3,3\%, mulheres. Os homens, em compensação, estão deixando mais o cigarro: $25 \%$ se declararam ex-fumantes, enquanto $19 \%$ das mulheres afirmaram terem sido tabagistas. As capitais onde mais se fuma são Porto Alegre (23\%), Curitiba (20\%) e São Paulo (19\%). No Nordeste estão as capitais com menor incidência de tabagismo entre seus moradores: Maceió (8\%), João Pessoa, Aracaju e Salvador (todas com 9\%) ${ }^{29}$.

\section{Prevenção primordial do tabagismo}

Entende-se por prevenção primordial do tabagismo, a prevenção da iniciação de fumar. Quanto mais cedo o indivíduo começa a fumar, mais provável que se torne um fumante adulto. Após um ano, as crianças inalam a mesma quantidade de nicotina por cigarro que os adultos; elas experimentam, igualmente, os sintomas da dependência e da abstinência ${ }^{30}$; tal dependência pode se desenvolver muito rapidamente nas crianças. Cerca de $80 \%$ de todos os indivíduos que começam a fumar na adolescência continuarão a fazê-lo na idade adulta, e um terço destes morrerá prematuramente devido a doenças relacionadas ao tabagismo ${ }^{31,32}$.

\section{Fatores que contribuem para a iniciação de fumar}

1. Atitudes e crenças - um estudo com adolescentes ${ }^{33}$ mostrou que $40 \%$ daqueles que nunca haviam fumado se tornaram experimentadores e $8 \%$ tiveram o hábito de fumar por 4 anos consecutivos. A firme decisão de não fumar foi o mais forte preditor para evitar o tabagismo. As atitudes que levam a fumar são influenciadas por vários fatores: influência de amigos e familiares; pressão social entre os adolescentes; idade; falsa concepção (os adolescentes tendem a superestimar a frequência de fumar dos adultos e subestimar a sua própria); propaganda. $^{33}$

2. Dependência da nicotina - a nicotina é uma substância altamente aditiva e muitos indivíduos desenvolvem dependência após dias ou semanas de exposição. Os jovens são mais vulneráveis à dependência da nicotina que os adultos. ${ }^{34,35}$

3. Depressão: a maioria dos estudos mostra relação entre a presença de depressão e a iniciação de fumar, embora não esteja claro se a associação é causal. ${ }^{36}$

4. Desempenho escolar insuficiente: faltar às aulas e mau desempenho escolar estão associados à iniciação e continuidade de fumar. ${ }^{34,35}$

5. Experiências adversas: separação dos pais ou divórcio, emoções físicas; abusos emocional, físico ou sexual; crescimento entre membro familiar viciado, doente mental ou aprisionado. ${ }^{36}$

6. Abuso de substância: existe alta frequência de fumantes entre adolescentes que usam drogas ilícitas. ${ }^{37}$ Assim, todo adolescente que fuma deverá ser visto como, potencialmente, engajado em outros comportamentos de risco. ${ }^{38}$

\section{Estratégias no combate à iniciação de fumar ${ }^{37}$}

Uma maneira de abordar a prevenção primordial é por grupos etários observando-se, para cada grupo, cinco principais itens (5 As):

Grupo de 0 a 4 anos: auscultar (no sentido de inquerir, perguntar) os pais e outros membros da família sobre seus hábitos de fumar; aconselhar a manter o ambiente livre da fumaça do cigarro; a mensagem deve incluir a informação sobre os riscos aos pais e crianças, bem como a importância do modelo parental para as crianças; avaliar a disposição para cooperar entre os pais e outros membros da família; ajudar os pais na tentativa de parar de fumar, informando sobre material de auxílio próprio e/ou referendando aos seus próprios médicos; agendar visita dentro de 3 meses se um parente for fumante; checar o progresso dos pais em cada visita pediátrica posterior.

Grupo de 5 a 12 anos: auscultar a criança sobre como ela se sente quando alguém por perto está fumando e o que ela faz quanto a isso; também, se ela considera perigoso tentar fumar e se pensa que vai fumar quando for mais velha; e mais, se ela já tentou fumar ou se tem amigos que fumam; aconselhar a criança a não experimentar fumar, elogiá-la por 
permanecer um não fumante e/ou fora da exposição à fumaça do cigarro; lembrá-la sobre os efeitos negativos do tabaco a curto prazo, como redução do olfato e da capacidade atlética, bem como sobre riscos à saúde pessoal (ex.: exacerbação da asma); aconselhar aos pais a parar de fumar e a dar claras informações antifumo às suas crianças; avaliar os fatores de risco de iniciar a fumar ou da progressão de fumar regularmente, incluindo o nível de experimentação, o fumar entre os amigos, os sintomas depressivos, o desempenho escolar e as experiências adversas; auxiliar os pais na tentativa de parar de fumar; ajudar as crianças a desenvolver habilidades para recusar o fumo e à sua exposição; ajudar os pais nos esforços para prevenir o tabaco nas suas crianças, através do modelo parental e de firmes mensagens antifumo; agendar visita dentro de 1 a 2 meses para qualquer criança que esteja experimentando fumar ou tenha preocupantes fatores de risco para fazê-lo, referendando conforme necessário em casos de dificuldades sociais ou de aprendizado, bem como, nos distúrbios mentais.

Grupo de adolescentes e adultos jovens: auscultar o adolescente sobre o comportamento de fumar, de forma confidencial, sobre amigos fumantes e sobre cigarros leves; aconselhar os adolescentes parar de fumar, reforçando os riscos à saúde pessoal e perigo de adição; elogiar os adolescentes que não estão fumando e relembrar os riscos para a saúde; avaliar a motivação e os sintomas da dependência do tabaco entre adolescentes que estejam fumando; avaliar os fatores de risco de iniciação de fumar entre aqueles que não estão fumando; ajudar os adolescentes que estão fumando na tentativa de parar de fumar, incluindo reposição de nicotina e referendar se necessário; ajudar aos pais nos esforços de prevenção da iniciação de fumar de suas crianças por meio do modelo parental e firmes informações antifumo; agendar uma visita dentro de um mês para cada adolescente que esteja fumando, dando suporte na tentativa de parar de fumar ou avaliar a motivação e barreiras para parar; referendar conforme necessário se forem identificados fatores de risco como dificuldades sociais ou de aprendizado, ou achados de distúrbios mentais.

A prevenção primordial cardiovascular engloba evitar a instalação dos fatores de risco cardiovascular modificáveis, entre eles o tabagismo, e construir estratégias eficazes para que se faça a promoção da saúde cardiovascular do indivíduo e da população. Para tanto, torna-se necessária a ação conjunta de equipes multidisciplinar (médicos, enfermeiros, psicólogos, educadores físicos, pedagogos, nutricionistas, assistentes sociais, comunicadores, gestores) e intersetoriais (família, escola, governo, sociedade de especialistas, universidade) de forma contínua e simultânea.

\section{Como tratar a dependência psicológica do fumante}

Existem dois tipos de abordagem:

Abordagem básica (PAAPA) onde o objetivo é perguntar se fuma, avaliar o perfil de fumante, aconselhar a parar de fumar, preparar para a cessação e acompanhar o fumante para a interrupção do tabagismo. Esta abordagem deve ser sempre realizada pelo médico durante a consulta de rotina, com duração, no mínimo, de 3 minutos e, no máximo, de 5 minutos, em média, em cada contato que o paciente faz. $\mathrm{O}$ paciente deve ser questionado e perguntado sistematicamente a cada consulta e retorno sobre a evolução do processo de cessação. Esta abordagem é indicada a todos os fumantes. Uma meta-análise envolvendo 29 estudos mostrou que as taxas de cessação foram de 19,9\% para os que sofreram intervenção médica ${ }^{39}$.

Abordagem intensiva específica: é realizada por profissionais da saúde disponíveis e treinada para fazer um acompanhamento mais aprofundado com o paciente, inclusive o médico. Neste caso o profissional deverá ter um programa estruturado à disposição do paciente com sessões programadas (oito sessões em grupo/individual), e será utilizada medicação de referência nacional para tratamento do tabagismo, assim como a abordagem cognitivo-comportamental. Se possível deverá ser acompanhado até completar um ano de tratamento. A cognitivo-comportamental é uma abordagem psicológica que se baseia em trabalhar os pensamentos automáticos que o fumante tem e que o levam a buscar o cigarro. ${ }^{39}$

$\mathrm{Na}$ abordagem cognitivo-comportamental as técnicas comportamentais mais utilizadas, são: auto-observação, o controle de estímulos ou gatilhos que o levam a fumar (telefone, computador, bebida alcoólica, banheiro, carro), identificação e aprendizado de padrões de pensamentos funcionais, técnicas de relaxamento, de respiração profunda, de adiamento e de quebra de condicionamento, treino de assertividade (para que o paciente possa enfrentar situações nas quais se sente tentado a fumar), autoinstrução (situação em que o participante é ensinado a argumentar consigo mesmo sobre a situação que tenta induzi-lo a fumar) e solução de problemas, para que o paciente seja ensinado sobre formas adequadas de resolver uma situação problemática ${ }^{39}$

\section{Instrumentos que ajudam na avaliação e na} compreensão do perfil do paciente:

- Escala de Prochaska e Di Clemente para mudança de comportamento: essa escala traz um modelo que permite avaliar em que fase de mudança de comportamento o paciente está de forma clara e objetiva. Parar de fumar é um processo dinâmico que se repete ao longo do tempo e tem diferentes estágios. Em cada estágio, o indivíduo lança mão de diferentes processos cognitivos e comportamentais ${ }^{40}$. Os autores propõem cinco estágios diferentes neste processo: pré-contemplação, caracterizada pela ausência de intenção de mudar o comportamento, ou seja, indivíduo não percebe, neste caso, o ato de fumar como um problema; contemplação implica alguma consciência do problema. Ele é percebido, existe a intenção de mudar, mas não existe noção de quando, nem há um compromisso em relação a isso; preparação é o estágio prévio à ação. Existe uma clara intenção de mudar, o indivíduo já tem algumas iniciativas em relação à mudança, mas a ação ainda não está efetivada; ação já é uma mudança de comportamento para tentar resolver o problema. O indivíduo despende tempo procura tratamentos, e promove mudanças que devem ser duráveis e manutenção é o estágio no qual, tais mudanças devem ser consolidadas, abrangendo tudo o que foi conquistado no estágio da ação. Os estágios ocorrem de forma não linear, isto é, em espiral, 
o que significa que cada estágio não observado, leva ao estagio inicial.

- Entrevista Motivacional: é uma alternativa viável no tratamento de comportamentos dependentes, dentro das intervenções breves, uma vez que o impacto inicial parece ter influência na motivação para a mudança de comportamento. Estratégias para entrevista motivacional: oferecer orientação, remover as barreiras/auxiliar nos obstáculos, proporcionar escolhas alternativas a fumar, diminuir o aspecto indesejável do comportamento, praticar empatia, dar feedbacks, esclarecer objetivos e ajudar ativamente e cuidar da prevenção de recaídas enfrentamento da abstinência ${ }^{41}$.

- Escala de Fagerström: é uma escala de avaliação que permite verificar o grau de dependência de física de nicotina. Deve ser utilizada na avaliação inicial do fumante quando ele chega para o tratamento. No caso de necessidade de medicação, ajuda a definir qual a melhor medicação e em que quantidade a mesma deve ser tomada. ${ }^{42}$ Nesse caso vale ressaltar que não se deve considerar utilizar a medicação somente nos casos em que o Fagerström for $>5$. Sabe-se hoje por estudos científicos que um Fargeström muito baixo significa que a dependência psicológica é muito alta e, neste caso, a medicação ajuda na redução dos sintomas de abstinência ${ }^{42}$.

- Escala de razões para fumar: é uma escala de avaliação que permite verificar em quais situações o fumante usa o cigarro. Tem relação com dependência física, psicológica e condicionamento e ajuda a clarear para o fumante as situações de risco do seu dia a dia. Esta escala avalia: estimulação, manuseio (ritual), prazer de fumar, redução de tensão/relaxamento, dependência física, hábito/ automatismo e tabagismo social. Estes itens devem ser trabalhados durante todo processo da abordagem intensiva do fumante ${ }^{43,44}$.

\section{Tratamento Farmacológico do Tabagismo}

Existem evidências consistentes de que os fármacos antitabaco aumentam a taxa de sucesso na cessação do tabagismo ${ }^{37}$. O seu uso duplica ou até quadruplica as possibilidades de abstinência ${ }^{37}$. Os repositores de nicotina (TRN), bupropiona e vareniclina são considerados de primeira linha no tratamento do tabagismo e são recomendados para prescrição em guias nacionais ${ }^{45} \mathrm{e}$ internacionais ${ }^{37}$. Outros medicamentos como a nortriptilina, apesar da eficácia comprovada, apresentam efeitos colaterais e contra-indicações que podem limitar seu uso ${ }^{37}$, por isso são considerados de segunda linha.

Alguns medicamentos surgem como promissores para cessação do tabagismo pois, de alguma forma, atuam nos vários circuitos cerebrais envolvidos na dependência da nicotina ${ }^{46}$. No entanto, as avaliações sistematizadas não comprovam a eficácia esperada. Entre eles destacamos a falta de consistência nos resultados com o uso de clonidina ${ }^{47}$, naltrexona ${ }^{48}$, inibidores da recaptação de serotonina ${ }^{49} \mathrm{e}$ ansiolíticos ${ }^{50}$. Condição bem diferente dos medicamentos de primeira linha, que têm eficácia comprovada por agirem primordialmente no sistema dopaminérgico, reconhecidamente relacionados com os sistemas de recompensa e mesolímbico ${ }^{51}$, é crucial no processo da abstinência e dependência.

Não existem critérios definidos para escolha entre eles. Na prática clínica, a prescrição é feita considerando-se contraindicações específicas do fármaco, disponibilidade do produto na rede pública, disponibilidade financeira do paciente para sua aquisição, experiência clínica do profissional, entre outros, não havendo critérios técnicos de escolha bem estruturados. Em alguns serviços, a avaliação da dependência da nicotina e tentativas pregressas com medicação fazem parte de um algoritmo para definir a escolha do fármaco de primeira linha para início do tratamento, mas isso se restringe à experiência local ${ }^{52,53}$, faltando, portanto, subsídios para adoção de forma sistematizada da mesma.

A prescrição dos fármacos antitabaco é fundamental para melhora da eficácia do tratamento do tabagismo, como também são fundamentais a realização de consultas de acompanhamento e o incentivo a promoção de mudanças de hábitos e comportamento dos pacientes ${ }^{53,54}$.

As principais características dos medicamentos antitabaco de primeira linha são as descritas a seguir.

\section{Repositores de nicotina}

A nicotina é a principal responsável pela dependência atribuída ao cigarro e as terapias de reposição nicotínica são utilizadas desde 1984 no tratamento para cessação do tabagismo. As formas de terapias de reposição nicotínicas (TRN) atualmente utilizadas e disponíveis no Brasil são a transdérmica e a oral (pastilhas e gomas). Ambas são eficazes na cessação do tabagismo e costumam ser utilizadas em associação, podendo dobrar a taxa de sucesso em comparação com o placebo ${ }^{55}$.

Nicotina transdérmica

- Eficácia em comparação com o placebo: (RR:1,9; IC 95:1,7-2,2),

- Taxa de Abstinência em 6 meses (RR: 23,4; IC 95:21,325,8)

- Doses: $21 \mathrm{mg} ; 14 \mathrm{mg} ; 7 \mathrm{mg}$.

- Apresentação: adesivos de aplicação transdérmica.

- Via (s) de administração: aplicação transdérmica com substituição diária.

- Esquema posológico: utilização de cada apresentação por 4 semanas em média, com redução de dose progressiva. Ex: (21, depois 14, depois $7 \mathrm{mg} / \mathrm{dia})$.

- Cuidados na administração: aplicação na parte superior do tórax, regiões anterior, posterior e superior lateral do braço.

- Reações adversas: prurido e vermelhidão no local da aplicação, náuseas, enjoo e taquicardia quando em dose excessiva.

- Contraindicações: doenças dermatológicas que impeçam a aplicação do adesivo, período de 15 dias após episódio de infarto agudo do miocárdio, gestação e amamentação.

- Superdosagem (toxicidade): náuseas, enjoo, taquicardia e crise hipertensiva. 
Nicotina de uso oral - goma ou pastilha de nicotina

- Eficácia em comparação com o placebo: (RR: 2,2; IC95:1,5-3,2),

- Taxa de Abstinência em 6 meses: (RR:26,1; IC95:9,7$33,6)$

- Doses: 2 e 4 mg.

- Apresentação: goma de mascar ou pastilha.

- Via de administração: oral.

- Esquema posológico: quando houver vontade intensa de fumar, em substituição aos cigarros (1 a 15 gomas /dia).

- Cuidados na administração: ingerir um copo de água antes do uso para neutralizar o pH bucal, devido à alteração pelo consumo de alimentos e retirada de resíduos alimentares, que podem diminuir a absorção pela mucosa oral.

- Reações adversas: a goma de nicotina pode provocar dor na articulação temporo-mandibular quando mascada de forma rápida e incessante, além de irritação na orofaringe e náuseas quando mascada de forma rápida e frequente. A pastilha de nicotina pode ocasionar irritação na orofaringe e náuseas quando mastigada em vez de dissolver na boca, ou pelo uso excessivo.

- Contra-indicações:

- Goma de nicotina - Incapacidade de mascar, úlcera péptica ativa, período de 15 dias após IAM.

- Pastilha de nicotina - úlcera péptica ativa, período de 15 dias após IAM.

- Superdosagem (toxicidade): náuseas, enjoo, taquicardia, e crise hipertensiva.

\section{Cloridrato de bupropiona}

A bupropiona é um inibidor da recaptação de dopamina e norepinefrina que se mostra efetiva na cessação do tabagis$\mathrm{mo}^{37,56,57}$, diminuindo os sintomas de abstinência de nicotina. Por ser um antidepressivo auxilia no controle de sintomas depressivos que podem surgir durante o processo de cessação do tabagismo.

- Eficácia em comparação com o placebo (RR:2.0; IC95:1,8-2,2)

- Taxa de abstinência em 6 meses - (RR:24,2; IC95:22,226,4)

- Apresentação: comprimidos de liberação prolongada de 150mg.

- Via de administração: oral.

- Esquema posológico: 1 comp. ao dia por 4 dias, depois aumentar para 1 comp. duas vezes ao dia com intervalo mínimo entre as doses de 8 horas.

- Cuidados na administração: evitar administração noturna para minimizar o risco de insônia.

- Reações adversas: boca seca, insônia (sono entrecortado), constipação intestinal, epigastralgia, tontura.

- Contraindicações:

- Absolutas: risco de convulsão (antecedente de convulsão, epilepsia, convulsão febril na infância, anormalidades conhecidas no eletroencefalograma
(EEG)); alcoolismo; uso de inibidor da monoamina oxidase (IMAO) nos últimos 14 dias; doença cerebrovascular; tumor no sistema nervoso central (SNC) e, traumatismo craniano.

- Advertências/Precauções: A associação de bupropiona com reposição de nicotina, principalmente na forma de adesivos, pode elevar a pressão arterial e o uso com álcool pode predispor a convulsão.

- Superdosagem (toxicidade): convulsões.

Tartarato de vareniclina

A vareniclina ${ }^{37,58}$ é um agonista parcial do receptor nicotínico no sistema nervoso central.Dentre os medicamentos de primeira linha para o tratamento do tabagismo, a vareniclina é a medicação mais eficaz ${ }^{59,60}$.

- Eficácia em comparação com o placebo (RR:3,1; IC95:2,5- 3,8),

- Taxa de Abstinência em 6 meses (RR:33,2; IC95:28,9$37,8)$

- Doses: Comprimidos de 0,5 e $1 \mathrm{mg}$ de tartarato de vareniclina.

- Via de administração: via oral.

- Esquema posológico: Iniciar com 0,5 mg 1 vez ao dia. No 4 o dia prescrever $0,5 \mathrm{mg} 2$ vezes ao dia. No $7 \underline{0}$ dia prescrever $1 \mathrm{mg} 2$ vezes ao dia. Prescrever por 12 a 24 semanas. A terapia com vareniclina não requer cessação imediata do tabagismo. Recomenda-se a interrupção do tabagismo a partir do 14을 dia após o início do medicamento.

- Reações adversas: O efeito colateral mais esperado com o uso desta substância é a náusea (30\% dos pacientes). que é minimizada ingerindo-se a medicação após refeições e com um copo de água. Menos de 6\% dos pacientes suspendem a medicação por esta razão.

- Contraindicações: Absoluta - pacientes com insuficiência renal terminal, grávidas e mulheres amamentando. ajustar a dose em paciente com insuficiência renal grave (verificar tabela de ajuste).

- Precaução no uso: Deve-se ter cautela no uso em pacientes com histórico de doenças psiquiátricas como depressão grave, transtorno bipolar e síndrome do pânico. Embora não se tenha demonstrado a conexão causal e considerando-se que pacientes fumantes têm maior risco de apresentar depressão e pensamento suicida ${ }^{61}$, a Food And Drug Administration (FDA) dos EUA, em $2009{ }^{62}$, fez advertência sobre a possibilidade de alterações de humor, agitação e pensamentos suicidas entre os usuários de vareniclina, e por isso não se recomenda usá-la em pacientes com doenças psquiátricas não estabilizadas. ${ }^{63}$

Em 2011, Sigh e cols. ${ }^{63}$ realizou metanálise com alguns estudos com vareniclina alertando para possíveis riscos de eventos cardiovasculares entre seus usuários. Após análise criteriosa do estudo, concluiu-se que um número significativo de pacientes que usaram vareniclina em estudos randomizados não foram incluídos na metanálise e não apresentaram evento cardiovascular. Foi realizada metanálise mais abrangente, ${ }^{64}$ incluindo todos os estudos com vareniclina e não constatando risco de 
evento cardiovascular aumentado no grupo vareniclina versus placebo. A segurança e a eficácia da vareniclina foram avaliadas e demonstradas por Rigottie cols. ${ }^{65}$, de forma randomizada e controlada por placebo, em pacientes com doença cardiovascular.

- Superdosagem (toxicidade): náuseas, enjoo, vômitos.

\section{Medicamento de segunda linha}

\section{Nortriptilina}

A nortriptilina é um antidepressivo tricíclico que bloqueia a recaptação de noradrenalina no sistema nervoso central. É uma droga de segunda linha no tratamento do tabagismo. A FDA ainda não aprovou seu uso para este fim, pois, apesar de sua eficácia ser similar à obtida com a TRN ou com a bupropiona, há maior risco de efeitos colaterais ${ }^{37,56}$. A posologia recomendada é de $25 \mathrm{mg} /$ dia, em dose única, com incremento gradual até atingir 75 a 100 mg/dia. O uso não é recomendado a pacientes com cardiopatia estrutural de qualquer natureza, devido ao risco de induzir distúrbios de condução e arritmia.

\section{Associações de medicamentos antitabaco}

A eficácia dos medicamentos antitabaco de primeira linha situa-se entre $20 \%$ e $25 \%$ para reposição de nicotina e bupopriona, não ultrapassando $35 \%$ com vareniclina ${ }^{37}$.

Alguns estudos com combinação de adesivos e nicotina oral comprovam melhora dos resultados. A metanálise de nove estudos ${ }^{56}$ que combinaram um adesivo de nicotina com um medicamento de liberação rápida de nicotina (gomas, aerosol, pastilha) demonstrou que a combinação teve maior eficácia do que um único tipo de TRN (RR 1,34; IC 95\%: 1.18-1.51).

A combinação de TRN e bupropiona foi mais eficaz do que a bupropiona isoladamente na metanálise de quatro estudos ${ }^{53}$ (RR 1,24; IC95\%: 1,06-1,45).

A associação de vareniclina e bupropiona parece ser a mais efetiva de todas ${ }^{66}$, contudo, estudos randomizados ${ }^{67}$, de maior consistência, encontram-se em andamento para comprovar sua indicação.

Tabela 2.1 - Grau de recomendação e Nível de evidência para o tratamento do fumo na prevenção cardiovascular

\begin{tabular}{|c|c|c|}
\hline Recomendação & Classe & $\begin{array}{l}\text { Nível de } \\
\text { evidência }\end{array}$ \\
\hline $\begin{array}{l}\text { - O fumo é um fator de risco independente para } \\
\text { doença cardiovascular, portanto deve ser evitado }\end{array}$ & I & B \\
\hline $\begin{array}{l}\text { - A exposição passiva ao tabaco aumenta o risco de } \\
\text { doenças cardiovasculares e deve ser evitada }\end{array}$ & I & B \\
\hline - Tratamento farmacológico do tabagismo & I & A \\
\hline Repositor de nicotina & 1 & A \\
\hline Cloridrato de bupropiona & 1 & A \\
\hline Tartarato de vareniclina & I & A \\
\hline
\end{tabular}




\section{Dieta, suplementos e vitaminas}

\section{Introdução}

Embora possam modular uma série de mecanismos fisiopatológicos relacionados com a aterosclerose, estudos prospectivos falharam em mostrar benefício do consumo sob forma de suplementação de vitaminas e ácidos graxos ômega 3 para a prevenção da doença cardiovascular (DCV). Ainda necessitamos de mais dados sobre a vitamina D e os ácidos alfa-linolênico, contudo à luz do conhecimento atual também não se pode recomendar o uso desses suplementos para prevenir a DCV. Os resumos das recomendações para o consumo desses suplementos encontram-se nas Tabelas 3.1 a 3.3.

\section{Carotenoides}

Os carotenoides são uma classe de mais de 600 compostos, responsáveis pelos pigmentos amarelo, vermelho e laranja em plantas, sendo o $\alpha$-caroteno, $\beta$-caroteno, $\beta$-criptoxantina, licopeno, luteína e zeaxantina os mais encontrados nos alimentos. Conhecido principalmente como precursores de vitamina $\mathrm{A}$, os carotenoides também são importantes supressores de radicais livres e agem como potentes antioxidantes ${ }^{68}$.

A evidência para um papel de carotenoides na DCV surgiu a partir de estudos que mostraram que o maior consumo de frutas e vegetais foi associado com menor risco de doenças cardiovasculares ${ }^{69}$.

Uma série de estudos longitudinais retrospectivos e prospectivos identificou uma associação inversa entre a ingestão de carotenoides e o risco de DVC ${ }^{69}$. No entanto o efeito dos carotenóides é complexo e provavelmente não é devido a um único composto isolado.

Diferentemente, estudos prospectivos randomizados não mostraram benefício da suplementação de carotenóides sobre a DCV ${ }^{70,71}$.

Portanto, não é recomendado o uso de suplementos únicos com carotenoides, $\beta$-caroteno ou outros. Em vez disso, os esforços devem ser direcionados para o aumento do consumo de frutas e vegetais ricos neste nutriente.

\section{Vitamina $\mathrm{E}$}

A vitamina E é o principal antioxidante solúvel em gordura no corpo humano e está presente num complexo de quatro isômeros $(\alpha, \beta, \gamma, \delta$ - tocoferol). O interesse no benefício potencial da vitamina $\mathrm{E}$ no risco de DCV foi relacionado com a sua capacidade antioxidante e a hipótese da modificação da liporpoteína de baixa densidade oxidada (LDL-ox), particularmente envolvida na aterogênese ${ }^{72}$. Entretanto, estudos prospectivos randomizados como o ATBC, CHAOS, GISSI, e HOPE não mostraram benefício da suplementação da vitamina $E$ sobre a DCV ${ }^{70,71,73}$. Apesar de uma teoria sólida da base molecular do estresse oxidativo e do seu papel na aterosclerose, estes ensaios clínicos não sustentam o uso de suplemento de vitamina E na prevenção de DCV, sendo mais eficaz e seguro o consumo quando obtido a partir de alimentos. Dessa forma, não se recomenda a suplementação de vitamina $\mathrm{E}$ para a prevenção da doença cardiovascular

\section{Vitamina C}

A vitamina $\mathrm{C}$ ou ácido ascórbico é solúvel em água e um antioxidante muito eficaz, uma vez que perde elétrons facilmente. A teoria dos radicais livres do processo de enveIhecimento elucida o seu papel na progressão das doenças crônicas ${ }^{74}$.

Apesar de apoiados por estudos observacionais, ensaios clínicos randomizados não confirmam um papel da suplementação da vitamina $C$ na prevenção primária ou secundária de doenças cardiovasculares ${ }^{74}$. Dessa forma, não se recomenda a suplementação de vitamina $C$ para a prevenção da doença cardiovascular.

\section{Vitamina D}

A vitamina D é um nutriente solúvel em gordura, que desempenha diversas funções no organismo, sendo a principal no metabolismo ósseo. No entanto, a vitamina D tem muitas outras funções e o uso de suplementos desta vitamina para a prevenção e tratamento de uma ampla gama de doenças aumentou consideravelmente na última década ${ }^{75}$.

Suas duas formas principais são as vitaminas D2 (ergocalciferol) e D3 (colecalciferol). A vitamina D3 pode ser sintetizada pelos seres humanos nas células da pele após a exposição à radiação UV-B da luz solar. Na ausência de luz solar, a ingestão de vitamina D é crucial. A vitamina D e os suplementos de dieta são absorvidos pelo intestino e, em seguida, convertidos em 25 - hidroxivitamina D3 [25(OH)D] no fígado, e 1,25 di-hidroxivitamina D3 [1,25(OH)2D3], a forma ativa de vitamina $D$, no rim.

Zittermanne cols. ${ }^{76}$ resumiram os mecanismos subjacentes para um possível papel da vitamina D na prevenção de doença coronariana. Estes incluem a inibição da proliferação do músculo liso vascular, a supressão da calcificação vascular, a regulação negativa de citocinas pró-inflamatórias, a regulação aumentada de citocinas antiinflamatórias e a ação da vitamina D como um regulador negativo endócrino do sistema renina-angiotensina.

Baixas concentrações de vitamina D circulantes têm sido associadas a hipertensão arterial, obesidade, diabetes mellitus e síndrome metabólica, além disso, a deficiência desta vitamina foi associada a risco de doença cardiovascular em estudos recentes ${ }^{76,77}$.

Há evidências de um papel da vitamina D na DCV em estudos ecológicos, com um aumento de eventos de doença cardíaca com a latitude geográfica, ou seja, associadas a menor exposição aos raios solares, sendo que a concentração de vitamina D diminui com a latitude. Vários estudos prospectivos investigaram a concentração plasmática de 25-hidroxi $(\mathrm{OH})$ vitamina $\mathrm{D}$ em relação a doenças cardiovasculares, sendo resultados tendenciosos para relação entre baixa concentração deste marcador e aumento de risco para doença cardiovascular ${ }^{77-78}$. Enquanto o efeito protetor da vitamina D em eventos cardiovasculares é apoiado pela evidência epidemiológica, não há evidência suficiente até o presente momento para se recomendar sua suplementação para a prevenção da doença cardiovascular. Dessa forma, não se recomenda a suplementação de vitamina $\mathrm{D}$ para $a$ prevenção da doença cardiovascular . 


\section{Vitaminas B e Folato}

Evidência de uma ligação entre a vitamina B e DCV foram demonstradas pelo efeito destas vitaminas na diminuição da homocisteína ${ }^{79,80}$. A homocisteína, um aminoácido contendo enxofre, é um metabólito produzido indiretamente na desmetilação de metionina. Estudos prospectivos mostraram uma associação independente, porém, de modesta intensidade das concentrações plasmáticas da homocisteína com o risco de DCV ${ }^{80}$. Certo número de fatores foi identificado como associados a concentrações elevadas de homocisteína. Estes incluem ingestão inadequada de ácido fólico, vitaminas B6 e/ou B12, doença aterosclerótica preexistente, o consumo de café, tabagismo, consumo de álcool, diabetes, uso de drogas antiepilépticas ou metotrexato, insuficiência renal, artrite reumatoide, hipotireoidismo, e mutações na cistationa-beta sintase e metilenotetrahidrofolato redutase.

Estudos prospectivos randomizados com grande número de eventos cardiovasculares falharam em mostrar benefício da suplementação de folato e complexo B com intuito de reduzir a homocisteína e prevenção da DCV ${ }^{80}$.

A discordância em resultados de estudos epidemiológicos e ensaios clínicos pode ser devida, em parte, à inclusão de diferentes populações e ao uso de alimentos fortificados com ácido fólico em alguns países.

Não se recomenda a suplementação de ácido fólico ou complexo B para a prevenção da doença cardiovascular.

\section{Tabela 3.1 - Resumo das recomendações para não consumo de suplementos de vitaminas para a prevenção da doença cardiovascular.}

\begin{tabular}{lcc}
\hline \multicolumn{1}{c}{ Indicação } & Classe & $\begin{array}{c}\text { Nível de } \\
\text { evidência }\end{array}$ \\
\hline $\begin{array}{l}\text { Não há evidência de benefício da suplementação } \\
\text { de vitamina A ou beta-caroteno para prevenção } \\
\text { primária ou secundária de doença cardiovascular }\end{array}$ & III & A \\
$\begin{array}{l}\text { Suplementos de vitamina B e ácido fólico } \\
\text { não são efetivos para prevenção de doença } \\
\text { cardiovascular primária ou secundária }\end{array}$ & III & A \\
$\begin{array}{l}\text { Não há evidência de benefício da suplementação } \\
\text { de vitamina C para prevenção, progressão ou } \\
\text { mortalidade por doença cardiovascular }\end{array}$ & II & A \\
$\begin{array}{l}\text { Não é recomendada a suplementação de vitamina } \\
\text { D para prevenção de doença cardiovascular } \\
\text { em pessoas com níveis sanguíneos normais } \\
\text { desta vitamina. Da mesma forma, não há } \\
\text { evidências que sua suplementação em } \\
\text { indivíduos com deficiência prevenirá a DCV. }\end{array}$ & & CII \\
\hline
\end{tabular}

Ácidos graxos poliinsaturados ômega-3 de origem marinha (docosaexaenoico (DHA) e eicosapentaenoico (EPA)

Os ácidos graxos ômegas-3 de origem marinha, ácido docosaexaenoico (DHA) e ácido eicosapentaenoico (EPA), exercem inúmeros efeitos sobre diferentes aspectos fisiológicos e do metabolismo que podem influenciar a chance de desenvolvimento de doenças cardiovasculares ${ }^{81,82}$. Embora seja consensual que o consumo regular de peixes ricos em ácido graxos ômega-3 faça parte de uma dieta saudável, a recomendação de suplementar a dieta com cápsulas de óleo de peixe cerca-se por controvérsias, fomentadas por resultados conflitantes de estudos clínicos ${ }^{83-86}$.
Estudos clínicos mostram que a suplementação com $2 \mathrm{~g}$ a $4 \mathrm{~g}$ de EPA/DHA ao dia pode diminuir os níveis de triglicérides (TG) em até $25 \%$ a $30 \%$, aumentar discretamente os de HDL-C (1\% a 3\%) e elevar os de LDL-C em até $5 \%$ a $10 \%{ }^{86}$. A capacidade de reduzir os níveis de TG depende da dose, com uma redução aproximada de $5 \%$ a $10 \%$ para cada $1 \mathrm{~g}$ de EPA/DHA consumido ao dia, sendo maior nos indivíduos com níveis basais mais elevados de TG.

Em uma metanálise de 36 ensaios clínicos randomizados, a suplementação com óleo de peixe (dose mediana de 3,7 g/dia) mostrou reduzir a pressão arterial sistólica em 3,5 mmHg e a diastólica em 2,4 mmHg ${ }^{87}$. A redução de tônus adrenérgico e da resistência vascular sistêmica é um mecanismo proposto.

Apesar de várias evidências antigas sugerirem efeito protetor de peixes e dos ácidos graxos ômega-3 de origem marinha sobre eventos cardiovasculares ${ }^{87}$ sobretudo em indivíduos que já apresentavam doença cardiovascular, os estudos mais recentes não mostraram benefícios da suplementação com ômega-3 em sujeitos que já haviam apresentado ou não manifestações de doença aterosclerótica ${ }^{83,84}$. Uma das possíveis razões relaciona-se com o perfil da população estudada, principalmente no que se referem ao uso mais frequente de medicamentos sabidamente protetores (ex: estatinas, betabloqueadores, inibidores da enzima de conversão da angiotensina), ao controle mais agressivo dos fatores de risco tradicionais, e ao maior número de procedimentos de revascularização nos estudos mais contemporâneos. Desta forma, questiona-se se os ácidos graxos ômega-3 podem trazer reais benefícios adicionais quando o paciente é manejado de acordo com as recomendações atuais.

Como a maioria dos estudos avaliou EPA e DHA de forma combinada, no momento não existe evidência suficiente para se fazer recomendações separadas para cada um destes ácidos graxos.

Não se recomenda a suplementação de EPA e DHA para a prevenção da doença cardiovascular

Tabela 3.2 - Recomendações para consumo de produtos ricos em ácido graxo ômega-3

\begin{tabular}{|c|c|c|}
\hline Indicação & Classe & $\begin{array}{l}\text { Nível de } \\
\text { evidência }\end{array}$ \\
\hline $\begin{array}{l}\text { Suplementação com ômega-3 marinho ( } 2-4 \mathrm{~g} / \mathrm{dia}) \text { ou } \\
\text { até em doses mais elevadas deve ser recomendada } \\
\text { para hipertrigliceridemia grave (> } 500 \mathrm{mg} / \mathrm{dl}) \text {, com } \\
\text { risco de pancreatite, refratária a medidas não- } \\
\text { farmacológicas e tratamento medicamentoso. }\end{array}$ & I & $A$ \\
\hline $\begin{array}{l}\text { Pelo menos } 2 \text { refeições a base de peixe por } \\
\text { semana, como parte de uma dieta saudável, } \\
\text { devem ser recomendadas para diminuir o risco } \\
\text { cardiovascular. Tal recomendação é particularmente } \\
\text { dirigida para indivíduos de alto risco, como os } \\
\text { que já apresentaram infarto do miocárdio. }\end{array}$ & I & $B$ \\
\hline $\begin{array}{l}\text { Não se recomenda a suplementação de } \\
\text { EPA +DHA para indivíduos sob risco de } \\
\text { doença cardiovascular utilizando tratamentos } \\
\text { preventivos baseados em evidências }\end{array}$ & III & $A$ \\
\hline
\end{tabular}

Ácidos graxos poliinsaturados ômega-3 de origem vegetal

O ácido graxo alfa-linolênico (ALA) tem demonstrado efeitos inconsistentes sobre os níveis lipídicos. ${ }^{88,89}$ Em uma revisão sistemática e metanálise de 14 ensaios randomizados 


\section{Diretrizes}

e controlados com suplementação com ALA, não se observou influência significativa sobre colesterol total, LDL-C ou triglicérides, encontrando-se um efeito mínimo sobre o HDL-C (redução de $0,4 \mathrm{mg} / \mathrm{dL}$ ) ${ }^{90}$.

Especificamente, os efeitos da linhaça em animais de experimentação variam de nulo a discreta redução lipídica, e uma revisão sugeriu um efeito redutor de triglicérides pelo consumo de grandes quantidades de óleo de linhaça em humanos ${ }^{90}$. Estudos observacionais sugerem uma modesta redução no risco de DCV com o consumo de $\mathrm{ALA}^{90}$. Dados do estudo alpha-ômega mostraram ausência de benefícios da suplementação do ALA para prevenção da DCV em indivíduos que haviam apresentado doença cardiovascular prévia $^{85}$. Entretanto, há necessidade de mais estudos com a suplementação de ALA visando a prevenção da $\mathrm{DCV}^{90}$. Não se recomenda a suplementação com ALA para a prevenção da doença cardiovascular.

As recomendações para o consumo e suplementação de ALA encontram-se na Tabela 3.3.

Tabela 3.3 - Recomendação para consumo de produtos ricos em ácido graxo ômega-3 de origem vegetal

\begin{tabular}{lcc}
\hline \multicolumn{1}{c}{ Recomendação } & Classe & $\begin{array}{c}\text { Nivel de } \\
\text { Evidência }\end{array}$ \\
\hline $\begin{array}{l}\text { Estimular o consumo de ácidos graxos poliinsaturados } \\
\text { ômega-3 de origem vegetal, como parte de uma } \\
\text { dieta saudável, pode ser recomendado para } \\
\text { reduzir o risco cardiovascular, embora o real } \\
\text { benefício desta recomendação seja discutível }\end{array}$ & Illb & B \\
e as evidências não sejam conclusivas. & & \\
$\begin{array}{l}\text { Não se recomenda a suplementação com } \\
\text { ALA para a prevenção da DCV. }\end{array}$ & III & B \\
\hline
\end{tabular}




\section{Obesidade e sobrepeso}

\section{Introdução}

Nas últimas décadas o Brasil apresentou um processo chamado de transição nutricional ${ }^{91}$, um conceito que se refere a mudanças seculares nos padrões de nutrição e estado nutricional, modificações importantes da ingestão alimentar e dos padrões de atividade física, como consequência de transformações econômicas, sociais, demográficas e sanitárias ${ }^{92}$.

No Brasil, a prevalência de sobrepeso e obesidade aumenta continuamente desde 1974 até os dias atuais entre adultos de ambos os sexos. Porém, a partir de 2002-2003 a prevalência de sobrepeso, maior entre as mulheres, passou a ser maior entre os homens, aumentando de $18,5 \%$ para $50,1 \%$ em todas as regiões, com exceção apenas do Nordeste, enquanto entre as mulheres passou de $28,7 \%$ para $48 \%{ }^{93}$.

Em um período de 34 anos, a prevalência de obesidade aumentou em mais de quatro vezes para os homens (de $2,8 \%$ para $12,4 \%$ ) e em mais de duas vezes para as mulheres (de $8 \%$ para 16,9\%) ${ }^{94,95}$. Atualmente o Brasil ocupa o quarto lugar entre os países com maior prevalência de obesidade ${ }^{96}$ e pela primeira vez o número de adultos com sobrepeso ultrapassará o de baixo peso ${ }^{96}$. Nas crianças e adolescentes, observa-se uma importante ascensão do sobrepeso e obesidade, independente do sexo e das classes sociais, e uma proporção significativa das crianças obesas irão tornar-se adultos obesos.

De natureza multifatorial, a obesidade é um dos fatores preponderantes para explicar o aumento da carga das doenças crônicas não transmissíveis (DCNTs), uma vez que está associada frequentemente a enfermidades cardiovasculares como hipertensão arterial, dislipidemias, diabetes tipo 2, osteoartrites e certos tipos de câncer, sendo também apontada como importante condição que predispõe à mortalidade ${ }^{96,97}$.

\section{Prevenção Primária}

É importante identificar em que momento biológico é possível prevenir o ganho de peso. No caso das mulheres, o momento de maior risco de ganho de peso parece ser a idade reprodutiva, especificamente a gestação e os dois primeiros anos pós-parto ${ }^{97,98}$.

Entre crianças e adolescentes, era esperada uma prevenção do ganho excessivo de peso justamente porque a fase de crescimento necessita de energia extra ao mesmo tempo em que a possibilidade de gasto de energia é maior em relação às outras fases da vida. Porém, esses possíveis facilitadores parecem não suplantar os fatores associados à obesidade e os responsáveis pelo crescimento desta epidemia também nestas faixas etárias e fases de vida ${ }^{99}$.

Neste sentido, é importante destacar o chamado "ambiente obesogênico", ou seja: o papel da indústria de alimentos, das cadeias de fast food, das propagandas e programações de TV, filmes, videogames, enfim, situações que mantêm as crianças mais sedentárias e submetidas ao consumo excessivo. As intervenções mais adequadas devem combinar mudanças ambientais e comportamentais ${ }^{100-102}$.

Crianças e adolescentes: ver capítulo específico.

\section{Adultos}

Entre adultos, diversos estudos evidenciam o declínio do consumo de arroz e feijão, o aumento da ingestão de produtos industrializados (principalmente biscoitos e refrigerantes), o consumo excessivo de açúcar, o aumento sistemático no teor de gorduras e a ingestão insuficiente de frutas, legumes e verduras (FLV), configurando um quadro de tendências desfavoráveis a um padrão alimentar saudável e diretamente associado ao aumento das DCNTs, em que se destaca a obesidade, um quadro semelhante ao observado nos grupos etários anteriores ${ }^{103,104}$.

As recomendações são as seguintes:

- Três refeições (café da manhã, almoço e jantar) e dois lanches saudáveis por dia. Não pular as refeições. Evitar comer entre as refeições.

- Ficar atento aos rótulos dos alimentos e escolher aqueles com menores quantidades de gorduras trans.

- Evitar refrigerantes e sucos industrializados, bolos, biscoitos doces e recheados, sobremesas doces e outras guloseimas.

- Dar preferência ao consumo de água nos intervalos das refeições.

- Fazer pelo menos 30 minutos de atividade física todos os dias.

- Porém, aqueles com tendência a obesidade ou com perfil familiar, devem fazer 45-60 minutos de atividade física de intensidade moderada por dia; os que foram obesos e perderam peso devem fazer 60-90 minutos para evitar recuperar o peso.

- Mesmo em idosos a prática de atividades físicas e exercícios podem prevenir o ganho de peso e a obesidade. ${ }^{105}$

- Evitar o consumo excessivo de bebidas alcoólicas ${ }^{106}$.

Tabela 4.1 - Resumo das recomendações para obesidade e sobrepeso na prevenção primária da doença cardiovascular

\begin{tabular}{|c|c|c|}
\hline Indicação & Classe & $\begin{array}{l}\text { Nível de } \\
\text { Evidência }\end{array}$ \\
\hline $\begin{array}{l}\text { Três refeições (café da manhã, almoço e } \\
\text { jantar) e dois lanches saudáveis por dia }\end{array}$ & $\|$ & $A$ \\
\hline $\begin{array}{l}\text { Ficar atento aos rótulos dos alimentos e escolher } \\
\text { aqueles com menores quantidades de gorduras trans }\end{array}$ & $\|$ & A \\
\hline $\begin{array}{l}\text { Evitar refrigerantes e sucos industrializados, } \\
\text { bolos, biscoitos doces e recheados, } \\
\text { sobremesas doces e outras guloseimas }\end{array}$ & 1 & A \\
\hline $\begin{array}{l}\text { Dar preferência ao consumo de água } \\
\text { nos intervalos das refeições }\end{array}$ & $\|$ & A \\
\hline $\begin{array}{l}\text { Fazer pelo menos } 30 \text { minutos de } \\
\text { atividade física todos os dias }\end{array}$ & I & A \\
\hline $\begin{array}{l}\text { Aqueles com tendência a obesidade ou com perfil } \\
\text { familiar, devem fazer } 45-60 \text { minutos de atividade } \\
\text { física de intensidade moderada por dia; os que } \\
\text { foram obesos e perderam peso devem fazer } \\
60-90 \text { minutos para evitar recuperar o peso }\end{array}$ & 1 & A \\
\hline Evitar o consumo excessivo de bebidas alcoólicas & I & A \\
\hline
\end{tabular}

\section{Prevenção Secundária}

A intervenção proposta neste nível visa à modificação do estilo de vida e outras ações, tanto para crianças como para adolescentes e adultos. 
É considerada, muitas vezes, uma estratégia aceitável para se atingir a redução de peso necessária no início do processo. Esta redução diária pode promover a diminuição de cerca de 500g por semana ${ }^{107}$.

A intensificação dos exercícios físicos como caminhada, ciclismo, natação, aeróbica, 30 a 45 minutos 3 a 5 vezes na semana pode contribuir para a redução de fatores de risco cardiovascular É importante o aumento da massa magra, por isso a combinação de exercícios aeróbicos com os isométricos/estáticos é fundamental.

Devem-se minimizar as atividades sedentárias, como ficar sentado por longos períodos assistindo televisão, no computador ou jogando videogames. Além disso, constituir atividade na jornada de trabalho, como, por exemplo, tomar as escadas em vez do elevador, dar um passeio na hora do almoço, e incentivar a alimentação saudável para crianças e adolescentes.

Tabela 4.2 - Resumo das recomendações para obesidade e sobrepeso na prevenção secundária da doença cardiovascular

\begin{tabular}{lcc}
\hline \multicolumn{1}{c}{ Indicação } & Classe & $\begin{array}{c}\text { Nível de } \\
\text { evidência }\end{array}$ \\
\hline $\begin{array}{l}\text { Dieta com uma redução calórica de } \\
\text { aproximadamente } 500 \text { kcal/dia }\end{array}$ & I & A \\
$\begin{array}{l}\text { Intensificação de exercícios físicos como } \\
\text { caminhada, ciclismo, natação, aeróbica, } 30\end{array}$ & I & A \\
$\begin{array}{l}\text { a } 45 \text { minutos, } 3 \text { a } 5 \text { vezes na semana } \\
\text { Minimizar atividades sedentárias, como ficar } \\
\begin{array}{l}\text { sentado por longos períodos assistindo televisão, } \\
\text { no computador ou jogando videogames }\end{array}\end{array}$ & । & B \\
$\begin{array}{l}\text { Incentivar a alimentação saudável } \\
\text { para crianças e adolescentes. }\end{array}$ & I & B \\
$\begin{array}{l}\text { Usar sibutramina para perda de peso em } \\
\text { pacientes com doença cardiovascular } \\
\text { Cirurgia bariátrica para pacientes selecionados }\end{array}$ & III & B \\
\hline
\end{tabular}

Assim, a quantidade de perda de peso recomendada e o cronograma para determinar esta perda poderão variar, dependendo do grau de obesidade e da natureza e gravidade das complicações e das demais características inerentes aos indivíduos e seu estilo de vida.

\section{Terapia Medicamentosa}

Existem dois medicamentos aprovados para o tratamento de obesidade no Brasil: o orlistate e a sibutramina. A sibutramina, apesar de liberada no Brasil, não deve ser utilizada em pacientes com $\mathrm{DCVs}^{107}$. Ambos promovem perda de peso modesta, de modo sustentado, sendo indicados para o tratamento a longo prazo da obesidade em conjunto com um plano alimentar reduzido em calorias e a prática regular de atividade física.

\section{Cirurgia Bariátrica}

As comorbidades associadas à obesidade apresentaram melhora após a cirurgia bariátrica. O Estudo Adelaide mostrou que $60 \%$ dos pacientes que inicialmente tinham comorbidades relacionadas com a obesidade conseguiram manter-se sem medicamentos por três anos após a cirurgia ${ }^{108,109}$.

A intervenção cirúrgica é uma opção para pacientes cuidadosamente selecionados, com obesidade clinicamente grave (índice de massa corporal [IMC] $\geq 40 \mathrm{~kg} / \mathrm{m}^{2}$ sem comorbidades ou $35 \mathrm{~kg} / \mathrm{m}^{2}$ com comorbidades), quando os tratamentos clínicos falharam.

É necessário o acompanhamento multidisciplinar do paciente devido a possíveis alterações nutricionais. 


\section{Hipertensão arterial}

A hipertensão arterial sitêmica (HAS) é o mais importante fator de risco para o desenvolvimento de doença arterial coronariana, insuficiência cardíaca, doença cerebrovascular, doença renal crônica e fibrilação atrial ${ }^{110,111}$ e tem sido associada ao desenvolvimento de déficit cognitivo e demência ${ }^{112}$

A mortalidade por DCV aumenta progressivamente com a elevação da pressão artrerial (PA) a partir de 115/75 mmHg de forma linear, contínua e independente ${ }^{113}$.

Em uma década, cerca de 7,6 milhões de mortes no mundo foram atribuídas à HAS (54\% por acidente vascular encefálico [AVE] e $47 \%$ por doença isquêmica do coração [DIC]), sendo a maioria em países de baixo e médio desenvolvimento econômico e mais da metade em indivíduos entre 45 e 69 anos ${ }^{114}$.

Considerando-se valores de PA iguais ou superiores a 140/90 mmHg, 22 estudos encontraram prevalências de HAS na população adulta entre 22,3\% e 43,9\% (média de 32,5\%), sendo superior a 50\% entre 60 e 69 anos e $75 \%$ acima de 70 anos ${ }^{115-118}$.

\section{Definição e classificação (VI DBH ${ }^{119}$ )}

Tabela 5.1 - Classificação da pressão arterial de acordo com a medida casual no consultório ( $>18$ anos)

\begin{tabular}{lcc}
\hline \multicolumn{1}{c}{ Classificação } & $\begin{array}{c}\text { Pressão sistólica } \\
(\mathbf{m m H g})\end{array}$ & $\begin{array}{c}\text { Pressão diastólica } \\
(\mathbf{m m H g})\end{array}$ \\
\hline Ótima & $<120$ & $<80$ \\
Normal & $<130$ & $<85$ \\
Limítrofe $^{*}$ & $130-139$ & $85-89$ \\
Hipertensão estágio 1 & $140-159$ & $90-99$ \\
Hipertensão estágio 2 & $160-179$ & $100-109$ \\
Hipertensão estágio 3 & $\geq 180$ & $\geq 110$ \\
Hipertensão sistólica isolada & $\geq 140$ & $<90$ \\
\hline Quando as pressões sistólica e diastólica situam-se em categorias diferentes, \\
a maior deve ser utilizada para classificação da pressão arterial. \\
\hline \multicolumn{2}{c}{ * Pressão normal-alta ou pré-hipertensão são termos que se equivalem na } \\
literatura.
\end{tabular}

\section{Medidas da pressão arterial}

Na primeira avaliação, as medidas devem ser obtidas em ambos os braços e, em caso de diferença, deve-se utilizar como referência sempre o braço com o maior valor para as medidas subsequentes. O indivíduo deverá ser investigado para doenças arteriais se apresentar diferenças de pressão entre os membros superiores maiores de 20/10 mmHg para as pressões sistólica/diastólica respectivamente ${ }^{120}$.

Em cada consulta deverão ser realizadas pelo menos três medidas, sugere-se o intervalo de um minuto entre elas ${ }^{121,122}$. A média das duas últimas deve ser considerada a PA real. Caso as pressões sistólicas e/ou diastólicas obtidas apresentem diferença maior que $4 \mathrm{mmHg}$, deverão ser realizadas novas medidas até que se obtenham medidas com diferença inferior.

A posição recomendada para a medida da pressão arterial é a sentada. As medidas nas posições ortostática e supina devem ser feitas pelo menos na primeira avaliação em todos os indivíduos e em todas as avaliações em idosos, diabéticos, portadores de disautonomias, alcoolistas e/ou em uso de medicação anti-hipertensiva (Tabela 5.1).

A MAPA (monitorização anbulatorial da pressão arterial), A MRPA (monitorização residencial da pressão arterial) e AMPA (auto-medida da pressão arterial) constituem ferramentas importantes na investigação de pacientes com suspeita de hipertensão ou para controle do tratamento. Recomenda-se, sempre que possível, a medida da PA fora do consultório para esclarecimento do diagnóstico, identificação da hipertensão do avental branco e da hipertensão mascarada, além do controle do tratamento anti-hipertensivo ${ }^{123,124}$.

\section{Avaliação inicial de rotina para o paciente hipertenso}

Deve constituir rotina básica de exames complementares para o hipertenso: análise de urina; potássio plasmático;creatinina plasmática e estimativa do ritmo de filtração glomerular por fómulas ${ }^{125-127}$; glicemia de jejum; colesterol total, HDLc, triglicérides plasmáticos; ácido úrico plasmático; eletrocardiograma convencional (ECG) ${ }^{119}$.

Tabela 5.2 - Avaliação inicial de rotina para o paciente hipertenso $0^{119}$

\begin{tabular}{ccc}
\hline Recomendação & Classe & $\begin{array}{c}\text { Nível de } \\
\text { Evidência }\end{array}$ \\
\hline Análise de Urina & $\mathrm{I}$ & $\mathrm{C}$ \\
Potássio plasmático & $\mathrm{I}$ & $\mathrm{C}$ \\
Creatinina plasmática & $\mathrm{I}$ & $\mathrm{B}$ \\
Estimativa do ritmo de filtração glomerular & $\mathrm{I}$ & $\mathrm{B}$ \\
Glicemia de jejum & $\mathrm{I}$ & $\mathrm{C}$ \\
Colesterol total, HDL-C, triglicerídeos plasmáticos & $\mathrm{I}$ & $\mathrm{C}$ \\
Ácido Úrico plasmático & $\mathrm{I}$ & $\mathrm{C}$ \\
Eletrocardiograma convencional & $\mathrm{I}$ & $\mathrm{B}$ \\
\hline
\end{tabular}

HDL-C- colesterol da lipoproteina de alta densidade

A avaliação complementar para o paciente hipertenso poderá incluir: ${ }^{119}$

a) Radiografia de tórax: recomendada para pacientes com suspeita clínica de insuficiência cardíaca, quando os demais exames não estão disponíveis, e para avaliação de acometimento pulmonar e de aorta.

b) Ecocardiograma: hipertensos estágios 1 e 2 sem hipertrofia ventricular esquerda ao ECG, mas com dois ou mais fatores de risco; hipertensos com suspeita clínica de insuficiência cardíaca.

c) Microalbuminúria em amostra isolada de urina (pela relação urinária albumina/creatinina): pacientes hipertensos diabéticos, hipertensos com síndrome metabólica e hipertensos com dois ou mais fatores de risco.

d) Ultrassom de artérias carótidas: pacientes com sopro carotídeo, com sinais de doença cerebrovascular, ou com doença aterosclerótica em outros territórios.

e) Teste ergométrico: suspeita de doença coronariana estável, diabético ou antecedente familiar para doença coronariana em paciente com pressão arterial controlada.

f) Hemoglobina glicada: em portadores de síndrome matabólica, diabéticos ou intolerantes à glucose. $\mathrm{Na}$ impossibilidade de realizar hemoglobina glicada, sugere-se a realização do teste oral de tolerância à 
glicose em pacientes com glicemia de jejum entre 100 e 126 mg/dl.

g) MAPA, MRPA e AMPA, segundo as indicações convencionais para os métodos.

h) Avaliação da rigidez arterial pela velocidade de onda de pulso ou outros métodos, se disponível.

i) Investigação de hipertensão secundária, quando indicada pela história, pelo exame físico ou pela avaliação laboratorial inicial.

Tabela 5.3 - Avaliação complementar para o paciente hipertenso ${ }^{119}$

\begin{tabular}{|c|c|c|}
\hline Recomendação & Classe & $\begin{array}{l}\text { Nível de } \\
\text { Evidência }\end{array}$ \\
\hline Radiografia de tórax & Ila & $\mathrm{C}$ \\
\hline $\begin{array}{c}\text { Ecocardiograma - hipertensos estágios } 1 \text { e } 2 \text { sem } \\
\text { HVE no ECG }\end{array}$ & Ila & C \\
\hline $\begin{array}{l}\text { - hipertensos com suspeita clinica } \\
\text { de IC }\end{array}$ & I & C \\
\hline Microalbuminúria - hipertensos e diabéticos & I & A \\
\hline $\begin{array}{l}\text { - Hipertensos com síndrome } \\
\text { metabólica }\end{array}$ & I & C \\
\hline $\begin{array}{l}\text { - Hipertensos com dois ou + fatores } \\
\text { de risco }\end{array}$ & I & C \\
\hline Ultrassonografia de carótida & Ila & $\mathrm{B}$ \\
\hline Teste ergométrico na suspeita de doença coronariana & Ila & C \\
\hline Hemoglobina glicada & Ila & B \\
\hline Velocidade de onda de pulso & Ilb & C \\
\hline
\end{tabular}

HVE- hipertrofia ventricular esquerda, ECG- eletrocardiograma,

IC- insuficiência cardíaca

\section{Identificação de lesões subclínicas de órgãos-alvo}

a) ECG com HVE (Sokolow-Lyon > $35 \mathrm{~mm}$; Cornell > 28 $\mathrm{mm}$ - para homens $[\mathrm{H}]$; $>20 \mathrm{~mm}$ - para mulheres [M]); b) Ecocardiograma com HVE (índice de massa de $V E>134 \mathrm{~g} / \mathrm{m}^{2}$ em H ou $110 \mathrm{~g} / \mathrm{m}^{2}$ em M); c) Espessura médio-intimal de carótida $>0,9 \mathrm{~mm}$ ou presença de placa de ateroma; d) Índice tornozelo braquial $<0,9$; e) depuração de creatinina estimada $<60 \mathrm{ml} / \mathrm{min} / 1,72$ $\mathrm{m}^{2}$; f) baixo ritmo de filtração glomerular ou depuração de creatinina ( $<60 \mathrm{ml} / \mathrm{min}$ ); g) microalbuminúria 30-300 mg/24 horas ou relação albumina/creatinina > 30 mg porg;

\section{Quadro 5.1 - Cálculo do clearance de creatinina e ritmo de filtração glomerular e interpretação dos valores para classificação de doença renal crônica de acordo com NKF'121}

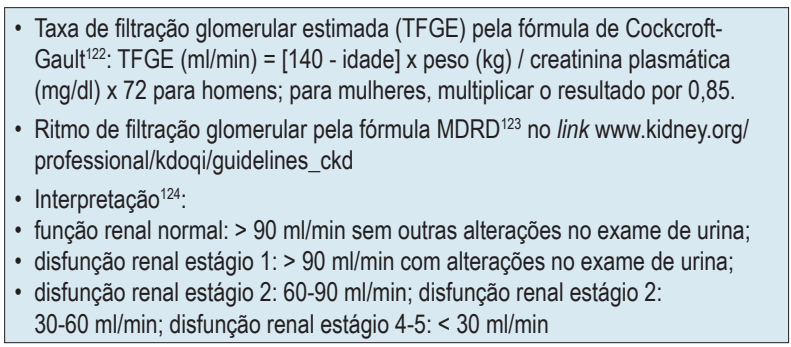

h) avaliação de rigidez arterial pela velocidade de onda de pulso $>12 \mathrm{~m} / \mathrm{s}^{125,126}$

\section{Prevenção}

Estudos clínicos demonstraram que a detecção, o tratamento e o controle da HAS são fundamentais para a redução dos eventos cardiovasculares. Meta-analise de 354 estudos clínicos releva que a redução da morbidade e mortalidade é proporcional à queda da pressão arterial, tanto sistólica quanto diastólica, podendo reduzir em até $46 \%$ a ocorrência de infartos do miocárdio e em $63 \%$ o número de acidentes vasculares encefálicos ${ }^{127}$. No Brasil, 14 estudos populacionais realizados nos últimos quinze anos, com 14.783 indivíduos (PA < 140/90 mmHg), revelaram baixos níveis de controle da PA $(19,6 \%)^{116-118}$.

\section{Prevenção Primária da HAS}

A hipertensão arterial pode ser prevenida ou postergada. As mudanças no estilo de vida são entusiasticamente recomendadas na prevenção primária da HAS, notadamente nos indivíduos com PA limítrofe. Tais adequações de estilo de vida reduzem a PA, bem como a mortalidade cardiovascular ${ }^{128}$.

Hábitos saudáveis de vida devem ser adotados desde a infância e a adolescência, respeitando-se as características regionais, culturais, sociais e econômicas dos indivíduos. As principais recomendações não medicamentosas para prevenção primária da HAS são: alimentação saudável, baixo consumo de sódio e álcool, adequada ingestão de potássio, combate ao sedentarismo e ao tabagismo e controle do peso corpóreo. Tais recomendações são indicadas tanto para a prevenção da hipertensão como coadjuvantes do tratamento medicamentoso de hipertensos ${ }^{129}$.

\section{Medidas não farmacológicas}

Tabela 5.4 - Tratamento não farmacológico no paciente hipertens $0^{119}$

\begin{tabular}{lcc}
\hline \multicolumn{1}{c}{ Recomendação } & Classe & $\begin{array}{c}\text { Nível de } \\
\text { Evidência }\end{array}$ \\
\hline Dieta - DASH & $\mathrm{I}$ & $\mathrm{A}$ \\
- Mediterrâneo & $\mathrm{I}$ & $\mathrm{B}$ \\
- Vegetariana & Ila & $\mathrm{B}$ \\
Sódio - consumo diário de $2 \mathrm{~g}$ & $\mathrm{I}$ & $\mathrm{A}$ \\
Álcool - não ultrapassar $30 \mathrm{~g}$ de etanol ao dia & $\mathrm{I}$ & $\mathrm{B}$ \\
Atividade física - 30 minutos/dia & $\mathrm{I}$ & $\mathrm{A}$ \\
dia/3 vezes por semana(mínimo) & $\mathrm{I}$ & $\mathrm{A}$ \\
Controle do peso - IMC entre 18,5 a $24,9 \mathrm{~kg} / \mathrm{m} 2$ & Ila & $\mathrm{B}$ \\
Controle do estresse psicossocial & $\mathrm{I}$ & $\mathrm{B}$ \\
\hline Equipe multiprofissional & &
\end{tabular}

DASH Dietary Approaches to Stop Hypertension IMC- índice de massa corporal,

\section{Dietas}

O padrão dietético DASH (Dietary Approaches to Stop Hypertension), rico em frutas, hortaliças, fibras, minerais e laticínios com baixos teores de gordura, tem importante impacto na redução da PA. Um alto grau de adesão a esse tipo de dieta reduziu em 14\% o desenvolvimento de hipertensão. Os benefícios sobre a PA têm sido associados ao alto consumo de potássio, magnésio e cálcio nesse padrão nutricional. A dieta DASH potencializa ainda o efeito de orientações nutricionais para emagrecimento, reduzindo também biomarcadores de risco cardiovascular ${ }^{130,131}$.

A dieta do mediterrâneo associa-se também à redução da PA. $\mathrm{O}$ alto consumo de frutas e hortaliças revelou ser inversamente proporcional aos níveis de PA, mesmo com um mais alto per- 
centual de gordura. A substituição do excesso de carboidratos nesta dieta por gordura insaturada induz à mais significativa redução da $\mathrm{PA}^{132,133}$.

Dietas vegetarianas são inversamente associadas com a incidência de doenças cardiovasculares. Isto se explica em razão de fornecerem menor quantidade de nutrientes, como gordura saturada e cholesterol. Entretanto, essas dietas são deficientes em micronutrientes como ferro, vitamina B12 e cálcio, sendo necessária a suplementação para atender às recomendações vigentes. As deficiências de micronutrientes, muitas vezes observadas em lacto-vegetarianos, têm sido identificadas como fatores predisponentes à HAS em adultos seguidores desse estilo alimentar. Fato relevante é a observação de que os vegetarianos apresentam, em geral, menor IMC, que, independentemente do tipo de dieta, se associa a menor $\mathrm{PA}^{134,135}$

\section{Sódio}

A quantidade considerada máxima saudável para a ingestão alimentar diária de cloreto de sódio (sal de cozinha) é de 5 g de (que corresponde a 2 g de sódio) ${ }^{136,137}$. Na prática, recomenda-se o consumo de, no máximo, 3 colheres de café rasas (3 g), que somados aos $2 \mathrm{~g}$ de sal já existentes nos próprios alimentos contemplaria o total de $5 \mathrm{~g}$.

\section{Álcool}

Em indivíduos hipertensos, a ingestão de álcool, agudamente e dependentemente da dose, reduz a PA, porém ocorre elevação algumas horas após o seu consumo. Tendo em vista a controvérsia em relação à segurança e ao benefício cardiovascular de baixas doses, assim como a ação nefasta do álcool na sociedade, devemos orientar àqueles que têm o hábito de ingerir bebidas alcoólicas a não ultrapassarem $30 \mathrm{~g}$ de etanol ao dia, para homens, de preferência não-habitualmente; sendo a metade dessa quantidade a indicada para as mulheres ${ }^{138,139}$. As quantidades máximas diárias sugeridas dos tipos de bebidas alcólicas mais comuns são: 2 latas $(350 \times 2=700 \mathrm{ml})$ ou 1 garrafa $(650 \mathrm{ml})$ de cerveja; 2 taças de $150 \mathrm{ml}$ ou 1 taça de $300 \mathrm{ml}$ de vinho; 2 doses de $50 \mathrm{ml}$ de uísque, vodca ou bebida destilada.

\section{Atividade física}

A prática regular de atividade física aeróbia, como caminhadas por, pelo menos, 30 minutos por dia, 3 vezes/semana, está indicada para a prevenção, sendo que para o tratamento recomenda-e o exercício diário supervisionado ${ }^{140}$. Exercícios resistidos podem ser associados aos aeróbios ${ }^{141}$.

\section{Controle de peso}

Manter o peso corporal na faixa normal (índice de massa corporal entre 18,5 a 24,9 kg/m²) e medidas de cincuferência abdominal abaixo de $102 \mathrm{~cm}$, para homens e $90 \mathrm{~cm}$, para mulheres ${ }^{142,143}$.

\section{Controle do estresse psicossocial}

Diferentes técnicas de controle do estresse têm sido avaliadas, porém com resultados conflitantes. Meditação, musicoterapia, biofeedback, yoga, entre outras técnicas de controle do estresse, foram capazes de reduzir discretamente a PA de hipertensos ${ }^{144}$.

\section{Equipe multiprofissional}

Como a HAS é uma síndrome clínica multifatorial, contar com a contribuição da equipe multiprofissional de apoio ao hipertenso é conduta desejável, sempre que possível ${ }^{145}$.

\section{Outras estratégias não farmacológicas para o controle da pressão arterial}

Estratégias específicas, como a adoção de ténicas de respiração lenta ${ }^{146}$, o uso de CPAP (pressão positiva contínua nas vias aéreas) em caso de síndrome a apnéia obstrutiva do sono ${ }^{147}$ e cirurgia bariática para obesidade avançada ${ }^{148}$, têm demonstrado significativo impacto na redução da pressão arterial.

\section{Medidas medicamentosas na prevenção da hipertensão}

Os estudos TROPHY ${ }^{149}$ e PHARAO ${ }^{150}$, avaliaram a eficácia e a segurança de medicamentos anti-hipertensivos, na prevenção da HAS. A estratégia medicamentosa, baseada no bloqueio do sistema renina-angitensina, foi bem tolerada e preveniu o desenvolvimento de HAS em populações jovens de alto risco. Contudo, até o presente, nenhum estudo já realizado tem poder suficiente para determinar a indicação de tratamento medicamentoso para indivíduos com PA limítrofe sem evidências de doença cardiovascular.

\section{Decisão terapêutica e categoria de risco}

O hipertenso deve ser classificado tendo como base o nível médio de sua pressão arterial e a presença ou não de fatores de risco associados, lesões de orgãos-alvo e doenças cardiovasculares ou renais já presentes.

A decisão terapêutica deverá basear-se na estratificação de risco, conforme Quadro 5.2 abaixo:

\section{Quadro 5.2 - Decisão terapêutica}

\begin{tabular}{|ll|}
\hline \multicolumn{1}{|c|}{ Categoria de risco } & \multicolumn{1}{c|}{ Considerar } \\
\hline - Sem risco adicional & - Tratamento não medicamentoso isolado \\
- Risco adicional baixo & - Tratamento não medicamentoso isolado por \\
& $\begin{array}{l}\text { até } 6 \text { meses. Se não atingir a meta, associar } \\
\text { tratamento medicamentoso }\end{array}$ \\
- Risco adicional médio, & - Tratamento não medicamentoso + \\
alto e muito alto & medicamentoso \\
\hline
\end{tabular}

\section{Tratamento Farmacológico}

O tratamento farmacológico da HAS muda de forma expressiva o prognóstico da doença, independente dos fármacos anti-hipertensivos utilizados tanto em monoterapia quanto em combinação. Inúmeros estudos randomizados e metanálises demonstraram os benefícios da redução dos níveis pressóricos sobre a morbidade e mortalidade cardiovasculares. Diversos ensaios clínicos demonstram redução da desfechos relevantes em estudos com diuréticos, betabloqueadores (BB), inibidores da enzima conversora da angiotensina (IECA), bloqueadores do receptor AT1 da angiotensina II (BRA II) e com antagonistas dos canais de cálcio (ACC) ${ }^{151}$. Uma vez que a monoterapia controla a pressão em menos de 1/3 dos hipertensos, a maioria dos ensaios clínicos utilizou associações de fármacos para o controle tensional, demonstrando que os benefícios alcançados independem das classes utilizadas.

Segundo as VI Diretrizes Brasileiras de Hipertensão devemos iniciar o tratamento com monoterapia nos pacientes em estágio 1 com risco baixo ou moderado, e com combinações de fármacos nos estágios 2 ou 3, ou estagio 1 com risco alto ou muito alto (Figura 5.1) ${ }^{119}$. 


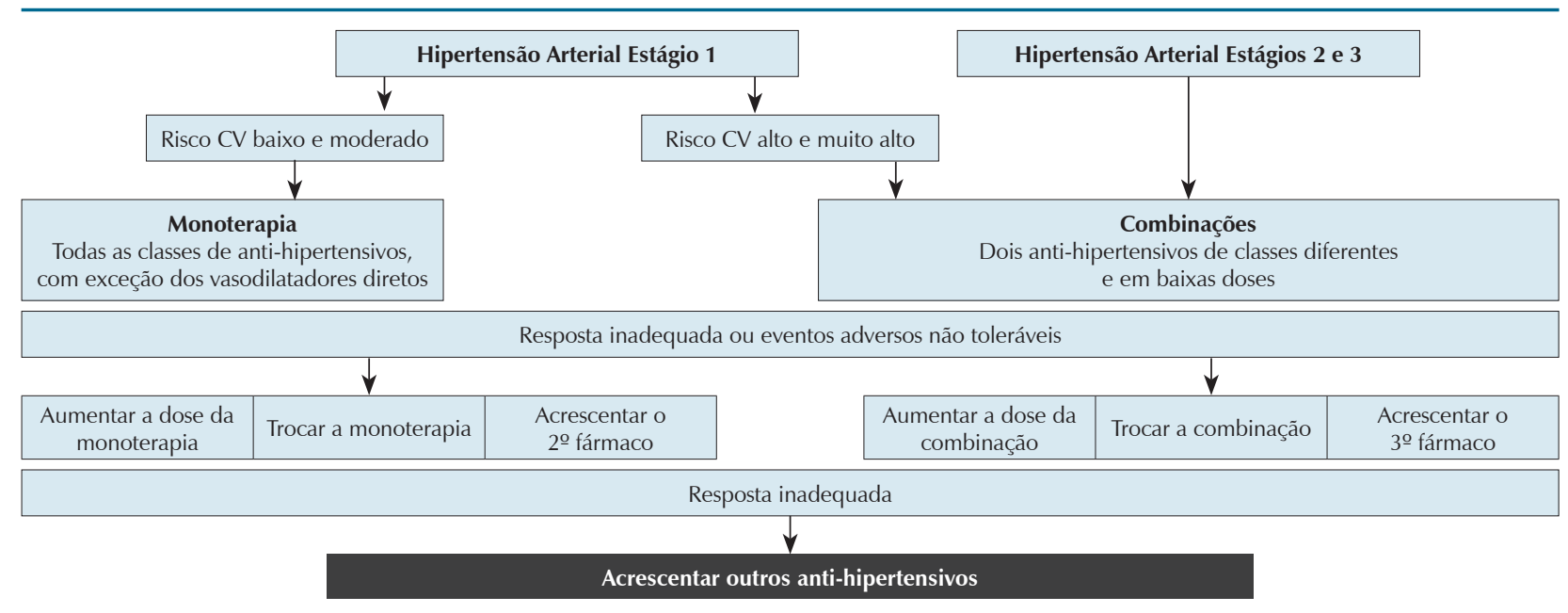

Figura 5.1 - Algoritmo do tratamento da hipertensão arterial segundo a VI Diretrizes Brasileiras de Hipertensão Arterial ${ }^{119}$.

Em relação às combinações medicamentosas recomendadas deve-se sempre levar em conta as comorbidades do paciente, entretanto, de forma geral, as melhores combinações em termos de efetividade são os fármacos que inibem o sistema renina angiotensina aldosterona (IECA ou BRA) com os antagonistas dos canais de cálcio ou diuréticos ${ }^{152}$.

1. Diuréticos: são efetivos em baixar os níveis pressóricos com comprovação na redução da morbimortalidade. Os diuréticos tiazídicos (hidroclorotiazida, clortalidona, indapamida) são os indicados. Os poupadores de potássio (amilorida e triantereno) apresentam baixa potencia diurética, mas quando associados aos tiazídicos ou aos de alça são úteis na prevenção da hipocalemia ${ }^{153}$. A espironolactona tem maior potencia anti-hipertensiva que os demais poupadores de potássio, sendo indicada, principalmente na hipertensão resistente.

2. Antagonistas dos canais de cálcio: são eficazes em reduzir a morbimortalidade. São indicados os de longa duração devido a redução de eventos e até superioridade na redução de acidentes vasculares encefálicos ${ }^{154}$. Os diidropiridínicos são os mais indicados, por exibirem maior potencia anti-hipertensiva.

3. Betabloqueadores: são eficazes na redução da pressão arterial, entretanto em algumas metanálises, os de primeira e segunda geração, utilizados isoladamente, promoveram menor proteção contra o acidente vascular cerebral em indivíduos acima de 55 anos. São bem indicados em situações especiais tais como arritmias, doença coronária e insuficiência cardíaca. Ensaios clínicos com carvedilol, metoprolol, bisoprolol e nebivolol têm demonstrado redução expressiva de mortalidade e morbidade cardiovascular em pacientes com insuficiência cardíaca, independentemente da faixa etária ${ }^{155}$.

4. IECA ou BRA. Ambas as classes são muito úteis no tratamento da maioria dos hipertensos, principalmente em populações de alto risco cardiovascular ou com comorbidades. Diversos ensaios clínicos comprovam efeitos benéficos na insuficiência cardíaca, na prevenção de acidentes vascular cerebrais e nos pacientes com diabetes melito que tenham comprometimento renal. Os BRA são equivalentes aos IECA em relação aos eventos coronarianos mas superiores na proteção cerebrovascular ${ }^{156,157}$.

5. outros agentes; a) o alisquireno, que é um inibidor direto da renina, se mostrou efetivo em reduzir os níveis pressóricos e útil em combinação com diuréticos ou antagonistas do cálcio. Entretanto a associação com outros IECA ou BRA se mostrou deletério. B) agentes de ação central e bloqueadores alfa adrenérgicos são mais úteis em combinações múltiplas ${ }^{158}$.

As metas pressóricas recomendadas segundo o "2013 ESH/ ESC Guidelines for the management of arterial hypertension" são de $<140 \mathrm{mmHg}$ para a pressão arterial sistólica (PAS) e $<90$ mmHg para a pressão arterial diastólica (PAD). Exceção são os pacientes diabéticos onde se recomenda PAD <85 $\mathrm{mmHg}$. Os pacientes com nefropatia e proteinúria a recomendação para a PAS é < 130 mmHg ${ }^{159}$.

\section{Metas terapêuticas}

As metas pressóricas a serem perseguidas, segundo as $\mathrm{VI}$ Diretrizes Brasileiras de Hipertensão, estão demonstradas na tabela abaixo ${ }^{119}$.

\section{Quadro 5.3 - Metas a serem atingidas em conformidade com as} características individuais

\begin{tabular}{|lc|}
\hline \multicolumn{1}{|c|}{ Categoria } & \multicolumn{1}{c|}{ Considerar } \\
\hline - Hipertensos estágios 1 e 2 com risco & $\cdot<140 / 90 \mathrm{mmHg}$ \\
cardiovascular baixo e médio & \\
- Hipertensos e comportamento limítrofe com & $\cdot 130 / 80 \mathrm{mmHg}$ \\
risco cardiovascular alto e muito alto, ou com 3 & \\
ou mais fatores de risco, DM, SM ou LOA & \\
- Hipertensos com insuficiência renal com & $\cdot 130 / 80 \mathrm{mmHg}$ \\
proteinúria > $>1,0 \mathrm{~g} / \mathrm{l}$ & \\
\hline
\end{tabular}

DM - diabetes melito; SM - síndrome metabólica; LOA- lesões em órgãos-alvo. 


\section{Dislipidemia}

O colesterol elevado pode ser considerado o principal fator de risco modificável da doença arterial coronariana $(D A C)^{160,161}$, e seu controle, principalmente do nível do colesterol da lipoproteína de baixa densidade (LDL-C), traz grande benefício na redução de desfechos cardiovasculares como infarto e morte por doença coronariana ${ }^{160}$

Após a estratificação de risco do paciente (abordada previamente), estabelecem-se as metas terapêuticas primária e secundária a serem atingidas no tratamento da dislipidemia, de acordo com o nível de risco global presente (baixo, intermediário ou alto). A meta primária a ser atingida é o valor recomendado do LDL-C e a secundária, o valor recomendado do colesterol não-HDL (lipoproteína de alta densidade), calculado pela subtração do HDL-C do colesterol total, representando a concentração de lipoproteínas aterogênicas no plasma (Tabela 6.1). Metas específicas são determinadas para os pacientes de alto risco e risco intermediário. Pacientes de baixo risco cardiovascular deverão ter as metas individualizadas de acordo com o julgamento clínico e os valores referenciais do perfil lipídico (Tabela 6.2).

Tabela 6.1 - Metas lipídicas de acordo com o risco cardiovascular. ${ }^{19}$

\begin{tabular}{lcc}
\hline \multicolumn{1}{c}{ Nível de risco } & $\begin{array}{c}\text { Meta primária } \\
(\mathrm{mg} / \mathrm{dl})\end{array}$ & Meta secundária $(\mathbf{m g} / \mathrm{dl})$ \\
\hline ALTO & $\mathrm{LDL}-\mathrm{C}<70$ & Colesterol não-HDL $<100$ \\
INTERMEDIÁRIO & $\mathrm{LDL}-\mathrm{C}<100$ & Colesterol não-HDL $<130$ \\
BAIXO* & Meta individualizada & Meta individualizada \\
\hline
\end{tabular}

${ }^{*}$ Pacientes de baixo risco CV deverão receber orientação individualizada, com as metas estabelecidas pelos valores referenciais do perfil lipídico (apresentados na Tabela 6.2) e foco no controle e prevenção dos demais fatores de risco $\mathrm{CV}$.

Tabela 6.2. - Valores referenciais do perfil lipídico para adultos maiores de 20 anos. ${ }^{19}$

\begin{tabular}{ccc}
\hline Lípides & Valores $(\mathbf{m g} / \mathbf{d l})$ & Categoria \\
\hline & $<100$ & Ótimo \\
LDL-C & $100-129$ & Desejável \\
& $130-159$ & Limítrofe \\
& $160-189$ & Alto \\
& $\geq 190$ & Muito Alto \\
& $<130$ & Ótimo \\
Colesterol não-HDL & $130-159$ & Desejável \\
& $160-189$ & Alto \\
& $\geq 190$ & Muito Alto \\
\hline
\end{tabular}

Em relação à hipertrigliceridemia, os pacientes com triglicérides acima de $500 \mathrm{mg} / \mathrm{dl}$ devem receber terapia medicamentosa para redução do risco de pancreatite. Aqueles com valores entre 150 e $499 \mathrm{mg} / \mathrm{dl}$ devem receber tratamento individualizado de acordo com o julgamento clínico, com base no risco cardiovascular e condições associadas. Não são propostas metas para o HDL-C, para as apolipoproteínas ou para a lipoproteína (a) [Lp(a)] (Tabela 6.3).

\section{Tratamento não medicamentoso das dislipidemias}

Terapia nutricional, perda de peso e atividade física devem ser recomendadas a todos os pacientes. Levando-se em conta que os níveis séricos de colesterol e triglicérides guardam correlação com o consumo aumentado de colesterol, carboidratos, ácidos graxos saturados e ácidos graxos trans, deve-se orientar a seleção dos alimentos, seu preparo, a quantidade a ser consumida e possíveis substituições. Recomendações dietéticas são apresentadas no Quadro 6.1. No tratamento da hipercolesterolemia, têm grande impacto a redução da ingesta de ácidos graxos saturados e de ácidos graxos trans e a ingestão de fitosteróis (2-3 g/dia). A ingestão de fibras solúveis apresenta impacto menor do que as medidas anteriores, mas também se mostra efetiva na redução do colesterol. Resultados menos expressivos são obtidos com aumento da atividade física, redução do peso e ingestão de proteínas de soja ${ }^{160,161}$.

No tratamento da hipertrigliceridemia tem grande impacto a redução do peso, da ingesta de bebidas alcoólicas, de açúcares simples, do consumo de carboidratos. O aumento da atividade física e a substituição dos ácidos graxos saturados pelos mono e poli-insaturados apresentam impacto moderado nos níveis séricos de triglicérides ${ }^{160,161}$.

Tabela 6.3 - Recomendações para o tratamento não medicamentoso da dislipidemia na prevenção cardiovascular ${ }^{19}$

\begin{tabular}{|c|c|c|}
\hline Indicação & Classe & $\begin{array}{l}\text { Nível de } \\
\text { evidência }\end{array}$ \\
\hline Controle do LDL-C & 1 & A \\
\hline Atingir o valor recomendado do LDL-C (meta primária) & I & $A$ \\
\hline Não são propostas metas para o HDL-C & 1 & A \\
\hline $\begin{array}{l}\text { Redução da ingesta de ácidos graxos } \\
\text { saturados, ácidos graxos trans e ingestão de } \\
\text { fitosteróis ( } 2-3 \mathrm{~g} / \text { dia) e de fibras solúveis }\end{array}$ & 1 & A \\
\hline Aumento da atividade física & I & $A$ \\
\hline $\begin{array}{l}\text { Redução do peso e da ingestão de proteínas } \\
\text { de soja e substituição dos ácidos graxos } \\
\text { saturados pelos mono e poli-insaturados }\end{array}$ & I & $\mathrm{B}$ \\
\hline $\begin{array}{l}\text { Atingir o valor recomendado do colesterol } \\
\text { não-HDL (meta secundária) }\end{array}$ & ॥ & A \\
\hline $\begin{array}{l}\text { Terapia apropriada quando triglicérides } \\
\text { acima de } 500 \mathrm{mg} / \mathrm{dl} \text { para redução do risco de } \\
\text { pancreatite e terapia individualizada quando } \\
\text { triglicérides entre } 150 \text { e } 499 \mathrm{mg} / \mathrm{dl}\end{array}$ & $\|$ & $A$ \\
\hline $\begin{array}{l}\text { Não são propostas metas para as } \\
\text { apolipoproteínas ou para a lipoproteína (a) }\end{array}$ & $\|$ & A \\
\hline
\end{tabular}

Tabela 6.4 - Recomendações para o tratamento farmacológico das dislipidemias $^{19}$

\begin{tabular}{lcc}
\hline \multicolumn{1}{c}{ Indicação } & Classe & $\begin{array}{c}\text { Nível de } \\
\text { evidência }\end{array}$ \\
\hline $\begin{array}{l}\text { Estatinas como primeira opção medicamentosa } \\
\text { na prevenções primária e secundária }\end{array}$ & I & A \\
$\begin{array}{l}\text { Uso de fibratos em monoterapia ou em } \\
\text { associação a estatina para prevenção de } \\
\text { doenças microvasculares em diabéticos tipo 2 }\end{array}$ & । & A \\
$\begin{array}{l}\text { Associação de ezetimiba ou resinas às estatinas } \\
\text { quando a meta de LDL-C não é alcançada }\end{array}$ & Ila & C \\
$\begin{array}{l}\text { Associação de niacina às estatinas } \\
\begin{array}{l}\text { Uso de ácidos graxos ômega 3 para } \\
\text { prevenção cardiovascular }\end{array}\end{array}$ & III & A \\
\hline
\end{tabular}




\section{Diretrizes}

Quadro 6.1 - Recomendações dietéticas para a redução da hipercolesterolemia. ${ }^{19}$

\begin{tabular}{|c|c|c|c|}
\hline & PREFERIR & CONSUMIR COM MODERAÇÃO & $\begin{array}{l}\text { OCASIONALMENTE EM } \\
\text { POUCA QUANTIDADE }\end{array}$ \\
\hline - CEREAIS & - Grãos integrais & $\begin{array}{l}\text { - Pão refinado, arroz e massas, biscoitos, } \\
\text { cereais açucarados }\end{array}$ & - Pães doces, bolos, tortas, croissants \\
\hline - VEGETAIS & - Vegetais crus e cozidos & & $\begin{array}{l}\text { - Vegetais preparados na manteiga ou } \\
\text { creme }\end{array}$ \\
\hline - LEGUMES & - Todos, incluindo soja e proteína de soja & & \\
\hline - FRUTAS & - Frutas frescas ou congeladas & $\begin{array}{l}\text { - Frutas secas, geleia, compotas, } \\
\text { sorvetes }\end{array}$ & \\
\hline - DOCES E ADOÇANTES & - Adoçantes não calóricos & - Mel, chocolates, doces & - Bolos e sorvetes \\
\hline - CARNES E PEIXES & $\begin{array}{l}\text { - Peixe magro e oleoso, frango sem a } \\
\text { pele }\end{array}$ & $\begin{array}{l}\text { - Cortes de carne bovina magra, carne de } \\
\text { porco, frutos do mar }\end{array}$ & $\begin{array}{l}\text { - Salsichas, salames, toucinho, costelas, } \\
\text { vísceras }\end{array}$ \\
\hline - ALIMENTOS LÁCTEOS E OVOS & $\begin{array}{l}\text { - Leite e iogurte desnatados, clara de } \\
\text { ovos }\end{array}$ & $\begin{array}{l}\text { - Leite semi-desnatado, queijos brancos } \\
\text { e derivados magros }\end{array}$ & $\begin{array}{l}\text { - Queijos amarelos e cremosos, gema de } \\
\text { ovo, leite e iogurte integrais }\end{array}$ \\
\hline $\begin{array}{l}\text { - MOLHOS PARA TEMPERAR E } \\
\text { COZINHAR }\end{array}$ & $\begin{array}{l}\text { - Vinagre, ketchup, mostarda, molhos } \\
\text { sem gordura }\end{array}$ & $\begin{array}{l}\text { - Óleos vegetais, margarinas leves, } \\
\text { molhos de salada, maionese }\end{array}$ & $\begin{array}{l}\text { - Manteiga, margarinas sólidas, gorduras } \\
\text { de porco e trans, óleo de coco }\end{array}$ \\
\hline - NOZES E SEMENTES & & - Todas & - Coco \\
\hline - PREPARO DOS ALIMENTOS & - Grelhados, cozidos e no vapor & - Assados e refogados & - Fritos \\
\hline
\end{tabular}

\section{Tratamento farmacológico das dislipidemias}

Os medicamentos disponíveis para o tratamento das dislipidemias são as estatinas (inibidores da hidroxi-metil-glutaril coenzima A [HMG CoA] redutase), a ezetimiba, as resinas ou sequestradores dos ácidos biliares, a niacina, os fibratos e os ácidos graxos ômega-3. Lomitapide e mipomerseno são medicações liberadas em alguns países para o tratamento de hipercolesterolemia familiar na forma homozigótica, mas ainda não no Brasil. Novos fármacos, como inibidores da PCSK9, encontram-se em estudos clínicos fase III.

\section{Estatinas}

As estatinas devem ser utilizadas como primeira opção medicamentosa na prevenção primária e secundária por constituírem a terapia mais validada por estudos clínicos na redução de eventos cardiovasculares. Observa-se redução no risco de morte por todas as causas em 10\% e da mortalidade por DAC em $20 \%$ para cada $40 \mathrm{mg} / \mathrm{dl}$ de redução do LDL-C com estatinas ${ }^{19,162-165}$.
A redução de LDL-C obtida varia muito entre as estatinas, sendo essa diferença fundamentalmente relacionada com a dose inicial (Figura 6.1). A cada vez que dobramos a dose de qualquer uma das estatinas, a redução média adicional do LDL-C será de $6 \%$ a $7 \%$.

Efeitos adversos com as estatinas são $\operatorname{raros}^{164,165}$. Mialgia com ou sem elevação da creatinoquinase (CK) ocorre em cerca de $10 \%$ dos pacientes, podendo surgir semanas ou anos após o início do tratamento. Alterações de CK são observadas em cerca de $3 \%$ dos pacientes, e rabdomiólise é extremamente rara ${ }^{164,165}$. O risco de miopatia pode ser reduzido evitando-se interações com niacina, fibratos (particularmente a genfibrozila), bloqueadores dos canais de cálcio (diltiazem, verapamil), macrolídeos (azitromicina, claritromicina, eritromicina), antifúngicos azólicos (fluconazol, itraconazol, cetoconazol), antirretrovirais inibidores da protease (amprenavir, indinavir, nelfinavir, ritonavir, saquinavir), imunossupressores (ciclosporina, tacrolimo), nefazodona, sildenafil e digoxina ${ }^{166,167}$. Consideram-se aceitáveis elevações

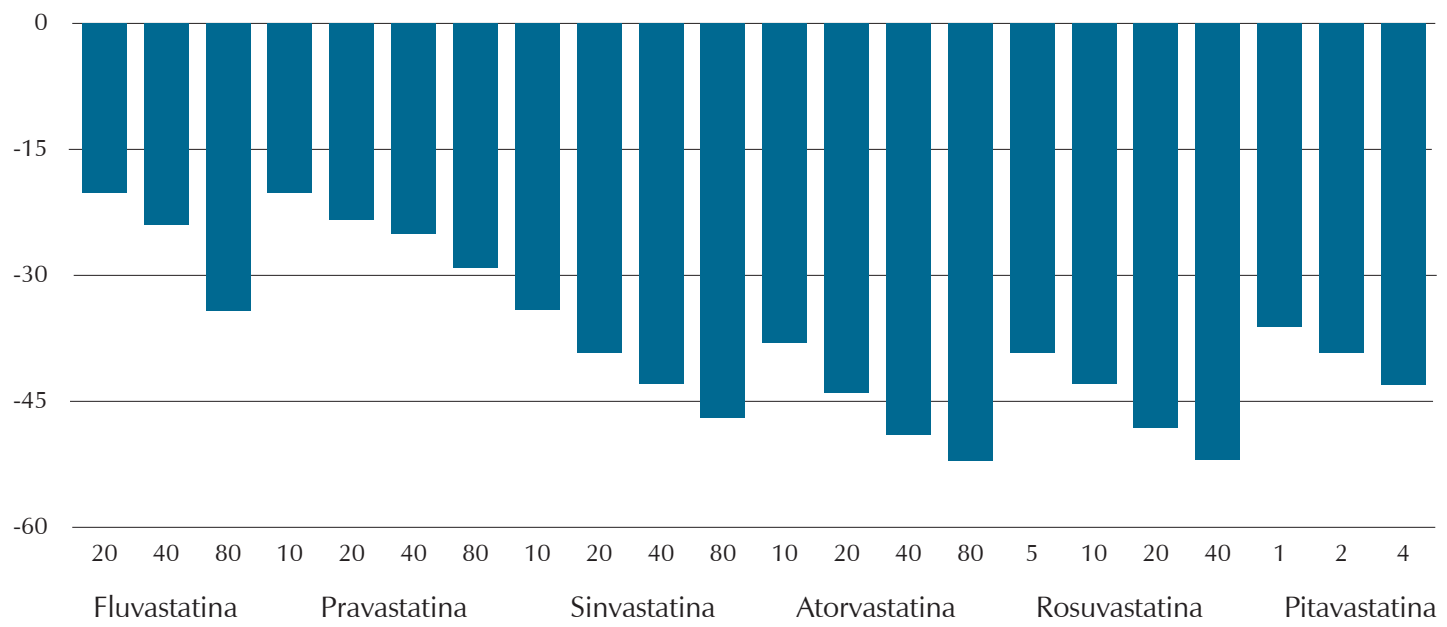

Figura 6.1. - Redução média do LDL-C com estatinas. ${ }^{19,161-163}$ 
de CK até 5 vezes o limite superior da normalidade. Deve-se considerar a suspensão do tratamento acima deste valor (5 a 10 vezes o limite superior), bem como na persistência de sintomas musculares. Nestas situações, doses menores ou outras estatinas podem ser tentadas.

Elevação significativa das enzimas hepáticas (acima de 3 vezes o valor de referência) ocorre em cerca de $1 \%$ dos pacientes, mas é normalmente reversível mesmo sem interrupção da terapia ${ }^{167}$. Em relação à toxicidade hepática, a suspensão temporária é aconselhada com elevações superiores a três vezes o valor de referência das transaminases, e a suspensão definitiva em casos com infecção hepática ativa ou disfunção hepática grave. As elevações estáveis das transaminases em pacientes sem evidência de doenças agudas e sem queixas, como frequentemente observado na esteatose hepática, não constituem contraindicações para o início de estatina.

Pelas razões previamente expostas, CK e transaminases hepáticas (em especial a transaminase glutâmico-pirúvica [TGP]) devem ser dosadas antes de se iniciar o tratamento e após 6-12 semanas. Novas dosagens podem ser realizadas após a modificação da dose da estatina, após associação com outros fármacos com poder de interação ou a critério clínico.

\section{Ezetimiba}

A adição da ezetimiba é recomendada quando a meta de LDL-C não é alcançada com o tratamento com estatinas, lembrando-se de que as estatinas devem ser usadas na maior dose tolerada para alcançar a meta de LDL-C antes de se optar por terapia combinada(9). A ezetimiba reduz de $10 \%$ a $25 \%$ os níveis plasmáticos de LDL-C e, associada à estatina, diminuiu eventos cardiovasculares em pacientes com estenose aórtica degenerativa e doença renal crônica em comparação com placebo ${ }^{168,169}$. Em comparação com estatina em monoterapia, um estudo está em andamento testando o benefício adicional da ezetimiba associada à estatina.

\section{Resinas}

As resinas podem ser associadas às estatinas quando a meta de LDL-C não é alcançada apesar do uso de estatinas potentes em doses efetivas. Entretanto não há estudo que tenha comprovado benefício clínico adicional desta medida. A redução do LDL-C é dose-dependente, variando de 5\% a 30\% nas doses de 4-24 g/dia, podendo ocorrer aumento dos triglicérides em indivíduos com hipertrigliceridemia acentuada (> $400 \mathrm{mg} / \mathrm{dl}$ ). No Brasil está disponível somente a colestiramina, testada contra placebo com redução de $19 \%$ no desfecho primário combinado de morte por doença coronariana e infarto do miocárdio ${ }^{170}$.

\section{Niacina}

A niacina é usada para redução dos triglicérides e aumento do HDL-C, mas não se observa benefício cardiovascular na associação de niacina à estatina em pacientes dentro da meta preconizada de LDL. O Coronary Drug Project ${ }^{170,171,172}$, realizado na década de 1970, demonstrou que o tratamento com niacina na sua forma cristalina pode reduzir a incidência de eventos cardiovasculares ${ }^{172}$. O tratamento com formulações mais toleráveis, como as formas estendidas, reduziu a espessura mediointimal mesmo em pacientes em uso de estatinas.
Entretanto, dois estudos clínicos recentes não demonstraram benefício na adição de niacina ao tratamento eficaz com estatinas com ou sem ezetimiba ${ }^{171,172}$.

\section{Fibratos}

Os fibratos também são usados para redução dos triglicérides e aumento do HDL-C. Há evidências de prevenção de doenças microvasculares (retinopatia e nefropatia) em diabéticos tipo 2 com o uso de fibratos tanto em monoterapia quanto em associação à estatina ${ }^{173,174}$.

Com relação a eventos cardiovasculares, a monoterapia com fibrato tem resultados inconsistentes nos estudos clínicos, e a associação de fibrato às estatinas não tem benefício demonstrado. Nos pacientes com hipertigliceridemia, particularmente naqueles com HDL-C baixo, é possível que haja benefício macrovascular conforme sugerido na análise de subgrupo, mas esta possibilidade requer confirmação.

O risco de miopatia aumenta com a associação de fibratos e estatinas, devendo-se evitar a sinvastatina e outros fármacos metabolizados pelo citocromo P450 e não se utilizar a genfibrozila pelo aumento acentuado do risco de rabdomiólise.

\section{Ácidos Graxos Ômega 3}

Ácidos graxos ômega-3 ( $\omega$-3) são poli-insaturados derivados do óleo de peixes e de certas plantas e nozes. O óleo de peixe contém tanto o ácido docosaexaenoico (DHA) quanto o ácido eicosapentaenoico (EPA), mas os óleos de origem vegetal contêm predominantemente o ácido alfa-linolênico (ALA). Em altas doses (4 a 10 g ao dia), reduzem os triglicérides e aumentam discretamente o HDL-C, mas podem aumentar também o LDL-C e metanálises não mostram benefício na redução de eventos clínicos ${ }^{175}$, não sendo recomendados, portanto, para prevenção cardiovascular. 


\section{Diretrizes}

\section{Diabetes}

A projeção de 300 milhões de adultos com diabete mellitus (DM) no mundo em 2030, com a atual faixa de mais de 180 milhões de indivíduos com o diagnóstico, desperta a necessidade urgente de atuar na prevenção em nível global. Os países em desenvolvimento apresentam as maiores incidências, que respondem por dois terços dos casos em todo o mundo ${ }^{176}$. No Brasil, dados regionais apontam a prevalência de DM em elevados níveis na população adulta, atingindo até $13,5 \%$ em alguns municípios ${ }^{177}$. O censo de 2010 apontava 128 milhões de adultos, o que pode representar uma população atual de até 17 milhões de indivíduos com DM. Esses números estão em elevação devido a fatores como crescimento e envelhecimento da população, urbanização, sedentarismo e obesidade crescentes. O aumento da prevalência de obesidade.

Números dos Estados Unidos de 2012 apontam o total de 245 bilhões de dólares de gastos, incluindo o custo direto com gastos médicos de 176 bilhões e 69 bilhões com a redução da produtividade dos indivíduos acometidos ${ }^{178}$. O custo do tratamento de um indivíduo com diabetes foi 2,3 mais elevado que naqueles sem diabetes no serviço de saúde. Em relação a 2007, os gastos totais foram $47 \%$ maiores, segundo o mesmo levantamento.

O controle metabólico de indivíduos com a doença em evolução consiste em um dos maiores desafios dos serviços de saúde pública ${ }^{179}$, por isso o desenvolvimento de programas eficazes e viáveis aos serviços públicos de saúde para a prevenção primária de DM tipo 2 em população de risco é necessário tanto para o controle de incidência de DM tipo 2 como também para a prevenção secundária de suas complicações metabólicas.

\section{Prevenção}

Mudanças no estilo de vida, como adequações na dieta ${ }^{180}$ e exercícios aeróbicos ${ }^{181}$, já demonstraram benefícios no manejo da glicemia e do peso. A ligação indiscutível da obesidade e do sobrepeso com o aumento da prevalência de diabetes coloca o controle do peso como meta principal para o controle da epidemia de diabetes ${ }^{182}$. A perda de peso se relaciona de maneira independente com a restauração da regulação normal da glicose em indivíduos pré-diabéticos, como foi demonstrado no estudo Diabetes Prevention Program (DPP) ${ }^{183}$. Medidas simples como redução da ingestão de gorduras para menos de $30 \%$ do total de calorias diárias e do total de calorias diárias com atividades físicas regulares podem levar á diminuição de 5\%-7\%do peso em longo prazo. A dieta deve provocar um déficit de calorias diárias de 500 a 1.000 Kcal, o que normalmente resulta em uma perda semanal de 450-900 gramas, chegando a um total de $8 \%$ de perda de peso em 6 meses $^{184}$.

A atividade física recomendada é de pelo menos 150 minutos de atividade aeróbica moderada a intensa por semana ou 90 minutos divididos em pelo menos três vezes por semana, evitando-se mais de dois dias sem atividade física ${ }^{185}$.

É importante salientar que a perda de peso é indicada para todos com sobrepeso ou obesidade que apresentam risco de desenvolver diabetes. As mudanças de estilo de vida são a via primária de redução do risco por diminuição do peso e atividades físicas regulares. A atividade física regular é um importante mecanismo de manutenção do peso ideal, além de melhorar a sensibilidade à insulina e o controle da glicemia, intervindo favoravelmente em fatores complicadores como hipertensão e dislipidemia e aumento de capacidade aeróbica.

A Tabela 7.1 delimita intervenções na dieta e atividades físicas.

Tabela 7.1 - Intervenções na dieta e atividade física no diabete para prevenção de doenças cardiovasculares

\begin{tabular}{lcc}
\hline \multicolumn{1}{c}{ Indicação } & Classe & $\begin{array}{c}\text { Nível de } \\
\text { evidência }\end{array}$ \\
\hline $\begin{array}{l}\text { Pelo menos } 150 \text { minutos de exercícios comedidos } \\
\text { associados à dieta moderada e restrição energética } \\
\text { para prevenir DM em indivíduos de risco }\end{array}$ & I & A \\
$\begin{array}{l}\text { Em razão dos efeitos da obesidade na } \\
\text { resistência à insulina, a perda de peso } \\
\text { é um importante objetivo terapêutico em } \\
\text { indivíduos com risco de desenvolver DM. }\end{array}$ & । & A \\
$\begin{array}{l}\text { Redução das gorduras para menos de } 30 \% \\
\text { da ingestão energética e redução na ingestão } \\
\text { energética nos indivíduos acima do peso }\end{array}$ & & A \\
\hline
\end{tabular}




\section{Síndrome Metabólica}

\section{Definição da Síndrome Metabólica}

A síndrome metabólica (SM) tem recebido uma atenção cada vez maior não somente pelo impacto de cada um dos seus componentes diagnósticos, mas principalmente porque a agregação dos fatores de risco cardiovascular tem sido cada vez mais prevalente.

Há várias versões de definição da SM, mas o critério adotado nesta Diretriz será o do posicionamento conjunto de várias organizações internacionais acerca do tema ${ }^{186}$.

O diagnóstico de SM requer a presença de três ou mais dos critérios expostos na Quadro 8.1.

\section{Quadro 8.1 - Critérios diagnósticos de síndrome metabólica}

\begin{tabular}{|ll|}
\hline \multicolumn{1}{|c|}{ Critérios } & \multicolumn{1}{c|}{ Definição } \\
\hline - Obesidade abdominal & $\cdot \geq 94 \mathrm{~cm}$ \\
- Homens & $\cdot \geq 80 \mathrm{~cm}$ \\
- Mulheres & $\cdot \geq 150 \mathrm{mg} / \mathrm{dl}$ \\
- Triglicérides & \\
- HDL-colesterol & $\cdot<40 \mathrm{mg} / \mathrm{dl}$ \\
- Homens & $\cdot<50 \mathrm{mg} / \mathrm{dl}$ \\
- Mulheres & \\
- Pressão arterial & $\cdot \geq 130 \mathrm{mmHg}$ ou tratamento para \\
- Sistólica & hipertensão arterial \\
- Diastólica & $\cdot \geq 85 \mathrm{mmHg}$ ou tratamento para \\
& hipertensão arterial \\
- Glicemia & $\cdot$ Jejum $\geq 100 \mathrm{mg} / \mathrm{dl}$ \\
\hline
\end{tabular}

Prevalência da síndrome metabólica em diferentes grupos populacionais

As informações sobre a prevalência da SM ainda são limitadas e incompletas ${ }^{187}$ e dependem do critério empregado para a sua definição, justificando a implementação de estratégias de tratamento e, sobretudo, de prevenção ${ }^{188,189,190}$.

Nos EUA, análise de dados do National Health and Nutrition Examination Survey (NHANES-1988-1994) de 8.814 indivíduos de ambos os sexos acima de 20 anos mostrou prevalência de SM (não ajustada e ajustada para a idade) de $21,8 \%$ e $23,7 \%$, respectivamente, pelos critérios do National Cholesterol Education Program - Adults Treatment Panel III (NCEP-ATP III). Observou-se aumento da prevalência com a idade: $6,7 \%$ (20-29 anos) e 43,5\% e 42\% (60-69 anos e 70 anos), com pequena diferença entre os sexos (24\% H e 23,4\% M, respectivamente) ${ }^{189}$. Dados do NHANES de 2003-2006 mostraram taxas de prevalência não ajustada ainda maiores (34\%) quando em comparação com as de 1988-1994: 29,2\% em indivíduos $\geq 20$ anos. Entre adultos (20-39 anos), a prevalência de SM aumentou de 10,8\% (1988-1994) para $15,6 \%$ (2003-2006) em mulheres e de 15,7\% (1998-1994) para 20,3\% (2003-2006) em homens ${ }^{189}$.

Estudo finlandês com 1.025 indivíduos entre 65 e 74 anos seguidos por 13 anos avaliou a prevalência de SM por seis diferentes critérios diagnósticos e encontrou taxas que variaram de 22,5\% (European Group for the Study of Insulin Resistance [EGIR]) a 66,4\% (American College of Endocrinology $[\mathrm{ACE}])^{191}$, enquanto estudo sueco em indivíduos não diabéticos encontrou taxas de 21,9\%, 20,7\% e 18,8\% pelos critérios da International Diabetes Federation (IDF), NCEP-ATP III e EGIR, respectivamente ${ }^{192}$.

No Japão, Nanrie cols. ${ }^{193}$ encontraram prevalência de SM em homens e mulheres adultos, em 2007, de 26,9\% e 9,9\%, respectivamente, enquanto Sakuraie cols. ${ }^{194}$, em coorte com 812 participantes e utilizando três diferentes critérios diagnósticos ( IDF, Japanese Society of Internal Medicine [JSIM] e American Heart Association and the National Heart, Lung and Blood Institute [AHA/NHLBI]), obtiveram valores de $44 \%$, $37,1 \%$ e $67,7 \%$, respectivamente ${ }^{194}$.

O Transition and Health Impact in North Africa (TAHINA) Project, com 4.654 indivíduos (1.840 homens e 2.814 mulheres) de 35 a 74 anos descreveu prevalência global de SM de $30 \%$ com os critérios do NCEP-ATP III (36,1\% em mulheres e 20,6\% em homens). Em ambos os sexos, a prevalência aumentou com a idade e foi maior em moradores de áreas urbanas $^{195}$.

O Estudo de Bogalusa avaliou adultos jovens entre 19 e 39 anos de uma comunidade semirrural dos EUA, sendo $61 \%$ do sexo feminino e $39 \%$ do masculino ( $80 \%$ brancos e $20 \%$ negros) e encontrou prevalência global de SM de 12,2\% (14,9\% em homens e 10,4\% em mulheres), sem diferença entre as diversas etnias (12,8\% em brancos e 9,6\% em negros). Entretanto os homens negros tinham maiores prevalências do que as mulheres brancas $(15,4 \% \times 5,8 \%)^{190}$.

No Brasil, os dados são ainda escassos, particularmente em jovens. Revisão de literatura com oito estudos com adolescentes (10-19 anos) utilizando os critérios de SM da Organização Mundial da Saúde (OMS) ou do NCEP-ATP III descreveu prevalência de SM de 4,2\% a 15,4\% (NCEP-ATP III) e de $4,5 \%$ a $38,7 \%$ (OMS), sendo que a elevação dos triglicérides foi o componente mais frequentemente alterado (4\% a $75 \%$ ), enquanto a alteração da glicose foi o menos observado ${ }^{196}$. No Estudo do Rio de Janeiro a presença de agregação de diversos fatores de risco cardiovascular e de SM também foi observada e se relacionou fortemente com a pressão arterial ${ }^{197}$.

\section{Riscos Cardiovascular e Metabólico Associados à SM}

A avaliação dos pacientes quanto ao seu perfil metabólico, com o reconhecimento precoce dos fatores de risco associados, é desejável para identificar e tratar pacientes de alto risco cardiovascular e metabólico. Em geral a SM está associada a um risco duas vezes maior para doenças cardiovasculares, como infarto do miocárdio, acidente vascular cerebral (AVC) e mortalidade cardiovascular; e uma vez e meia maior risco para mortalidade por qualquer causa ${ }^{198}$.

O risco de desenvolvimento de doença cardiovascular associado a SM foi demonstrado em metanálises, com risco relativo variando de 1,53 até 2,18 199 -201.

O mecanismo fisiopatológico pelo qual a SM aumenta o risco cardiovascular ainda está em debate, porém há forte evidência de que a resistência insulínica seja o fator principal. A progressão de resistência insulínica para hiperinsulinemia 
e hiperglicemia desencadeia vasoconstrição periférica e retenção de sódio. Há maior produção, em nível hepático, de triglicerídeos, colesterol da lipoproteína de baixa densidade (LDL-C), apoliproteína B e LDL-C denso e concentrado, situação que predispõe à aterosclerose. Esta situação desfavorável em relação aos lípides leva a um estado pró-trombótico e pró-inflamatório sistêmico. Com a obesidade central, observa-se a secreção pelos adipócitos de mediadores como o fator de necrose tumoral alfa (TNF-alfa) e a leptina, e, de forma independente, a obesidade leva a hipertensão arterial, dislipidemia e maior resistência insulínica ${ }^{186}$.

Há uma forte associação entre a SM e o desenvolvimento de diabetes, que se intensifica quanto maior o número de componentes da SM presente. O risco relativo de desenvolvimento de diabetes é 2,1 pela definição do ATPIII e 3,6 usando-se a definição da OMS, na qual a resistência insulínica deve estar presente ${ }^{202-206}$.

\section{Fatores de Risco para a Síndrome Metabólica}

Diversos fatores de risco para o desenvolvimento da SM têm sido identificados por meio de estudos transversais, prospectivos e de caso-controle, encontrando-se importantes disparidades de acordo com a definição utilizada em seu diagnóstico. ${ }^{207}$

Alguns fatores se associam à prevenção de algum componente da SM, sem necessariamente prevenir os outros componentes ou reduzir a incidência da síndrome como um todo. A frequência a atividades pré-escolares, por exemplo, associou-se a menor incidência de hipertensão arterial na vida adulta, mas não protegeu contra os outros componentes da $\mathrm{SM}^{207}$.

Alguns estudos identificam múltiplos fatores determinantes da SM, incluindo idade, sexo masculino, baixa escolaridade, inatividade física, história familial de diabetes e hipertensão e ingesta proteica inadequada ${ }^{208}$.

Um deficiente condicionamento físico e a excessiva adiposidade durante a adolescência também se relacionaram com aumento de risco para SM na vida adulta ${ }^{209}$. Diversos estudos correlacionam o comportamento sedentário com risco de $\mathrm{SM}^{210}$. Fatores nutricionais parecem estar relacionados com a SM. O consumo frequente de laticínios, como leite e iogurte, parece proteger contra o desenvolvimento da síndrome ${ }^{211}$. O consumo excessivo de frutose como adoçante artificial está relacionado com o desenvolvimento de SM em animais e humanos. ${ }^{212} \mathrm{O}$ consumo de refrigerantes, mesmo que sem açúcar, também foi relacionado com risco aumentado de $\mathrm{SM}^{213}$. O consumo de frutas, em contrapartida, parece proteger contra a $\mathrm{SM}^{212}$.

Diversos fatores étnicos e ambientais parecem modular o impacto de alguns dos fatores de risco para a SM. Na população da Tunísia, a prevalência encontrada foi maior entre mulheres do que entre homens. Em ambos os sexos a prevalência aumentava com a idade, mas o impacto deste fator foi maior entre as mulheres. A população urbana apresentou maior prevalência que a rural, sendo maior o risco entre indivíduos de maior escolaridade ${ }^{214}$.

Mulheres filipinas vivendo nos Estados Unidos apresentaram maior impacto de circunferência de cintura como componente da SM. Mulheres de mesma etnia vivendo nas Filipinas apresentaram baixos níveis de colesterol HDL como fator de maior impacto sobre a síndrome metabólica. ${ }^{215}$

Diversos transtornos psicológicos também parecem contribuir para a SM. Sintomas depressivos em policiais norte-americanos correlacionaram-se com maior prevalência de $\mathrm{SM}^{214}$ (nível de evidência B). Em estudo de caso-controle conduzido na Índia, demonstrou-se também maior prevalência de SM entre pacientes com diagnóstico de esquizofrenia do que entre os controles ${ }^{215-218}$.

\section{Prevenção da Síndrome Metabólica}

São escassos os dados da literatura acerca da prevenção da SM por meio de medidas não farmacológicas ou mesmo farmacológicas na população teoricamente saudável. As recomendações dos especialistas apontam que as estratégias de prevenção da SM devem ser as mesmas utilizadas no tratamento não farmacológico da síndrome.

Para os indivíduos sem SM ou diabetes melllitus tipo 2 (DM2) ou doenças cardiovasculares, mas com comprometimento da tolerância à glicose ou com a presença de alguns componentes da SM (indivíduos com risco metabólico) há evidências de que as modificações no estilo de vida podem prevenir a SM e/ou DM2 (Tabela 8.1).

Tabela 8.1 - Intervenções na síndrome metabólica para prevenção de doenças cardiovasculares

\begin{tabular}{|c|c|c|}
\hline Indicação & Classe & $\begin{array}{l}\text { Nível de } \\
\text { Evidência }\end{array}$ \\
\hline $\begin{array}{l}\text { Recomenda-se a redução de } 5 \% \text { a } 10 \% \\
\text { do peso em um ano e manutenção da } \\
\text { perda do peso posteriormente. }\end{array}$ & I & B \\
\hline $\begin{array}{l}\text { Dieta com baixa quantidade de gordura total e } \\
\text { saturada, assim como de gordura trans, além } \\
\text { de incluir quantidades adequadas de fibras }\end{array}$ & I & B \\
\hline $\begin{array}{l}\text { Atividade física por um período não } \\
\text { inferior a } 30 \mathrm{~min} / \mathrm{dia} \text {, preferencialmente } \\
\text { de } 45-60 \mathrm{~min} / \mathrm{dia} \text {, } 5 \text { dias/semana }\end{array}$ & 1 & B \\
\hline $\begin{array}{l}\text { Indivíduos com comprometimento da tolerância à } \\
\text { glicose em terapia medicamentosa podem ter redução } \\
\text { mais expressiva na incidência de SM ou DM2 }\end{array}$ & I & B \\
\hline $\begin{array}{l}\text { Para indivíduos com risco metabólico e circunferência } \\
\text { abdominal além dos limites preconizados recomenda- } \\
\text { se a redução de } 5 \% \text { a } 10 \% \text { do peso em um ano }\end{array}$ & Ila & B \\
\hline $\begin{array}{l}\text { Sugere-se a ingestão de menos de } 7 \% \text { do } \\
\text { total de calorias de gordura saturada e menos } \\
\text { de } 200 \mathrm{mg} / \text { dia de colesterol na dieta }\end{array}$ & Ila & $B$ \\
\hline
\end{tabular}

\section{Redução do peso}

Para aqueles com risco metabólico e que apresentarem sobrepeso ou obesidade abdominal recomenda-se a redução de $5 \%$ a $10 \%$ do peso em um ano e manutenção da perda do peso posteriormente. Aqueles que não estiverem com excesso de peso devem manter seu peso. A redução de peso deve ser feita por meio de um programa formal de modificações no estilo de vida e que deve compreender atividade física e ingestão calórica adequadas ${ }^{219-222}$.

\section{Obesidade Abdominal}

Indivíduos com risco metabólico e circunferência abdominal além dos limites preconizados devem seguir as mesmas recomendações do item anterior ${ }^{223-225}$. 


\section{Dieta saudável}

Recomenda-se que todos os indivíduos com e sem risco metabólico tenham uma dieta com baixa quantidade de gordura total e saturada, assim como de gordura trans, além de incluir quantidades adequadas de fibras. Sugere-se a ingestão de menos de $7 \%$ do total de calorias de gordura saturada e menos de $200 \mathrm{mg} /$ dia de colesterol na dieta ${ }^{225-227}$

Não há consenso sobre a quantidade ideal de carboidratos que a dieta deve conter. Recomenda-se que os indivíduos com risco metabólico aumentem substancialmente a ingestão de fibras, grãos não processados e gorduras não saturadas em suas dietas, assim como evitem alimentos com elevado índice glicêmico. ${ }^{225-227}$

\section{Exercício Físico}

Recomenda-se para os pacientes com risco metabólico um programa regular de atividade física moderada, a qual deve ser por um período não inferior a $30 \mathrm{~min} / \mathrm{dia}$, mas preferencialmente de 45-60 min/dia durante, pelo menos, cinco dias/ semana. Essas atividades podem ser caminhadas rápidas ou exercícios mais extenuantes ${ }^{223-227}$.

\section{Modificações no estilo de vida versus terapia farmacológica}

Indivíduos com comprometimento da tolerância à glicose podem ter redução mais expressiva na incidência de SM ou DM2 utilizando um programa de dieta e exercícios adequados quando em comparação com aqueles que usam terapia farmacológica (metiformina ou glitazonas). As principais razões para a escolha de modificações no estilo de vida em vez da utilização de drogas nesses pacientes com intolerância glicose incluem: as modificações no estilo de vida são pelo menos tão eficazes para reduzir a incidência de SM ou DM2 quanto as drogas; existem escassos dados na literatura sobre a segurança a longo prazo na utilização dessas drogas nesse grupo de indivíduos; a relação de custo-efetividade da terapia farmacológica nessa população ainda não foi adequadamente avaliada $223-227$. 


\section{Diretrizes}

\section{Atividade física, exercício físico e esporte}

O indivíduo fisicamente ativo tende a ser mais saudável, com maior qualidade e expectativa de vida ${ }^{228}$. A atividade física, o exercício físico e o esporte integram a abordagem médica para a prevenção das doenças cardiovasculares (DCVs).

\section{Conceitos e expressões mais relevantes}

Atividade física, exercício e esporte são termos correlatos, mas distintos. Atividade física pode ser definida como qualquer movimento corporal produzido pelos músculos esqueléticos que resulta em gasto energético ${ }^{229}$. Em termos práticos, pode ser classificada em ocupacional ou laboral (incluindo atividades domésticas), de transporte ou de lazer. A atividade física de lazer engloba aquelas eminentemente recreativas ou desportivas (esportes), com regras, pontuações, ganhadores, perdedores e as atividades voltadas para o condicionamento físico e a promoção da saúde. A esse último subgrupo de atividade física, mais estruturada e com propósito claramente definido de melhora de desempenho e/ou de saúde, convencionou-se denominar de exercício físico (para subclassificações ou tipos de exercício físico, consultar outra diretriz específica da Sociedade Brasileira de Cardiologia $[\mathrm{SBC}])^{230}$. Dentro dessa concepção, muito provavelmente, o cardiologista irá prescrever exercício físico, e não simplesmente atividade física para os seus pacientes.

Para a sobrevivência e a autonomia do indivíduo é necessário que haja algum grau de atividade física. Enquanto há uma clara tendência dos indivíduos jovens se movimen- tarem mais do que os idosos, os níveis de atividade física, especificamente de exercício físico, variam de pessoa para pessoa, aumentando com o avançar da idade. Dessa forma, exercícios físicos regulares se iniciam de forma progressiva, desde a imobilidade até níveis maiores, com durações mais longas e mais frequentes ${ }^{231}$.

Os indivíduos são classificados em cinco opções: sedentário (ou muito pouco ativo ou inativo), algo ativo, moderadamente ativo (ou simplesmente ativo), mais ou muito ativo e bastante ativo (ou excepcionalmente ativo). As Tabelas 9.1 e 9.2 apresentam os patamares recomendados de exercício físico semanal para a saúde e ilustram exemplos de como classificar o padrão de exercício físico e esporte para uma criança ou adolescente (5) , essa última incorporando a questão da necessidade de definir critérios distintos de acordo com as diferentes faixas etárias e uma estimativa do gasto energético médio por hora (MET/h) em vários exemplos de situações de atividade física, exercício físico e esporte. Maiores detalhes e sugestões para uma quantificação mais objetiva do padrão de exercício físico e esporte de um dado paciente podem ser encontradas em outra publicação da SBC ${ }^{232}$.

A aptidão física é caracterizada por uma série de condições que permitem o indivíduo realizar suas tarefas cotidianas e ter a capacidade física suficiente para se exercitar ou ser fisicamente ativo ${ }^{229}$. A aptidão física é composta de cinco componentes: condição aeróbica, força/potência muscular, flexibilidade, equilíbrio e composição corporal.

Tabela 9.1 - Níveis recomendados de exercício físico para promoção e manutenção da saúde (adaptado de Powell KE et al. ${ }^{228}$ )

\begin{tabular}{|c|c|c|}
\hline Características do exercício & Benefícios à saúde & Comentário \\
\hline$<150 \mathrm{~min} / \mathrm{semanais} \mathrm{de} \mathrm{intensidade} \mathrm{leve} \mathrm{a} \mathrm{moderada}$ & Algum & Algum exercício é certamente preferível ao sedentarismo \\
\hline $150-300 \mathrm{~min} / \mathrm{semanais} \mathrm{de} \mathrm{intensidade} \mathrm{moderada}$ & Substancial & Exercício de maior duração e/ou intensidade confere maiores benefícios \\
\hline$>300 \mathrm{~min} / \mathrm{semanais}$ de intensidade moderada a alta & Adicional & $\begin{array}{l}\text { Informação científica atual não delimita claramente um limite } \\
\text { superior para os benefícios ou para que se torne danoso } \\
\text { para um dado indivíduo aparentemente saudável }\end{array}$ \\
\hline
\end{tabular}

Tabela 9.2 - Exemplos de Classificação do Perfil de Exercício Física na infância (adaptado de Balassiano DH et al. ${ }^{232}$ )

\begin{tabular}{|c|c|c|}
\hline Escore & Definição & Infância/Adolescência \\
\hline 0 & Sedentário ou muito pouco ativo & Pedaladas eventuais, dispensas frequentes da educação física escolar \\
\hline 1 & Algo ativo & $\begin{array}{l}\text { Frequência normal à educação física escolar e períodos curtos e } \\
\text { intermitentes de prática desportiva ou de danças }\end{array}$ \\
\hline 2 & Ativo ou moderadamente ativo & $\begin{array}{l}\text { Participação regular, a maior parte do tempo, em escolinhas ou atividades } \\
\text { desportivas ou em academias de dança ou de lutas }\end{array}$ \\
\hline 3 & Mais ou muito ativo & Participação regular e frequente em várias atividades desportivas na maioria dos dias da semana \\
\hline 4 & Bastante ativo ou competitivo & $\begin{array}{l}\text { Participação, na maior parte do tempo, em treinamento e/ou competição desportiva } \\
\text { ou prática regular e frequente de exercicio predominantemente aeróbico }\end{array}$ \\
\hline
\end{tabular}

\section{Principais Efeitos Agudos e Crônicos do Exercício}

Para uma análise mais objetiva dos efeitos benéficos do exercício físico para a saúde, pode-se dividi-los em agudos (ou respostas) e crônicos (ou treinamento) ${ }^{233}$. O efeito agudo é aquele que se dissipa rapidamente, podendo ser de ação imediata após uma única sessão ou perdurar por até 24 horas (sendo aí classificado como subagudo). A melhora na resposta mediada pelo fluxo no que diz respeito à função endotelial é um exemplo de efeito agudo de uma única sessão de exercício. Já o efeito crônico é alcançado por repetidos efeitos agudos/subagudos. Pode ser avaliado no repouso, mesmo que distante da última sessão de exercício. A bradicardia observada em atletas de modalidades predominantemente aeróbicas é um exemplo de efeito crônico. Por outro lado, a repetição de respostas pode gerar um efeito crônico, como no caso da diminuição dos níveis pressóricos. 
Quadro 9.1 - Principais efeitos do exercício

\begin{tabular}{|c|c|}
\hline Agudo & Crônico \\
\hline Função endotelial & Função endotelial \\
\hline Débito cardíaco & $\mathrm{VO}_{2}$ máxima \\
\hline Fluxo sanguíneo muscular & Comprimento de telômeros \\
\hline Fluxo sanguíneo coronariano & $\begin{array}{l}\text { Proteção enzimática } \\
\text { antioxidativa }\end{array}$ \\
\hline $\begin{array}{l}\text { Proteção enzimática } \\
\text { antioxidativa }\end{array}$ & Sensibilidade à insulina \\
\hline Sensibilidade à insulina & Sensibilidade de barorreceptores \\
\hline Sensibilidade de barorreceptores & $\begin{array}{l}\text { Flexibilidade e mobilidade } \\
\text { articular }\end{array}$ \\
\hline Lipólise & $\begin{array}{l}\text { Massa, força e potência } \\
\text { muscular }\end{array}$ \\
\hline Taxa metabólica de repouso & Melhor controle do peso corporal \\
\hline $\begin{array}{l}\text { Substâncias vasoativas } \\
\text { (bradicinina, NO) }\end{array}$ & Massa óssea \\
\hline Hormônio do crescimento & Estrutura óssea trabecular \\
\hline Síntese proteica & $\begin{array}{l}\text { Economia de nitrogênio (efeito } \\
\text { poupador de proteína) }\end{array}$ \\
\hline Glicemia & Hemoglobina glicosilada \\
\hline Sistema autonômico & $\begin{array}{l}\text { Frequência cardíaca de repouso } \\
\text { e de exercício submáximo }\end{array}$ \\
\hline Hipertensão arterial & Pressão de pulso no exercício \\
\hline & Sistema autonômico \\
\hline Marcadores Inflamatórios & Rigidez arterial \\
\hline Hiperlipemia pós-prandial & Lipemia \\
\hline Velocidade da onda de pulso & $\begin{array}{l}\text { Risco de doenças degenerativas } \\
\text { cognitivas (demência, Alzheimer) }\end{array}$ \\
\hline $\begin{array}{l}\text { Hormônios grelina e pipar } Y \\
\text { (reguladores do apetite) }\end{array}$ & $\begin{array}{l}\text { Ansiedade e sintomas } \\
\text { associados à depressão }\end{array}$ \\
\hline & Risco de quedas nos idosos \\
\hline
\end{tabular}

\section{Fundamentação Epidemiológica dos \\ Benefícios do Exercício Físico}

Há evidências epidemiológicas consistentes sobre a relevância da aptidão física aeróbica para a saúde ${ }^{233-239}$ indicando que os componentes da aptidão aeróbica, em conjunto ou separadamente, podem ser associados ao prognóstico clínico e à expectativa de vida dos indivíduos de meia-idade e idosos ${ }^{240-242}$. Isto ratifica as recomendações de diretrizes nacionais $^{243}$ e internacionais ${ }^{244}$, contemplando a prática regular de exercícios aeróbios combinados com os de força muscular, como musculação. Além disso, os exercícios de alongamento e flexibilidade devem fazer parte de um programa mais completo e abrangente ${ }^{245}$.

Em relação à prática regular do exercício físico, o maior benefício ocorre quando comparamos sedentários com indivíduos que realizam nenhum ou apenas muito pouco exercício, já que o impacto positivo de abandonar o sedentarismo é muito significativo. Entretanto, comparando em escala crescente os diversos graus de aptidão física aeróbica, percebemos a existência de uma diminuição no risco de morte cardíaca e por todas as causas. Quanto maior a aptidão física aeróbica, menor o risco de morbimortalidade total e cardiovascular, tanto em indivíduos saudáveis quanto em portadores de DCV 233,234,236,238,243.

Vários estudos identificam a eficácia do exercício físico regular na prevenção da hipertensão arterial ${ }^{246}$ e dos níveis pressóricos de pacientes com hipertensão arterial sistêmica ${ }^{247}$, provavelmente devido a uma modulação autonômica mais favorável e de efeitos vasodilatadores locais sobre a musculatura lisa da parede arterial ${ }^{248}$. Esses efeitos benéficos ocorrem e se somam aos dos fármacos anti-hipertensivos, muitas vezes resultando em uma redução da dose das medicações. Os efeitos de redução dos níveis pressóricos pelo exercício ocorrem imediatamente após e têm duração de até algumas horas. Sendo assim, tal como acontece com os fármacos, esta atuação no sistema cardiovascular necessita ser repetida periodicamente para que o benefício seja cronicamente mantido. Nos anos mais recentes, contrariando dogmas do passado, a realização de exercícios de fortalecimento muscular também passou a ser aceita e até recomendada dentro da abordagem mais ampla de exercício físico para a prevenção das $\mathrm{DCV}^{248}$. Evidências recentes sugerem que indivíduos dislipidêmicos com maior aptidão cardiorrespiratória, mesmo sem o uso de estatinas, têm um risco menor que aqueles com baixa aptidão usando a medicação. Os que tinham maior aptidão física aeróbica e faziam uso de estatinas apresentaram menos mortalidade por todas as causas ${ }^{249}$. Recentemente surgiu a hipótese de que o uso concomitante das estatinas teria o potencial de reduzir alguns dos benefícios resultantes do treinamento físico aeróbico ${ }^{250}$.

\section{Riscos da Prática da Atividade Física, do Exercício Físico e do Esporte}

Indivíduos saudáveis possuem um risco extremamente baixo de falecerem em decorrência da prática regular de exercício. Estudo com mais de 20 mil médicos com tempo médio de 12 anos identificou que o risco de um evento fatal em indivíduos assintomáticos entre 40 e 84 anos de idade era de aproximadamente 1/1,5 milhão de exposições a exercício (durante e nos 30 minutos pós-exercício imediatos) ${ }^{251}$. Dessa forma, a recomendação de ser fisicamente ativo é bastante segura. Porém, apenas 30\% da nossa população se exercitam regularmente conforme as recomendações ${ }^{252}$. Recomenda-se o uso das diretrizes conjuntas das Sociedades Brasileiras de Cardiologia e de Medicina do Exercício e do Esporte $^{253}$, nas quais são estabelecidos critérios objetivos e detalhados para a avaliação pré-participação em programas de exercício ou atividades desportivas, apropriados para as várias faixas etárias e para a presença ou ausência de fatores de risco coronariano e/ou DCV.

Recentes revisões e alguns estudos observacionais ${ }^{253,254}$ têm identificado elevações de indicadores bioquímicos e de alterações de imagens cardíacas, sugerindo a presença de disfunção miocárdica induzida por períodos longos de treinamento e repetidas competições em eventos aeróbicos de longa duração (em geral mais de 4 horas) em uma pequena parcela desses indivíduos ${ }^{255,256}$. Devem-se identificar características clínicas e/ou demográficas que possam sinalizar maior probabilidade de desenvolver essas alterações e se existe um limite seguro para a quantidade e a intensidade de exercício físico ${ }^{253,254}$.

\section{Prescrição de Exercícios}

Os exercícios podem ser prescritos em relação às suas características como tipo (aeróbico, resistência muscular, flexibilidade), modalidade (caminhada, corrida, bicicleta, dança), duração (tempo de execução), frequência semanal e ajuste de sua intensidade. 


\section{Diretrizes}

Os exercícios físicos aeróbicos devem ser realizados, no mínimo, cinco vezes por semana, com duração de pelo menos 30 minutos, de modo contínuo ou intervalado, com o objetivo reduzir significativamente eventos cardiovasculares e contribuir para o controle dos fatores de risco ${ }^{253}$.

De modo geral, a intensidade deve ser moderada, a qual pode ser prescrita utilizando-se os métodos citados na
Tabela 9.1. Pacientes previamente sedentários podem iniciar os exercícios no limite inferior da prescrição e progredir a intensidade com a prática regular ${ }^{253}$. Pacientes já fisicamente ativos, de acordo com a avaliação individual, podem realizar exercícios em níveis mais intensos, com duração mínima de 20 minutos, três vezes por semana, sendo esta atividade segura e com benefícios adicionais.

Tabela 9.3 - Métodos de prescrição de intensidade moderada dos exercícios físicos aeróbicos ${ }^{253}$

\begin{tabular}{|c|c|}
\hline Método & Descrição \\
\hline Sensação Subjetiva de Esforço (Borg) & $\begin{array}{l}\text { Execução dos exercícios com a auto-percepção de esforço como "médio/moderado ou algo pesado". } \\
\qquad \begin{array}{c}2 \text { a } 4 \text { na escala de Borg 0-10 ou } \\
10-13 \text { na escala } 6-20 .\end{array}\end{array}$ \\
\hline Teste da Fala & $\begin{array}{l}\text { Execução dos exercícios em uma intensidade em que se sinta a respiração algo ofegante, } \\
\text { porém controlada, de modo que se consiga completar uma frase sem pausas. }\end{array}$ \\
\hline Utilização dos percentuais da FC pico & $\begin{array}{l}\text { Execução dos exercícios em intensidade que atinja } 60 \% \text { a } 85 \% \text { da FC pico* } \\
\qquad \mathrm{FC} \text { alvo }=\mathrm{FC} \text { pico* } \mathrm{x} \text { percentual }\end{array}$ \\
\hline Utilização da FC de Reserva (Karvonen) & $\begin{array}{l}\text { Execução dos exercícios em intensidade que atinja } 50 \% \text { a } 80 \% \text { da FC de reserva (FC pico* }- \text { FC repouso) } \\
\qquad F C \text { alvo }=\text { FC repouso + (FC pico* - FC de repouso) x percentual }\end{array}$ \\
\hline $\begin{array}{l}\text { Utilização dos Limiares Ventilatórios } \\
\text { no Teste Cardiopulmonar }\end{array}$ & $\begin{array}{l}\text { Execução dos exercícios em intensidade entre os limiares ventilatórios } 1 \text { e } 2 \\
\text { (limiar anaeróbico e ponto de compensação respiratório) }\end{array}$ \\
\hline
\end{tabular}

* É preferencial a utilização da FC pico obtida em um teste de esforço máximo, visto que pode haver variações individuais que levam a erros na predição da FC por idade, especialmente em pacientes em uso de medicações com efeito cronotrópico negativo. ${ }^{4,6}$

Os exercícios de resistência muscular localizada ou musculação também são benéficos para a saúde cardiovascular e osteomuscular. Devem ser realizados, no mínimo, duas vezes por semana, em intensidade moderada, envolvendo grandes grupos musculares de membros superiores, inferiores e tronco. A sua execução pode ser realizada com pesos livres, caneleiras, faixas elásticas e aparelhos de musculação. A intensidade da carga pode ser ajustada de modo que se consigam executar os exercícios em 8 a 15 repetições por série ${ }^{253}$.

Os exercícios de alongamento e flexibilidade podem ter benefícios osteomioarticulares, na qualidade de vida e prevenção de queda em idosos, podendo, inclusive, ser realizados com estes objetivos. Nestes exercícios, procura-se alcançar a amplitude máxima do movimento, chegando até o ponto de leve desconforto e mantida estaticamente a posição por 10 a 30 segundos. Os tipos de alongamento podem ser gerais ou individualizados a partir de avaliações específicas como o Flexiteste ${ }^{253}$.

A realização de avaliações de aptidão física aeróbica e não aeróbica permite uma melhor prescrição dos exercícios físicos, com o objetivo de obter os melhores resultados e, por meio da estratificação de risco e busca de cardiopatias ocultas, minimizar os riscos da prática dos exercícios de maiores intensidades ${ }^{257}$.

A avaliação inicial consiste em anamnese, exame físico e eletrocardiograma (ECG). Avaliações mais detalhadas deverão ser individualizadas, com teste ergométrico, teste cardiopulmonar, avaliação antropométrica, força muscular e flexibilidade $^{253}$. Na avaliação inicial podemos quantificar o déficit funcional frente ao desejável, bem como estabelecer metas a serem atingidas ${ }^{257,258}$. Torna-se fundamental para o paciente a reavaliação, com o intuito de estimular o comprometimento, bem como mensurar a evolução ocorrida no período. Os benefícios são proporcionais aos ganhos obtidos $257-259$.

\section{Atividade Física Formal e Informal: Estratégias para} Incentivar o Encaminhamento, o Implemento e a Adesão

Embora benefícios para a saúde ocorram com atividades de intensidade relativamente baixa, decorrentes das ações cotidianas informais, como andar, subir escadas, pedalar e dançar, o ideal é que ocorra também a prática regular de exercícios físicos (atividades formais), o que facilita a obtenção da dose ótima de atividade física, igual ou superior a $2.000 \mathrm{kcal}$ por semana (Quadro 9.2) ${ }^{260}$.

Quadro 9.2 - Tempo necessário para um indivíduo de $70 \mathrm{~kg}$ alcançar gasto calórico semanal de $2.000 \mathrm{kcal}$ em algumas atividades (valores aproximados)

\begin{tabular}{|llcc|}
\hline \multicolumn{1}{|c}{ Atividade } & $\begin{array}{l}\text { Tempo } \\
\text { semanal }\end{array}$ & $\begin{array}{c}\text { Tempo diário } \\
\text { (7x semana) }\end{array}$ & $\begin{array}{c}\text { Tempo diário } \\
\text { (5x semana) }\end{array}$ \\
\hline Caminhar no plano & $6 \mathrm{~h}$ & $50 \mathrm{~min}$ & $1 \mathrm{~h} 10 \mathrm{~min}$ \\
Pedalar & $7 \mathrm{~h} 30 \mathrm{~min}$ & 1h05min & $1 \mathrm{~h} 30 \mathrm{~min}$ \\
Correr devagar & $3 \mathrm{~h} 30 \mathrm{~min}$ & $30 \mathrm{~min}$ & $40 \mathrm{~min}$ \\
Correr rápido & $2 \mathrm{~h}$ & $20 \mathrm{~min}$ & $25 \mathrm{~min}$ \\
Jardinagem & $4 \mathrm{~h} 40 \mathrm{~min}$ & $40 \mathrm{~min}$ & \multicolumn{1}{c}{$\mathrm{h}$} \\
Dança de salão & $9 \mathrm{~h} 20 \mathrm{~min}$ & $1 \mathrm{~h} 20 \mathrm{~min}$ & $1 \mathrm{~h} 50 \mathrm{~min}$ \\
Fazer compras & $8 \mathrm{~h}$ & $1 \mathrm{~h} 10 \mathrm{~min}$ & $1 \mathrm{~h} 35 \mathrm{~min}$ \\
Nadar (crawl devagar) & $3 \mathrm{~h} 40 \mathrm{~min}$ & $30 \mathrm{~min}$ & $45 \mathrm{~min}$ \\
Nadar (crawl rápido) & $3 \mathrm{~h}$ & $30 \mathrm{~min}$ & $35 \mathrm{~min}$ \\
Varrer carpete ou tapete & $10 \mathrm{~h} 30 \mathrm{~min}$ & $1 \mathrm{~h} 30 \mathrm{~min}$ & $2 \mathrm{~h} 10 \mathrm{~min}$ \\
\hline
\end{tabular}

O encaminhamento para serviços estruturados de atividade física e reabilitação cardiovascular é de grande importância e pode impactar significativamente a saúde da população ${ }^{261}$.

Há necessidade de estratégias abrangentes, estabelecidas por meio de ações simultâneas, como, por exemplo, incremento da atividade física em programas escolares; políticas e sistemas de transporte que favoreçam deslocamentos por meio de caminhadas, ciclismo e veículos coletivos; educação pública, incluindo campanhas de esclarecimento da população; organização esportiva em vários níveis (escola, trabalho, comunidade etc.), com propostas que incentivem e permitam a prática esportiva por toda a vida, desde a infância até a idade avançada ${ }^{261}$. 


\section{Fatores de risco psicossociais}

\section{Definições e Impacto}

Condição socioeconómica baixa, falta de apoio social, estresse no trabalho e na vida familiar, depressão, ansiedade, hostilidade e personalidade tipo D são fatores de risco psicossociais para as doenças cardiovasculares (DCVs) quedificultam a adesão a estilo de vida saudável, orientações e tratamentos. Frequentemente, vários fatores de risco psicossociais coexistem. Assim, sujeitos ou populações de baixa condição socioeconômica e/ou com estresse crônico têm mais probabilidade de apresentar depressão, hostilidade e isolamento social. Por outro lado, as DCVs podem fragilizar os pacientes e desencadear distúrbios como depressão e ansiedade, criando um ciclo pernicioso. Entre os mecanismos que relacionam os fatores psicossociais com as DCVs incluem-se comportamentos inadequados (estilo de vida inadequado e baixa adesão a tratamentos), barreiras para acesso aos cuidados de saúde e alterações biológicas (sobre atividade endócrina, autonômica, hemostática, inflamatória, endotelial, entre outras) ${ }^{262}$.

Condição socioeconômica: vários estudos prospectivos, bem como revisões sistematicas, têm demonstrado que homens e mulheres com nível socioeconômico baixo, pouca escolaridade, baixa renda, emprego de pouco status, baixo apoio social ou vivendo em uma área residencial pobre têm maior risco cardiovascular ${ }^{263}$.

Depressão: diversas revisões sistemáticas e metanálises têm mostrado que os sintomas clínicos de depressão e humor depressivo aumentam a incidência e pioram o prognóstico da doença coronariana. O suporte social percebido parece reduzir e a falta dele, acentuar essa influência negativa da depressão ${ }^{264,265}$.

Ansiedade: grandes estudos epidemiológicos indicam que os ataques de pânico aumentam o risco de incidência de eventos cardiovasculares, enquanto ansiedade, fobia generalizada e ataques de pânico podem piorar a evolução das DCVs estabelecidas. Apesar de alguns dados contraditórios, duas metanálises recentes confirmaram que a ansiedade é um fator de risco independente para a incidência de doença coronariana e de eventos adversos após infarto do miocárdio ${ }^{266}$.

Hostilidade e raiva: ahostilidade é um traço da personalidade caracterizado por desconfiança, raiva e tendência a se envolver em relações sociais agressivas e desajustadas. Uma recente metanálise confirmou que hostilidade e raiva estão associadas a risco aumentado de eventos cardiovasculares tanto em indivíduos sadios como em portadores de DCVs. Os pacientes com DCV que suprimem a raiva têm um risco aumentado de eventos cardíacos adversos ${ }^{267}$.

Personalidade tipo D: personalidade tipo D ("angustiado") envolve uma tendência permanente de apresentar emoções negativas (afetividade negativa) e inibição social. A personalidade tipo $\mathrm{D}$ se associa a piora do prognóstico em pacientes com DCV, independentemente de sintomas depressivos, estresse e raiva ${ }^{268}$.

\section{Avaliação dos fatores de risco psicossociais ${ }^{269}$}

Como já visto, os fatores psicossociais aumentam a vulnerabilidade às doenças e, assim, a sua avaliação é fundamental para planejar a prevenção de acordo com o perfil de risco individual $^{270}$. Contudo ainda há poucas evidências sobre os beneficios de incluir essa avaliação na rotina de atendimento. Instrumentos e questionários para avaliar ansiedade, depressão, hostilidade, status socioeconômico, apoio social, estresse psicossocial e personalidade tipo $D$ padronizados e validados em nosso país estão disponíveis. Como opção prática, uma avaliação simplificada pode ser feita com algumas perguntas, conforme se segue.

\section{Baixo nível socioeconômico}

Qual é o seu grau de escolaridade?

Você é um trabalhador braçal?

\section{Trabalho e estresse familiar}

Você não consegue cumprir as tarefas no trabalho?

A recompensa pelo seu esforço é inadequada?

Você tem problemas sérios com o seu cônjuge?

\section{Isolamento social}

Você está vivendo em paz?

Sente falta de um confidente próximo?

\section{Depressão}

Você se sente para baixo, deprimido e sem esperança?

Você perdeu o interesse e prazer na vida?

\section{Ansiedade}

Você se sente nervoso, ansioso ou no limite frequentemente?

Você se sente frequentemente incapaz de parar ou controlar as preocupações?

\section{Hostilidade}

Você costuma sentir raiva por coisas pequenas?

Você se sente incomodado com os hábitos de outras pessoas frequentemente?

\section{Personalidade tipo D}

Você frequentemente se sente ansioso, irritado ou deprimido?

Você evita compartilhar seus pensamentos e sentimentos com outras pessoas?

\section{Valor das Intervenções sobre os Fatores} de Risco Pricossociais ${ }^{269}$

Mudar comportamentos é complexo, pois envolve aspectos individuais, culturais e ambientais, entre outros. Desse modo, é fundamental adotar estratégias simples e efetivas, destacando-se entre elas as intervenções comportamentais multimodais e a comunicação adequada, simples e compreensível.

Métodos cognitivo-comportamentais: são recomendados por serem eficazes no apoio a pessoas na adoção de um estilo de vida saudável. Entretanto há evidências limitadas para determinar as intervenções mais eficazes para grupos específicos quanto a idade, sexo e nível socioeconomico, por exemplo.

Apoio social pode ajudar as pessoas na adesão a hábitos saudáveis e aos conselhos médicos, sendo de especial importância para explorar as experiências de cada paciente, pensamentos e preocupações, conhecimento prévio e as circunstâncias da vida cotidiana. Aconselhamento individualizado é a base para ganhar motivação e compromisso do 
paciente. A tomada de decisão deve ser compartilhada com pacientes e cuidadores. Um passo crucial é ajudar o indivíduo a estabelecer metas realistas que depois podem ser ampliadas.

Para indivíduos com alto risco de DCV estão indicadas intervenções multimodais, integrando educação sobre estilo de vida saudável e recursos médicos, atividade física, controle do estresse e aconselhamento sobre fatores de risco psicossociais. Pessoas de nível socioeconômico baixo, de idade avançada ou sexo feminino podem precisar de programas individualizados para atender a suas necessidades específicas de informação e apoio emocional.

Sempre que possível, o atendimento multimodal deve ser feito com médicos, enfermeiros, psicólogos e especialistas em nutrição, reabilitação cardíaca e medicina esportiva.

Comunicação adequada: deve obedecer a alguns princípios como:

- dispensar tempo suficiente para criar um bom relacionamento;

- reconhecer a visão do indivíduo sobre a doença e os fatores contribuintes;

- incentivar a expressão sobre preocupações e ansiedades, autoavaliação e motivação para a mudança bem-sucedida de comportamento;

- utilizar a linguagem do paciente e ser solidário com cada melhoria no estilo de vida;

- verificar se a pessoa entendeu as orientações e tem todo o apoio de que necessita para segui-las;

- reconhecer a dificuldade para alteração de hábitos ao longo da vida e que mudança gradual sustentável pode ser mais eficiente do que mudanças rápidas;

- aceitar a necessidade de apoio por longo tempo e de esforços repetidos para estimular e manter a mudança de vida;

- certificar-se de que todos os profissionais da saúde envolvidos fornecem informação consistente.

As diretrizes europeias recomendam 10 passos estratégicos práticos para aumentar a eficiencia do aconselhamento para mudaças comportamentais, conforme a seguir.

\section{"Dez passos estratégicos" para melhorar o} aconselhamento para mudanças comportamentais

1. Desenvolver uma aliança terapêutica.

2. Aconselhar todos os indivíduos em situação de risco ou com DCV.

3. Ajudar as pessoas a compreender a relação entre comportamento e saúde.

4. Ajudar as pessoas a avaliar as barreiras à mudança de comportamento.

5. Obter compromissos dos indivíduos para promover a mudança de comportamento.

6. Envolver pessoas em identificar e selecionar os fatores de risco a serem modificados.

7. Combinar estratégias, incluindo o reforço da capacidade individual para a mudança.

8. Projetar um plano de modificação do estilo de vida.
9. Envolver a equipe de saúde, sempre que possível.

10. Monitorar o progresso durante o seguimento.

Intervenções sobre depressão, ansiedade e angústia: o tratamento dessas condições melhora a qualidade de vida e deve ser sempre considerado por ser seguro em cardiopatas. Porém ainda faltam evidências conclusivas sobre a influência deles sobre desfechos cardiovasculares, mesmo para a depressão, que foi a mais estudada 271,272 .

Programas de gerenciamento de estresse melhoram o bem-estar, fatores de risco e os desfechos das DCVs. Intervenções para controle da hostilidade em pacientes coronarianos podem levar a diminuição dos níveis de hostilidade comportamental e depressão, melhora de parâmetros fisiológicos (resposta autonômica, reatividade ao estresse mental), reforço do apoio social e de satisfação com a vida ${ }^{273}$. Recentemente, um programa de redução de estresse para as mulheres prolongou a vida independentemente de outros fatores prognósticos ${ }^{274}$.

Programas em ambientes de trabalho destinados melhorar a autonomia e aumentar o controle podem reduzir o estresse de trabalhadores de todos os níveis hierarquicos ${ }^{273}$.

\section{Futuras Direções}

Apesar da falta de evidências definitivas, tudo sugere que as intervenções psicológicas para combater o estresse psicossocial e promover comportamentos saudáveis podem contribuir para a prevenção e o controle das DVs. Portanto elas devem ser implementadas e devidamente avaliadas para produzir dados que permitam desenvolver estratégias de atendimento mais eficientes.

Tabela 10.1 - Classe de recomendação e nível de evidência na abordagem dos fatores psicossociais na prevenção primária

\begin{tabular}{ccc}
\hline Recomendação & Classe & $\begin{array}{c}\text { Nível de } \\
\text { evidência }\end{array}$ \\
\hline $\begin{array}{c}\text { Mudança comportamental com estratégia } \\
\text { cognitivo-comportamental (motivacional) }\end{array}$ & I & $\mathrm{A}$ \\
$\begin{array}{c}\text { Integração de educação e estratégiasmotivacionais } \\
\text { com equipe multiprofissional sempre que possivel } \\
\text { Consulta psicológica ou psiquiátrica para } \\
\text { casos mais expressivos de distúrbio }\end{array}$ & $\mathrm{I}$ & $\mathrm{A}$ \\
$\begin{array}{c}\text { Avaliação de fatores de risco psicossociais } \\
\text { Tratamento farmacológico e psicoterápico nos } \\
\text { pacientes com depressão, ansiedade, hostilidade } \\
\text { de grande repercussão objetivando melhor } \\
\text { qualidade de vida, apesar da falta de evidências }\end{array}$ & $\mathrm{lll}$ & $\mathrm{C}$ \\
\hline
\end{tabular}

Adesão às estratégias em prevenção cardiovascular: estilo de vida e medicamentos

\section{Definição}

Define-se adesão permanente como a medida do comportamento de uma pessoa em termos de tomar a medicação conforme as recomendações dadas pelo provedor de saúde e persistência. a duração global do tratamento durante o qual os pacientes continuam a tomar os medicamentos prescritos ${ }^{274}$. A persistência é particularmente importante para o controle de condições crônicas (como insuficiência cardíaca) e/ou assintomáticas (como hipertensão e dislipidemia). 


\section{Impacto}

Numerosos estudos têm demonstrado que a adesão à medicação por indivíduos de alto risco e e portadores de DCV é baixa, com piores resultados e maiores custos de saúde. Por exemplo, meses após o infarto agudo do miocárdio (IAM), 25\%-30\% dos pacientes param pelo menos um medicamento, com um declínio progressivo da adesão ao longo do tempo. Após um ano, apenas $50 \%$ dos pacientes referem uso de estatinas, betabloqueadores (BBs) e anti-hipertensivos. O estudo PURE ${ }^{275}$ mostrou que o uso de antiplaquetários, BBs, inibidores da enzima de conversão da angiotensina (IECAs), bloqueadores dos receptores da angiotensina e estatinas em indivíduos com história de doença coronariana (DAC) ou acidente vascular cerebral (AVC) é baixo em todo o mundo, especialmente em países de baixa renda e áreas rurais.

\section{Causas}

Adesão e persistência são processos dinâmicos e multifatoriais que requerem atenção e intervenções contínuas a longo prazo. A Organização Mundial da Saúde (OMS) as classifica em cinco grandes agrupamentos de fatores que influenciam a baixa adesão ${ }^{276}$.

- Sistema de saúde - baixa qualidade de atendimento; pouco conhecimento sobre a medicação e/ou baixa aceitação de orientações; falta de comunicação adequada (p. ex., orientações complexas ou confusas), falta de acesso aos cuidados de saúde e falta de continuidade dos cuidados.

- Condição do paciente - doença crônica assintomática; comorbidades mentais (como depressão ou comprometimento cognitivo) ou físicas que causam dependência (como problemas de visão ou locomoção); fatores psicológicos/comportamentais (falta de percepção e motivação sobre o tratamento, impulsividade); faixa etaria mais baixa.

- Tratamento - complexidade do regime terapêutico; efeitos adversos.

- Socioeconômicos - baixa alfabetização; custos da medicação; falta de apoio social.

- As causas da baixa adesão foram tambem classificadas em previsiveis (baixa alfabetização, falta de cumprimento da primeira prescrição, falta de resposta ao tratamento, irregularidade na busca dos medicamentos, custos) e imprevisiveis (doença mental grave, efeitos adversos graves) ${ }^{276}$

Esses fatores tendem a se agrupar e trazer dificuldades. Por exemplo, regimes complexos de medicação são frequentemente necessários em indivíduos com doença crônica assintomática ou múltiplos fatores de risco, pouco motivados e sem uma percepção adequada sobre as razões e os esquemas do tratamento. Outro fator complicador é a associação entre doenças/fatores de risco cardiovasculares e alterações cognitivas ${ }^{277}$, bem como entre depressão e declínio cognitivo ${ }^{278}$.

\section{Avaliação}

A identificação do paciente com baixa adesão é difícil. A aferição de adesão e/ou persistência apresenta obstáculos.
Ela se baseia em autorrelatos, uso de questionários ou instrumentos como a escala de Morisky (Quadro10.1) ${ }^{279}$, relatórios médicos para Sistema de Monitorização, embalagens "inteligentes", contagem de comprimidos, registros de obtenção de medicamentos em farmácias (recarga?) e concentrações séricas de drogas. Na maioria dos estudos a adesão e/ou a persistência foram medidas por autorrelato, com as limitações óbvias.

Sabe-se que a adesão depende do momento da avaliação. Ela é maior no período entre cinco dias antes e após o contato com o prestador de saúde ("adesão do jaleco branco"), mas geralmente decresce significativamente em 30 dias. Esse conhecimento influi nas estratégias de intervenção que visam melhorar a adesão.

As Diretrizes Europeias de Prevenção recomendam fortemente "que os médicos avaliem a adesão e identifiquem as razões para a não- adesão a fim de adotar intervenções adicionais individualizadas".

\section{Quadro10.1 - Escala de adesão à medicação de Morisky ${ }^{279}$}

1. Você às vezes se esquece de tomar os seus comprimidos?

2. Nas últimas 2 semanas, você deixou de tomar os seus comprimidos algum dia?

3. Alguma vez você parou de tomar os remédios sem falar com o médico por se sentir pior ao tomá-los?

4. Quando você sai de casa ou viaja, às vezes se esquece de levar os seus remédios?

5. Você tomou o remédio ontem?

6. Quando você sente a pressão controlada, às vezes para de tomar os remédios?

7. Em algum momento você se sente cansado por ser obrigado a tomar os remédios?

8. É frequente você ter dificuldades para lembrar de tomar os remédios?

\section{Intervenções}

Muitas intervenções têm sido desenvolvidas e avaliadas, porém a maioria tem produzido resultados apenas modes$\operatorname{tos}^{280,281}$.

Uma revisão sistemática recente sobre intervenções que visam melhorar a adesão para DCVs e diabetes, centrada no mecanismo de transferência de informação para os pacientes, concluiu que as maiores taxas de sucesso foram obtidas com as intervenções: eletrônicas; presenciais realizadas por farmacêuticos em um local de distribuição de medicamentos; e presenciais dirigidas a pacientes no momento da alta hospitalar ${ }^{282}$.

Recentemente, uma cuidadosa revisão sobre intervenções utilizadas na comunidade em pacientes com hipertensão, dislipidemia, insuficiência cardíaca congestiva ou doença isquêmica concluiu que as intervenções comportamentais mostraram o maior sucesso em relação às estratégias educacionais $^{282}$. As estratégias comportamentais incluem aconselhamento motivacional, automonitoramento (com uso de diários, registros, embalagem com calendários, lembretes eletrônicos e alertas), reforço positivo (p. ex., mecanismos de resposta digital, tendências, incentivos e recompensas) e parcerias com provedores e grupos de apoio na web. Vale mencionar que essa revisão citou apenas um trabalho realizado em nosso meio ${ }^{283}$. 


\section{Diretrizes}

Além da relativa pobreza de dados disponíveis, devem ser consideradas diferenças importantes entre pesquisas e mundo real (como tipo de paciente, perfil do médico, motivação, monitorização e acompanhamento evolutivo), que podem promover, na prática clínica, resultados inferiores aos obtidos pela pesquisa.

A aplicação das estratégias clínicas para melhorar a adesão (Quadro10.2) deve empregar aquelas baseadas em evidências, de modo integrado, e considerar as peculiaridades em cada caso. O objetivo delas deve ser compartilhado e envolver todos os membros da equipe de saúde, o paciente, familiares, provedores, contatos comunitários e formuladores da política de saúde. Ações estratégicas locais, ainda que restritas, podem trazer resultados e ensinamentos ${ }^{276}$.

\section{Quadro 10.2 - Estratégia clínica para melhorar a adesão ${ }^{276}$}

\begin{tabular}{|c|c|}
\hline \multicolumn{2}{|c|}{ Estratégias para melhorar a adesão } \\
\hline - Simplificar a posologia & $\begin{array}{l}\text { - Diminuir o número de comprimidos e o de } \\
\text { doses ao dia }\end{array}$ \\
\hline - Diminuir os custos & $\begin{array}{l}\text { - Medicamentos de menor custo } \\
\text { - Medicamentos genéricos } \\
\text { - Subsídios governamentais e programas de } \\
\text { baixo custo }\end{array}$ \\
\hline - Comunicação adequada & $\begin{array}{l}\text { - Prestar informações claras sobre os } \\
\text { benefícios, possíveis efeitos adversos e } \\
\text { duração do tratamento } \\
\text { - Avaliar, sem julgar ou criticar, a presença de } \\
\text { má adesão } \\
\text { - Verificar ativamente a presença de possiveis } \\
\text { efeitos colaterais (p. ex.:disfunção sexual, } \\
\text { tosse, sangramento) } \\
\text { - Evitar utilizar termos técnicos e } \\
\text { sobrecarregar o paciente com muita } \\
\text { informação }\end{array}$ \\
\hline - Estratégias comportamentais & $\begin{array}{l}\text { - Incorporar o uso de medicações à rotina } \\
\text { dos pacientes, adequando a posologia às } \\
\text { atividades, refeições e horário que costuma } \\
\text { dormir } \\
\text { - Utilizar porta-comprimidos, dispositivos } \\
\text { eletrônicos de alerta, diários, embalagens } \\
\text { com calendário } \\
\text { - Grupos de suporte pela internet } \\
\text { - Reforço positivo (incentivos, recompensas) } \\
\text { - Orientar automonitoramento } \\
\text { - Aconselhamento motivacional }\end{array}$ \\
\hline
\end{tabular}

Baixa adesão/persistência exige uma solução multifacetada. Muitas intervenções poderiam, se efetivamente aplicadas, ter impacto na melhoria da saúde pública. Um passo inicial é a busca de soluções de algumas das questões-chave envolvendo representantes de governo, indústria (farmacêutica, embalagens), seguradoras, empregadores, prestadores de serviços e pacientes. A deficiência principal tem sido a incapacidade de medir e monitorar a adesão na rotina de atendimento ${ }^{276}$.

Tecnologia que permita troca de informações contínua entre pacientes e provedores pode ser uma ferramenta importante. Incentivos, inclusive financeiros, a pacientes e provedores devem ser considerados.

Tabela 10.2 - Classe de recomendação e nível de evidência na adesão às estratégias em prevenção cardiovascular, estilo de vida e medicamentosa

\begin{tabular}{lcc}
\hline \multicolumn{1}{c}{ Recomendação } & Classe & $\begin{array}{c}\text { Nível de } \\
\text { evidência }\end{array}$ \\
\hline $\begin{array}{l}\text { Avaliação e identificação das causas da falta de } \\
\text { adesão para definir orientações adequadas }\end{array}$ & $\mathrm{I}$ & $\mathrm{A}$ \\
$\begin{array}{l}\text { Uso de estratégias comportamentais e motivacionais } \\
\text { para os pacientes com falta de adesão persistente }\end{array}$ & $\mathrm{\| l}$ a & $\mathrm{A}$ \\
\hline
\end{tabular}




\section{Infância e adolescência}

Dislipidemia

\section{Epidemologia no Brasil}

Estudos brasileiros populacionais demonstram, segundo região e critério, prevalências de 10\% a 35\% de dislipidemias em crianças e adolescentes ${ }^{283}$.

\section{Triagem}

A dosagem sérica do perfil lipídico de crianças deve ocorrer a partir dos 2 anos, pois até esta idade há a necessidade de maior ingestão de gorduras para a mielinização. Antes disso, os casos devem ser analisados individualmente, segundo doenças concomitantes, terapêuticas e história familiar ${ }^{284}$.

Devemos triar o perfil lipídico em criança entre 2 e 10 anos, quando:

- tenham familiares (pais ou avós) do sexo masculino com história de doença arterial isquêmica com menos de 55 anos e do sexo feminino com menos de 65 anos;

- tenham pais com colesterol total superior a $240 \mathrm{mg} / \mathrm{dl}$;

- apresentem outros fatores de risco, como hipertensão arterial sistêmica, obesidade, tabagismo, diabetes mellitus (DM), nascidos pequenos para a idade gestacional;

- sejam portadoras de doenças que cursam com dislipidemia (síndrome da imunodeficiência humana, colestases crônicas, hipotireoidismo, síndrome nefrótica, obesidade, doenças inflamatórias crônicas);

- utilizem medicamentos que alteram perfil lipídico (ácido valproico, betabloqueador, tabagismo, anticoncepcionais, corticosteroides, nutrição parenteral, amiodarona);

- possuam manifestações clínicas de dislipidemias (xantomas, xantelasma, arco corneal, dores abdominais recorrentes, pancreatite).

Acima de 10 anos, toda criança deve ter dosado ao menos uma vez seu colesterol total, independentemente da presença de fatores de risco.

\section{Valores de referência}

Os valores de referência para lípides e lipoproteínas em crianças e adolescentes estão descritos na Tabela $11.1^{285}$.

\section{Tratamento}

Na maioria dos casos, a dislipidemia é decorrente de maus hábitos de vida: dieta inadequada (rica em gorduras saturadas ou trans) e sedentarismo. A obesidade exerce também um efeito metabólico desfavorável, com aumento de triglicerídeos e colesterol da lipoproteína de baixa densidade (LDL-C) e diminuição do colesterol da lipoproteína de alta densidade (HDL-C), além de alterar as subfrações dos lípides, aumentando a concentração das frações pró-aterogênicas ${ }^{286}$.

\section{Mudança do estilo de vida ${ }^{286}$}

A dieta saudável, em qualidade e quantidade para a idade, é a base da prevenção da dislipidemia na infância, salvo os casos de hipercolesterolemia familiar, que necessitam de abordagem específica. Ela consiste em uma alimentação o mais variada possível, equilibrada em quantidades de pro- teínas, carboidratos e gorduras. Deve-se dar preferência às gorduras de origem vegetal naturais, monoinsaturadas ou poli-insaturadas (óleos vegetais e amêndoas). Recomenda-se evitar frituras, alimentos industrializados ricos em gorduras trans e gorduras visíveis das carnes ou pele de aves. Também é muito importante dar preferência a alimentos ricos em fibras insolúveis (frutas, verduras, legumes e cereais integrais) e solúveis (leguminosas, frutas ricas em pectina e cereais integrais). Para facilitar a orientação populacional, sugere-se utilizar, sempre que possível, cereais integrais e cinco porções diárias de frutas ou verduras.

No tratamento da dislipidemia, há duas fases da dieta, segundo a concentração de lípides e lipoproteínas no sangue.

- Dieta tipo I: até 30\% de calorias advindas de gorduras, até $10 \%$ de gorduras saturadas e até $100 \mathrm{mg} / 1.000 \mathrm{Cal}$ de colesterol (máximo 300 mg/d).

- Dieta tipo II: até 20\% de calorias advindas de gorduras, até $7 \%$ de gorduras saturadas e até 60 mg/1.000 Cal de colesterol (máximo de 200 mg/d).

Quando há a necessidade de prescrição dessa dieta, a criança ou o adolescente deve idealmente ser acompanhado por um nutricionista, pelo risco de comprometimento do crescimento ou do desenvolvimento. Estudos recentes mostram benefícios da alimentação vegetariana em qualquer idade, desde que balanceada, como indutora de adequados crescimento e desenvolvimento e menor risco de desenvolver doenças crônicas não transmissíveis, entre elas a aterosclerose $\mathrm{e}^{287}$.

A atividade física deve ser estimulada tanto se buscando um dia a dia ativo quanto com atividades programadas ou supervisionadas. Toda criança ou adolescente deve praticar ao menos 30 minutos diários de atividade moderada. Em nível populacional, deve-se recomendar o estímulo da prática da atividade recreativa, não estruturada. Quanto mais variada e lúdica é esta atividade física, maior é a chance de que esta prática se mantenha durante a adolescência e a vida adulta. ${ }^{286}$

\section{Terapia medicamentosa}

A terapia hipolipemiante pode ser iniciada após os 8 anos de idade, salvo casos muito graves e com avaliação individualizada. A Figura 11.1 ilustra o fluxo ideal de conduta na triagem e no tratamento das dislipidemias na criança ou no adolescente, e a Figura 11.2, o algoritmo do tratamento com estatinas em caso de necessidade de terapia medicamentosa ${ }^{288,289}$.

Os medicamentos mais utilizados são ${ }^{290}$ :

- estatinas: é o medicamento mais frequentemente utilizado, recomendado acima dos 8 anos de idade. Não há evidência suficiente para consenso de quando começar estatinas na infância ou qual a meta em criança ${ }^{290}$. As doses de hipolipemiantes geralmente utilizadas em crianças e adolescentes são descrita no Quadro 11.1.

- Inibidores da absorção do colesterol (ezetimiba): recomenda-se seu uso como monoterapia a partir dos 5 anos e, em associação com estatina, acima de 8 anos, diminuindo os efeitos colaterais destas. 


\section{Diretrizes}

- Sequestrantes dos ácidos biliares: podem ser utilizados em qualquer idade, de forma associada com estatinas, em horários diferentes. Pelo risco de desnutrição relacionado com as vitaminas lipossolúveis, recomendam-se monitoração nutricional e suplementação segundo critérios objetivos de deficiência.

- Suplementos: a suplementação de 1,2 g a 1,5 g de fitosteróis pode diminuir os níveis de colesterol total e LDL-C ${ }^{290}$.

Tabela 11.1 - Valores de referência para lípides e lipoproteínas em crianças e adolescentes

\begin{tabular}{lcccc}
\hline \multicolumn{1}{c}{ Parâmetro } & Aceitável & Limítrofe & Alto (p95) & Baixo (p5) \\
\hline CT & $<170$ & $170-199$ & $>200$ & \\
LDL-C & $<110$ & $110-129$ & $>130$ & \\
n-HDL-C & 123 & $123-143$ & $>144$ & \\
TG (0-9a) & $<75$ & $75-99$ & $>100$ & \\
TG (10-19a) & $<90$ & $90-129$ & $>130$ & \\
HDL-C & $>45$ & $35-45$ & & $<35$ \\
Apo A1 & $>120$ & $110-120$ & & $<110$ \\
Apo B & $<90$ & $90-109$ & $>110$ & \\
\hline
\end{tabular}

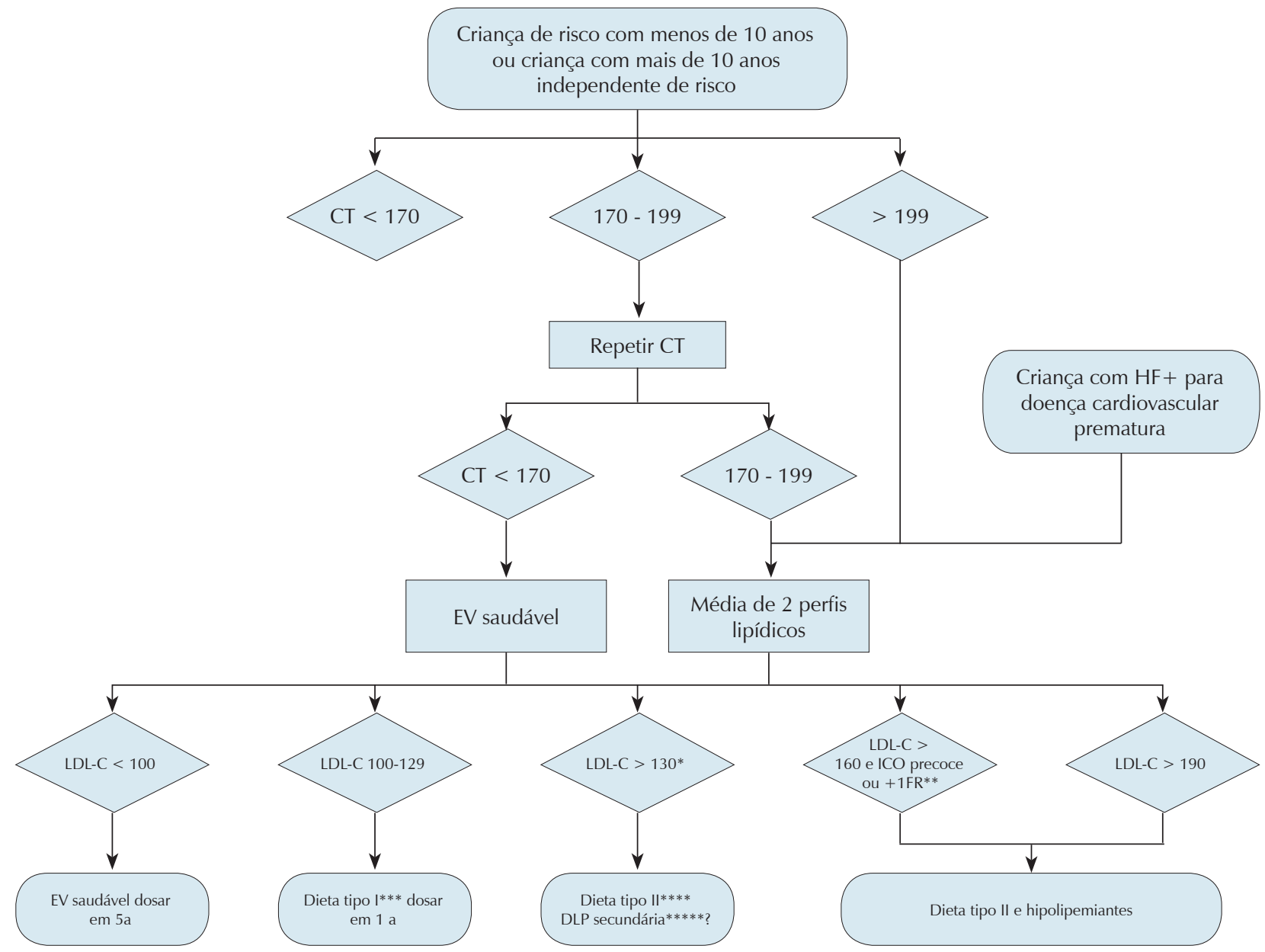

Alvo terapeutico

Figura 11.1 - Algoritmo de diagnóstico e conduta na dislipidemia na infância com base em fatores de risco e níveis de lípides (em mg/dl). Adaptado de Giuliano I. e Caramelli B. ${ }^{290}$

Legenda: CT: colesterol total; HF: história familiar; LDL-C: colesterol da lipoproteína de baixa densidade.

Notas:

*Na presença de DM, infecção pelo HIV, doença de Kawasaki, síndrome nefrótica e lúpus eritematoso sistêmico, o tratamento medicamentoso deve ser instituído com valores de LDL-C acima de $130 \mathrm{mg} / \mathrm{dl}$, após mudanças do estilo de vida.

${ }^{*}$ A presença de fatores de risco emergentes - valores elevados de lipoproteína(a), homocisteína e proteína $\mathrm{C}$ reativa - é considerada determinante do uso de hipolipemiantes em crianças com niveis de LDL-C acima de $160 \mathrm{mg} / \mathrm{dl}$ por alguns autores.

***Dieta tipo l: até $30 \%$ de calorias de gorduras, até $10 \%$ de gorduras saturadas, até $100 \mathrm{mg} / 1.000 \mathrm{Cal}$ de colesterol, no máximo $300 \mathrm{mg} / \mathrm{d}$.

****Dieta tipo Il: até $20 \%$ de calorias de gorduras, até $7 \%$ de gorduras saturadas, até $60 \mathrm{mg} / 1.000$ Cal de colesterol, no máximo $200 \mathrm{mg} / \mathrm{d}$.

*****Toda criança com diagnóstico de hipercolesterolemia deve ter afastada causa secundária para a dislipidemia e/ou a triagem lipídica de seus familiares de 10 grau. 


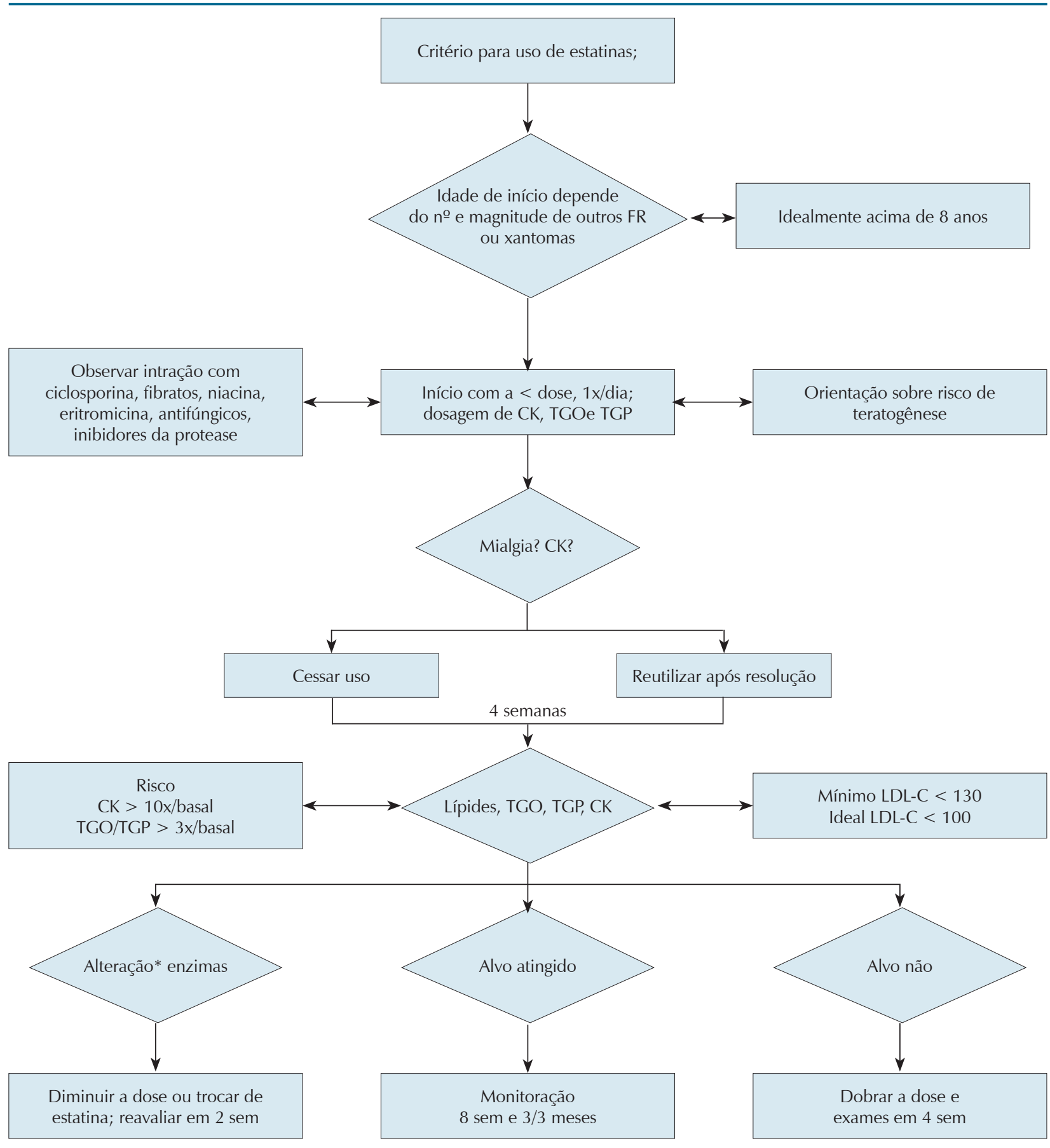

Figura 11.2 -Algoritmo de monitoração do uso de estatinas em crianças e adolescentes. Adaptado de Giuliano I. e Caramelli B. ${ }^{290}$

Legenda:

${ }^{*}$ CPK: sintomático + 3 a $10 x$

Assintomático $>10 x$ 
Quadro 11.1 - Doses de hipolipemiantes utilizadas em crianças e adolescentes

\begin{tabular}{|lc|}
\hline Fármaco & Doses $(\mathrm{mg} / \mathrm{d})$ \\
Lovastatina & $10-40$ \\
Pravastatina & $10-40$ \\
Sinvastatina & $10-40$ \\
Rosuvastatina & $5-40$ \\
Atorvastatina & $10-40$ \\
Colestiramina & $4-16$ \\
Ezetimibe & $10-$ \\
\hline
\end{tabular}

Obesidade

\section{Definição e Epidemiologia}

A mudança de hábitos de vida, como padrões alimentares inadequados associados ao sedentarismo, vem contribuindo para o aumento da prevalência de obesidade nas últimas décadas, levando a Organização Mundial da saúde (OMS) a declarar a obesidade como uma epidemia global ${ }^{291}$. Uma revisão de 450 estudos de prevalência em 144 países mostrou que havia 43 milhões de crianças com excesso de peso no mundo em 2010, sendo 35 milhões em países em desenvolvimento. Em 2020, estima-se que cerca de 9\% das crianças no mundo todo serão obesas, ou seja, um total de 60 milhões de crianças $^{292}$. No Brasil, aproximadamente um terço $(33,5 \%)$ das crianças de 5 a 9 anos de idade apresentam sobrepeso ${ }^{293}$.

\section{Prognóstico}

Crianças e adolescentes com excesso de peso têm risco elevado para obesidade na vida adulta, em um fenômeno conhecido como fenômeno de trilha. A proporção de adolescentes com sobrepeso que se tornam adultos com sobrepeso pode variar de $22 \%$ a $58 \%{ }^{294}$.

Além disso, diversos estudos demonstraram que crianças/ adolescentes com sobrepeso ou obesidade têm maior risco de, na vida adulta, apresentar DM, acidente vascular cerebral (AVC), dislipidemia, doença arterial coronariana e hipertensão e mortalidade precoce ${ }^{295}$.

\section{Diagnóstico}

O diagnóstico de obesidade ou excesso de peso na criança é clínico, estabelecido pela história e pelo exame físico, seguidos da comparação dos dados antropométricos com parâmetros populacionais, por meio de curvas do índice de massa corporal (IMC) para a idade. As curvas anteriormente usadas, as do National Center for Health Statistics (NCHS/1977) ${ }^{296}$ e do Centers for Disease Control and Prevention (CDC/2000) eram baseadas em populações de crianças americanas e que receberam aleitamento artificial, portanto tendiam a subestimar a prevalência de obesidade e superestimar a de desnutrição, alterando significativamente a conduta clínica. A OMS desenvolveu um estudo multicêntrico e, em 2006, foram publicadas as novas curvas para avaliação do estado nutricional de crianças de zero a cinco anos (WHO Multicentre Growth Reference Study Group. WHO Child Growth Standards based on length/height, weight and age ${ }^{297}$. Estas curvas baseiam-se em dados de seis países, incluindo o Brasil, e são prescritivas, ou seja, baseiam-se em crianças com aleitamento natural e alimentação adequada na primeira infância ${ }^{298}$. Em 2007, a OMS publicou as curvas de referência para crianças acima de $5 \operatorname{anos}^{299}$. A utilização desse padrão foi recomendada pelo Ministério da Saúde do Brasil em 2007, sendo as curvas de crescimento incluídas na Caderneta de Saúde da Criança.

Após a aferição do peso e estatura, é calculado o IMC (peso $(\mathrm{kg}) /$ estatura $\left(\mathrm{m}^{2}\right)$. São considerados peso excessivo os valores acima do percentil 85 ou do escore $z+2$, e obesidade grave os valores acima do percentil 97 ou +3 no escore z do IMC. Para os cálculos é possível também utilizar o software gratuito disponível na página da $\mathrm{OMS}^{300}$ ou na página do telessaúde ${ }^{301}$.

Os exames subsidiários podem ser utilizados para avaliação mais detalhada da composição corporal, para investigação de causas secundárias e para identificação de consequências da obesidade, como alterações dos perfis metabólico e inflamatório, alterações ortopédicas e do sono.

\section{Prevenção e Tratamento}

Em uma perspectiva do curso da vida, a prevenção inicia antes do nascimento, no que se denomina prevenção primordial, ou seja, evitar que a criança desenvolva um perfil de risco. Assim, a prevenção inclui nutrição adequada durante a gestação, estímulo ao aleitamento materno ${ }^{302}$ e identificação de fatores de risco familiares, além de um acompanhamento cuidadoso do crescimento e desenvolvimento da criança ${ }^{303}$.

De forma semelhante, o tratamento da obesidade na criança e no adolescente (prevenção primária) é baseado principalmente na mudança de hábitos, especialmente na adoção de uma alimentação saudável e no aumento global da atividade física. É importante envolver toda a família da criança, pais, professores e profissionais da saúde, além de uma equipe multidisciplinar ${ }^{303-307}$.

\section{Hipertensão Arterial Sistêmica}

A prevalência de hipertensão arterial sistêmica (HAS) na infância e na adolescência varia de 0,8\% a 8,2\% $\%^{308-312}$. Alguns estudos apontam prevalência média de 3,5\%, quando o diagnóstico é realizado por medidas repetidas, tanto para o diagnóstico de hipertensão quanto para o de pré-hipertensão, mas outros referem prevalência de pré-hipertensão de 12\% a $17 \%$, em medidas isoladas, principalmente em adolescentes com sobrepeso e obesidade ${ }^{308-313}$.

Embora em crianças a hipertensão arterial mais comum seja a secundária, com etiologia definida, a hipertensão arterial primária é cada vez mais frequentemente diagnosticada, principalmente em crianças maiores e adolescentes, quando outros fatores de risco são associados, entre os quais o sobrepeso e a obesidade são os mais frequentes.

As consequências da HAS geralmente são evidentes após a quinta década de vida, mas há evidências de que a HAS primária se origine na infância e que níveis pressóricos elevados nessa fase da vida sejam fortes preditivos de HAS na vida adulta. Sabe-se também que a hipertrofia ventricular esquerda detectada pela ecocardiografia, considerada o maior marcador de lesão de órgão-alvo pela HAS em crianças e adolescentes, encontra-se presente em 34\% a 38\% dos indivíduos nessa fai- 
xa etária que apresentam hipertensão moderada e não estão em tratamento. Além disso, a HAS primária em crianças e adolescentes encontra-se comumente associada a excesso de peso e ambos estão presentes na síndrome metabólica (SM), que inclui ainda elevação dos triglicerídeos, baixos níveis de HDL-C, obesidade central e hiperinsulinemia, reconhecidos fatores de risco para o desenvolvimento de aterosclerose. Dos estudos de necropsia em crianças, adolescentes e adultos jovens sabe-se que, à medida que aumenta o número de fatores de risco para aterosclerose, eleva-se também o número e a extensão das estrias gordurosas e das placas fibrosas na aorta e coronárias dos seus portadores s13-315. $^{31}$.

Considera-se obrigatória a medida da pressão arterial (PA) a partir dos 3 anos de idade, anualmente, ou antes dessa idade quando a criança apresenta antecedentes mórbidos neonatais, doenças renais ou fatores familiares de risco ${ }^{316-318}$. A hipertensão arterial é definida pelo percentil da PA em relação a idade, sexo e altura. As tabelas com os percentis de idade e altura podem se obtidas dos gráficos de crescimento do CDC, no endereço eletrônico http:// www.cdc.gov/growthcharts/2000growthchart-us.pdf. Uma vez definido o percentil de altura para sexo e idade, o mesmo deve ser correlacionado com o percentil 90, 95 ou 99 referente à PA obtida ${ }^{318-319}$. A Tabela $\mathbf{1 1 . 2}$ mostra os níveis de PA em crianças e adolescentes normais e hipertensos. O diagnóstico de HAS deve ser realizado após três medidas em ocasiões diferentes.

Tabela 11.2 - Classificação da pressão arterial em crianças e adolescentes ${ }^{318-319}$

\begin{tabular}{lc}
\hline \multicolumn{1}{c}{ Classe } & $\begin{array}{c}\text { Percentil de pressão arterial } \\
\text { sistólica ou diastólica }\end{array}$ \\
\hline Normal & $<90$ \\
\hline $\begin{array}{l}\text { Préhipertensão(9) } \\
\text { Normal alta (10) }\end{array}$ & 90 a $<95$ ou PA $\geq 120 \times 80 \mathrm{~mm} \mathrm{Hg}$ \\
HAS estágio 1 & 95 a 99 acrescido de $5 \mathrm{~mm} \mathrm{Hg}$ \\
HAS estágio 2 & $>99$ acrescido de $5 \mathrm{~mm} \mathrm{Hg}$ \\
\hline
\end{tabular}

Estudos sugerem que existe uma taxa de progressão de aproximadamente $7 \%$ por ano da pré-hipertensão para a hipertensão e que esta persiste em aproximadamente um terço dos meninos e um quarto das meninas em acompanhamento longitudinal de dois anos ${ }^{318-319}$.

Em todas as crianças e adolescentes com PA persistentemente igual ou acima do percentil 95, a avaliação inicial deve tentar identificar a etiologia, quando existente, mediante dados sobre hábitos de sono, história familiar, de fatores de risco, dieta, tabagismo e ingestão alcoólica. O estudo complementar inicial deve incluir hemograma, dosagem de ureia, creatinina, sódio, potássio, cálcio, ácido úrico, sumário de urina, urocultura e ultrassonografia renal. Glicemia de jejum, colesterol total, LDL-C, HDL-C e triglicerídeos devem ser solicitados para todas as crianças com HAS e também para aquelas com PA limítrofe que apresentem excesso de peso, doença renal crônica ou que possuam história familiar de doença cardiovascular (DCV).
Radiografia de tórax, eletrocardiograma e ecocardiograma. A ecocardiografia deve ser solicitada para avaliar a hipertrofia ventricular esquerda ou outras alterações cardíacas em todas as crianças e adolescentes com HAS e naquelas com PA limítrofe que apresentem comorbidades (incluindo DM e doença renal). Outros exames que investigam lesão de órgãos-alvo da HAS, como a avaliação da espessura da média-íntima das carótidas e a dosagem da microalbuminúria, ainda não têm recomendação para utilização rotineira.

Em crianças e adolescentes, a monitoração ambulatorial da pressão arterial (MAPA) está indicada para investigar a HAS do avental branco, para avaliar a eficácia terapêutica em hipertensos ou os sintomas relacionados à hipotensão na vigência do uso de anti-hipertensivos, investigar elevações episódicas da PA e para avaliar padrões de PA ao longo do dia em indivíduos com diabetes, doença renal crônica, ou disfunção autonômica. Exames complementares adicionais são necessários quando da suspeita de uma doença que curse com a elevação da PA e incluem: polissonografia, dosagem da renina ou da atividade da renina no plasma, cintilografia renal com administração de captopril, dosagem de catecolaminas plasmáticas e urinárias, dosagem de esteroides no plasma e na urina, ressonância nuclear magnética, angiografia digital e arteriografia renal $^{318-319}$.

A obesidade é provavelmente a condição associada mais importante para a hipertensão arterial primária em crianças e adolescentes, sendo responsável por mais da metade do risco para desenvolvimento de $\mathrm{HAS}^{320-322}$. Assim, a dieta, o exercício físico e a perda de peso são citados como fatores importantes na mudança de estilo de vida ${ }^{317}$. Estudos observacionais e de intervenção mostraram efeitos benéficos da redução do peso corporal em pacientes pediátricos ${ }^{321,322}$, e a perda de peso melhora não só a pressão arterial, mas também outros fatores de risco cardiovascular que se associam à obesidade, $\backslash$ como a resistência á insulina e a dislipidemia. Algumas recomendações podem ser citadas em relação às mudanças de estilo de vida ${ }^{317}$ : atividade física aeróbica moderada (ver capítulo específico); evitar ingestão excessiva de açúcar, refrigerantes, gordura saturada e sal e ingerir frutas, vegetais e grãos; implementar as mudanças de comportamento (atividade física e dieta) adaptadas ás características individuais e familiares; envolver os parentes e a família como parte do processo; providenciar suporte educacional e material; estabelecer metas realistas; desenvolver um sistema de recompensa de promoção em saúde; os esportes competitivos devem ser limitados na vigência de hipertensão não controlada no estágio 2. As metas são adequadas ao IMC, sendo que, quando está abaixo do percentil 85, deve manter o peso; entre os percentis 85 e 89 é indicado manter o peso para crianças ou a perda gradual de peso em adolescentes para reduzir o IMC para o percentil < 85. e quando o IMC encontra-se acima do percentil 95, é indicada a perda gradual de peso ( 1 a $2 \mathrm{~kg} / \mathrm{mês}$ ) até atingir valores inferiores ao percentil $85^{316,317}$.

A redução do peso corporal pode tornar o tratamento farmacológico desnecessário, mas não deve atrasar o seu início, quando indicado ${ }^{316}$, assim como a redução da ingestão de sódio para 1,2 g/dia para crianças de 4 a 8 anos de idade e de 1,5 g/dia para crianças maiores de 8 anos de idade e para adolescentes parece ser uma medida eficaz ${ }^{312,316}$. 
As mudanças no estilo de vida constituem a recomendação terapêutica inicial da HAS primária em crianças e adolescentes. O tratamento medicamentoso está indicado para indivíduos com hipertensão sintomática, hipertensão secundária, lesão em órgãos-alvo da HAS, diabetes tipos 1 e 2 e HAS persistente a despeito da adoção das medidas não farmacológicas, situação na qual estas medidas são coadjuvantes do tratamento medicamentoso ${ }^{317,322}$.

\section{Atividade física}

A redução da mortalidade cardiovascular em países desenvolvidos e em desenvolvimento tem como estratégia na atualidade a prevenção dos seus mais importantes fatores de risco por meio da adoção de hábitos saudáveis (especialmente aqueles relacionados com atividade física e dieta), começando o mais precocemente possível na vida dos indivíduos ${ }^{323,324}$. E como a atividade física (AF) em jovens é o maior preditor de manutenção da mesma na vida adulta, esse é um forte argumento para o incentivo da sua permanente realização em crianças e adolescentes ${ }^{324}$.

Crianças e adolescentes são fisicamente mais ativos que os adultos ${ }^{325}$, entretanto acredita-se que esteja ocorrendo atualmente a redução progressiva e importante da AF diária em indivíduos de todas as idades como consequência de inúmeras transformações ocorridas na sociedade, entre as quais se destaca a facilidade de transporte das pessoas para os diferentes lugares (carros, ônibus, metrôs), dispensando a caminhada ou a bicicleta, por exemplo. A redução da AF no lazer é favorecida pela violência urbana, pela ausência de áreas seguras de lazer nas grandes cidades e pela jornada de trabalho de ambos os pais, que terminam por confinar os filhos em casa, além da maior propensão a hábitos que não requerem gasto energético (assistir televisão/vídeo, usar o computador e o celular). Há relatos de que a inatividade física em municípios brasileiros pode atingir 93,5\% dos seus jovens ${ }^{310}$.

Essa crescente inatividade entre indivíduos que se encontram numa fase de vida natural e biologicamente de grande atividade pode gerar consequências imediatas e negativas para a saúde das crianças (como o excesso de peso e suas comorbidades) ${ }^{326-329}$, além de conduzi-las (tracking) a um hábito (de não propensão para a AF) que pode se estender ao longo da vida do indivíduo ${ }^{330,331}$, contribuindo, assim, em longo prazo, para a ocorrência das doenças crônico-degenerativas do adulto, entre as quais a doença aterosclerótica cardiovascular ${ }^{332}$

Assim, a AF deve ser incentivada em crianças e adolescentes para que eles adquiram um hábito ativo que permaneça ao longo da vida e para que a AF funcione como agente: a) auxiliar do crescimento (fortalecendo músculos, ossos e articulações); b) terapêutico (naquelas que possuem outros fatores de risco cardiovascular, como obesidade, HAS, DM, dislipidemia, SM, ansiedade e depressão); c) de prevenção, inclusive da DCV nos adultos ${ }^{332-335}$. Uma revisão sistemática de 18 artigos envolvendo 12.742 participantes de 0 a 4 anos demonstrou que níveis elevados de atividade física estão associados a melhores parâmetros de adiposidade, de saúde óssea e muscular, de desenvolvimento motor e cognitivo e de saúde cardiovascular, mesmo nessa faixa etária precoce da vida ${ }^{336}$.
Assim, crianças e adolescentes devem ser incentivados a engajar-se em atividades físicas que lhes sejam prazerosas em casa, na escola e no lazer; por meio de aulas de educação física, prática de esportes, jogos, brincadeiras; no deslocamento ativo para a escola (caminhando, em bicicleta), entre outras ${ }^{337-340}$. Para tanto é necessária a ação conjunta: a) da família (que deve ser ativa em conjunto, e não apenas cobrar dos filhos a prática de AF); b) dos profissionais da saúde (pela investigação do nível de AF realizada pela criança e seus familiares; incentivo a um estilo de vida ativo; investigação de condições mórbidas que limitam a realização de AF ou exigem cuidados especiais); c) da escola (pela oferta de classes regulares de educação física, esportes; promoção da educação em saúde; inclusão dos pais nos programas de AF; abertura da escola para a comunidade; d) da comunidade (reivindicação de programas de AF nas escolas e de áreas de lazer nas cidades, bem como de uma política de promoção à saúde que inclua a AF na educação, no desporto e na atenção à saúde) $)^{332-335}$.

De uma maneira geral, recomenda-se que crianças e adolescentes participem de AF moderada a intensa ("que os faça transpirar, ficar ofegantes ou com as pernas cansadas"), com duração de pelo menos 60 minutos, preferencialmente todos os dias da semana ${ }^{332-335}$. Essa recomendação inclui atividade intensa no mínimo três dias por semana e atividades que promovam força muscular e óssea no mínimo três dias por semana ${ }^{337}$. Um maior nível de atividade física diária promoverá mais benefícios à saúde ${ }^{337}$.

Na estruturação de um estilo de vida ativo nas crianças e adolescentes, é também de extrema importância a redução do número diário de horas utilizadas em atividades sedentárias (TV, videogames, computador, telefone) $)^{341,342}$. Estudo realizado em uma capital brasileira mostra que jovens de 7 a 17 anos assistem em torno de três horas diárias (mediana) de $\mathrm{TV}^{343}$. Há evidências de que o tempo gasto assistindo TV na infância e adolescência é maior que o tempo gasto na escola; de que a prevalência de obesidade aumenta em $2 \%$ para cada hora adicional de assistência à TV; de que 4 ou mais horas assistindo TV associa-se a maior frequência de tabagismo, comportamento hostil, depressão e consumo de álcool; e de que um elevado número de horas frente à TV na infância e adolescência associa-se a obesidade, baixa aptidão física, tabagismo e hipercolesterolemia na vida adulta ${ }^{341,342}$. Assim, sugere-se que o tempo diário em atividades sedentárias seja de, no máximo, 2 horas.

A análise sistemática dos estudos de efetividade das intervenções para promoção de AF na faixa etária pediátrica (mais particularmente em adolescentes) demonstrou melhores resultados quando há associação de ações na escola envolvendo a família ou a comunidade e de ações educacionais envolvendo políticas ambientais e de saúde ${ }^{338}$.

Por isso recomenda-se que o planejamento da AF para crianças e adolescentes seja baseado na identificação de mediadores cognitivo-comportamentais (autopercepção, autoestima, conhecimento, intenção de tornar-se ativo, atividades prazerosas, atividades preferidas) e de suporte social (família, amigos) ${ }^{338}$ que possam ser utilizados para avaliar a eficiência das estratégias escolhidas, para que as melhores continuem sendo utilizadas em futuros programas destinados a esse público ${ }^{337-339}$. 
Tabela 11.3 - Grau de recomendação e nível de evidência da presença de doenças cardiovasculares em crianças e adolescentes

\begin{tabular}{|c|c|c|}
\hline Recomendação & Classe & $\begin{array}{l}\text { Nível de } \\
\text { evidência }\end{array}$ \\
\hline \multicolumn{3}{|l|}{ Rastreamento da obesidade } \\
\hline $\begin{array}{l}\text { - Rastreamento da obesidade por meio do IMC em crianças a partir dos } 6 \text { anos, oferecendo ou encaminhando a intervenções } \\
\text { comportamentais intensivas dirigidas à obtenção de um peso saudável } \\
\text { - Incluir pergunta sobre história familiar de DAC precoce na anamnese para identificar crianças em risco } \\
\text { - Se identificada história familiar, está indicada a avaliação de todos os membros da familia, principalmente os pais }\end{array}$ & 1 & B \\
\hline $\begin{array}{l}\text { - Em crianças a partir de } 2 \text { anos com IMC } \geq 85^{\circ} \text { Percentil } \\
\text { - Reforçar as orientações preventivas (ver adiante) } \\
\text { - Identificar complicações e fatores de risco: PAS, sintomas de doença da vesícular biliar, diabetes, apneia do sono, hipotireoidismo, } \\
\text { problemas ortopédicos, perfil lipídico }\end{array}$ & 1 & C \\
\hline \multicolumn{3}{|l|}{$\begin{array}{l}\text { Em crianças a partir de } 2 \text { anos com IMC } \geq 85^{\circ}-94^{\circ} \text { percentil } \\
\text { - Todas as medidas acima mais: } \\
\text { - regulação do ganho de peso e da ingesta de gorduras, com atenção para nutrição e desenvolvimento } \\
\text { - tratamento dos fatores de risco e complicações } \\
\text { - abordagem multidisciplinar de moderada a alta intensidade } \\
\text { - testar aspartato transaminase (AST), aspartato alanina transaminase (ALT) e glicemia em crianças } \geq 10 \text { anos de idade }\end{array}$} \\
\hline $\begin{array}{l}\text { Em crianças a partir de } 2 \text { anos com } \mathrm{IMC} \geq 95^{\circ} \text { percentil } \\
\text { - Todas as medidas acima, mais: } \\
\text { - Objetivo de longo prazo manter } \mathrm{IMC}<85\end{array}$ & 1 & B \\
\hline $\begin{array}{l}\text { - Considerar abordagens mais agressivas se estratégias conservadoras falharem } \\
\text { - Testar ureia e creatinina } 2 / 2 \text { anos }\end{array}$ & I & $A$ \\
\hline
\end{tabular}

\section{Nutrição \\ Leite/outras bebidas}

Aleitamento materno exclusivo até os 6 meses de idade

Dos 12 aos 24 meses, transição para leite com teor reduzido de gordura ( $2 \%$ ou desnatado) não aromatizado

Dos 2 aos 21 anos, a principal bebida deve ser o leite desnatado não aromatizado

Evitar bebidas açucaradas, estimular a ingesta de água

Gorduras na dieta

A ingestão de gorduras por crianças com menos de 12 meses de idade não deve ser restringida sem indicação médica

Dos 12 aos 24 meses, transição para refeições da família, com gorduras 30\% da

ingesta calórica total, sendo $8 \%-10 \%$ de gorduras saturadas

Dos 2 aos 21 anos, gorduras 25-30\% da ingesta calórica total, sendo 8-10\% de gorduras saturadas

Evitar gorduras trans

Colesterol $<300 \mathrm{mg} / \mathrm{dl}$

$\begin{array}{ll}\text { I } & \text { B } \\ \text { I } & \text { B } \\ \text { I } & \text { A } \\ \text { I } & \text { B }\end{array}$

\section{Outros}

Dos 2 aos 21 anos, estimular a ingesta de fibras na dieta, limitar ingesta de sódio e estimular

hábitos saudáveis: refeições em família, café da manhã, limitar lanches rápidos

$\begin{array}{ll}\text { I } & \text { C } \\ \text { I } & \text { B } \\ \text { I } & \text { A } \\ \text { I } & \text { B } \\ \text { I } & \text { A }\end{array}$

\section{Atividade física}

Pais devem criar um ambiente que promova a atividade física e limite as atividades sedentárias, e servirem como modelos

Limitar as atividades sedentárias, especialmente TV/vídeo

।

B

Atividade física moderada a vigorosa todos os dias

$\begin{array}{ll}\text { I } & \text { C } \\ \text { I } & \text { B } \\ \text { I } & \text { A }\end{array}$




\section{Diretrizes}

\section{Legislação e prevenção dos fatores de riscos para doenças cardiovasculares}

\section{Introdução}

Algumas considerações devem ser feitas quanto à relação entre a legislação e a prevenção dos fatores de riscos (FRs) para as doenças cardiovasculares (DCVs), começando por questões singelas como: a existência de leis sanitárias específicas pode cumprir papel efetivo na promoção da saúde e na prevenção das DCVs?

Em princípio, a resposta é afirmativa. O conhecimento dos FRs para o desenvolvimento das DCVs é o primeiro passo para mudanças no estilo de vida da população, subsidiando a prevenção das mesmas. Estimular a prevenção e controle das DCVs, promover e criar ambientes saudáveis, requer, tanto da população quanto dos gestores, estar bem informado sobre a importância da vigilância, prevenção, assistência, reabilitação e promoção da saúde.

Para tanto é necessária a formulação de políticas públicas que tenham apoio da população, fortalecendo a ação da comunidade e reorientando os serviços de saúde. Assim, faz-se necessário o desenvolvimento de ações de promoção da saúde e prevenção de doenças que integrem as ações individuais e de assistência às ações populacionais de abrangência coletiva, intervindo positivamente sobre os FRs das DCVs tanto por meio de ações de regulação e legislações, como de ações de educação, informação e mobilização da comunidade.

As duas últimas décadas mostraram evidências de restrições legais relativas:

1. à propaganda de cigarro nos veículos de comunicação;

2. ao teor de nicotina e de substâncias que potencializam a sua ação;

3. ao uso do fumo em recintos públicos fechados;

4. à venda de cigarros a menores de idade, entre outras - e de suma importância - em associação a medidas educativas.

Estas restrições resultaram em redução significativa (cerca de $50 \%$ ) da população de fumantes no país ${ }^{340}$.

Como o tabagismo é um dos FRs maiores para o grupo de DCV, havia a expectativa de estabilização ou decréscimo, nas estatísticas de morbimortalidade desse período, do elenco de doenças relacionadas ao hábito de fumar. Isso, de fato, foi observado, de acordo com vários artigos científicos publicados nos recentes anos e dados divulgados pelos sistema de informações sobre mortalidade do país ${ }^{341,342}$.

Podemos inferir, portanto, que ações normativas e legislativas podem exercer papel efetivo na prevenção das doenças relacionadas ao tabagismo, como doença arterial coronariana (DAC) e acidente vascular cerebral (AVC), e no grupo das DCVs e doenças do aparelho respiratório, como enfisema pulmonar, doença pulmonar obstrutiva crônica (DPOC) e as neoplasias de pulmão ${ }^{343,344}$.

Desenvolver um sistema de comunicação em saúde aproveitando recursos locais (rádio, jornais locais e de grande circulação, programas de televisão, web), desenvolver e manter campanhas educativas com informações claras e acessíveis que ajudem a população na mudança dos hábitos de vida, formular estratégias de adesão ao tratamento medicamentoso, construir o empoderamento do indivíduo para o autogerenciamento das suas doenças e dos seus riscos são estratégias relevantes que contribuem para a redução do impacto das DCVs. A apropriação do conhecimento sobre os FRs, reconhecidos cientificamente como aqueles envolvidos na gênese das DCVs, tem proporcionado novas e mais eficazes medidas relacionadas à sua prevenção.

As pesquisas epidemiológicas desenvolvidas na cidade americana de Framingham (Framingham Heart Study) ao final da década de 1940 constituem o marco inicial e um dos mais importantes avanços científicos que estabeleceram a base de conhecimentos capaz de correlacionar FR e DCV de forma inequívoca. E, muito importante, a possibilidade de intervir de forma estrategicamente efetiva sobre os FRs e reduzir a prevalência da morbimortalidade das DCVs $\mathrm{s}^{344,345}$.

Dois aspectos importantes devem ser considerados, do ponto de vista estratégico, quanto aos FRs relacionados às $\mathrm{DCV}$ s e à expectativa de resposta às ações de controle - normas, regulamentos e legislação - emanadas pelas autoridades da área da saúde: potencial de resposta às intervenções e possibilidade de as ações normativas e da legislação induzirem mudanças efetivas no perfil epidemiológico da população.

Quanto ao potencial de resposta às intervenções, já existe um acúmulo de conhecimentos a indicar que as ações preventivas são eficazes no sentido de reduzir a prevalência das DCVs, conforme o que foi constatado na diminuição do consumo de cigarros, por exemplo. Após a primeira década dessas mudanças nos hábitos da população já era possível observar os reflexos do fenômeno nas estatísticas de morbimortalidade ${ }^{340}$.

Com a evolução dos conhecimentos na área médica ocorrida nos últimos anos, por meio, principalmente, da medicina baseada em evidências (MBE), já é possível quantificar ou categorizar as respostas às intervenções de acordo com o grau de evidência observado.

A partir dos conceitos da MBE foram estabelecidas quatro categorias hierárquicas de resposta às intervenções:

a) as que comprovadamente diminuem o risco de DCV;

b) as que claramente reduzem o risco;

c) as que podem reduzir o risco;

d) as que estão associadas ao aumento das DCVs, mas que não são modificáveis.

No primeiro grupo - que comprovadamente diminuem - estão listados os seguintes fatores de risco: tabagismo, LDL-C, dietas ricas em gorduras/colesterol, hipertensão arterial sistêmica (HAS), hipertrofia ventricular esquerda, fatores trombogênicos.

No segundo - claramente reduzem - aparecem: diabetes, sedentarismo, HDL-C; triglicerídeos, LDL, obesidade, período pós-menopausa.

No terceiro grupo - podem reduzir - estão: fatores psicossociais, lipoproteína (a), homocisteína, estresse oxidativo; não consumo de álcool. 
No quarto - não modificáveis - surgem idade, sexo masculino, baixa condição socioeconômica, história de DCV precoce $^{345}$.

A Organização Mundial da Saúde (OMS) divulgou, em 2011, as intervenções mais custo-efetivas, sendo algumas delas ainda consideradas as "melhores apostas" (best buy) (ações que devem ser executadas imediatamente para que produzam resultados acelerados em termos de vidas salvas, doenças prevenidas e custos altos evitados). A OMS divulgou, ainda, intervenções custo-efetivas de âmbito populacional (promoção da saúde) e também em relação às prevenções primária e secundária e ao tratamento. Existem ainda outras medidas que são promissoras, pois os estudos ainda estão em andamento. O Quadro 12.1 detalha as medidas propostas pela OMS que podem ser efetivas para a redução da DCV ${ }^{346}$.

\section{Quadro 12.1 - Evidências de Intervenções em DCV}

1. Intervenções populacionais consideradas as melhores apostas (best buy) pela OMS:

- Aumentar impostos e preços sobre os produtos do tabaco

- Proteger as pessoas da fumaça do cigarro, proibir que se fume em lugares públicos e advertir sobre os perigos do consumo de tabaco

- Fazer cumprir a proibição da propaganda, do patrocínio e da promoção de tabaco

- Restringir a venda de álcool no varejo

- Reduzir a ingestão de sal e do conteúdo de sal nos alimentos

- Substituir gorduras trans em alimentos por gorduras poli-insaturadas

- Promover o esclarecimento do público sobre alimentação e atividade física, inclusive pela mídia de massa

2. Outras intervenções de base populacional custo-efetivas e de baixo custo:

- Promoção da amamentação adequada e alimentação complementar

- Aplicação das leis do álcool e direção

- Restrições sobre o marketing de alimentos e bebidas com muito sal, gorduras e açúcares, especialmente para crianças

- Impostos sobre alimentos e subsídios para alimentação saudável

3.Intervenções com evidências promissoras e estudos ainda em andamento:

- Ambientes de nutrição saudável nas escolas

- Informação nutricional e aconselhamento em atenção à saúde

- Diretrizes nacionais em atividade física

- Programas de atividade física para crianças com base na escola

- Programas de atividade física e alimentação saudável nos locais de trabalho

- Programas comunitários de atividade física e alimentação saudável

- Construção de ambientes que promovam atividade física

4. Intervenções voltadas para o cuidado da saúde de grupos específicos:

- Terapia de ácido acetil salicílico (AAS), estatinas e anti-hipertensivo na prevenção de infarto agudo do miocárdio e outras doenças cardiovasculares - Aconselhamento e terapia multidrogas, incluindo o controle da glicemia para o diabetes, para pessoas com mais de 30 anos de idade, prevenindo contra evento cardiovascular fatal ou não fatal

- Tratamento da dependência da nicotina

- Financiamento e fortalecimento dos sistemas de saúde para oferecer intervenções individuais custo-efetivas por meio da abordagem da atenção primária

Com relação às "possibilidades de ações normativas e legislação na redução e no Controle das DCVs", pode-se ter a expectativa da efetividade destas intervenções desde que precedidas/acompanhadas por ações educativas e de que as leis e as normas sanitárias se originem de amplos debates com a comunidade. Afinal, trata-se da difícil tarefa de interferir na liberdade individual dos cidadãos em relação aos seus hábitos de vida: dieta inadequada x alimentação saudável; vida sedentária x prática correta de exercícios; uso livre e exagerado de álcool x uso moderado.
Voltando-se ao exemplo do tabagismo, vale lembrar que a campanha antifumo do Ministério da Saúde, ao final da década de 1980, foi planejada e executada com a participação efetiva de amplos setores sociais, aí incluídas universidades, entidades representativas dos profissionais da saúde - principalmente das áreas de oncologia, pneumologia e cardiologia -, representantes e líderes comunitários, representantes da classe política, tudo com a colaboração das pessoas que, historicamente, estiveram no front da luta antitabágica.

A partir das ações de natureza educativa, com apelos e mensagens bem diferentes de campanhas anteriores, foi possível iniciar, gradativamente, as ações legais e normas restritivas, as quais foram bem assimiladas pela população em geral e pelo contingente de fumantes com resultados positivos.

Cabe analisar, finalmente, qual o estado da arte em relação ao tema "legislação e controle das DCVs", aferindo:

- que lugar ocupam as ações normativas e a legislação nas estratégias de controle das DCVs, nos órgãos de saúde dos três níveis de governo;

- de que forma esse aparato normativo interage com as ações educativas e com a sociedade;

- o que existe de leis e normas, no plano federal, gerais e específicas, direcionadas ao controle das DCVs;

- o que estaria faltando ao aparato normativo e que poderia constituir-se em lacuna a ser preenchida por novas leis, normas e regulamentos;

- quais medidas parecem mais adequadas para trabalhar, estrategicamente, o uso da Legislação disponível e a ser criada, eventualmente, para a obtenção do controle efetivo dos FRs envolvidos nas DCVs;

- quais os FRs prioritários a serem abordados cuja redução e/ou controle resultaria em impactos efetivos na morbimortalidade das DCVs.

Vamos considerar, em bloco, as indagações listadas no item anterior.

- Pode-se afirmar que, de maneira geral, existe uma grande expectativa positiva, por parte da população e dos dirigentes da saúde, em relação à força coercitiva/normativa de leis e regulamentos. Se essas leis e regulamentos estão sendo efetivamente obedecidos é um detalhe que, na maioria das vezes, não é levado na devida conta. O importante é a simples existência das normas.

- Daí decorre o problema da efetiva valorização da norma como elemento ou componente estratégico das ações preventivas em saúde. Recorrendo a exemplos, para esclarecer este argumento, tomemos o conteúdo de sal (cloreto de sódio) em alimentos industrializados para consumo humano. É reconhecida a importância do controle da ingesta de sal nas prevenções primária e secundária da hipertensão arterial. Torna-se, portanto, essencial a fiscalização, por parte dos organismos oficiais, do conteúdo de sódio dos alimentos e se há coerência real entre este conteúdo e o que está declarado nos rótulos dos mesmos. Isso é ação preventiva em saúde.

- Se o aparato normativo não interage com a sociedade, por meio de ações educativas permanentes, a tendência é que haja o afrouxamento gradativo das suas normas, 
colocando em risco desnecessário a população sob sua responsabilidade. Deve-se levar em conta que é o próprio usuário/consumidor um dos fiscais do cumprimento das leis, desde que alertado e plenamente educado para o exercício dessa tarefa.

- Existe todo um conjunto de leis e normas federais direcionadas ao controle das DCV. Elas têm origem em organismos de vigilância e segurança alimentar e nutricional voltados para crianças, adultos e idosos, e, teoricamente, poderão cumprir importante papel na prevenção e controle das doenças crônicas não transmissíveis. Outras normas são originárias de instâncias governamentais específicas, com aquelas voltadas para detecção e controle das DCVs. A parte mais significativa desse arcabouço normativo está relacionada nos Anexos desta Diretriz.

Em relação aos FRs que, num primeiro momento, devem ser assumidos como prioritários, serão escolhidos aqueles considerados estratégicos. Como tal são relacionados aqueles cuja intervenção diminui - comprovadamente - os riscos cardiovasculares. Propõe-se a intervenção em três FRs de alta pontuação no potencial de resposta às intervenções por meio de medidas educativas - mudança de estilo de vida - e medicamentosas: tabagismo, hipertensão arterial e dislipidemia. Estes fatores serão abordados de maneira específica a seguir, ficando evidente que esta indicação estratégica de prioridade não se faz em detrimento de outros FRs, também importantes para o controle das DCVs.

Estabelecida a estreita correlação entre hábitos de vida x DCV, hipertensão arterial x DCV e diabetes mellitus (DM) $x$ DCV, é essencial identificar o ponto comum de interação entre estes fatores. As evidências apontam para a obesidade e o sobrepeso como fatores que claramente se associam a hipertensão arterial, dislipidemia, diabetes e aterosclerose.

A partir de mudanças observadas em alguns importantes determinantes sociais da saúde, a obesidade vem se tornando epidêmica em vários países e independe do grau de desenvolvimento econômico e tecnológico por eles alcançado. A obesidade e o sobrepeso corporal constituem, hoje, um grave problema de saúde pública. Afeta milhões de pessoas, repercute seriamente sobre os serviços assistenciais e impacta a qualidade de vida e a capacidade produtiva de homens e mulheres, geralmente no ápice da sua capacidade funcional.

Mudanças nos hábitos de vida como forma motorizada de se locomover de casa para o trabalho e vice-versa, induzindo a adoção de hábitos sedentários de vida; uso abusivo de fast food e de alimentos processados; introdução do açúcar e hidratos de carbono na dieta; excessivo estresse da vida urbana; e uso do álcool etílico de forma abusiva se combinaram para produzir indivíduos com excesso de peso e agregação de riscos, e cujo metabolismo propicia o aparecimento das chamadas doenças da vida moderna. $E$ tudo isso provocado pelo rápido processo de urbanização.

Do ponto de vista fisiopatológico, a obesidade se relaciona de forma inequívoca com o diabetes e a resistência à insulina, com a dislipidemia e com a hipertensão arterial, resultando, como desfecho final desse ciclo patológico, em aterosclerose.
Sabe-se que, no indivíduo obeso: desenvolve-se resistência à insulina, bloqueando os receptores desse hormônio nos tecidos; produz-se elevação do colesterol total e do LDL-C pelo aumento da produção de ácidos graxos; por meio da resistência à insulina ocorre o aumento gradativo do hormônio, resultando em ativação crônica do sistema simpático e HAS.

Pode-se concluir, portanto, que o controle da obesidade/ sobrepeso, por meio de leis, normas e regulamentos, conceitualmente torna-se uma medida capaz de produzir impactos epidemiológicos sensíveis nas estatísticas de morbimortalidade das DCVs.

No entanto existem duas variáveis que dificultam a aplicação plena dessa medida.

A primeira refere-se a dificuldades de adesão da população das diversas faixas de idade a mudanças nos seus hábitos alimentares e nos seus padrões culturais/comportamentais. São necessárias campanhas educacionais permanentes, com enfoque estratégico prioritário na escola, com o objetivo de formar adultos aptos a manter hábitos saudáveis de vida. Quanto a crianças e adolescentes, deve-se compartilhar ações educativas no âmbito familiar voltadas precipuamente para os pais. O teor de sal, gorduras e gorduras trans e o consumo de alimentos saudáveis nas cantinas escolares devem merecer cuidado especial dos educadores e das autoridades de saúde. Medidas legais e normativas são perfeitamente cabíveis nesse contexto.

A segunda variável, talvez mais complexa e que impõe imensas dificuldades e desafios às autoridades governamentais da área da saúde, reside na atitude da indústria produtora de alimentos, que está repetindo o que fizeram, no passado, os fabricantes de cigarros, que resolveram colocar em seus produtos aditivos fortemente indutores da dependência do fumo, igualmente adicionando substâncias capazes de viciar o consumidor em alimentos nocivos à sua saúde, tornando-os mais atraentes e mais baratos. Estudos sobre o comportamento dos consumidores, incluindo crianças e jovens, mostra como afastá-los dos alimentos saudáveis, fazendo-os preferir produtos alimentícios com alto teor de açúcar e pobres em nutrientes ${ }^{347}$.

Neste contexto destacamos, no Quadro 12.2, as principais ações normativas e a legislação referentes às estratégias de vigilância, prevenção, assistência, reabilitação e promoção da saúde no Brasil.

Ressalta-se que o Brasil assumiu compromissos de prevenção e cuidado com as DCNTs e lançou o Plano de Ações Estratégicas para o Enfrentamento das Doenças Crônicas Não Transmissíveis (DCNT), 2011-2022, que define e prioriza as ações e os investimentos necessários para preparar o país para enfrentar e deter as DCNTs e seus fatores de risco nos próximos 10 anos. O plano aborda os quatro principais grupos de doenças (cardiovasculares, câncer, respiratórias crônicas e diabetes) e seus fatores de risco em comum modificáveis (tabagismo, álcool, inatividade física, alimentação inadequada e obesidade) e define três diretrizes estratégicas: a) vigilância, informação, avaliação e monitoramento; b) promoção da saúde; c) cuidado integral. O plano define metas e compromissos assumidos pelo Brasil em relação às DCNTs ${ }^{340,348,349}$.

A DCV é multifacetada em seus FRs e o seu o controle demanda ações promocionais e preventivas articuladas que impactam, como o combate ao sedentarismo e à obesidade 
Quadro 12.2 - Principais ações normativas e a legislação referentes às estratégias de vigilância, prevenção, assistência, reabilitação e promoção da saúde no Brasil

\begin{tabular}{|c|c|}
\hline Portaria/Lei & Conteúdo \\
\hline - Portaria n $687 /$ GM/MS, de 30 de março de 2006 & - Política de Promoção da Saúde \\
\hline - Portaria n 971/GM/MS, de 3 de maio de 2006 & - Política Nacional de Práticas Integrativas e Complementares (PNPIC) no Sistema Único de Saúde (SUS) \\
\hline - Lei No 11.347 , de 27 de setembro de 2006 & $\begin{array}{l}\text { Dispõe sobre a distribuição gratuita de medicamentos e materiais necessários à sua aplicação e à } \\
\text { monitoração da glicemia capilar aos portadores de diabetes inscritos em programas de educação para } \\
\text { diabéticos }\end{array}$ \\
\hline - Portaria $n^{0} 2.583$, de 10 de outubro de 2007 & $\begin{array}{l}\text { - Define elenco de medicamentos e insumos disponibilizados pelo SUS, nos termos da Lei n } 11.347 \text {, de } \\
2006 \text {, aos usuários portadores de diabetes mellitus }\end{array}$ \\
\hline - Portaria $n^{0} 1.559 / \mathrm{GM} / \mathrm{MS}$, de $1^{0}$ de agosto de 2008 & - Política Nacional de Regulação do SUS \\
\hline - Portaria n 992/GM/MS, de 13 de maio de 2009 & - Política Nacional de Saúde Integral da População Negra; \\
\hline - Portaria nº 4.279/GM/MS, de 30 de dezembro de 2010 & - Estabelece diretrizes para a organização da Rede de Atenção à Saúde no âmbito do SUS \\
\hline - Portaria $n^{0} 4.217$, de 28 de dezembro de 2010 & - Componente Básico da Assistência Farmacêutica \\
\hline - Portaria n 1.600/GM/MS, de 7 de julho de 2011 & $\begin{array}{l}\text { - Reformula a Política Nacional de Atenção às Urgências e institui a Rede de Atenção às Urgências no } \\
\text { SUS }\end{array}$ \\
\hline - Portaria n 2.029 de 24 de agosto de 2011 & - Institui a Atenção Domiciliar no âmbito do SUS \\
\hline - Portaria $n^{0} 2.488$, de 21 de outubro de 2011 & $\begin{array}{l}\text { - Aprova a Política Nacional de Atenção Básica, estabelecendo a revisão de diretrizes e normas para a } \\
\text { organização da Atenção Básica, para a Estratégia Saúde da Família (ESF) e o Programa de Agentes } \\
\text { Comunitários de Saúde (PACS) }\end{array}$ \\
\hline - Portaria n².715/GM/MS, de 17 de novembro de 2011 & - Atualiza a Política Nacional de Alimentação e Nutrição (PNAN) \\
\hline - Portaria $n^{0}$ 971, de 15 de maio de 2012 & - Programa Farmácia Popular do Brasil \\
\hline - Portaria $n^{0} 252$, de 19 de fevereiro de 2013 & - Institui a Rede de Atenção à Saúde das Pessoas com Doenças Crônicas no âmbito do SUS \\
\hline - Portaria $n^{0} \mathrm{XX}$, de 19 de março de 2013 & - Cria a Linha de Cuidados Prioritários do Sobrepeso e da Obesidade no SUS \\
\hline
\end{tabular}

e o controle do tabagismo, e de serviços de saúde integrados para o diagnóstico e o acompanhamento dos casos detectados e tratados. As leis e portarias vigentes no país são subsídios para o enfretamento das DCNTs, em especial as DCVs, que exigem esforços do setor saúde articulados com os demais setores governamentais, não governamentais e privados, tanto na formulação, no desenvolvimento e na implantação e implementação de políticas específicas, e que articulem e integrem ações de vigilância, prevenção, assistência, reabilitação e promoção da saúde, produzindo qualidade de vida e cidadania.

Assim, a abordagem aos formuladores de políticas públicas implicará a adoção e formulação de políticas e ações de saúde pública abrangentes e integradas, apoiadas em ações intersetoriais, levando em conta os vários ciclos da vida, as condições e necessidades locais. 


\section{Tópicos em prevenção}

\section{Doenças autoimunes e doença cardiovascular}

Tabela 13.1 - Recomendação para abordagem das doenças autoimunes na prevenção das doenças cardiovasculares

\begin{tabular}{ccc}
\hline Recomendação & Classe & $\begin{array}{c}\text { Nível de } \\
\text { evidência }\end{array}$ \\
\hline $\begin{array}{c}\text { No contexto da prevenção de eventos } \\
\text { cardiovasculares, o benefício da utilização de alvos } \\
\text { terapêuticos mais rigorosos, especificamente devido } \\
\text { à presença de doenças autoimunes, é incerto. }\end{array}$ & $\mathrm{llb}$ & $\mathrm{C}$ \\
\hline
\end{tabular}

Diversas doenças autoimunes podem acometer o coração por meio de manifestações variadas que incluem arritmias, pericardiopatias, miocardiopatias e coronariopatia. Em relação a esta última complicação, os avanços e pesquisas no campo da aterosclerose têm reforçado cada vez mais a participação do sistema imune na sua fisiopatologia. A presença de linfócitos e macrófagos dentro das placas de ateroma sugere que a inflamação seja um fator primordial na cascata de evolução da doença. Em pacientes com doenças autoimunes reumáticas tal processo inflamatório é exacerbado e o resultado pode ser a ocorrência de aterosclerose acelerada ${ }^{350}$. O uso de certos medicamentos imunossupressores, como corticoides, também pode contribuir para esta piora do perfil de risco cardiovascular. A aterosclerose acelerada talvez seja a principal explicação para os elevados percentuais de morbimortalidade cardiovascular que estes pacientes apresentam ${ }^{350,352}$. Entre as doenças que podem cursar com esta característica fisiopatológica vale destacar: artrite reumatoide (AR), lúpus eritematoso sistêmico (LES), psoríase e certas vasculites primárias como a granulomatose de Wegener ${ }^{166,350,352}$.

A AR está associada a uma redução de até três vezes na sobrevida, apresentando a doença isquêmica do coração como a sua principal causa de morte ${ }^{353}$. Além disso, o risco de infarto agudo do miocárdio (IAM) é cerca de duas vezes maior do que na população geral, e o prognóstico após o evento tende a ser pior $^{166}$. Este perfil começa a ser desenvolvido no início da doença e de maneira independente de outros fatores classicamente associados à aterosclerose $\mathrm{e}^{354}$. $\mathrm{O}$ uso de metotrexato também pode contribuir para este cenário, talvez pela elevação concomitante de homocisteína durante o seu uso. Nestes casos, a suplementação com folato parece reduzir este risco, inclusive com evidências de redução de mortalidade cardiovascular $^{355}$. Ainda assim, a limitação funcional e o consequente sedentarismo impostos pela doença também podem elevar a probabilidade de desenvolvimento de outros fatores de risco, como obesidade, hipertensão arterial e diabetes. A dislipidemia é outra condição frequentemente encontrada nestes pacientes, com uma prevalência que pode chegar a $65 \%{ }^{356}$.

Assim como a AR, o LES também se comporta como um fator de risco independente para doença cardiovascular (DCV), com uma prevalência de coronariopatia de até 10\% e um risco até oito vezes acima da população gera| ${ }^{351,357}$. Alguns trabalhos sugerem que o IAM pode ser a causa de morte em até $25 \%$ dos casos, principalmente nos pacientes com mais tempo de doença ${ }^{358}$. O risco desta complicação pode chegar a 52 vezes acima da população sem a doença, quando o tempo de evolução ultrapassa cinco anos ${ }^{351}$. Ao mesmo tempo, a prevalência dos principais fatores de risco cardiovasculares, como hipertensão arterial, diabetes, obesidade, sedentarismo e dislipidemia, também é maior nos indivíduos com LES ${ }^{352}$. O uso frequente de corticoides para o manejo da doença é outra condição que auxilia na piora do perfil metabólico, embora doses diárias de prednisona inferiores a $10 \mathrm{mg}$ pareçam ser seguras neste aspecto, assim como os antimaláricos ${ }^{352,359}$. De qualquer forma, o fato de a coronariopatia associada ao LES ser mais frequentemente associada à aterosclerose do que à vasculite reforça ainda mais a importância destes fatores neste contexto. Por outro lado, a relação entre a síndrome do anticorpo antifosfolipídio, frequentemente associada ao LES, e a aterosclerose acelerada não está tão clara, apesar de ela reconhecidamente aumentar o risco de eventos trombóticos ${ }^{350}$.

$\mathrm{A}$ aterosclerose acelerada associada à psoríase também confere a esta doença um risco comprovadamente maior de IAM. Porém, diferentemente do LES, esta complicação tende a ocorrer com mais frequência em indivíduos mais jovens e naqueles com maior gravidade de doença. Tal característica poderia ser consequência de um quadro inflamatório mais exuberante, o que estaria associado a maior ativação do sistema imune ${ }^{166}$.

As vasculites primárias formam outro grupo de doenças com relevância neste contexto, cursando com inflamação sistêmica de etiologia autoimune que acomete o leito vascular de forma variada. O processo inflamatório inerente a essas doenças compõe um aspecto importante da fisiopatologia, principalmente quando são acometidos vasos de médio e grande calibres, aumentando, assim, o risco de eventos cardiovasculares. Entretanto, o que tem sido cada vez mais reconhecido é a relação deste grupo de doenças como a aterosclerose, apesar de ainda ser menos evidente do que nas doenças reumatológicas ${ }^{350}$. O remodelamento vascular com disfunção endotelial, a maior formação do colesterol da lipoproteína de baixa densidade (LDL-C) oxidado e o tratamento prolongado com corticoides são fatores importantes envolvidos neste processo ${ }^{352}$. No entanto, os estudos clínicos ainda são escassos nesta área, existindo apenas alguns trabaIhos com avaliações de desfechos intermediários, como o aumento da espessura mediointimal carotídea na granulomatose de Wegener ${ }^{350}$. Ainda assim, deve ser lembrado que as outras doenças deste grupo, como arterite de Takayasu, poliarterite nodosa e doença de Kawasaki, podem potencialmente acometer a circulação coronariana, mesmo que na maioria das vezes isto ocorra independentemente da aterosclerose.

A maioria das doenças autoimunes é mais comum entre as mulheres, podendo chegar a uma prevalência até nove vezes maior, como no $\mathrm{LES}^{352}$. Isto torna particularmente relevante a estratificação minuciosa do risco cardiovascular no sexo feminino na presença destas condições, mesmo numa faixa etária em que habitualmente a doença coronariana seria mais rara (< 65 anos). De qualquer forma, a questão fundamental é a ausência de estudos clínicos que demonstrem um benefício de tratar mais agressivamente este grupo de pacientes. Até o momento, não existem evidências de que os alvos terapêuticos de pressão arterial, glicemia, LDL-C, ou qualquer outro fator de risco, deveriam ser modificados devido à presença de uma doença autoimune.

Os trabalhos realizados nesta área focaram principalmente em desfechos substitutos, como a redução da espessura me- 
diointimal carotídea em pacientes com LES tratados com atorvastatina. Porém vale ressaltar que este mesmo estudo mostrou um aumento da ocorrência de efeitos adversos hepáticos e musculares nos pacientes tratados com a droga ${ }^{360}$. Isto sugere que esta conduta deve ser tomada com cautela, uma vez que expõe o paciente a um risco maior de efeitos adversos, sem necessariamente fornecer um benefício clínico. Além disso, este risco não parece ser restrito ao LES, pois cerca de $80 \%$ dos pacientes com artrite reumatoide possuem no mínimo um fator de risco para miopatia associada a estatinas ${ }^{361}$. O uso de anti-inflamatórios ou corticoides poderia também elevar o risco de hemorragias se associados à aspirina, frequentemente utilizada no cenário da prevenção primária e secundária de eventos cardiovasculares ${ }^{362}$. Entretanto, a prevalência relativamente baixa destas doenças na população é o principal fator que limita a realização de estudos de boa qualidade para responder a estas questões. Possivelmente o próprio tratamento direcionado à doença de base poderia reduzir o risco cardiovascular ao controlar o processo inflamatório, embora esta hipótese também necessite ser estudada. A complexidade torna-se ainda maior quando a medicação utilizada no manejo da doença sabidamente pode piorar o perfil metabólico, como no caso dos corticoides. Portanto, é essencial que cada caso seja individualizado, com constantes reavaliações ao longo da evolução da doença dos potenciais riscos e benefícios do tratamento.

As recomendações dessa diretriz para doenças autoimunes e doenças cardiovasculares podem ser vistas na Tabela 13.1.

\section{Influenza e doença cardiovascular}

Tabela 13.2 - Recomendação para abordagem da influenza na prevenção das doenças cardiovasculares

\begin{tabular}{ccc}
\hline Recomendação & Classe & $\begin{array}{c}\text { Nível de } \\
\text { evidência }\end{array}$ \\
\hline $\begin{array}{c}\text { - Indicar a vacinação contra influenza anualmente para } \\
\text { pacientes com doença coronariana ou cerebrovascular } \\
\text { estabelecida, independentemente da idade }\end{array}$ & I & B \\
- Indicar a vacinação contra influenza anualmente \\
$\begin{array}{c}\text { para pacientes com alto risco para eventos } \\
\text { coronarianos, porém sem doença cardiovascular } \\
\text { estabelecida, independentemente da idade }\end{array}$
\end{tabular}

A possível relação entre o vírus da influenza e doenças cardiovasculares foi aventada pela primeira vez no início do século XX, principalmente após a pandemia de gripe espanhola de $1918^{363}$. Desde então diversos estudos observacionais têm reforçado esta relação, com evidências cada vez mais consistentes de que não se trata de um achado ao acaso. Neste contexto, foi observado, ao longo dos últimos 100 anos, que as epidemias de influenza tendem a ser acompanhadas de um aumento significativo de mortes e eventos cardiovasculares $^{364,365}$. Inclusive, durante a pandemia do vírus H1N1 de 2009, foi constatado no Brasil que a doença cardiovascular crônica foi a comorbidade mais prevalente $(23,8 \%)$ entre os pacientes que evoluíram a óbito ${ }^{366}$. Além disso, atualmente já é reconhecido que a maior parte dos eventos cardiovasculares que acometem estes pacientes ocorre nos meses de inverno, acompanhando a tendência sazonal do vírus ${ }^{365}$.

Os mecanismos envolvidos nesta relação ainda não são inteiramente compreendidos, mas especula-se que o vírus possa atuar diretamente na desestabilização de placas ateroscleróti- cas vulneráveis, o que torna a sua infecção particularmente relevante nos indivíduos que sabidamente possuem doença coronariana e/ou cerebrovascular. Esta característica o distingue de outros agentes infecciosos que também já foram relacionados com maior risco cardiovascular, como a Chlamydia pneumonia e o Mycoplasma pneumonia, que promovem um processo inflamatório mais sistêmico. A perda das propriedades anti-inflamatórias do colesterol da lipoproteína de alta densidade (HDL-C) e a disfunção endotelial também são fatores possivelmente envolvidos na fisiopatologia ${ }^{367,368}$. De qualquer forma, independentemente do mecanismo, o risco de IAM parece ser maior nos primeiros 10 dias de evolução da infecção respiratória ${ }^{369}$. Os benefícios da vacinação contra influenza já foram investigados por diversos estudos observacionais e, embora os resultados não tenham sido unânimes, foi verificado um efeito protetor na maioria deles, principalmente em relação aos desfechos cardíacos ${ }^{364}$. A maior coorte já realizada neste contexto acompanhou mais de 102 mil indivíduos com mais de 65 anos, portadores ou não de DCV, ao longo de 10 meses. Os mais de 35 mil participantes que foram vacinados apresentaram percentuais menores e estatisticamente significantes de morte total, morte cardíaca e acidente vascular cerebral (AVC), quando em comparação com o grupo que não foi vacinado ${ }^{370}$. Ainda que este resultado seja expressivo, é preciso considerar os vieses que acompanham a interpretação de qualquer estudo observacional. Estudos de caso-controle dentro deste tema também já foram publicados, apresentando em sua maioria resultados semelhantes e com as mesmas limitações ${ }^{364}$.

Três ensaios clínicos já foram realizados buscando avaliar o efeito da vacinação contra influenza sobre a prevenção de eventos cardiovasculares. Entretanto, todos incluíram apenas pacientes com doença coronariana estabelecida, utilizando a vacina como uma estratégia de prevenção secundária ${ }^{367,371-373}$. Foram estudados pacientes com ou sem passado de IAM, assim como aqueles submetidos ou não a intervenções Coronarianas. Apesar de o número de participantes ter variado entre 200 e 658 nos estudos, todos mostraram resultados parecidos, com uma redução de desfechos cardiovasculares combinados (morte, IAM, necessidade de internação por isquemia ou de revascularização) no grupo vacinado, ao longo de 12 meses de acompanhamento ${ }^{371-373}$. No entanto, apenas o estudo Flu vaccination in acute coronary syndromes and planned percutaneous coronary interventions (FLUVACS) mostrou uma redução significativa de morte cardiovascular, especificamente entre os pacientes com passado de IAM ${ }^{373}$. Uma revisão sistemática publicada em 2009 também sugeriu este mesmo benefício ao analisar conjuntamente os dados dos estudos FLUVACS e Influenza vaccination in secondary prevention from coronary ischaemic events in coronary artery disease (FLUCAD), embora o resultado tenha sido claramente influenciado pelos achados do primeiro ${ }^{364}$.

Estes trabalhos também apresentaram limitações que devem ser consideradas mediante a análise dos resultados. Entre elas pode-se destacar o número pequeno de pacientes e de desfechos, a ausência de cegamento e a unicentricidade. Além disso, os resultados não podem ser generalizados para aqueles indivíduos sem doença aterosclerótica estabelecida, como uma estratégia de prevenção primária de eventos cardiovasculares, embora o efeito protetor da vacina sobre a infecção respiratória permaneça. Do mesmo modo, o impacto 
da vacinação sobre a redução de eventos cerebrovasculares ainda não está estabelecido, ainda que resultados positivos tenham sido sugeridos por diversos estudos observacionais ${ }^{373}$. Mesmo assim, apesar da relevância destas ressalvas, estas evidências foram fundamentais para, no mínimo, afastar a hipótese previamente levantada de que o período imediatamente após a vacinação poderia elevar o risco cardiovascular.

As recomendações dessa diretriz para influenza e doenças cardiovasculares podem ser vistas na Tabela 13.2.

\section{Doença Renal crônica}

Tabela 13.3 - Recomendação para abordagem da doença renal crônica (DRC) na prevenção das doenças cardiovasculares

\begin{tabular}{ccc}
\hline Recomendação & Classe & $\begin{array}{c}\text { Nível de } \\
\text { evidência }\end{array}$ \\
\hline $\begin{array}{c}\text { Pacientes com doença renal crônica devem } \\
\text { ser considerados de risco muito alto para a }\end{array}$ & \\
abordagem dos fatores de risco cardiovascular, & & \\
sendo necessário avaliar fatores como o grau \\
de redução da taxa de filtração glomerular \\
(TFG) e a presença de comorbidades
\end{tabular}

A relação entre DRC e DCV está bem estabelecida, e múltiplas interações entre ambas são descritas. Além de ambas apresentarem fatores de risco em comum, a DRC é fator de risco independente para o desenvolvimento de doença coronariana $^{374,375}$.

Em geral, os pacientes com DRC têm aumentos variáveis no risco de desenvolvimento de eventos cardiovasculares, sendo menor (43\%) nos pacientes com taxa de filtração glomerular (TFG) entre $45-59 \mathrm{ml} / \mathrm{min}$ e maior (343\%) naqueles com TFG $<15 \mathrm{ml} / \mathrm{min}^{376}$.

Além disso, a presença de proteinúria, independente de idade, sexo, função renal e diabetes, aumenta o risco de doença coronariana e perpetua a lesão renal crônica ${ }^{377}$.

Entretanto, a discussão sobre considerar a DRC equivalente de doença coronariana é extensa e controversa. Em 2003, a recomendação do National Kidney Foundation (EUA) considerava de fato a DRC um equivalente de doença coronariana ${ }^{378}$. entretanto fatores como o grau de redução da TFG, a presença de comorbidades associadas, como albuminúria, e sobretudo o comportamento dinâmico da doença, fazem que mesmo os pacientes que apresentem semelhantes TFGs possam apresentar riscos cardiovasculares distintos. Assim, estudos mais recentes consideram a DRC importante fator de risco fator para DCV, e não um equivalente desta doença ${ }^{379}$.

Desta forma, a DRC deve ser considerada no contexto global do risco cardiovascular de cada indivíduo, não devendo ser generalizada como equivalente de DCV para todos os pacientes. As diretrizes da Sociedade Brasileira de Cardiologia (SBC) já vêm assim considerando a DRC, seja como lesão de órgão-alvo na VII Diretriz de Hipertensão Arterial Sistêmica ${ }^{119}$, seja como fator agravante do risco cardiovascular na Diretriz de Dislipidemia ${ }^{22}$. Devido à grande relação entre os fatores de risco para as duas doenças, as medidas de prevenção cardiovascular nesses pacientes se assemelham às medidas terapêuticas para cada uma delas em separado.

Desta forma, interrupção do tabagismo ${ }^{380}$, atividade física aeróbica $^{381}$ e redução do peso ${ }^{382}$ fazem parte da abordagem inicial destes pacientes e devem ser sempre encorajadas.
Além do controle da hipertensão para valores inferiores a 130/80 mmHg ${ }^{119}$, o controle do diabetes visando uma hemoglobina glicosilada (HbA1c) < 7\% e a correção da anemia, quando indicada, devem ser medidas a serem alcançadas.

O uso de estatinas na prevenção primária nesta população foi avaliado em diversos estudos ${ }^{383,384}$ e mostrou redução da mortalidade por todas as causas, da mortalidade cardiovascular $^{383}$ e do número de eventos mediados por doença aterosclerótica ${ }^{384}$. Apesar disso, não há consenso sobre a dose ou os alvos do perfil lipídico a serem atingidos ${ }^{379,384}$ e, portanto, recomendamos a avaliação do risco global do paciente de acordo coma a diretriz da SBC sobre o tratamento das dislipidemias, ${ }^{22}$ levando-se em consideração que a presença de TFG $<60 \mathrm{ml} / \mathrm{min}$, creatinina plasmática $>1,5 \mathrm{mg} / \mathrm{dl}$ e/ ou presença de microalbuminúria são consideradas fatores agravantes de risco cardiovascular.

Ao se optar pelo início da terapia com estatinas, qualquer dos fármacos pode ser utilizado, sempre iniciando com a menor dose possível e aumentos graduais até atingir o alvo terapêutico, com monitorações frequentes das enzimas hepáticas e da creatinofosfoquinase (CPK).

Quanto à antiagregação plaquetária para a prevenção primária em pacientes portadores de DRC, as evidências não mostram redução significativa na mortalidade global ou AVC, com elevação importante nas taxas de sangramento ${ }^{384,386}$. Em recente metanálise com mais de 27 mil pacientes, o uso destas medicações reduziu a incidência de infarto fatal ou não fatal (redução de três eventos para cada 1.000 pacientes tratados), porém à custa de aumento significativo na incidência de sangramentos maiores (15 eventos para cada 1.000 pacientes tratados), sem redução nas frequências de AVC ou mortalidade ${ }^{387}$.

Recomendamos, assim, a avaliação do risco cardiovascular global do paciente, e não apenas a consideração da DRC como suficiente para o início do tratamento com essas medicações. Aspirina em baixas doses é a medicação de escolha devido à possível redução na eficácia do clopidogrel em pacientes com DRC ${ }^{388-390}$.

As recomendações dessa diretriz para abordagem da doença renal crônica na prevenção das doenças cardiovasculares podem ser vistas na Tabela 13.3.

\section{Doença Arterial Obstrutiva}

Tabela 13.4 - Recomendação para abordagem da doença arterial obstrutiva na prevenção das doenças cardiovasculares

\begin{tabular}{ccc}
\hline Recomendação & Classe & $\begin{array}{c}\text { Nível de } \\
\text { evidência }\end{array}$ \\
\hline $\begin{array}{c}\text { Pacientes com doença arterial obstrutiva devem } \\
\text { ser considerados de risco muito alto, semelhante } \\
\text { ao da doença coronariana manifesta, para a } \\
\text { abordagem dos fatores de risco cardiovascular }\end{array}$ & । \\
\hline
\end{tabular}

Devido ao fato de a aterosclerose ser uma doença sistêmica, o comprometimento de um leito arterial frequentemente está associado ao comprometimento de outros leitos, como, por exemplo, os territórios carotídeo e coronariano ${ }^{391}$, e desta forma, a presença de doença arterial periférica (DAP) estabelecida, mesmo na ausência de diabetes mellitus (DM), é considerada um equivalente de doença coronariana ${ }^{22}$, compartilhando, portanto, aspectos da prevenção secundária desta última ${ }^{392,393}$. 
Portanto, assim como na DRC, a DAP compartilha fatores de risco com as DCVs, de modo que a abordagem para a prevenção primária nestes pacientes se confunde com as recomendações para o tratamento das DCVs.

Modificações no estilo de vida, como controle do peso (manter índice de massa corporal [IMC] $\leq 25 \mathrm{~kg} / \mathrm{m}^{2}$ ), dieta adequada, controle do diabetes (alvo de $\mathrm{HbA} 1 \mathrm{C}<7 \%$ ), interrupção do tabagismo e controle da hipertensão visando níveis tensionais $\leq 130 / 80 \mathrm{mmHg}$, são medidas que fazem parte da abordagem destes pacientes.

O controle dos lípides séricos deve ser rigoroso, preferencialmente com drogas inibidoras da 3-hidroxi-3-metil-glutaril-coenzima-A redutase (HMG-Coa-R), visto que vários estudos mostraram redução de eventos cardiovasculares quando utilizadas em pacientes com DAP ${ }^{393-395}$. No Heart Protection Study (HPS) ${ }^{396}$, por exemplo, o uso de estatina promoveu redução de 19\% (risco relativo) na incidência de eventos cardiovasculares maiores em cinco anos nos pacientes com DAP mesmo sem DCV comprovada.

Assim, a recomendação é de que a meta deve ser a mesma para pacientes com doença coronariana manifesta, objetivando manter o LDL-C em níveis inferiores a 100 mg/dl ou, em casos selecionados, como nos pacientes com aterosclerose difusa ou com eventos recorrentes, em níveis inferiores a $70 \mathrm{mg} / \mathrm{dl}^{20,22,391}$.

No que tange ao uso de antiagregantes plaquetários, recomendamos aspirina em baixas doses (75-100 mg/dia) para pacientes com DAP mesmo sem evidência de doença coronariana manifesta. Embora os benefícios sejam mais evidentes nos pacientes com DAP sintomática (exceto nos casos de doença carotídea), prescrevemos o uso mesmo nos pacientes assintomáticos, visto que as diferenças nas apresentações clínicas podem representar um fator de confundimento ${ }^{392,397-399}$. O clopidogrel é uma alternativa ao uso de aspirina nesta população ${ }^{400}$.

As recomendações dessa diretriz para abordagem da doença arterial obstrutiva na prevenção das doenças cardiovasculares podem ser vistas na Tabela 13.4.

\section{Fatores Socioeconômicos}

Tabela 13.5 - Recomendação para abordagem dos fatores socioeconômicos na prevenção das doenças cardiovasculares

\begin{tabular}{ccc}
\hline Recomendação & Classe & $\begin{array}{c}\text { Nível de } \\
\text { evidência }\end{array}$ \\
\hline $\begin{array}{c}\text { Os indicadores socioeconômicos devem } \\
\text { ser investigados na avaliação clínica e } \\
\text { considerados na abordagem do paciente para } \\
\text { melhorar a qualidade de vida e o prognóstico } \\
\text { das doenças do aparelho circulatório. }\end{array}$ & lla & B \\
\hline
\end{tabular}

A relação entre taxas elevadas de mortalidade e baixo nível socioeconômico já foi demonstrada no Brasil e mesmo nos países desenvolvidos. Relações entre redução nas taxas de mortalidade por doenças do aparelho circulatório (DAC) e melhora nos indicadores socioeconômicos de cada região são evidentes ${ }^{401,402}$. Vários estudos prospectivos têm demonstrado que baixo nível socioeconômico, definido como baixo nível educacional, baixa renda, um emprego de baixo status, ou viver em áreas residenciais mais pobres, tem contribuído para o aumento de todas as causas de morte, bem como do risco

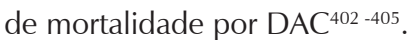

Entre 1930 e 1980, ocorreu no Brasil grande crescimento econômico que, apesar da concentração de renda, possibilitou melhorias educacionais, sanitárias, econômicas e de infraestrutura, com redução de doenças infecciosas e de processos inflamatórios decorrentes. Em países desenvolvidos, o declínio da mortalidade por DAC iniciou-se cerca de 15 anos após o término da Segunda Guerra Mundial, que sucedeu a grande depressão ocorrida no início da década de 1930 e a pandemia de influenza de 1918. No Brasil, esse mesmo declínio começou pouco mais de 40 anos após o início do período de crescimento econômico. A exposição a agentes infecciosos e outras condições insalubres nos primeiros anos de vida podem tornar os indivíduos mais suscetíveis ao desenvolvimento da aterotrombose vascular. A queda da mortalidade infantil precedeu a da mortalidade por DAC. É possível também que a redução da exposição às doenças infecciosas nas fases iniciais da vida esteja relacionada com o declínio observado na mortalidade cardiovascular dos adultos ${ }^{406-409}$.

Foram demonstradas fortes correlações entre a queda da mortalidade infantil, a elevação do produto interno bruto (PIB) per capita e o aumento da escolaridade com a redução na mortalidade por doenças do aparelho circulatório em adultos, a partir de 1980, nos estados do Rio de Janeiro, São Paulo e Rio Grande do Sul, evidenciando que a melhoria nos indicadores socioeconômicos precedeu a redução dos óbitos cardiovasculares. A grande elevação da escolaridade no decorrer das últimas décadas, que praticamente dobrou nos três estados, teve grande impacto na mortalidade, estando relacionada com a redução de mais de 100 óbitos por DAC com o aumento de um ano na média de anos de estudo em adultos ${ }^{410}$.

Medidas abrangentes de melhora dos indicadores socioeconômicos devem fazer parte do paradigma para o controle das doenças cardiovasculares. Programas de desenvolvimento socioeconômico deverão ser incluídos nas políticas para este controle. As reduções das taxas de mortalidade por doenças isquêmicas do coração e por doenças cerebrovasculares não dependem apenas do setor de saúde, mas também de políticas sociais que incluam acesso a educação, emprego, redução dos riscos ambientais e proteção contra o empobrecimento evolutivo. Essas relações sinalizam a importância da melhoria das condições de vida da população para se reduzir a mortalidade cardiovascular ${ }^{411,412}$.

A avaliação de fatores sociais em pacientes e pessoas com fatores de risco cardiovasculares é essencial como um meio para estratificar os esforços preventivos futuros com o perfil de risco do indivíduo ${ }^{413}$.

As recomendações dessa diretriz para abordagem dos fatores socioeconômicos na prevenção das doenças cardiovasculares podem ser vistas na Tabela 13.5.

\section{Apneia obstrutiva do sono}

Tabela 13.6 - Recomendação para abordagem da apneia obstrutiva do sono na prevenção das doenças cardiovasculares

\begin{tabular}{ccc}
\hline Recomendação & Classe & $\begin{array}{c}\text { Nível de } \\
\text { evidência }\end{array}$ \\
\hline $\begin{array}{c}\text { Todos os pacientes com apneia obstrutiva } \\
\text { do sono devem ser considerados potenciais } \\
\text { candidatos a prevenção primária, ser submetidos } \\
\text { a estratificação do risco cardiovascular e tratados } \\
\text { conforme estimativa de risco observada }\end{array}$ & Ila & $\mathrm{A}$ \\
\hline
\end{tabular}




\section{Diretrizes}

A apneia obstrutiva do sono é caracterizada pela obstrução recorrente, parcial ou total, das vias áreas superiores com dessaturação de oxigênio e fragmentação do sono. A prevalência em adultos vem aumentando devido à crescente obesidade e ao aumento da expectativa de vida da população mundial. A prevalência estimada dos distúrbios respiratórios do sono moderados a importantes (índice de apneia-hipopneia medido por eventos/hora $\geq 15$ ) entre homens adultos é de $10 \%$ (intervalo de confiança [IC] 95\% = 7,12) nos de 30-49 anos e de $17 \%$ (IC $95 \%=15,21$ ) nos de $50-70$ anos. Nas mulheres é relativamente menor, registrando-se 3\% (IC 95\% = 2,4) entre 30-49 anos e $9 \%(I C=7,11)$ entre $50-70$ anos. A prevalência estimada aumentou relativamente de $14 \%$ para $50 \%$ nas duas últimas décadas na dependência do grupo etário considerado ${ }^{414}$.

Está representada por uma variedade de sintomas, dos quais podemos destacar o ronco e o cansaço durante o período diurno, e foi associada, nos estudos observacionais, a aumento do risco cardiovascular, alterações cognitivas e problemas mentais. O padrão-ouro para o diagnóstico é a polissonografia realizada em laboratório no período noturno. Obesidade, hipertensão, depressão e diabetes têm sido encontrados com frequência nos pacientes com apneia obstrutiva do sono. A mudança do estilo de vida e o emprego da pressão positiva contínua nas vias aéreas é o tratamento inicial de escolha ${ }^{415}$.

O aumento da atividade simpática, com repercussão sobre a pressão arterial, e do estresse oxidativo resulta em episódios de hipoxemia e é descrito como mecanismo intermediário associado a aumento dos mediadores inflamatórios e aparecimento de disfunção endotelial e aterosclerose ${ }^{416}$.

A apneia obstrutiva do sono está associada a aumento de $70 \%$ do risco relativo de morbidade e mortalidade cardiovasculares e parece apresentar uma complexa relação bidirecional, sendo causa e consequência de insuficiência cardíaca, hipertensão arterial, arritmia e doença coronariana e podendo agravar o curso dessas patologias. Embora o tratamento da apneia obstrutiva do sono reduza o agravamento das doenças cardiovasculares crônicas, a reversão do risco relacionada ao tratamento não está bem estabelecida, sendo necessária a realização de estudos multicêntricos randomizados e controlados para que possamos elucidar essa questão ${ }^{417}$.

Todos os pacientes com apneia obstrutiva do sono devem ser considerados potenciais candidatos a prevenção primária, ser submetidos a estratificação do risco cardiovascular e tratados conforme estimativa de risco observada ${ }^{166}$.

As recomendações dessa diretriz para abordagem da apneia obstrutiva do sono na prevenção das doenças cardiovasculares podem ser vistas na Tabela 13.6.

\section{Disfunção erétil}

Tabela 13.7 - Recomendação para abordagem da disfunção erétil na prevenção das doenças cardiovasculares

\begin{tabular}{ccc}
\hline Recomendação & Classe & $\begin{array}{c}\text { Nível de } \\
\text { evidência }\end{array}$ \\
\hline $\begin{array}{c}\text { Todos os homens com disfunção erétil devem } \\
\text { ser considerados como potenciais candidatos a } \\
\text { prevenção primária e devem ser submetidos a } \\
\text { estratificação do risco cardiovascular e tratados } \\
\text { conforme estimativa de risco observada }\end{array}$ & Ila & B \\
\hline
\end{tabular}

A disfunção erétil é definida como a incapacidade de alcançar e manter uma ereção satisfatória para a atividade sexual. Acomete $52 \%$ dos homens adultos na faixa etária de 40-70 anos e aumenta com o avanço da idade. Nos EUA, estima-se que afete 18 milhões de homens com 20 anos ou mais e a projeção para 2025 é de que atinja cerca de 300 milhões de homens no mundo. Atualmente acredita-se que poderia representar um marcador sentinela para $\mathrm{DCV}^{418}$.

Pode resultar de desordens psicológicas, neurológicas, hormonais, arterial ou local no seio cavernoso, ou, ainda, da associação desses fatores. A disfunção erétil está associada a doença aterosclerótica estabelecida e aumento do risco cardiovascular, porém a pesquisa sistemática desse acometimento não melhorou a predição do risco de desenvolver DCVs, além do risco já atribuído aos tradicionais fatores de risco ${ }^{166}$.

Metanálise de 20 estudos de coorte prospectivos envolvendo 36.744 participantes sugeriu que a disfunção erétil aumenta significativamente o risco de doença isquêmica do coração, AVC e todas as causas de mortalidade e concluiu que poderia ter um papel aditivo na quantificação do risco cardiovascular com base nos tradicionais fatores de risco ${ }^{419}$.

Recente estudo australiano ${ }^{420}$ de base populacional realizado com 95.038 homens com idade maior ou igual a 45 anos demonstrou que o risco de doenças cardiovasculares relaciona-se com a severidade da disfunção erétil em homens sem e com DCV estabelecida. No primeiro grupo observou-se aumento de risco de 1,60 (IC =1,31-1,95) para a doença isquêmica do coração, 8 (IC = 2,64-24,2) para a insuficiência cardíaca e 1,92 (IC 95\% = 1,12-3,29) para doença vascular periférica, entre outras. No grupo com doença já estabelecida, o risco relativo correspondente foi de 1,70 (IC 95\% = 1,46-1,98), 4,40 (IC 95\% = 2,64-7,33) e 2,46 (1,63-3, 70) ${ }^{420}$.

Modificação do estilo de vida e drogas empregadas para o tratamento dos fatores de risco tradicionais são efetivas para melhorar a disfunção sexual nos homens. Todos os homens com disfunção erétil devem ser considerados potenciais candidatos a prevenção primária, ser submetidos a estratificação do risco cardiovascular e tratados conforme estimativa de risco observada ${ }^{166}$.

As recomendações dessa diretriz para abordagem da disfunção erétil na prevenção das doenças cardiovasculares podem ser vistas na Tabela 13.7.

\section{Periodontite}

Tabela 13.8 - Recomendação para abordagem da peridontite na prevenção das doenças cardiovasculares

\begin{tabular}{ccc}
\hline Recomendação & Classe & $\begin{array}{c}\text { Nível de } \\
\text { evidência }\end{array}$ \\
\hline $\begin{array}{c}\text { Pacientes com periodontite devem } \\
\text { serconsiderados para estratificação do risco } \\
\text { cardiovascular e tratamento intensivo local }\end{array}$ & lla & B \\
\hline
\end{tabular}

O processo inflamatório tem um importante papel na patogênese da aterosclerose, e doenças inflamatórias sistêmicas crônicas, como a periodontite, têm sido associadas a desfechos cardiovasculares adversos.

A periodontite se caracteriza por uma infecção crônica do tecido que circunda os dentes e se associa à elevação de biomarcadores como a proteína $\mathrm{C}$ reativa, citocinas proinflamatórias como o fator de necrose tumoral alfa (TNF- $\alpha$ ), inter- 
leucina 1 (IL-1 $\beta)$, interferon gama (IFN- $\gamma$ ) e prostaglandina E2 (PGE2), além de outros mediadores da inflamação. Estudos de coorte e caso-controle demonstraram a associação entre periodontite e disfunção endotelial, aterosclerose e aumento do risco de IAM e AVC, não sendo possível afastar fatores de confundimento como os socioeconômicos, tabagismo, entre outros ${ }^{421}$.

Estudo randomizado, controlado e simples-cego com 120 pacientes com periodontite importante demonstrou melhora da disfunção endotelial após seis meses de tratamento periodontal intensivo ${ }^{421}$.

Mais recentemente tem sido demonstrada a associação da DRC com a periodontite, sendo indicado seu diagnóstico e tratamento para evitar a progressão da doença renal, devido à disfunção endotelial e à aterosclerose que estão presentes de forma concomitante ${ }^{422}$. O mesmo foi observado na associação com $\mathrm{DM}^{423}$.

A periodontite pode ser considerada um indicador para o estado de saúde cardiovascular, estando indicado o tratamento intensivo local e dos fatores de risco associados ${ }^{166}$

As recomendações dessa diretriz para abordagem da periodontite na prevenção das doenças cardiovasculares podem ser vistas na Tabela 13.8. 


\section{Referências bibliográficas}

1. Buttler D.Un targets top killers. Nature.2011;477:260-1.

2. Beaglehole R, Bonita R.Global public health: a scorecard. Lancet. 2008;372(9654):1988-96.

3. Yusuf S, Hawken S, Ounpuu S, Dans T, Avezum A, Lanas F, et al; INTERHEART Study Investigators Population Health Research Institute. Effect of potentially modifiable risk factors associated with myocardial infarction in 52 countries (the INTERHEART study): case-control study. Lancet. 2004;364(9438):937-52.

4. Beaglehole R, Bonita R, Horton R, Ezzati M, Bhala N, AmuyunzuMinamongo $M$, et al. Measuring Progress on NCDs - One goal and five targets. Lancet. 2012;380(9850):1283-5.

5. Sociedade Brasileira de Cardiologia - Carta do Rio de Janeiro - II Brasil Prevent/I America Latina Prevent. Jadelson Andrade, Donna Arnett, Fausto Pinto, Daniel Pinero, Sidney Smith e col. Arq. Bras. Cardiologia 2013:100(1)3-5

6. Desfechos clínicos em 30 dias dos Registros Brasileiros Cardiovasculares nas Síndromes Coronarianas Agudas - ACCEPT - Luis A.P. Mattos, O. Berwanger, E.Silva Santos e col. Arq. Bras. Cardiol. 2013;100(1):6-13

7. I Diretriz de Ressuscitação Cardiopulmunar e cuidados Cardiovasculares da Sociedade Brasileira de Cardiologia. Gonzalez M.M., Timermann S., Gianoto-Oliveira R, Polastri T. R., Canesin M.F., Lages G et al. Arq. Bras. Cardiol. 2013;101(2supl3)1:221

8. Editorial - Programa Nacional de Qualificação de Médicos na Prevenção e Ação Integral as Doenças Cardiovasculares - Jadelson Andrade, Luis A. P. Mattos, Antonio C. Carvalho, Carlos A. Machado, Glaucia M. M. Oliveira. Arq. Bras. Cardiol. 2013:100(3):2003-201

9. World Health Organization(WHO). 65th World Health Assembly closes with new global health measures. [Access in 2013 Nov 1]. Available from: http://www.who.int/mediacentre/news/releases/2012/what65 closes_20/20526/en/

10. SIGN (Scottish Intercollegiate Guidelines Network). Risk estimation and the prevention of cardiovascular disease:a national clinical guideline. 2007. [Cited in 2013 Nov 1]. Available from: http://www.sign.ac.uk/pdf/ sign97.pdf.

11. Wilson PW, D'Agostino RB, Levy D, Belanger AM, Silbershatz H, Kannel WB. Prediction of coronary heart disease using risk factor categories. Circulation. 1998;97(18):1837-47.

12. Executive Summary of The Third Reportof the National Cholesterol Education Program (NCEP) Expert Panel on Detection, Evaluation, and Treatment of High Blood Cholesterol in Adults (Adult Treatment Panel III). JAMA. 2001;285(19):2486-97.

13. Ridker PM, Buring JE, Rifai N, Cook NR. Development and validation of improved algorithms for the assessment of global cardiovascular risk in women: the Reynolds Risk Score. JAMA. 2007;297(6):611-9.

14. Ridker PM, Paynter NP, Rifai N, Gaziano JM, Cook NR. C-reactive protein and parental history improve global cardiovascular risk prediction: the Reynolds Risk Score for men. Circulation. 2008;118(22):2243-51.

15. D'Agostino RB, Vasan RS, Pencina MJ, Wolf PA, Cobain M, Massaro JM, et al. General cardiovascular risk profile for use in primary care: the Framingham Heart Study. Circulation. 2008;117(6):743-53.

16. Lloyd-Jones DM, Leip EP, Larson MG, D'Agostino RB, Beiser A, Wilson PW, et al. Prediction of lifetime risk for cardiovascular disease by risk factor burden at 50 years of age. Circulation. 2006;113(6):791-8.

17. Berry JD, Dyer A, Cai X, Garside DB, Ning H, Thomas A, et al. Lifetime risks of cardiovascular disease. N Engl J Med. 2012;366(4):321-9.

18. Fox CS, Pencina MJ, Wilson PW, Paynter NP, Vasan RS, D'Agostino RB Sr. Lifetime risk of cardiovascular disease among individuals with and without diabetes stratified by obesity status in the Framingham Heart Study. Diabetes Care.2008;31(8):1582-4
19. Xavier HT, Izar MC, Faria Neto JR, Assad MH, Rocha VZ, Sposito AC, et al. Sociedade Brasileira de Cardiologia. V Diretriz brasileira de dislipidemia e prevenção da aterosclerose. Arq Bras Cardiol.2013;101(4 supl.1):1-36.

20. Reiner Z, Catapano AL, De Backer G, Graham I, Taskinen MR, Wiklund O, et al; European Association for Cardiovascular Prevention Rehabilitation. ESC/EAS guidelines for the management of dyslipidaemias the Task Force for the Management of Dyslipidaemias of the European Society of Cardiology (ESC) and the European Atherosclerosis Society (EAS). Eur Heart J. 2011;32(14):1769-818.

21. Mosca L, Benjamin EJ, Berra K, Bezanson JL, Dolor RJ, Lloyd-Jones DM, et al. Effectiveness-based guidelines for the prevention of cardiovascular disease in women - 2010 update. A guideline from the American Heart Association. Circulation. 2011;123(22):1243-62.

22. Sposito AC, Caramelli B, Fonseca FA, Bertolami MC, Afiune Neto A, Souza AD, et al; Sociedade Brasileira de Cardiologia. IV Diretriz brasileira sobre dislipidemias e prevenção da aterosclerose. Arq Bras Cardiol.2007;88(supl. 1):1-18.

23. Alberti KG, Zimmet P, Shaw J; IDF Epidemiology Task Force Consensus Group. The metabolic syndrome--a new worldwide definition. Lancet.2005;366(9491):1059-62.

24. IDF Clinical Guidelines Task Force. Global Guideline for Type 2 Diabetes: recommendations for standard, comprehensive, and minimal care. Diabet Med. 2006;23(6):579-93.

25. Den Ruijter HM, Peters SA, Anderson TJ, Britton AR, Dekker JM, Eijkemans MJ, et al. Common carotid intima-media thickness measurements in cardiovascular risk prediction:a meta-analysis. JAMA. 2012;308(8):796803.Erratum in JAMA. 2013;310(16):1739.

26. Yeboah J, McClelland LR, Polonski TS, Burke GL, Sibley CT, O'Leary D, et al. Comparison of novel risk markers for improvement in cardiovascular risk assessment in intermediate-risk individuals. JAMA. 2012;308(8):788-95.

27. World Health Organization. (WHO). Global status report on noncommunicable diseases, 2010. [Cited in 2013 Oct 21]. Available from:http://www.who.int/nmh/publications/ncd_report2010/

28. Edwards R. The problem of tobacco smoking. BMJ.2004;328(7433):217-9.

29. PNAD - Pesquisa especial sobre tabagismo (PETab), 2008. [Acesso em 2013 nov 1]. Disponível em http://www.ibge.gov.br/home/estatistica/ populacao/trabalhoerendimento/pnad2008/suplementos/tabagismo/ pnad_tabagismo.pdf

30. Thun MJ, Myers DG, Day-Lally C, Namboodin MM, Calle EE, Flanders $W D$,et al. Age and the exposure-response relationships between cigarette smoking and premature death in Cancer Prevention Study II. [Cited in 2013 Nov 8]. Available from: http://www.bvsde.paho.org/bvsaud/cd26/ monografia8/m8_5.pdf.

31. DiFranza JR, Savageau JA, Fletcher K, O'Loughlin J, Pbert L, Ockene JK,et al.Symptoms of tobacco dependence after brief intermittent use: the Development and Assessment of Nicotine Dependence in Youth-2 study. Arch Pediatr Adolesc Med. 2007;161(7):704-9.

32. National Center for chronic Disease Prevention and Health Promotion (US), Office on Smoking and Health (US). Center for Disease Control and Prevention; How Tobacco Smoke Causes Disease:The Biology and Behavioral Basis for Smoking Attributable Disease. A Report of theSurgeon Centers for Disease Control and Prevention (US); Atlanta (GA): 2010.

33. Pierce JP, Choi WS, Gilpin EA, Farkas AJ, Merritt RK Validation of susceptibility as a predictor of which adolescents take up smoking in the United States. Health Psychol. 1996;15(5):355-8.

34. Kaufman NJ, Castrucci BC, Mowery PD, Gerlach KK, Emont S, Orleans CT. Predictors of change on the smoking uptake continuum among adolescents. Arch Pediatr Adolesc Med. 2002;156(6):581-7.

35. Siqueira L, Diab M, Bodian C, Rolnitzky LJ Adolescents becoming smokers: the roles of stress and coping methods. Adolesc Health. 2000;27(6):399401. 
36. Acierno R, Kilpatrick DG, Resnick H, Saunders B, De Arellano M, Best C. Assault, PTSD, family substance use, and depression as risk factors for cigarette use in youth: findings from the National Survey of Adolescents. J Trauma Stress. 2000;13(3):381-96

37. Clinical Practice Guideline Treating Tobacco Use and Dependence 2008 Update Panel, Liaisons, and Staff. A clinical practice guideline for treating tobacco use and dependence: 2008 update. A U.S. Public Health Service report. Am J Prev Med. 2008;35(2):158-76.

38. Mucha L, Stephenson J, Morandi N, Dirani R. Meta-analysis of disease risk associated with smoking, by gender and intensity of smoking. Gend Med.2006;3(4):279-91.

39. Lancaster T, Stead L. Physician advice for smoking cessation. Cochrane Database Syst Rev.2004 Oct 18(4):CD000165.

40. Prochaska JD, Di Clemente CC, Norcross JC. In search how people change: applications to addictive behavior. Am Psychol.1992;47(9):1102-14 .

41. Miller WR, Rollnick S. O que motiva as pessoas à mudança? In: Entrevista Motivacional. Porto Alegre:Artmed; 2001. p.30-42.

42. Fagerström KO, Schneider NG. Measuring nicotine dependence: a review of the Fagerström Tolerance Questionnaire. J Behav Med.1989;12(2):15982.

43. Rosemberg J. Nicotina: droga universal. São Paulo:S.E.S./CVE;2003.

44. Souza ES, Crippa JA, Pasian SR, Martinez JA. Escala de razões para fumar modificada: tradução e adaptação cultural para o português para uso no Brasil e avaliação da confiabilidade teste-reteste. J Bras Pneumol. 2009;35(7):683-9.

45. Reichert J, Araújo AJ, Gonçalves CM, Godoy I, Chatkin JM, Sales MP, et al. Sociedade Brasileira de Pneumologia e Tisiologia. Smoking cessation guidelines - 2008. J Bras Pneumol.2008;34(10):845-80

46. Hughes J, Hatsukami D. Signs and symptoms of tobacco withdrawal. Arch Gen Psychiatr. 1986;43(3):289-94.

47. Gourlay SG, Stead LF, Benowitz N. Clonidine for smoking cessation. Cochrane Database SystRev.2004;(3):CD000058.

48. David SP, Lancaster T, Stead LF, Evins AE, Prochaska JJ. Opioid antagonists fo smoking cessation. Cochrane Database Syst Rev. 2013 Jun 6:CD003086.

49. Hughes JR, Stead LF, Lancaster T. Antidepressants for smoking cessation. Cochrane Database Syst Rev. 2007 Jan 24;(1):CD000031.

50. Hughes JR, Stead LF, Lancaster T. Anxiolytics for smoking cessation. Cochrane Database Syst Rev. 2000;(4):CD002849.

51. Jarvis MJ. Why people smoke. BMJ.2004;328(7434):277-9.

52. Issa JS, Perez GH, Diament J, Zavattieri AG, de Oliveira KU. Efetividade da bupropiona no tratamento de pacientes tabagistas com doença cardiovascular. Arq Bras Cardiol.2007;88(4):434-40.

53. Issa JS, Forti N, Giannini SD, Diament J. Intervenção sobre tabagismo realizada por cardiologista em rotina ambulatorial. Arq Bras Cardiol.1998;70(4):271-4.

54. Ussher MH, Taylor A, Faulkner G. Exercise interventions for smoking cessation. Cochrane Database Syst Rev. 2012 Jan 18;(1):CD002295.

55. Stead LF, Lancaster T. Behavioural interventions as adjuncts to pharmacotherapy for smoking cessation. Cochrane Database Syst Rev. 2012;12:CD009670.

56. Stead LF, Perera R, Bullen C, Mant D, Hartmann-Boyce J, Cahill K, et al. Nicotine replacement therapy for smoking cessation. Cochrane Database Syst Rev. 2012 Nov 14;11:CD000146.

57. Scharf D, Shiffman S. Are there gender differences in smoking cessation, with and without bupropion? Pooled- and meta-analyses of clinical trials of Bupropion SR. Addiction. 2004;99(11):1462-9.

58. Cahill K, Stead LF, Lancaster T. Nicotine receptor partial agonists for smoking cessation. Cochrane Database Syst Rev. 2012 Apr 18;4:CD006103.
59. Aubin HJ, Bobak A, Britton JR, Oncken C, Billing CB Jr, Gong J, et al Varenicline versus transdermal nicotine patch for smoking cessation: results from a randomised open-label trial. Thorax. 2008;63(8):717-24

60. Nides M, Glover ED, Reus VI, Christen AG, Make BJ, Billing CB Jr, et al. Varenicline versus bupropion $S R$ or placebo for smoking cessation: a pooled analysis. Am J Health Behav. 2008;32(6):664-75.

61. Koob GF, Volkow ND. Neurocircuitry of addiction Neuropsychopharmacology. 2010;35(1):217-38. Erratum in Neuropsychopharmacology. 2010;35(4):1051.

62. US Food and Drug Administration. Information for Healthcare Professionals: Varenicline (marketed as Chantix) and Buproprion (marketed as Zyban, Wellbutrin, and genics). [Cited in 2012 Jan 12]. Available from: http://www.fda.gov/Drugs/DrugSafety/ PostmarketDrugSafetyInformationforPatientsandProviders/ucm124818. htm

63. Singh S, Loke YK, Spangler JG, Furberg CD. Risk of serious adverse cardiovascular events associated with varenicline: a systematic review and meta-analysis CMAJ.2011;183(12):1359-66

64. Prochaska JJ, Hilton JF. Risk of cardiovascular serious adverse events associated with varenicline use for tobacco cessation: systematic review and meta-analysis. BMJ. 2012;344:e2856.

65. Rigotti NA, Pipe AL, Benowitz NL, Arteaga C, Garza D, Tonstad S Efficacy and safety of varenicline for smoking cessation in patients with cardiovascular disease: a randomized trial. Circulation. 2010;121(2):221

66. Ebbert JO, Croghan IT, Sood A, Schroeder DR, Hays JT, Hurt RD. Varenicline and bupropion sustained-release combination therapy for smoking cessation. Nicotine Tob Res. 2009;11(3):234-9.

67. Devaraj S, Tang R, Adams-Huet B, Harris A, Seenivasan T, de Lemos JA, et al. Effect of high dose alpha-tocopherol supplementation on biomarkers of oxidative stress and inflammation and carotid atherosclerosis in patients with coronary artery disease. Am J Clin Nutr. 2007;86(5):1392-8.

68. Voutilainen ST, Nurmi J, Mursu T, Rissanen H. Carotenoids and cardiovascular health. Am J Clin Nutr. 2006;83(6):1265-71.

69. Vivekananthan DP, Penn MS, Sapp SK, Hsu A, Topol EJ. Use of antioxidant vitamins for the prevention of cardiovascular disease: meta-analysis of randomised trials. Lancet. 2003;361(9374):2017-23.

70. Ye Y, Li J, Yuan Z. Effect of antioxidant vitamin supplementation on cardiovascular outcomes: a meta-analysis of randomized controlled trials. PLoS One. 2013;8(2):e56803.

71. Devaraj S, Leonard S, Traber MG, Jialal I. Gamma-tocopherol supplementation alone and in combination with alpha-tocopherol alters biomarkers of oxidative stress and inflammation in subjects with metabolic syndrome. Free Radic Biol Med. 2008;44(6):1203-8.

72. Bjelakovic G, Nikolova D, Gluud LL, Simonetti RG, Gluud C. Mortality in randomized trials of antioxidant supplements for primary and secondary prevention: systematic review and meta-analysis. JAMA. 2007;297(8):84257.

73. Blomhoff R. Dietary antioxidants and cardiovascular disease. Curr Opin Lipidol. 2005;16(1):47-54.

74. Bjelakovic G, Nikolova D, Gluud LL, Simonetti RG, Gluud C. Antioxidant supplements for prevention of mortality in healthy participants and patients with various diseases. Cochrane Database Syst Rev. 2012 Mar 14;3:CD007176.

75. Michos ED, Blumenthal RS. Vitamin D supplementation and cardiovascula disease risk. Circulation.2007;115(7):827-8.

76. Zittermann A, Gummert JF, Börgermann J. The role of vitamin D in dyslipidemia and cardiovascular disease. Curr Pharm Des. 2011;17(9):93342 . 
77. Wang TJ, Pencina MJ, Booth SL, Jacques PF, Ingelsson E, Lanier K, et al. Vitamin D deficiency and risk of cardiovascular disease. Circulation. 2008;117(4):503-11.

78. Zittermann A, Börgermann J, Gummert JF, Pilz S. Future directions in vitamin D and cardiovascular research. Nutr Metab Cardiovasc Dis. 2012;22(7):541-6.

79. Bazzano LA, Reynolds K, Holder KN, He J. Effect of folic acid supplementation on risk of cardiovascular diseases: a meta-analysis of randomized controlled trials. JAMA. 2006;296(22):2720-6.

80. Homocysteine Studies Collaboration. Homocysteine and risk of ischemic heart disease and stroke: a meta-analysis. JAMA. 2002;288(16):2015-22.

81. Balk EM, Lichtenstein AH, Chung M, Kupelnick B, Chew P, Lau J. Effects of omega- 3 fatty acids on serum markers of cardiovascular disease risk: a systematic review. Atherosclerosis. 2006;189(1):19-30.

82. Dietary supplementation with $\mathrm{n}-3$ polyunsaturated fatty acids and vitamin E after myocardial infarction: results of the GISSI-Prevenzione trial. Gruppo Italiano per lo Studio della Sopravvivenza nell'Infarto miocardico. Lancet.1999;354(9177):447-55. Erratum in: Lancet.2007;369(9556):106. Lancet.2001;357(9256):642.

83. Yokoyama M, Origasa H, Matsuzaki M, Matsuzawa Y, Saito Y, Ishikawa $Y$,et al. Effects of eicosapentaenoic acid on major coronary events in hypercholesterolaemic patients (JELIS): a randomised open-label, blinded endpoint analysis. Lancet. 2007;369(9567):1090-8.

84. Kromhout D, Giltay EJ, Geleijnse JM; Alpha Omega Trial Group. n-3 fatty acids and cardiovascular events after myocardial infarction. N Engl J Med. 2010;363(21):2015-26.

85. Roncaglioni MC, Tombesi M, Avanzini F, Barlera S, Caimi V, Longoni P, et al. Risk and Prevention Study Collaborative Group.n-3 fatty acids in patients with multiple cardiovascular risk factors. N Engl J Med. 2013;368(19):18008. Erratum in: N Engl J Med. 2013;368(22):2146.

86. Santos RD, Gagliardi AC, Xavier HT, Magnoni CD, Cassani R, Lottenberg AM. I Diretriz sobre o consumo de gorduras e saúde cardiovascular. Arq Bras Cardiol.2013;100(1 Suppl 3):1-40.

87. Geleijnse JM, Giltay EJ, Grobbee DE, Donders AR, Kok FJ. Blood pressure response to fish oil supplementation: metaregression analysis of randomized trials. J Hypertens.2002;20(8):1493-9.

88. Wendland E, Farmer A, Glasziou P, Neil A.Effect of alpha linolenic acid on cardiovascular risk markers: a systematic review.Heart. 2006;92(2):166-9.

89. Prasad K. Flaxseed and cardiovascular health.J Cardiovasc Pharmacol. 2009;54(5):369-77.

90. Pan A, Chen M, Chowdhury R, Wu JH, Sun Q, Campos H, et al. D-Linolenic acid and risk of cardiovascular disease: a systematic review and metaanalysis. Am J Clin Nutr. 2012;96(6):1262-7.

91. Batista Filho M, Souza Al, Miglioli TC, Santos MC. Anemia e obesidade: um paradoxo da transição nutricional brasileira.Cad Saúde Pública. 2008;24(supl. 2):247-57.

92. Peña $M$, Bacallao J. La obesidad en la pobreza: un nuevo reto para la salud pública. Washington (DC): OPAS: 2000.

93. Instituto Brasileiro de Geografia e Estatística(IBGE). Pesquisa de orçamentos familiares 2008-2009: análise da disponibilidade domiciliar de alimentos e do estado nutricional no Brasil. Rio de Janeiro; 2010.

94. World Health Organization. (WHO). Preventing chronic diseasesa vital investment.Geneva; 2005.

95. Caballero B. The global epidemic of obesity: an overview. Epidemiol Rev. 2007;29:1-5.

96. World Health Organization. (WHO). Global strategy on diet, physical activity and health. [Cited in 2009 Jan 1]. Available from: http://www.who. int/gb/ebwha/pdf_files/WHA57/A57_R17-en.pdf

97. Population-based prevention strategies for childhood obesity: report of a WHO Forum and Technical Meeting. Geneva: WHO Press; 2009
98. Kinnunen TI,Pasanen M,Aittasalo M, Fogelholm M, Weiderpass E, Luoto R. Reducing postpartum weight retention - a pilot trial in primary health care. NutrJ.2007,6:21.

99. Sichieri R, Souza RA. Estratégias para prevenção da obesidade em crianças e adolescentes. Cad Saúde Pública.2008;24(sup 2):S209-234.

100. Ministério da Saúde. Secretaria de Política de Saúde. Organização Pan Americana da Saúde. Guia alimentar para crianças menores de dois anos / Secretaria de Políticas de Saúde, Organização Pan Americana da Saúde. Brasília; 2002.(Série A. Normas e Manuais Técnicos; n. 107).

101. Arenz S, Rückerl R, Koletzko B, von Kries R. Breast-feeding and childhood obesity-a systematic review. Int J Obes Relat Metab Disord. 2004;28(10):1247-56.

102. Owen CG, Martin RM, Whincup PH, Smith GD, Cook DG. Effect of infant feeding on the risk of obesity across the life course: a quantitative review of published evidence. Pediatrics. 2005;115(5):1367-77.

103. Levy-Costa RB, Sichieri R, Pontes NS, Monteiro CA. Disponibilidade domiciliar de Alimentos no Brasil: distribuição e evolução (1974-2003). Rev SaudePublica.2005;39(4):530-40.

104. Mendonça CP, Dos Anjos LA. Aspectos das práticas alimentares e da atividade física como determinantes do crescimento do sobrepeso/ obesidade no Brasil. Cad Saúde Pública.2004;20(3):698-709.

105. Cuppari L. Guias de Medicina ambulatorial e hospitalar: clínica no adulto. São Paulo: Editora Manole;2005

106. National Institute for Health and Clinical Excellence. Obesity: the prevention, identification, assessment and management of overweight and obesity in adults and children. London; 2006. [Cited in 2013 Jun 10]. Available from: http://www.nice.org.uk/guidance/CG43/guidance/ section $5 \mathrm{~b} /$ word/English

107. Caterson ID, Finer N, Coutinho W, Van Gaal LF, Maggioni AP, Torp-Pedersen C, et al; SCOUT Investigators.Maintained intentional weight loss reduces cardiovascular outcomes: results from the Sibutramine Cardiovascular OUTcomes (SCOUT) trial. Diabetes Obes Metab. 2012;14(6):523-30.

108. Hall JC, Watts JM, O'Brien PE, Dunstan RE, Walsh JF, Slavotinek AH, et al. Gastric surgery for morbid obesity. The Adelaide Study. Ann Surg. 1990;211(4):419-27.

109. Brolin RE, Kenler HA, Gorman JH, Cody RP. Long-limb gastric bypass in the superobese. a prospective randomized study. Ann Surg. 1992;215(4):38795.

110. MacMahon S, Peto R, Cutler J, Collins R, Sorlie P, Neaton J, et al. Blood pressure, stroke, and coronary heart disease. Part 1, Prolonged differences in blood pressure: prospective observational studies corrected for the regression dilution bias. Lancet. 1990;335(8692):765-74.

111. Wattigney WA, Mensah GA, Croft JB. Increasing trends in hospitalization for atrial fibrillation in the United States, 1985 through 1999: implications for primary prevention. Circulation. 2003;108(6):711-6.

112. Skoog I, Lernfelt B, Landahl S, Palmertz B, Andreasson LA, Nilsson L, et al. 15-year longitudinal study of blood pressure and dementia. Lancet. 1996;347(9009):1141-5.

113. Lewington S, Clarke R, Qizilbash N, Peto R, Collins R; Prospective Studies Collaboration. Age-specific relevance of usual blood pressure to vascular mortality: a meta-analysis of individual data for one million adults in 61 prospective studies. Lancet.2002;360(9349):1903-13. Erratum in Lancet.2003:361(9362):1060.

114. Williams B. The year in hypertension. J Am Coll Cardiol.2009;55(1):66-73.

115. Cesarino CB, Cipullo JP, Martin JF, Ciorlia LA, Godoy MR, Cordeiro JA, et al. Prevalência e fatores sociodemográficos em hipertensos de São José do Rio Preto. Arq Bras Cardiol. 2008;91(1):29-35. 
116. Rosário TM, Scala LC, França GV, Pereira MR, Jardim PC. Prevalência, controle e tratamento da hipertensão arterial sistêmica em Nobres, MT. Arq Bras Cardiol. 2009;93(6):622-8, 672-8

117. Pereira M, Lunet N, Azevedo A, Barros H. Differences in prevalence, awareness, treatment and control of hypertension between developing and developed countries. J Hypertens. 2009;27(5):963-75.

118. Jardim PC, Gondim Mdo R, Monego ET, Moreira HH, Vitorino PV, Souza WK, et al. Hipertensão arterial e alguns fatores de risco em uma capital brasileira. Arq Bras Cardiol. 2007;88(4):452-7.

119. Sociedade Brasileira de Cardiologia / Sociedade Brasileira de Hipertensão/ Sociedade Brasileira de Nefrologia. VI Diretrizes brasileiras de hipertensão. Arq Bras Cardiol. 2010;95(1 supl.1):1-51.

120. O'Brien E, Asmar R, Beilin L, Imai Y, Mancia G, Mengden T, et al. European Society of Hypertension Working Group on Blood Pressure Monitoring. Practice guidelines of the European Society of Hypertension for clinic, ambulatory and self blood pressure measurement.J Hypertens. 2005;23(4):697-701.

121. Koehler NR, Figueiredo CE, Ribeiro AC. Serial blood pressure measurements. Braz J Med Biol Res. 2002;35(5):555-9.

122. Kohler NR, Poli de Figueiredo CE, Mendes-Ribeiro AC. Time interval between pairs of arterial blood pressure measurements - Does it matter? Am J Hypertens. 2004;17(2):194-6.

123. World Hypertension League. Self-measurement of blood pressure. BullWorld Health Organ (WHO). 1988;66(2):155-9.

124. Sociedade Brasileira de Cardiologia / Sociedade Brsileira de Hipertensão / Sociedade Brasileira de Nefrologia. V Diretrizes Brasileiras de Monitorização Ambulatorial da Pressão Arterial (MAPA V) e III Diretrizes Brasileiras de Monitorização Residencial da Pressão Arterial (MRPA III). Arq Bras Cardiol. 2011;97(3 supl 3):1-24

125. Cockcroft DW, Gault MH. Prediction of creatinine clearance from serum creatinine. Nephron. 1976;16(1):31-41.

126. Levey AS, Coresh J, Greene T, Stevens LA, Zhang YL, Hendriksen S, et al. Using standardized serum creatinine values in the modification of diet in renal disease study equation for estimating glomerular filtration rate. Ann Intern Med. 2006;145(4):247-54. Erratum in: Ann Intern Med. 2008;149(7):519.

127. Law MR, Wald NJ, Morris JK, Jordan RE.Value of low dose combination treatment with blood pressure lowering drugs: analysis of 354 randomised trials. BMJ.2003;326(7404):1427.

128. World Health Organization. Obesity: preventing and managing the global epidemic. Genebra, jun 1997.

129. Willett WC, Dietz WH, Colditz GA. Guidelines for healthy weight. N Engl J Med. 1999;341(6):427-34.

130. Sacks FM, Svetkey LP, Vollmer WM, Appel LJ, Bray GA, Harsha D, et al; DASH-Sodium Collaborative Research Group. Effects on blood pressure of reduced dietary sodium and the Dietary Approaches to Stop Hypertension (DASH) diet. DASH-Sodium Collaborative. Research Group. N Engl J Med. 2001;344(1):3-10

131. Babyak MA, Hinderliter A, Watkins LL, Craighead L, Lin PH, Caccia C, et al. Effects of the DASH diet alone and in combination with exercise and weight loss on blood pressure and cardiovascular biomarkers in men and women with high blood pressure: the ENCORE study. Arch Intern Med. 2010;25;170(2):126-35.

132. Núñez-Córdoba JM, Valencia-Serrano F, Toledo E, Alonso A, MartínezGonzález MA. The Mediterranean diet and incidence of hypertension: the Seguimiento Universidad de Navarra (SUN) Study. Am J Epidemiol.2009;169(3):339-46.

133. Alonso A, de la Fuente C, Martín-Arnau AM, de Irala J, Martínez JA, Martínez- González MA. Fruit and vegetable consumption is inversely associated with blood pressure in a Mediterranean population with a high vegetable-fat intake: the Seguimiento Universidad de Navarra (SUN) Study. Br J Nutr. 2004;92(2):311-9.
134. Craig WJ, Mangels AR; American Dietetic Association. Position of the American Dietetic Association: vegetarian diets. J Am Diet Assoc. 2009; 109(7):1266-82.

135. Chiplonkar SA, AgteVV, Tarwadi KV, Paknikar KM, Diwate UP. Micronutrient deficiencies as predisposing factors for hypertension in lacto-vegetarian Indian adults. J Am Coll Nutr. 2004;23(3):239-47.

136. Dumler F. Dietary sodium intake and arterial blood pressure. J Ren Nutr. $2009 ; 19(1): 57-60$

137. Pimenta E, Gaddam KK, Oparil S, Aban I, Husain S, Dell'Italia LI, et al. Effects of dietary sodium reduction on blood pressure in subjects with resistant hypertension: results from a randomized trial. Hypertension. 2009;54(3):475-81.

138. O'Keefe JH, Bybee KA, Lavie CJ. Alcohol and cardiovascular health:the razor-sharp double-edged sword. J Am Coll Cardiol. 2007;50(11):1009-14

139. Xin X, He J, Frontini MG, Ogden LG, Motsamai OI, Whelton PK. Effects of alcohol reduction on blood pressure:a meta-analysis of randomized controlled trials. Hypertension. 2001;38(5):1112-7.

140. Fagard RH, Cornelissen VA. Effect of exercise on blood pressure control in hypertensive patients. Eur J Cardiovasc Prev Rehabil. 2007;14(1):12-7.

141. Cornelissen VA, Fagard RH. Effect of resistance training on resting blood pressure: a meta-analysis of randomized controlled trials. J Hypertens. $2005 ; 23(2): 251-9$

142. Stevens VJ, Obarzanek E, Cook NR, Lee IM, Appel LJ, Smith West D, et al; Trials for the Hypertension Prevention Research Group. Long-term weight loss and changes in blood pressure: results of the trials of hypertension prevention, phase II. Ann Intern Med. 2001;134(1):1-11.

143. Sociedade Brasileira de Cardiologia. Sociedade Brasileira de Hipertensão / Sociedade Brasileira de Nefrologia. I Diretriz brasileira de diagnóstico e tratamento da síndrome metabólica. Arq Bras Cardiol. 2005:84(supl 1):1-2.

144. Dimsdale JE. Psychological stress and cardiovascular disease. J Am Coll Cardiol. 2008:51(13):1237-46.

145. Carter BL, Rogers M, DalyJ, Zheng S, James PA. The potency of team-based care interventions for hypertension: a meta-analysis. Arch Intern Med. 2009;169(19):1748-55.

146. Parati G, Carretta R. Device-guided slow breathing as a nonpharmacological approach to antihypertensive treatment: efficacy, problems and perspectives. J Hypertens. 2007; 25(1):57-61.

147. Haentjens P, Van Meerhaeghe A, Moscariello A, De Weerdt S, Poppe K, Dupont $A$, et al. The impact of continuous positive airway pressure on blood pressure in patients with obstructive sleep apnea syndrome:evidence from a meta-analysis of placebo-controlled randomized trials.Arch Intern Med. 2007; 167(8):757-65.

148. Sjostrom L, Lindroos AK, Peltonen M, Torgerson J, Bouchard C, Carlsson $B$, et al. Lifestyle, diabetes, and cardiovascular risk factors 10 years after bariatric surgery. N Engl J Med. 2004;351(26):2683-93

149. Williams SA, Michelson EL, Cain VA, Yang M, Nesbitt SD, Egan BM et al; TROPHY Study Investigators. An evaluation of the effects of an angiotensin receptor blocker on health-related quality of life in patients with high-normal blood pressure (prehypertension) in the Trial of Preventing Hypertension (TROPHY). J Clin Hypertens(Greenw ch).2008;10(6):436-42.

150. Lüders S, Schrader J, Berger J, Unger T, Zidek W, Böhm M,et al. PHARAO Study Group. The PHARAO study: prevention of hypertension with the angiotensin-converting enzyme inhibitor ramipril in patients with high-normal blood pressure: a prospective, randomized, controlled prevention trial of the German Hypertension League. J Hypertens.2008; 26(7):1487-96.

151. Psaty BM, Smith NL, Siscovick DS, Koepsell TD, Weiss NS, Heckbert SR, et al. Health outcomes associated with antihypertensive therapies used as firstline agents:a systematic review and meta-analysis. JAMA.1997;277(9):73945 . 
152. Gradman AH, Basile JN, Carter BL, Bakris GL; American Society of Hypertension Writing Group. Combination therapy in hypertension. J Clin Hypertens. 2011;13(3):146-54

153. ALLHAT Officers and Coordinators for the ALLHAT Collaborative Research Group. Major outcome in high-risk hypertensive patients to angiotensinconverting enzyme inhibitor or calcium channel blocker vs. diuretic:the Antihypertensive and Lipid-Lowering Treatment to PreventHeart Attack Trial (ALLHAT). JAMA. 2002;228(23):2981-97. Erratum in JAMA. 2004;291(18):2196, JAMA. 2003;289(2):178.

154. Pahor M, Psaty BM, Alderman MH, Applegate WB, Williamson JD, Cavazzini $\mathrm{C}$, et al. Health outcomes associated with calcium antagonists compared with other first-line antihypertensive therapies: a meta-analyses of randomized controlled trials. Lancet. 2000;356(9246):1949-54.

155. Pedersen ME, Cockcroft JR. The vasodilatory beta-blockers. Curr Hypertens Rep. 2007;9(4):269-77.

156. Giatras I, Lau J, Levey AS. Effect of angiotensin-converting enzyme inhibitors on the progression of non-diabetic renal disease: a meta-analysis of randomized trials. Angiotensin-Converting-Enzyme Inhibition and Progressive Renal Disease Study Group. Ann Intern Med. 1997;127(5):33745.

157. Cheung BM, Cheung GT, Lauder IJ, Lau CP, Kumana CR. Meta-analysis of large outcome trials of angiotensin receptor blockers in hypertension. J Hum Hypertens. 2006;20(1):37-43.

158. Major cardiovascular events in hypertensive patients randomized to doxazosin vs. chlorthalidone:theantihypertensive and lipid-lowering treatment to prevent heart attack trial(ALLHAT). The ALLHAT Officers and Coordinators for the ALLHAT Collaborative Research Group. JAMA. 2000;283(15):1967-75

159. Mancia G, Fagard R, Narkiewicz K, Redon J, Zanchetti A, Böhm M, et al. 2013 ESH/ESC guidelines for the Management of Arterial Hypertension:the Task Force for the management of arterial hypertension of the European Society of Hypertension (ESH) and of the European Society of Cardiology (ESC). Eur Heart J.2013;34(28):2159-219.

160. Baigent C, Blackwell L, Emberson J, Holland LE, Reith C, Bhala N, et al; Cholesterol Treatment Trialists (CTT) Collaboration. Efficacy and safety of more intensive lowering of LDL cholesterol: a meta-analysis of data from 170,000 participants in 26 randomised trials. Lancet. 2010;376(9753):1670-81.

161. Lewington S, Whitlock G, Clarke R, Sherliker P, Emberson J, Halsey J, et al; Prospective Studies Collaboration. Blood cholesterol and vascular mortality by age, sex, and blood pressure: a meta-analysis of individual data from 61 prospective studies with 55,000 vascular deaths. Lancet. 2007;370(9602):1829-39.

162. Weng TC, Yang YH, Lin SJ, Tai SH. A systematic review and meta-analysis on the therapeutic equivalence of statins. J Clin Pharm Ther. 2010;35(2):13951 .

163. Mukhtar RY, Reid J, Reckless JP. Pitavastatin. Int J Clin Pract. 2005;59(2):23952.

164. Naci H, Brugts J, Ades T. Comparative tolerability and harms of individual statins: a study-level network meta-analysis of 246955 participants from 135 randomized, controlled trials. Circ Cardiovasc Qual Outcomes. 2013;6(4):390-9.

165. Thompson PD, Clarkson PM, Rosenson RS; National Lipid Association Statin Safety Task Force Muscle Safety Expert Panel.An assessment of statin safety by muscle experts. Am J Cardiol. 2006;97(8A):69C-76C.

166. Perk J, De Backer G, Gohlke H, Graham I, Reiner Z, Verschuren M, et al; European Association for Cardiovascular Prevention \& Rehabilitation (EACPR); ESC Committee for Practice Guidelines (CPG). European Guidelines on cardiovascular disease prevention in clinical practice (version 2012). The FifthjointTask Force of the EuropeanSociety of Cardiology and Other Societies on Cardiovascular Disease Prevention in Clinical Practice (constituted by representatives of nine societies and by invited experts). European Association for Cardiovascular Prevention \& Rehabilitation (EACPR); ESC Committee for Practice Guidelines (CPG). Eur Heart J.2012;33(13):1635-701. Erratum in Eur Heart J. 2012;33(17):2126.

167. Kashani A, Phillips CO, Foody JM, Wang Y, Mangalmurti S, Ko DT, et al. Risks associated with statin therapy: a systematic overview of randomized clinical trials. Circulation. 2006;114(25):2788-97.

168. Baigent C, Landray MJ, Reith C, Emberson J, Wheeler DC, Tomson C, et al. The effects of lowering LDL cholesterol with simvastatin plus ezetimibe in patients with chronic kidney disease (Study of Heart and Renal Protection): a randomised placebo-controlled trial. Lancet. 2011;377(9784):2181-92.

169. Rossebo AB, Pedersen TR, Boman K, Brudi P, Chambers JB, Egstrup K, et al. Intensive lipid lowering with simvastatin and ezetimibe in aortic stenosis. N Engl JMed. 2008;359(13):1343-56.

170. The Lipid Research Clinics Coronary Primary Prevention Trial results. I. Reduction in incidence of coronary heart disease. JAMA. 1984;251(3):35164.

171. Haynes R, Jiang L, Hopewell JC. HPS2-THRIVE randomized placebocontrolled trial in 25673 high-risk patients of ER niacin/laropiprant: trial design, pre-specified muscle and liver outcomes, and reasons for stopping study treatment. Eur Heart J.2013;34(17):1279-91.

172. Boden WE, Probstfield JL, Anderson T, Chaitman BR, Desvignes-Nickens P, Koprowicz K, et al; AIM-HIGH Investigators. Niacin in patients with low HDL cholesterol levels receiving intensive statin therapy. N Engl J Med.2011;365(24):2255-67.

173. Clofibrate and niacin in coronary heart disease. JAMA.1975;231(4):36081

174. Ginsberg HN, Elam MB, Lovato LC, Crouse JR 3rd, Leiter LA, Linz P, et al; ACCORD Study Group. Effects of combination lipid therapy in type 2 diabetes mellitus. N Engl J Med.2010;362(17):1563-74.Erratum in N Engl Med. 2010;362(18):1748

175. Kotwal S, Jun M, Sullivan D, Perkovic V, Neal B. Omega 3 Fatty acids and cardiovascular outcomes: systematic review and meta-analysis. CircCardiovasc Qual Outcomes. 2012;5(6):808-18.

176. Wild S, Roglic G, Green A, Sicree R, King H. Global prevalence of diabetes: estimates for year 2000 and projections for 2030. Diabetes Care. $2004 ; 27(5): 1047-53$

177. Bosi PL, Carvalho AM, Contrera D, Casale G, Pereira MA, Gronner M et al. Prevalência de diabete melito e tolerância à glucose diminuída na população urbana de 30 a 79 anos da cidade de São Carlos, São Paulo. Arq Bras EndocrinolMetabol.2009;53(6):726-32.

178. American Diabetes Association.Economic costs of diabetesin the U.S. in 2012.Diabetes Care. 2013;36(4):1033-46

179. Donahue RP, Orchard TJ. Diabetes mellitus and macrovascular complications: an epidemiological perspective. Diabetes Care. 1992;15(9):1141-55

180. Franz MJ, Bantle JP, Beebe CA, BrunzellJD,ChiassonJL,GargA, et al. American Diabetes Association: Nutrition principles and recommendations in diabetes. DiabetesCare.2004;27(Suppl 1)S36-46.

181. Sigal RJ, Kenny GP, Wasserman DH, Castaneda-Sceppa C: Physical activity/ exercise and type 2 diabetes. Diabetes Care.2004;27(10):2518-39.

182. Must A, Spadano J, Coakley EH, Field AE, Colditz G, Dietz WH. The disease burden associated with overweight and obesity. JAMA.1999;282(16):1523-

183. Perreault L, Kahn SE, Christophi CA, Knowler WC, Hamman RF. Regression from pre-diabetes to normal glucose regulation in the diabetes prevention program. Diabets Care.2009;32(9):1583-8.

184. Clinical Guidelines on the Identification, Evaluation, and Treatment of Overweight and Obesity in Adults--The Evidence Report. National Institutes 
of Health. Obes Res. 1998;6 Suppl 2:51S-209S. Erratum in Obes Res 1998 Nov;6(6):464.

185. Buse JB, Ginsberg HN, Bakris Gl, Clark NG, Costa F, Eckel R, et al. Primary prevention of cardiovascular disease in people with diabetes mellitus. Diabetes Care.2007;30(1):162-72.

186. Alberti KG, Eckel RH, Grundy SM, Zimmet PZ, Cleeman JI, Donato KA, et al. Harmonizing the Metabolic Syndrome. A Joint Interim Statement of the International Diabetes Federation Task Force on Epidemiology and Prevention; National Heart, Lung, and Blood Institute; American Heart Association; World Heart Federation; International Atherosclerosis Society; and International Association for the Study of Obesity. Circulation. 2009; 120(16):640-5.

187. Oda E. Metabolic syndrome:its history, mechanisms, and limitations. Acta Diabetol. 2012;49(2):89-95

188. Grundy SM. Metabolic syndrome pandemic. Arterioscler Thromb Vasc Biol. 2008:28(4):629-36.

189. Ford ES, Giles WH, Dietz WH. Prevalence of the metabolic syndrome among us adults: findings from the Third National Health and Nutrition Examination Survey. JAMA. 2002;287(3):356-9

190. Deshmukh-Taskar PR, O'Neil CE, Nicklas TA, Yang SJ, Liu Y, Gustat J, et al. Dietary patterns associated with metabolic syndrome, sociodemographic and lifestyle factors in young adults: the Bogalusa Heart Study. Public Health Nutr. 2009;12(12):2493-503

191. Wang J, Ruotsalainer S, Moilanen L, Lepisto P, Laakso M, Kuusisto J. The metabolic syndrome predicts cardiovascular mortality: a 13-years follow-up in elderly non-diabetic Finns. EurHeart J.2007; 28(7):857-64

192. Nilsson PM, Engstrom G, Hedblad B. The metabolic syndrome and incidence of cardiovascular disease in non-diabetic subjects-a populationbased study comparing three different definitions. Diabet Med. 2006;24(5):464-72.

193. Nanri A, Tomita K, Matsushita Y, Ichikawa F, Yamamoto M, Nagafuchi $Y$, et al. Effect of six months lifestyle intervention in Japanese men with metabolic syndrome: randomizedcontrolled trial. J Occup Health. 2012;54(3):215-22.

194. Sakurai T, limoro S, Araki A, Umegaki H, Ohashi Y, Yokono K,et al. Ageassociated increase in abdominal obesity and insulin resistance and usefulnessof AHA/NHLBI Definition of Metabolic Syndrome for predicting cardiovascular disease in Japanese elderly with type2 Diabetes mellitus. Gerontology.2010;56(2):141-9.

195. Belfki H, Ali SB, Aounnallah-Skhiri H, Traissac P, Bougatef S, Maire B, et al. Prevalence and determinants of the metabolic syndrome among Tunisian adults: results of the Transition and Health Impact in North Africa (TAHINA) project. Public Health Nutr.2013;16(4):582-90.

196. Moraes AC, Fulaz CS, Netto-Oliveira ER, Reichert FF. Prevalência de síndrome metabólica em adolescentes: uma revisão sistemática. Cad Saude Publica.2009;25(6):1195-202

197. Brandão AP, Brandão AA, de MagalhãesME, Pozan R. Management of metabolic syndrome in young population. Am J Ther.2008;15(4):356-61.

198. Mottillo S, Filion KB, Genest J, Joseph L, Pilote L, Poirier P, et al. The metabolic syndrome and cardiovascular risk a systematic review and metaanalysis. J Am Coll Cardiol. 2010;56(14):1113-32.

199. Ford ES. Risks for all-cause mortality, cardiovascular disease, and diabetes associated with the metabolic syndrome: a summary of the evidence. Diabetes Care. 2005;28(7):1769-78

200. Galassi A, Reynolds K, He J. Metabolic syndrome and risk of cardiovascular disease: a meta-analysis. Am J Med. 2006;119(10):812-9.

201. Gami AS, Witt BJ, Howard DE, Erwin PJ, Gami LA, Somers VK, et al. Metabolic syndrome and risk of incident cardiovascular events and death: a systematic review and meta-analysis of longitudinal studies. J Am Coll Cardiol. 2007:49(4):403-14
202. Wilson PW, D'Agostino RB, Parise H, Sullivan L, Meigs JB. Metabolic syndrome as a precursor of cardiovascular disease and type 2 diabetes mellitus. Circulation. 2005;112(20):3066-72.

203. Grundy SM, Hansen B, Smith SC Jr, Cleeman JI, Kahn RA;American Heart Association; National Heart, Lung, and Blood Institute; American Diabetes Association.Clinical management of metabolic syndrome: report of the American Heart Association/National Heart, Lung, and Blood Institute/ American Diabetes Association conference on scientific issues related to management. Circulation. 2004;109(4):551-6.

204. Klein BE, Klein R, Lee KE. Components of the metabolic syndrome and risk of cardiovascular disease and diabetes in Beaver Dam. Diabetes Care. 2002;25(10):1790-4

205. D'Onise K, Lynch JW, McDermott RA. Does an early childhood intervention affect cardiometabolic risk in adulthood? Evidence from a longitudinal study of preschool attendance in South Australia. Public Health 2012;126(8):682-9.

206. Alkerwi A, Donneau AF, Sauvageot N, Lair ML, Albert A, Guillaume M Dietary, behavioural and socio-economic determinants of the metabolic syndrome among adults in Luxembourg: findings from the ORISCAV-LUX study. Public Health Nutr. 2012 May; 15(5):849-59.

207. Jekal Y, Kim Y, Yun JE, Kim ES, Naruse M, Park JH, et al. The association of adolescent fatness and fitness with risk factors for adult metabolic syndrome: a 22-year follow-up study.J Phys Act Health. 2013 May 23. [Epub ahead of print].

208. Edwardson CL, Gorely T, Davies MJ, Gray LJ, Khunti K, Wilmot EG, et al Association of sedentary behaviour with metabolic syndrome: a metaanalysis. PLoS One. 2012;7(4):e34916.

209. Kim J. Dairy food consumption is inversely associated with the risk of the metabolic syndrome in Korean adults. J Hum Nutr Diet. 2013;26 Suppl $1: 171-9$

210. Miller A, Adeli K. Dietary fructose and the metabolic syndrome. Curr Opin Gastroenterol.2008;24(2):204-9.

211. Duffey KJ, Steffen LM, Van Horn L, Jacobs DR Jr, Popkin BM. Dietary patterns matter: diet beverages and cardiometabolic risks in the longitudina Coronary Artery Risk Development in Young Adults (CARDIA) Study. Am J Clin Nutr.2012;95(4):909-15.

212. Hong S, Song $\mathrm{Y}$, Lee $\mathrm{KH}$, Lee $\mathrm{HS}$, Lee $\mathrm{M}$, Jee $\mathrm{SH}$, et al. A fruit and dairy dietary pattern is associated with a reduced risk of metabolic syndrome. Metabolism.2012;61(6):883-90.

213. Ancheta IB, Battie CA, Tuason T, Ancheta CV. A comparison of metabolic syndrome (MetS) risk factors in Filipino women and Filipino American women: a pilot study. Ethn Dis. 2012;22(4):404-9.

214. Hartley TA, Knox SS, Fekedulegn D, Barbosa-Leiker C, Violanti JM, Andrew $\mathrm{ME}$, et al. Association between depressive symptoms and metabolic syndrome in police officers: results from two cross-sectional studies. J Environ Public Health. 2012;2012:861219.

215. Subashini R, Deepa M, Padmavati R, Thara R, Mohan V. Prevalence of diabetes, obesity, and metabolic syndrome in subjects with and without schizophrenia (CURES-104). J Postgrad Med.2011;57(4):272-7.

216. Kosaka K, Noda M, Kuzuya T. Prevention of type 2 diabetes by lifestyle intervention: a Japanese trial in IGT males. Diabetes Res Clin Pract.2005;67(2):152-62.

217. Pan XR, Li GW, Hu YH, Wang JX, Yang WY, An ZX, et al. Effects of diet and exercise in preventing NIDDM in people with impaired glucose tolerance. The Da Qing IGT andDiabetes Study. Diabetes Care.1997;20(4):537-44

218. Elliott SS, Keim NL, Stern JS, Teff K, Havel PJ.Fructose, weight gain, and the insulin resistance syndrome. Am J Clin Nutr.2002;76(5):911-22.

219. Orchard TJ, Temprosa M, Goldberg R, Haffner S, Ratner R, Marcovina $S$, et al; Diabetes Prevention Program Research Group.The effect of metformin and intensive lifestyle intervention on the metabolic syndrome: the Diabetes Prevention Program randomized trial. Ann Intern Med.2005;142(8):611-9. 
220. Eriksson KF, Lindgarde F.Prevention of type 2 (non-insulin-dependent) diabetes mellitus by diet and physical exercise. The 6-year Malmo feasibility study. Diabetologia.1991;34(12):891-8.

221. Knowler WC, Barrett-Connor E, Fowler SE, Hamman RF, Lachin JM, Walker EA, et al; Diabetes Prevention Program Research Group. Reduction in the incidence of type 2 diabetes with lifestyle intervention or metformin. N Engl J Med.2002;346(6):393-403.

222. Gross LS, Li L, Ford ES, Liu S.Increased consumption of refined carbohydrates and the epidemic of type 2 diabetes in the United States: an ecologic assessment. Am J Clin Nutr.2004;79(5):774-9.

223. Knowler WC, Hamman RF, Edelstein SL, Barrett- Connor E, Ehrmann DA Walker EA, etal; Diabetes Prevention Program Research Group.Prevention of type 2 diabetes with troglitazone in the Diabetes Prevention Program. Diabetes.2005:54(4):1150-6.

224. Gerstein HC, Yusuf S, Bosch J, Pogue J, Sheridan P, Dinccag N, et al; DREAM Trial Investigators. Effect of rosiglitazone on the frequency of diabetes in patients with impaired glucose tolerance or impaired fasting glucose: a randomized controlled trial. Lancet.2006;368(9541):1096-105.Erratum in Lancet. 2006;368(9549):1770.

225. Dormandy JA, Charbonnel B, Eckland DJ, Erdmann E, Massi-Benedetti $\mathrm{M}$, Moules IK, et al; PROactive investigators.Secondary prevention of macrovascular events in patients with type 2 diabetes in the PROactive Study (PROspective pioglit Azone Clinical Trial In macro Vascular Events): a randomised controlled trial. Lancet.2005;366(9493):1279-89.

226. Erdmann E, Dormandy JA, Charbonnel B, Massi-Benedetti M, Moules IK, Skene AM. The effect of pioglitazone on recurrent myocardial infarction in 2,445 patients with type 2 diabetes and previous myocardial infarction: results from the PROactive (PROactive 05) Study. J Am Coll Cardiol.2007;49(17):1772-80.

227. Nissen SE, Wolski K.Effect of rosiglitazone on the risk of myocardial infarction and death from cardiovascular causes. N Engl J Med.2007;356(24):245771. Erratum in N Engl J Med. 2007;357(1):100

228. Powell KE, Paluch AE, Blair SN. Physical activity for health: What kind? How much? How intense? On top of what? Annu Rev Public Health. 2011;32:349-65.

229. Caspersen CJ, Powell KE, Christenson GM. Physical activity, exercise, and physical fitness: definitions and distinctions for health-related research. Public Health Rep. 1985;100(2):126-31.

230. Godoy M, Bellini AJ, Passaro LC, Mastrocolla LE, Sbissa AS, Araújo CG. I Consenso Nacional de Reabilitação Cardiovascular. Arq Bras Cardiol.1997;69(4):267-91.

231. Araújo CG. Quantificando na consulta médica o padrão de exercício físico e de esporte do paciente. Rev DERC.2013;19(1):24-5.

232. Balassiano DH, de AraújoCG. Frequência cardíaca máxima: influência da experiência desportiva na infância e adolescência. Arq Bras Cardiol. 2013;100(4):333-8

233. Thompson PD, Crouse SF, Goodpaster B, Kelley D, Moyna N, Pescatello L. The acute versus the chronic response to exercise. Med Sci Sports Exerc. 2001;33(6 Suppl):S438-45.

234. Blair SN, Kohl HW 3rd, Barlow CE, Paffenbarger RS Jr, Gibbons LW, Macera CA. Changes in physical fitness and all-cause mortality. A prospective study of healthy and unhealthy men. JAMA. 1995;273(14):1093-8.

235. Blair SN, Kohl HW 3rd, Paffenbarger RS Jr, Clark DG, Cooper KH, Gibbons LW. Physical fitness and all-cause mortality. A prospective study of healthy men and women. JAMA. 1989;262(17):2395-401.

236. Eriksson JG, Kajantie E, Lampl M, Osmond C, Barker DJ. Markers of biological fitness as predictors of all-cause mortality. Ann Med. 2013;45(2):156-61.

237. Kokkinos P, Myers J, Faselis C, Panagiotakos DB, Doumas M, Pittaras A, et al. Exercise capacity and mortality in older men: a 20-year follow-up study. Circulation. 2010;122(8):790-7.
238. Laukkanen JA, Kurl S, Salonen JT. Cardiorespiratory fitness and physical activity as risk predictors of future atherosclerotic cardiovascular diseases. Curr Atheroscler Rep. 2002;4(6):468-76.

239. Laukkanen JA, Lakka TA, Rauramaa R, Kuhanen R, Venalainen JM, Salonen $R$, et al. Cardiovascular fitness as a predictor of mortality in men. Arch Intern Med. 2001;161(6):825-31.

240. Myers J, Prakash M, Froelicher V, Do D, Partington S, Atwood JE. Exercise capacity and mortality among men referred for exercise testing. $\mathrm{N} \mathrm{Engl} \mathrm{J}$ Med. 2002;346(11):793-801.

241. deBritoLB, Ricardo DR, de AraújoDS, Ramos PS, de Araújo CG. Ability to sit and rise from the floor as a predictor of all-cause mortality. Eur J Prev Cardiol. Epub 2012 Dec 13.[Epub ahead of print].

242. Metter EJ, Talbot LA, Schrager M, Conwit RA. Arm-cranking muscle power and arm isometric muscle strength are independent predictors of all-cause mortality in men. J Appl Physiol. 2004;96(2):814-21.

243. Carvalho T, Araújo CG, Cortez AA, Ferraz A, A.C.L. N, Brunetto AF, et al. Diretriz de reabilitação cardiopulmonar e metabólica: aspectos práticos e responsabilidades. Arq Bras Cardiol. 2006;86(1):74-82.

244. Haskell WL, Lee IM, Pate RR, Powell KE, Blair SN, Franklin BA, et al;American College of Sports Medicine; American Heart Association. Physical activity and public health: updated recommendation for adults from the American College of Sports Medicine and the American Heart Association. Circulation. 2007;116(9):1081-93.

245. Araújo CG, Carvalho T, Castro CL, Costa RV, Moraes RS, Oliveira Filho JA, et al. Normatização dos equipamentos e técnicas da reabilitação cardiovascular supervisionada. Arq Bras Cardiol.2004;83(5):448-52.

246. Chase NL, Sui X, Lee DC, Blair SN. The association of cardiorespiratory fitness and physical activity with incidence of hypertension in men. Am JHypertens. 2009;22(4):417-24.

247. Laterza MC, de Matos LD, Trombetta IC, Braga AM, Roveda F, Alves MJ, et al. Exercise training restores baroreflex sensitivity in never-treated hypertensive patients. Hypertension. 2007;49(6):1298-306.

248. Williams MA, Haskell WL, Ades PA, Amsterdam EA, Bittner V, Franklin BA, et al; American Heart Association Council on Clinical Cardiology; American Heart Association Council on Nutrition, Physical Activity, and Metabolism. Resistance exercise in individuals with and without cardiovascular disease: 2007 update: a scientific statement from the American Heart Association Council on Clinical Cardiology and Council on Nutrition, Physical Activity, and Metabolism. Circulation. 2007;116(5):572-84.

249. Kokkinos PF, Faselis C, Myers J, Panagiotakos D, Doumas M. Interactive effects of fitness and statin treatment on mortality risk in veterans with dyslipidaemia: a cohort study. Lancet. 2013;381(9864):394-9

250. Mikus CR, Boyle LI, Borengasser SJ, Oberlin DJ, Naples SP, Fletcher J, et al. Simvastatin impairs exercise training adaptations. J Am Coll Cardiol.2013;62(8):709-14

251. Albert CM, Mittleman MA, Chae CU, Lee IM, Hennekens CH, Manson JE. Triggering of sudden death from cardiac causes by vigorous exertion. N Engl Med.2000;343(19):1355-61.

252. Ministério da Saúde. Secretaria de Vigilância em Saúde. Vigitel Brasil 2011: Vigilância de fatores de risco e proteção para doenças crônicas por inquérito telefônico. Brasília; 2012.(Série G. Estatística e Informação em Saúde).

253. Ghorayeb N, Costa RV, Castro I, Daher DJ, Oliveira Filho JA, de Oliveira MA. Diretriz em cardiologia do esporte e do exercício da Sociedade Brasileira de Cardiologia e da Sociedade Brasileira de Medicina do Exercício e do Esporte. Arq Bras Cardiol. 2013;100(1supl 2):1-41.

254. O'Keefe JH, Lavie CJ. Run for your life ... at a comfortable speed and not too far. Heart. 2013;99(8):516-9.

255. La Gerche A. Can intense endurance exercise cause myocardial damage and fibrosis? Curr Sports Med Rep. 2013;12(2):63-9.

256. Trivax JE, Franklin BA, Goldstein JA, Chinnaiyan KM, Gallagher MJ, de Jong AT, et al. Acute cardiac effects of marathon running. J Appl Physiol. 2010;108(5):1148-53. 
257. Herdy AH, Uhlendorf D. Valores de referência para o teste cardiopulmonar para homens e mulheres sedentários e ativos. Arq Bras Cardiol.2011;96(1):54-9.

258. deAraujoCG, Herdy AH, Stein R. Medida do consumo de oxigênio: valioso marcador biológico na saúde e na doença. Arq Bras Cardiol.2013;100(4):e51-3.

259. Wing RR, Bolin P, Brancati FL, Bray GA, Clark JM, Coday M, et al; Look AHEADResearch Group.Cardiovascular effects of intensive lifestyle intervention in type 2 Diabetes N Engl J Med.2013;369(2):145-54.

260. Carvalho T, Nóbrega AC, Lazzoli JK, Magni JR, Rezende L, Drumond FA, et al.Posição oficial da Sociedade Brasileira de Medicina do Esporte: atividade física e saúde. Rev Bras Med Esport.1996;2(4):79-81.

261. Cortes-Bergoderi M, Lopez-Jimenez F,Herdy AH, Zeballos C, Anchique C, Santibañez C, et al. Availability and characteristics of cardiovascular rehabilitation programs in South America. J Cardiopulm Rehabil Prev.2013;33(1):33-41.

262. Fraguas R, Andrei A, Serrano CV, Wajngarten M. Interface da psiquiatria com as outras especialidades médicas: interconsulta em cardiologia. In: Miguel EC, Gattaz WF, Gentil Fo V. Clínica psiquiátrica. Barueri(SP): Manole;2011. p.2231.

263. Stringhini S, Sabia S, Shipley M, Brunner E, Nabi H, Kivimaki M, et al. Association of socioeconomic position with health behaviors and mortality. JAMA. 2010;303(12):1159-66.

264. Nicholson A, Kuper H, Hemingway H. Depression as an aetiologic and prognostic factor in coronary heart disease: a meta-analysis of 6362 events among 146538 participants in 54 observational studies. EurHeart J. 2006;27(23):2763-74.

265. Horsten M, Mittleman MA, Wamala SP, Schenck-Gustafsson K, OrthGomér K. Depressive symptoms and lack of social integration in relation to prognosis of CHD in middle-aged women. The Stockholm Female Coronary Risk Study.Eur Heart J. 2000;21(13):1072-80.

266. Frasure-Smith N, Lesperance F. Depression and anxiety as predictors of 2-year cardiac events in patients with stable coronary artery disease. Arch Gen Psychiatry. 2008;65(1):62-71.

267. Denollet J, Gidron Y, Vrints CJ, Conraads VM. Anger, suppressed anger, and risk of adverse events in patients with coronary artery disease. Am J Cardiol. 2010;105(11):1555-60.

268. Denollet J, Schiffer AA, Spek V. A general propensity to psychological distress affects cardiovascular outcomes: evidence from research on the type D (distressed) personality profile. Circ Cardiovasc Qual Outcomes.2010;3(5):546-57.

269. Lichtman JH, Bigger JT Jr, Blumenthal JA, Frasure-Smith N, Kaufmann PG, Lespérance $\mathrm{F}$, et al; American Heart Association Prevention Committee of the Council on Cardiovascular Nursing; American Heart Association Council on Clinical Cardiology; American Heart Association Council on Epidemiology and Prevention; American Heart Association Interdisciplinary Council on Quality of Care and Outcomes Research; American Psychiatric Association.Depression and coronary heart disease: recommendations for screening, referral, and treatment: a science advisory from the American Heart Association Prevention Committee of the Council on Cardiovascular Nursing, Council on Clinical Cardiology, Council on Epidemiology and Prevention, and Interdisciplinary Council on Quality of Care and Outcomes Research: endorsed by the American Psychiatric Association.Circulation. 2008;118(17):1768-75

270. Von Korff M, Katon WJ, Lin EH, Ciechanowski P, Peterson D, Ludman EJ, et al.Functional outcomes of multi-condition collaborative care and successful ageing: results of randomised trial. BMJ.2011;343:d6612.

271. Orth-Gomer K, Schneiderman N, Wang HX, Walldin C, Blom M, Jernberg T. Stress reduction prolongs life in women with coronary disease: the Stockholm Women's Intervention Trial for Coronary Heart Disease (SWITCHD). Circ Cardiovasc Qual Outcomes. 2009;2(1):25-32.
272. Gulliksson M, Burell G, Vessby B, Lundin L, Toss H, Svärdsudd K. Randomized controlled trial of cognitive behavioral therapy vs standard treatment to prevent recurrent cardiovascular events in patients with coronary heart disease: Secondary Prevention in Uppsala Primary Health Care project (SUPRIM). Arch Intern Med. 2011;171(2):134-40.

273. Theorell T, Emdad R, Arnetz B, Weingarten AM. Employee effects of an educational program for managers at an insurance company. Psychosom Med. 2001;63(5):724-33.

274. Van Dalem J, Krass I, Aslani P. Interventions promoting adherence to cardiovascular medicines. Int J Clin Pharm.2012;34(2):295-311.

275. Yusuf S, Islam S, Chow CK, Rangarajan S, Dagenais G, Diaz R, et al. Prospective Urban Rural Epidemiology(PURE) Study Investigators. Use of secondary prevention drugs for cardiovascular disease in the community in high-income, middle-income, and low-income countries (the PURE Study): a prospective epidemiological survey.Lancet. 2011;378(9798):1231-43

276. Bosworth HB, Granger BB, Mendys P,Brindis R, Burkholder R, Czajkowski SM, et al. Medication adherence: a call for action. Am Heart J.2011;162(3):412-24.

277. de Toledo Ferraz Alves TC, Ferreira LK, Wajngarten M, Busatto GF. Cardiac disorders as risk factors for Alzheimer's disease. J Alzheimers Dis. 2010;20(3):749-63.

278. Richard E, Reitz C, Honig NH,Schupf N, Tang MX, Manly JJ, et al. Late-life depression, mild cognitive impairment and dementia. JAMA Neurol. 2013;70(3):374-82.

279. Morisky DE, Green LW, Levine DM. Concurrent and predictive validity of a self-reported measure of medication adherence. Med Care. 1986;24(1):67-74

280. Cutrona SL, Choudry NK, Fischer MA, Servi A, Liberman JN, Brennan TA et al.Modes of delivery for interventions to improve cardiovascular and diabetes medication adherence. Am J Manag Care. 2010;16(12):929-42.

281. de Castro SM, Fuchs FD, Santos MC, Maximiliano P, Gus M, Moreira LB, et al.Pharmaceutical care program for patients with uncontrolled hypertension:report of a double-blind clinical trial with ambulatory blood pressure monitoring. Am JHypertens. 2006;19(5):528-33.

282. Elley CR, Gupta AK, Webster R, Selak V, Jun M, Patel A, et al. The efficacy and tolerability of 'polypills': meta-analysis of randomised controlled trials. PLoS One. 2012;7(12):e52145

283. Giuliano Ide C, Coutinho MS, Freitas SF, Pires MM,Zunino JN, Ribeiro RQ Lípides séricos em crianças e adolescentes da rede escolar de Florianópolis, SC - Estudo Floripa Saudável 2040. ArqBrasCardiol.2005;85(2):85-91.

284. Daniels SR, Greer FR;Committee on Nutrition. Lipid screening and cardiovascular health in childhood. Pediatrics.2008;122(1):198-208.

285. Kwiterovich PO Jr. Recognition and management of dyslipidemia in children and adolescents.J Clin Endocrinol Metab.2008;93(11):4200-9.

286. Jellinger PS, Smith DA, Mehta AE, Ganda O, Handelsman Y, Rodbard HW, et al. American Association of Clinical Endocrinologists' Guidelines for Management ofDyslipidemia and Prevention of Atherosclerosis. Endocr Pract.2012;18 Suppl 1:1-78.

287. Kavey RE, Allada V, Daniels SR, Hayman LL, McCrindle BW, Newburger JW, et al; American Heart Association Expert Panel on Population and Prevention Science;American Heart Association Council on Cardiovascular Disease in the Young; American Heart Association Council on Epidemiology and Prevention;American Heart Association Council on Nutrition, Physical Activity and Metabolism;American Heart Association Council on High Blood Pressure Research;American Heart Association Council on Cardiovascular Nursing;American Heart Association Council on the Kidney in Heart Disease; Interdisciplinary Working Group on Quality of Care and Outcomes Research. Cardiovascular risk reduction in high-risk pediatric patients: a scientific statement from the American Heart Association Expert Panel on Population and Prevention Science; the Councils on 
Cardiovascular Disease in the Young, Epidemiology and Prevention, Nutrition, Physical Activity and Metabolism, High Blood Pressure Research, Cardiovascular Nursing, and the Kidney in Heart Disease; and the Interdisciplinary Working Group on Quality of Care and Outcomes Research: endorsed by the American Academy of Pediatrics. Circulation. 2006;114(24):2710-38.

288. Lebenthal Y, Horvath A, Dziechciarz P, Szajewska H, Shamir R. Are treatment targets for hypercholesterolemia evidence based? Systematic review and meta-analysis of randomised controlled trials. Arch Dis Child.2010;95(9):673-80.

289. Amundsen AL, Ntanios F, Put N, Ose L. Long-term compliance and changes in plasma lipids, plant sterols and carotenoids in children and parents with FH consuming plant sterol ester-enriched spread. Eur J Clin Nutr. 2004;58(12):1612-20.

290. Giuliano IC, Caramelli B. Dislipidemia na infância e na adolescência. Pediatria (São Paulo). 2008;29(4):275-85.

291. Mullis RM, Blair SN, Aronne LJ, Bier DM, Denke MA, Dietz W, et al. Prevention Conference VII Obesity, a worldwide epidemic related to heart disease and stroke:Group IV: prevention/treatment.Circulation.20 04;110(18):e484-8.

292. Blössner M, Borghi E. Global prevalence and trends of overweight and obesity among preschool children. Am J Clin Nutr. 2010;92(5):1257-64.

293. Instituto Brasileiro de Geografia e Estatística. (IBGE). Síntese de indicadores sociais: uma análise das condições de vida. Rio de Janeiro; 2008. (Estudos e Pesquisa).

294. Singh AS, Mulder C, Twisk JW, vanMechelen W, Chinapaw MJ. Tracking of childhood overweight into adulthood: a systematic review of the literature. Obes Rev. 2008;9(5):474-88.

295. Juonala M, Magnussen CG, Berenson GS, Venn A, Burns TL, Sabin MA, et al. Childhood adiposity, adult adiposity, and cardiovascular risk factors. N Engl J Med. 2011;365(20):1876-85.

296. Reilly JJ, Kelly J. Long-term impact of overweight and obesity in childhood and adolescence on morbidity and premature mortality in adulthood: systematic review. IntJObes (Lond).2011;35(7):891-8.

297. WHO Multicentre Growth Reference Study Group. WHO Child Growth Standards based on length/height, weight and age. Acta Paediatr Suppl. 2006; 450:76-85.

298. Victora CG, Araújo CL. Uma nova curva de crescimento para o século XXI. [Citado em2010 abr 26]. Disponível em: http://nutricao.saude.gov.br/ documentos/nova_curva_cresc_sec_xxi.pdf).

299. deOnis M, Onyango AW, Borghi E, Siyam A, Nishida C, Siekmann JJ. Development of a WHO growth reference for school-aged children and adolescents. BullWorld The WHO Health Organ. 2007;85(9):660-7.

300. World Health Organization. (WHO). Child growth standards. [Cited in 2013 Mar 10]. Available from: http://www.who.int/childgrowth/en

301. Ministério da Saúde. Programa Telessaúde Brasil. [Citado em 2013 Jan 10]. Disponível em http://www.telessaudebrasil.org.br/apps/ calculadoras/?page $=7$

302. Araújo CL, Victora CG, Hallal PC, Gigante DP. Breastfeeding and overweight in childhood: evidence from the Pelotas 1993 birth cohort study. IntjObes (Lond).2006;30(3):500-6.

303. Sociedade Brasileira de Pediatria S. Manual de Orientação da obesidade na infância e adolescência. São Paulo: Departamento de Nutrologia; 2008.

304. de Mello ED, Luft VC, Meyer F. Atendimento ambulatorial individualizado versus programa de educação em grupo: qual oferece mais mudança de hábitos alimentares e de atividade física em crianças obesas? J Pediatr. 2004;80(6):468-74

305. Okihiro M, Pillen M, Ancog C, Inda C, Sehgal V. Implementing the obesity care model at a community health center in Hawaii to address childhood obesity. J Health Care Poor Underserved. 2013;24(2 Suppl):1-11.
306. Sbruzzi G, Eibel B, Barbiero SM, Petkowicz RO, Ribeiro RA, Cesa CC, et al.Educational interventions in childhood obesity: a systematic review with meta-analysis of randomized clinical trials. PrevMed.2013;56(5):254-64 .

307. Economos CD, Hyatt RR, Must A, Goldberg JP, Kuder J, Naumova EN, et al. Shape Up Somerville two-year results: a community-based environmental change intervention sustains weight reduction in children. Prev Med. 2013;57(4):322-7.

308. Meyers K, Falkner B. Hypertension in children and adolescents: an approach to management of complex hypertension in pediatric patients. Curr Hypertens Rep. 2009;11(5):315-22.

309. OliveiraRG,Lamounier JA, Oliveira AD, Castro MD, Oliveira JS.Pressão arterial em escolares e adolescentes-O estudo de Belo Horizonte.J Pediatr (Rio J).1999;75(4):256-66

310. Silva MA, Rivera IR, Ferraz MR,Pinheiro AJ, Alves SW, Moura AA, et al. Prevalência de fatores de risco cardiovascular em crianças e adolescentes da rede de ensino da cidade de Maceió. Arq BrasCardiol.2005;84(5):387-92.

311. Hansen ML, Gunn PW, Kaelber DC. Underdiagnosis of hypertension in children and adolescents. JAMA. 2007;298(8):874-9.

312. Riley M, Bluhm B. High blood pressurein children and adolescents. Am Fam Physician. 2012;85(7):693-700.

313. Redwine KM, Daniels SR. Prehypertension in adolescents: risk and progression. J Clin Hypertens(Greenwich). 2012;14(6):360-4.

314. Bao W, Threefoot SA, Srinivasan SR,Berenson GS. Essential hypertension predicted by tracking of elevated blood pressure from childhood to adulthood: the Bogalusa Heart Study.Am J Hypertens. 1995;8(7):657-65.

315. Berenson GS, Srinivasan SR, Bao W,Newman WP 3rd, Tracy RE, Wattigney WA.Association between multiple cardiovascular risk factors and atherosclerosis in children and young adults. The Bogalusa Heart Study. N Engl J Med. 1998;338(23):1650-6.

316. National High Blood Pressure Education Program Working Groupon High Blood Pressurein Children and Adolescents. The fourth report on the diagnosis, evaluation, and treatment of high blood pressure in children and adolescents. Pediatrics.2004;114(2 Suppl 4th Report):555-76.

317. Lurbe E, Cifkova R, Cruickshank JK,Dillon MJ, Ferreira I, Invitti C,et al; European Society of Hypertension.Management of high blood pressure in children and adolescents: recommendations of the European Society of Hypertension. J Hypertens. 2009;27(9):1719-42.

318. Expert Panel on Integrated Guidelines for Cardiovascular Health and Risk Reduction in Children and Adolescents; National Heart, Lung, and Blood Institute.Expert Panel on integrated guidelines for cardiovascular health and riskreduction in children and adolescents: summary report. Pediatrics. 2011;128Supl 5:S213-56.

319. Falkner B, Gidding SS, Portman R, Rosner B. Blood pressure variability and classification of prehypertension and hypertension in adolescence. Pediatrics. 2008;122(2):238-42.

320. Souza MG, Rivera IR, Silva MA, Carvalho AC. Relação da obesidade com a pressão arterial elevada em crianças e adolescentes. Arq Bras Cardiol.2010;94(6):714-9.

321. Sorof J, Daniels S. Obesity hypertension in children:a problem of epidemic proportions. Hypertension. 2002;40(4):441-7.

322. Rocchini AP, Karch V, Anderson J, Hinderliter J, Becque D, Martin M, et al. Blood pressure in obese adolescents: effect of weight loss. Pediatrics. 1988;82(1): 16-23.

323. Lloyd-Jones DM, Hong Y, Labarthe D, Mozaffarian D,Appel LJ, Van Horn L, et al. Defining and setting national goalsfor Cardiovascular Health promotion and disease reduction: The American Heart Association's Strategic Impact Goal through 2020 and beyond. Circulation.2010;121(4):586-613.

324. Graham I, Atar D, Borch-Johnsen K, Boysen G, Burell G, Cifkova R, et al; European Society of Cardiology (ESC); European Association for Cardiovascular Prevention and Rehabilitation (EACPR); Council on Cardiovascular Nursing; European Association for Study of Diabetes (EASD); International Diabetes Federation Europe (IDF-Europe); European 
Stroke Initiative (EUSI); International Society of Behavioural Medicine (ISBM); European Society of Hypertension (ESH); European Society of General Practice/Family Medicine (ESGP/FM/WONCA); European Heart Network (EHN). European Guidelines on cardiovascular disease prevention in clinical pratice: executive summary. Fourth Joint Task Force of the European Society of Cardiology and other societies on cardiovascular disease prevention in clinical practice (constituted by representatives of nine societies and by invited experts).Eur J CardiovascPrev Rehabil. 2007;14 Suppl 2:E1-40.

325. Williams CL, Hayman LL, Daniels SR, Robinson TN, Steinberger J, Paridon S, et al.Cardiovascular health in childhood:a statement for health professionals from the committee on atherosclerosis, hypertension, and obesity in the young (AHOY) of the Council on Cardiovascular Disease in the Young, American Heart Association. Circulation. 2002;106(1):143-60. Erratum in Circulation.2002;106(9):1178.

326. Li S, Chen W, Srinivasan SR,Bond MG, Tang R, Urbina EM,et al.Childhood cardiovascular risk factors and carotid vascular changes in adulthood: the Bogalusa Heart Study. JAMA. 2003;290(17):2271-6.Erratum in: JAMA. 2003;290(22):2943.

327. Daniels SR, ArnettDK, Eckel RH, Gidding SS, Hayman LL, Kumaniika S, et al. Overweight in children and adolescents: pathophysiology, consequences, prevention and treatment. Circulation. 2005;111(15):1999-2012.

328. Jessup A, Harrell J. The metabolic syndrome: look for it in children and adolescents, too!. Clinical Diabetes. 2005;23(1):26-32.

329. Ten S, MacLaren N. Insulin resistance syndrome in children. J Clin Endocrinol Metab. 2004;89(6):2526-39.

330. Raitakari OT, Porkka KV, Taimela S, Telama R, Rasanen L, Viikan JS. Effects of persistent physical activity and inactivity on coronary risk factors in children and young adults. The Cardiovascular Risk in Young Finns Study. Am J Epidemiol. 1994;140(3):195-205

331. Bao W, Srinivasan SR, Wattigney WA, Berenson GS. Persistence of multiple cardiovascular risks clustering related to syndrome $X$ from childhood to young adulthood. The Bogalusa Heart Study. Arch Inter Med. 1994;154(16):1842-7.

332. Sesso HD, Paffenbarger RS Jr, Lee IM. Physical activity and coronary heart disease in men. The Harvard Alumni Health Study. Circulation. 2000;102(9):975-80

333. Sociedade Brasileira de Cardiologia. Departamento de Aterosclerose. I Diretriz de prevenção da aterosclerose na infância e na adolescência da Sociedade Brasileira de Cardiologia. Arq Bras Cardiol.2005;85(supl 6):1-35.

334. Kavey RE, Daniels SR, Lauer RM, Atkins DL, Hayman LL, Taubert K;American Heart Association. American Heart Association guidelines for primary prevention of atherosclerotic cardiovascular disease beginning in childhood. Circulation. 2003;107(11):1652-66

335. Center for Disease Control and Prevention. USA. Department of Health and Human Services. Promoting better health for young people through physical activity and sports. 2000. [Cited in 2012 Jul 9]. Available from: http://www.cdc.gov/healthyyouth/physicalactivity/promoting_health/ pdfs/ppar.pdf

336. Timmons BW, LeBlanc AG, Carson V, Connor Gorber S, Dillman C, Janssen I, et al. Systematic review of physical activity and health in the early years (aged 0-4 years). Appl Physiol Nutr Metab. 2012;37(4):773-92.

337. Tremblay MS, Warburton DE, Janssen I, Paterson DH, Latimer AE, Rhodes RE, et al. New Canadian physical activity guidelines. Appl Physiol Nutr Metab. 2011:36(1):36-46

338. Silva MA, Rivera IR, Souza MG, Carvalho AC, Silva, RD, Oliveira BA, et al. Horas de assistência à TV X nível de atividade física e perfil nutricional em crianças e adolescentes da cidade de Maceió. Arq Bras Cardiol.2006;87(supl1):203.

339. Brown H, Hume C, Pearson N, Salmon J. A systematic review of intervention effects on potential mediators of children's physical activity. BMC Public Health. 2013:13:165.
340. Ministério da Saúde. Plano de ações estratégicas para o enfrentamento das doenças crônicas não transmissíveis (DCNT) no Brasil, 2011-2022. Brasília: Ministério da Saúde; 2011. [Acesso em 2012 jun 17]. Disponível em: <http://portal.saude.gov.br/portal/saude/profissional/area.cfm?id area $=1818$.

341. Schmidt MI, Duncan BB, Azevedo e Silva G, Menezes AM, Monteiro CA Barreto SM, et al. Chronic non-communicable diseases in Brazil: burden and current challenges. Lancet. 2011;377(9781):1949-61.

342. Moura EC, Neto OL, Malta DC, Moura L, Silva NN, Bernal R, et al Vigilância de fatores de risco para doenças crônicas por inquérito telefônico nas capitais dos 26 estados brasileiros e no Distrito Federal (2006). RevBrasEpidemiol.2008;11(supl 1):20-37.

343. Nobre F, Serrano Jr CV (eds). Tratado de cardiologia - SOCESP.Barueri (SP): Manole; 2005.

344. Gordon T,Kannel WB. Multiple risk functions for predicting coronary heart disease: the concept, accuracy and applications. AmHeart J.1982;103:1031-9.

345. Mion Jr D, Nobre F. Risco cardiovascular global - da teoria à prática. São Paulo: Lemos; 2000

346. Wold Health Organization (WHO). Global status report on noncommunicable diseases 2010. Geneva;2011.

347. Moss M. Salt sugar fat: how the food giants. Hooked US. New York: Randon House; 2012.

348. Council Foreign Relations. Political declaration of the high-level meeting of the General Assembly on the prevention and control of non-communicable diseases. In: VN General Assembly meeting on September 19-20, 2011.

349. Malta DC, Morais Neto OL,Silva Junior JB. Apresentação do plano de ações estratégicas para o enfrentamento das doenças crônicas não transmissíveis no Brasil, 2011 a 2022.EpidemiolServ Saúde. 2011;20(4):425-38.

350. Shoenfeld Y, Gerli R, Doria A, Matsuura E, Cerinic MM, Ronda N, et al.Accelerated atherosclerosis in autoimmune rheumatic diseases. Circulation.2005;112(21):3337-47

351. Manzi S, Meilahn EN, Rairie JE, Conte CG, Medsger TA Jr, JansenMcWilliams L, et al. Age-specific incidence rates of myocardial infarction and angina in women with systemic lupus erythematosus: comparison with the Framingham study. Am J Epidemiol. 1997;145(5):408-15.

352. Kazelian L. Autoimune diseases promoting coronary artery disease in women. Rev Argent Cardiol.2013;81:330-4.

353. Van Doornum S, Mc Coll G, Wicks IP. Accelerated atherosclerosis: an extraarticular feature of rheumatoid arthritis? Arthritis Rheum. 2002;46(4):862-73.

354. Solomon DH, Karlson EW, Rimm EB, Cannuscio CC, Mandl LA, Manson $\mathrm{JE}$, et al. Cardiovascular morbidity and mortality in women diagnosed with rheumatoid arthritis. Circulation. 2003;107(9):1303-7.

355. Hornung N, Ellingsen T, Stengaard-Pedersen K, Poulsen JH. Folate, homocysteine, and cobalamin status in patients with rheumatoid arthritis treated with methotrexate, and the effect of low dose folic acid supplement. J Rheumatol. 2004;31(12):2374-81

356. Toms TE, Panoulas VF, Kitas GD. Dyslipidaemia in rheumatological autoimmune diseases. Open Cardiovasc Med J. 2011;5:64-75.

357. Petri M, Perez-Gutthann S, Spence D,Hochberg MC. Risk factors for coronary artery disease in patients with systemic lupus erythematosus. Am J Med. 1992:93(5):513-9.

358. Cervera R, Khamashta MA, Font J,Sebastiani GD,Gil A,Lavilla P, et al.Morbidity and mortality in systemic lupus erythematosus during a 5 year period: a multicenter prospective study of 1000 patients. European Working Party on Systemic Lupus Erythematosus. Medicine(Baltimo re).1999; 78(3):167-75. 
359. Thamer M, Hernan M, Zhang Y,Cotter D, Petri M. Prednisone, lupus activity, and permanent organ damage. J Rheumatol. 2009;36(3):560-4.

360. Petri M, Kiani AN, Post W, Cristopher-Stine L, Magder LS. Lupus Atherosclerosis Prevention Study (LAPS): a randomized double blind placebo controlled trial of atorvastatin versus placebo. AnnRheum Dis. 2011;70(5):760-5.

361. Toms TE, Smith JP, Panoulas VF, Douglas KM, Saratzis AN, KitasGD Prevalence of risk factors for statin-induced myopathy in rheumatoid arthritis patients. Musculoskeletal Care. 2010;8(1):2-9.

362. U.S. Preventive Services Task Force. Aspirin for the prevention of cardiovascular disease: U.S. Preventive Services Task Force Recommendation Statement.AnnInternMed. 2009:150(6):396-404.

363. Public Health Weekly Reports for November 11,1932. Public Health Rep. 1932;47(46):2159-89.

364. Warren-Gash C, Smeeth L, Hayward AC. Influenza as a trigger for acute myocardial infarction or death from cardiovascular disease: a systematic review. Lancet Infect Dis. 2009;9(10):601-10.

365. Madjid M, Miller CC, Zarubaev VV, Marinich IG, Kiselev OI,Lobzin YV, et al. Influenza epidemics and acute respiratory disease activity are associated with a surge in autopsy- confirmed coronary heart disease death: results from 8 years of autopsies in 34,892 subjects. Eur Heart J. 2007;28(10):1205-10.

366. Ministério da Saúde. Secretaria de Vigilância em Saúde. Situação epidemiológica da Influenza Pandêmica (H1N1) 2009 no Mundo e no Brasil, até semana epidemiológica 44 de 2009. Informe Epidemiológico Influenza A(H1N1) - 2009;10(11):1-14.

367. Rogers KC, Wallace JP, Foster SL, Finks SW. Annual influenza vaccination: offering protection beyond infection. SouthMed J. 2012;105(7):379-86.

368. Madjid M, Naghavi M, Litovsky S, Casscells SW. Influenza and cardiovascular disease: a new opportunity for prevention and the need for further studies. Circulation. 2003;108(22):2730-6.

369. Meier CR, Jick SS, Derby LE, Vasilakis C, Jick H. Acute respiratory-tract infections and risk of first-time acute myocardial infarction. Lancet. 1998;351(9114):1467-71.

370. Wang CS, Wang ST, Lai CT, Lin LJ, Chou P. Impact of influenza vaccination on major cause-specific mortality. Vaccine. 2007;25(7):1196-203.

371. Gurfinkel EP, Leon de la Fuente R, Mendiz O, Mautner B. Flu vaccination in acute coronary syndromes and planned percutaneous coronary interventions (FLUVACS) study. Eur Heart J. 2004;25(1):25-31.

372. Ciszewski A, Bilinska ZT, Brydak LB, Kepka C, Kruk M, Romanowska $M$, et al. Influenza vaccination in secondary prevention from coronary ischaemic events in coronary artery disease: FLUCAD study. Eur Heart J. 2008;29(11):1350-8.

373. Phrommintikul A, Kuanprasert S, Wongcharoen W, Kanjanavanit $\mathrm{R}$, Chaiwarith $\mathrm{R}$, Sukonthasarn $\mathrm{A}$. Influenza vaccination reduces cardiovascular events in patients with acute coronary syndrome. Eur Heart J. 2011;32(14):1730-5.

374. Sarnak MJ, Levey AS, Schoolwerth AC, Coresh J, Culleton B, Hamm LL, et al;American Heart Association Councils on Kidney in Cardiovascular Disease, High Blood Pressure Research, Clinical Cardiology, and Epidemiology and Prevention. Kidney disease as a risk factor for development of cardiovascular disease: a statement from the American Heart Association Councils on Kidney in Cardiovascular Disease, High Blood Pressure Research, Clinical Cardiology, and Epidemiology and Prevention. Circulation. 2003;108(17):2154-69.

375. Ix JH, Shlipak MG, Liu HH, Schiller NB, Whooley MA. Association between renal insufficiency and inducible ischemia in patients with coronary artery disease: the heart and soul study. J Am Soc Nephrol. 2003;14(12):3233-8. Erratum in J Am Soc Nephrol. 2004;15(2):following 508.
376. Go AS, Chertow GM, Fan D, McCulloch CE, Hsu CY. Chronic kidney disease and the risks of death, cardiovascular events, and hospitalization. N Engl J Med. 2004;351(13):1296-305. Erratum in N Engl J Med. 2008;18(4):4.

377. Klausen K, Borch-Johnsen K, Feldt-Rasmussen B, Jensen G, Clausen P, Scharling $\mathrm{H}$, et al. Very low levels of microalbuminuria are associated with increased risk of coronary heart disease and death independently of renal function, hypertension, and diabetes. Circulation. 2004;110(1):32-5.

378. Levey AS, Coresh J, Balk E, Kausz AT, Levin A, Steffes MW, et al;National Kidney Foundation. National Kidney Foundation practice guidelines for chronic kidney disease: evaluation, classification, and stratification. Ann Intern Med. 2003;139(2):137-47.

379. Andrassy KM. Comments on KDIGO 2012 clinical practice guideline for the evaluation and management of chronic kidney disease. Kidney Int.2013;84(3):622-3.

380. Halimi JM, Giraudeau B, Vol S, Cacès E, Nivet H, Lebranchu Y, et al. Effects of current smoking and smoking discontinuation on renal function and proteinuria in the general population. Kidney Int. 2000;58(3):1285-92.

381. Boyce ML, Robergs RA, Avasthi PS, Roldan C, Foster A, Montner P, et al. Exercise training by individuals with predialysis renal failure: cardiorespiratory endurance, hypertension, and renal function. Am J Kidney Dis. 1997;30(2):180-92

382. Navaneethan SD, Yehnert H, Moustarah F, Schreiber MJ, Schauer $\mathrm{PR}, \mathrm{Beddhu} \mathrm{S}$, et al. Weight loss interventions in chronic kidney disease: a systematic review and meta-analysis. Clin J Am Soc Nephrol. 2009;4(10):1565-74.

383. Navaneethan SD, Pansini F, Perkovic V, Manno C, Pellegrini F, Johnson DW, et al. HMG CoA reductase inhibitors (statins) for people with chronic kidney disease not requiring dialysis. Cochrane Database Syst Rev. 2009Apr 15; (2):CD007784.

384. Upadhyay A, Earley A, Lamont JL, Haynes S, Wanner C, Balk EM.Lipidlowering therapy in persons with chronic kidney disease: a systematic review and meta-analysis. Ann Intern Med. 2012;157(4):251-62.

385. Jardine MJ, Ninomiya T, Perkovic V, Cass A, Turnbull F, Gallagher MP, et al. Aspirin is beneficial in hypertensive patients with chronic kidney disease: a post-hoc subgroup analysis of a randomized controlled trial. J Am Coll Cardiol. 2010;56(12):956-65.

386. Angiolillo DJ, Bernardo E, Capodanno D, Vivas D, Sabaté M, Ferreiro JL, et al. Impact of chronic kidney disease on platelet function profiles in diabetes mellitus patients with coronary artery disease taking dual antiplatelet therapy. J Am Coll Cardiol. 2010;55(11):1139-46.

387. Bartolucci AA, Tendera M, Howard G. Meta-analysis of multiple primary prevention trials of cardiovascular events using aspirin. Am J Cardiol. 2011;107(12):1796-801.Erratum in Am J Cardiol. 2011;108(4):615.

388. Wali RK. Aspirin and the prevention of cardiovascular disease in chronic kidney disease: time to move forward? J Am Coll Cardiol. 2010;56(12):966-

389. Palmer SC, Di Micco L, Razavian M, Craig JC, Perkovic V, Pellegrini F, et al. Antiplatelet agents for chronic kidney disease. Cochrane Database Syst Rev.2013 Feb 28;2:CD008834.

390. Best PJ, Steinhubl SR, Berger PB,Dasgupta A, Brennan DM, Szczech LA, et al; CREDO Investigators. The efficacy and safety of short- and long-term dual antiplatelet therapy in patients with mild or moderate chronic kidney disease: results from the Clopidogrel for the Reduction of Events During Observation (CREDO) trial. Am Heart J. 2008;155(4):687-93.

391. Tendera M, Aboyans V, Bartelink ML, Baumgartner I, Clement D, ColletJP, et al. ESC Guidelines on the diagnosis and treatment of peripheral artery diseases: Document covering atherosclerotic disease of extracranial carotid and vertebral, mesenteric, renal, upper and lower extremity arteries: the Task Force on the Diagnosis and Treatment of Peripheral Artery Diseases of 
the European Society of Cardiology (ESC). Eur Heart J.2011;32(22):2851906.

392. Anderson JL, Halperin JL, Albert NM, Bozkurt B, Brindis RG, Curtis LH, et al. Management of patients with peripheral artery disease (compilationof 2005 and 2011 ACCF/AHA guideline recommendations): a reportof the American College of Cardiology Foundation/American Heart Association Task Force on Practice Guidelines. Circulation. 2013;127(13):1425-43.

393. Schillinger M, Exner M, Mlekusch W, Amighi J, Sabeti S, Muellner M, et al. Statin therapy improves cardiovascular outcome of patients with peripheral artery disease. Eur Heart J. 2004;25(9):742-8.

394. Feringa HH, van Waning VH, Bax JJ, Elhendy A, Boersma E, Schouten $\mathrm{O}$, et al. Cardioprotective medication is associated with improved survival in patients with peripheral arterial disease. J Am Coll Cardiol. 2006;47(6):1182-7.

395. Heart Protection Study Collaborative Group. Randomized trial of the effects of cholesterol-lowering with simvastatin on peripheral vascular and other major vascular outcomes in 20,536 people with peripheral arterial disease and other high-risk conditions. J Vasc Surg. 2007;45(4):645-54.

396. Collins R, Armitage J, Parish S, Sleigh P, Peto R; Heart Protection Study Collaborative Group. MRC/BHF Heart Protection Study of cholesterollowering with simvastatin in 5963 people with diabetes: a randomised placebo-controlled trial. Lancet. 2003;361(9374):2005-16.

397. Catalano M, Born G, Peto R;Critical Leg Ischaemia Prevention Study (CLIPS) Group. Prevention of serious vascular events by aspirin amongst patients with peripheral arterial disease: randomized, double-blind trial. J Intern Med. 2007;261(3):276-84.

398. Belch J, MacCuish A, Campbell I, Cobbe S, TaPrevention of Progression of Arterial Disease and Diabetes Study Group; Diabetes Registry Group; Royal College of Physicians Edinburghr R, Prescott R, et al; Prevention of Progression of Arterial Disease and Diabetes Study Group; Diabetes Registry Group; Royal College of Physicians Edinburgh. The prevention of progression of arterial disease and diabetes (POPADAD) trial: factorial randomised placebo controlled trial of aspirin and antioxidants in patients with diabetes and asymptomatic peripheral arterial disease. BMJ. 2008;337:a1840.

399. Fowkes FG, Price JF, Stewart MC, Butcher I, Leng GC, Pell AC, et al; Aspirin for Asymptomatic Atherosclerosis Trialists.Aspirin for prevention of cardiovascular events in a general population screened for a low ankle brachial index: a randomized controlled trial. JAMA. 2010;303(9):841-8.

400. CAPRIE Steering Committee. A randomised, blinded, trial of clopidogrel versus aspirin in patients at risk of ischaemic events (CAPRIE). Lancet.1996;348(9038):1329-39.

401. World Health Organization. (WHO). The 10 leading causes of death by broad income group (2008). [Cited in 2013 May 10]. Available from: http:// www.who.int/multicentre/factsheets/fs310 2008.pdf

402. Ministério da Saúde. Secretaria Executiva. Datasus. Informações de Saúde. Morbidade e informações epidemiológicas Consulta eletrônica. [Citado em 2013 set 20]. Disponível em: http://www.datasus.gov.br.

403. Woodward M, Brindle P, Tunstall-Pedoe $\mathrm{H}$; $\mathrm{SIGN}$ group on risk estimation Adding social deprivation and family history to cardiovascular risk assessment: the ASSIGN score from the Scottish Heart Health Extended Cohort (SHHEC). Heart. 2007;93(2):172-6.

404. Tonne C, Schwartz J, Mittleman M, Melly S, Suh H, Goldberg R. Longterm survival after acute myocardial infarction is lower in more deprived neighborhoods. Circulation. 2005;111(23):3063-70.

405. Albert MA, Glynn RJ, Buring J, Ridker PM. Impact of traditional and novel risk factors on the relationship between socioeconomic status and incident cardiovascular events. Circulation. 2006;114(24):2619-26.
406. Rahimi AR, Spertus JA, Reid KJ, Bernheim SM, Krumholz HM. Financia barriers to health care and outcomes after acute myocardial infarction. JAMA. 2007;297(10):1063-72.

407. Lesbaupin I, Mineiro A. O desmonte da nação em dados. Petrópolis: Vozes; 2002

408. Finch CE, Crimmins EM. Inflammatory exposure and historical changes in human life-spans. Science. 2004;305(5691):1736-9.

409. Bloom G. Equity in health in unequal societies: towards health equities during rapid social changes. London: IDS Working Paper; 2000.

410. World Development Report 2000/2001 - Attacking poverty. Oxford: Oxford University Press/World Bank; 2000.

411. Soares GP, Brum JD, Oliveira GM, Klein CH, Souza e Silva NA. Evolução de indicadores socioeconômicos e da mortalidade cardiovascular em três estados do Brasil. Arq Bras Cardiol.2013;100(2):147-56.

412. Lenfant C. Can we prevent cardiovascular diseases in low and middle income countries? Bull World Health Organ. 2001;79(10):980-2.

413. Albus C, Jordan J, Herrmann-Lingen C. Screening for psychosocial risk factors in patients with coronary heart disease - recommendations for clinical practice. Eur J Cardiovasc Prev Rehabil. 2004;11(1):75-9.

414. Peppard PE, Young T, BarnetJH, Palta M, Hagen EW, Hla KM. Increased prevalence of sleep-disordered breathing in adults. Am JEpidemiol.2013Apr 14. [Epub ahead of print].

415. Usmani ZA, Chai-CoetzerCL, Antic NA, Mc Evoy RD. Obstructive sleep apnoea in adults. Postgrad Med J.2013;89(1049):148-56

416. Gottlieb DJ, Yenokyan G, Newman AB, O'Connor GT, Punjabi NM, Quan $\mathrm{SF}$,et al. Prospective study of obstructive sleep apnea and incident coronary heart disease and heart failure: the sleep heart health study. Circulation. 2010;122(4):352-60

417. Lévy P, Ryan S, Oldenburg O, Parati G. Sleep apnoea and the heart. Eur Respir Rev. 2013;22(129):333-52

418. Araujo AB, Hall SA, Ganz P, Chiu GR, Rosen RC, Kupelian V, et al. Does erectile dysfunction contribute to cardiovascular diseaserisk prediction beyond the Framingham risk score? J Am Coll Cardiol. 2010;55(4):350-6.

419. Dong JY, Zhang YH, Qin LQ. Erectile dysfunction and risk of cardiovascular disease: meta-analysis of prospective cohort studies. J Am Coll Cardiol. 2011;58(13):1378-85.

420. Banks E, Joshy G, Abhayaratna WP, Kritharides L, Macdonald PS, Korda RJ et al. Erectile dysfunction severity as a risk marker for cardiovascular disease hospitalization and all-cause mortality: a prospective cohort study. PLoS Med. 2013;10(1):e1001372.

421. Tonetti MS, D'Aiuto F, Nibali L, Donald A, Storry C, Parkar M, et al Treatment of periodontitis and endothelial function. N Engl J Med. 2007:356(9):911-20.

422. Ismail G, Dumitriu HT, Dumitriu AS, Ismail FB. Periodontal Disease: A Covert Source of Inflammation in Chronic Kidney Disease Patients Int Nephrol. 2013;2013:515796.

423. Bansal M, Rastogi S, Vineeth NS. Influence of periodontal disease on systemic disease: inversion of a paradigm: a review. J Med Life.2013;6(2):126-30. 
